Portland State University

PDXScholar

$11-23-2020$

\title{
Use of Carbon Fiber Reinforced Polymer (CFRP) Including Sheets, Rods, and Ropes in Strengthening and Repairing Long Reinforced Concrete Columns
}

Yasir Matloob Saeed

Portland State University

Follow this and additional works at: https://pdxscholar.library.pdx.edu/open_access_etds

Part of the Civil Engineering Commons

Let us know how access to this document benefits you.

\section{Recommended Citation}

Saeed, Yasir Matloob, "Use of Carbon Fiber Reinforced Polymer (CFRP) Including Sheets, Rods, and Ropes in Strengthening and Repairing Long Reinforced Concrete Columns" (2020). Dissertations and Theses. Paper 5600.

https://doi.org/10.15760/etd.7472

This Dissertation is brought to you for free and open access. It has been accepted for inclusion in Dissertations and Theses by an authorized administrator of PDXScholar. Please contact us if we can make this document more accessible: pdxscholar@pdx.edu. 
Use of Carbon Fiber Reinforced Polymer (CFRP) including Sheets, Rods, and Ropes in Strengthening and Repairing Long Reinforced Concrete Columns

\author{
by \\ Yasir Matloob Saeed \\ A dissertation submitted in partial fulfillment of the \\ requirement for the degree of
}

\author{
Doctor of Philosophy \\ in \\ Civil and Environmental Engineering
}
Dissertation Committee:
Franz Rad, Chair
Arash Khosravifar
Thomas Schumacher
Hormoz Zareh

Portland State University

2020 
(C) 2020 Yasir Matloob Saeed 


\begin{abstract}
The use of FRP materials in strengthening and repairing of reinforced concrete (RC) structures has increased in the past two decades. Recently, FRP materials have become one of the most used materials in rehabilitation engineering. For seismic retrofitting of RC structures, usually the process involves strengthening or repairing the vertical support elements of the buildings or bridges. Several studies focused on the use of FRP materials in strengthening and repairing RC columns. Externally bonded (EB) FRP sheets or laminates and near-surface-mounted (NSM) FRP rods have been used for enhancing the strength and ductility of RC columns. Although glass FRP (GFRP) and basalt FRP (BFRP) rods have been used in flexural strengthening of RC columns, NSM-CFRP rods have not been used yet. In addition, studies in the use of CFRP ropes in flexural strengthening or repairing of RC columns are not available.
\end{abstract}

To address these gaps, an experimental investigation was conducted on the use of CFRP materials in strengthening and repairing RC columns. The investigation consisted of three main parts. The three parts focused on strengthening and repairing slender RC columns using CFRP materials. The first part of the investigation focused on the use of CFRP sheets, rods, and ropes in flexural strengthening of RC columns. Half scale square (150 x $150 \mathrm{~mm})$ RC columns were fabricated and tested. Each specimen consisted of two 1.065-meter long columns connected in the middle by a stiff element (concrete stub). All columns were designed based on older codes (pre 1970s). The specimens were (1) as built specimen, (2) strengthened with CFRP confinement only, (3) strengthened with CFRP confinement and NSM-CFRP rods, and (4) strengthened with CFRP confinement and NSM-CFRP ropes 
(two specimens). Another specimen was strengthened with EB-CFRP sheets. The results showed that both EB and NSM techniques can effectively be used in strengthening slender RC columns. In addition, CFRP ropes are very effective in strengthening RC columns. The strength enhancement ranged from $35 \%$ to $60 \%$. Finally, a theoretical model was created to predict the load-displacement response of RC columns strengthened with EB-CFRP sheets and NSM-CFRP rods and ropes. The theoretical results showed good agreement with the experimental results. The second part of the investigation focused on the use of CFRP sheets and ropes in repairing damaged RC columns. Recently, RC columns have been upgraded and strengthened with FRP confinement all around the globe. Future cases of repair will likely encounter RC columns that were strengthened previously with FRP confinement. However, studies on repairing damaged columns that were enhanced by confinement before damage are not currently available. Moreover, there is a vital need for an emergency repair technique that can be used to rapidly repair damaged columns of essential structures after a seismic event. In this study, the time required to complete the repair was a key factor to propose a rapid CFRP-based repair technique. A total of four specimens, each one representing two columns, were fabricated and tested. The technique was applied to square RC columns (150 mm x $150 \mathrm{~mm}$ x 1,065 mm) subjected to combined axial and cyclic lateral loads. The process of applying the repair technique was completed in three days. Test results showed that the proposed repair technique was effective not only by restoring the original strength, but also by improving the strength significantly. Moreover, the measured and idealized load-displacement response showed that the 
ductility of the repaired column was reasonably sufficient. The proposed technique appears promising and may be considered as a permanent repair technique.

The third part of the investigation focused on the tensile strength of CFRP ropes anchored to concrete using chemical epoxy. One of the major problems with using fiber reinforced polymer (FRP) in strengthening reinforced concrete (RC) structures is premature debonding of FRP. Anchoring FRP materials to concrete has become associated with most of the strengthening techniques. One of the anchoring techniques is using handmade anchors made from FRP materials. In previous studies, most FRP anchors were made from rolling pre-cut FRP sheets with short embedment $(<100 \mathrm{~mm})$ as they were used for flexural or shear strengthening of RC beams. In the present study, FRP anchors were made from carbon fiber reinforced polymer (CFRP) ropes and had long embedment to be used for flexural strengthening of RC columns. A total of twenty-one pullout tests were conducted on CFRP rope anchors bonded to concrete using chemical epoxy. The test parameters included embedment lengths of $45 \mathrm{~mm}, 90 \mathrm{~mm}, 135 \mathrm{~mm}, 180 \mathrm{~mm}, 270 \mathrm{~mm}$, and $315 \mathrm{~mm}$; anchor hole diameters of $12.7 \mathrm{~mm}, 19.1 \mathrm{~mm}$, and $25.4 \mathrm{~mm}$; and two epoxy types, Hilti 500 and MasterBrace SAT 4500. Test results showed that the pullout strength of CFRP anchors increased with the increase in embedment length, and no significant effect of the hole diameter on the pullout strength was observed. However, the bond strength increased with decreasing embedment length and hole diameter. For shorter embedment lengths, the distribution of the bond stress along the length of the anchor is expected to be more uniform than that of anchors with longer embedment lengths. The average bond stress (strength) is calculated by dividing the maximum pullout force by the embedment length. Therefore, 
increasing the embedment length without significant improvement in the pullout load results in lower bond strength. The observed pullout results and failure modes were compared to the predictions using available models. Finally, a modified model was proposed to predict the pullout strength of CFRP rope anchors. 


\section{Dedication}

This work is dedicated, first, to my parents for their endless love, support, and inspiration. They have always encouraged me to be a doctor. I was not able to be a medical doctor, but I did my best to be a doctor in the field that I love (engineering). This is part of my appreciation for their sacrifices and unconditional love.

Second, it is dedicated to my wife and son. I spent most of my time in the past four years away from them as I was busy with writing this dissertation and publishing scientific papers. My son, Ryan, is now four, and I lost so much time not being with him. I hope that this dedication will help my son and wife forgive me for the time we did not spend together.

Finally, this work is dedicated to all of those who seek knowledge despite their difficult circumstances and to those who cannot afford education. 


\section{Acknowledgements}

First and foremost, many thanks to Allah (God) for giving me the faith and strength to finish this scientific work despite all challenges and difficulties. My faith guided me to be positive and patient even in times when I almost lost hope.

I also would like to express my deep gratitude to Professor Franz Rad, the supervisor and the chair of the dissertation committee, for his generous help, support, and countless time of reviewing, editing, and advising. I would also like to extend my appreciation to Professors Arash Khosravifar, Thomas Schumacher, and Hormoz Zareh for serving as committee members, reviewing the manuscript, and offering valuable comments. This piece of science has become more informative and practically useful with their comments and recommendations.

My deep gratitude to my "big” family (parents, sisters, and brothers) and my smaller family (wife and son) for the emotional and financial support during my academic journey. They have sacrificed so much in order for me to earn this degree. My thanks and gratitude are extended to my American family (John and Kerstin Hilton) for their amazing support during my study in the United States.

I am extremely grateful and thankful to all friends and colleagues: Ahmed Nayyef's family, Ali Ahmadalipour, Ali Hafiz, Amin Varnousfaderani, Anas Yosefani, Anis Raad, Anwer Mohammed, Aqeel Al-Bahadily, Atieh Alipour, Aws Al-Shaikhly's family, Bahareh Gharib, Bashar Al-Domi, Bassam Altaee's family, Behzad Ahmadi, Evgeny Kozyaev, Faiz Al Falahi, Hamid Moradkhani, Hawwa Kadum, Hawraa Al khafagi, Hosam Al- 
Azzawi, Jill Townley, Karen Popp, Leena Alomar, Mahkameh Zarekarizi, Mohammad Azzawi's family, Mohammad Taha, Mohammed Alsaedi, Naowar Al-Abbas, Naseem Ali, Neera Malhotra, Omar Mohsin, Patricia Binder, Peyman Abbaszadeh, Qabas Hameed, Rania Ayoub, Riyadh Muttaleb, Ryan Gregory, Sabah Alomar's family, Safa Al-Dulaimi, Salah Saleh's family, Sarah Dys, Sepideh Khajehei, Taif Al-Jubaree's family, Wajdi Said, Wisam Aules, Yasir Kamil's family, and Yeganeh Jalalpour. All these friends helped me overcome so many life challenges and difficulties while I was working on my dissertation. It might be difficult to believe this, but the life circumstances I faced during my study required the help of all these great friends. Without their support, I would not have been able to finish this work.

Special thanks are offered to the personnel in the Department of Civil and Environmental Engineering at Portland State University (PSU) for their continuous care and support. Profound appreciation is offered to Tom Bennett, the Developmental Engineer in the Department of Civil and Environmental Engineering, for his invaluable help with the experimental work.

I would like to express special thanks to Dr. Maseeh and the Dean's Office of the Maseeh College of Engineering and Computer Science for awarding me the Maseeh Fellowship 2019-2020. Without the Maseeh Fellowship, it would have been financially challenging to complete the requirements of this degree. Finally, many thanks and appreciation go to the Office of Graduate School and the Office of International Student and Scholar Services for their financial support. 


\section{Table of Contents}

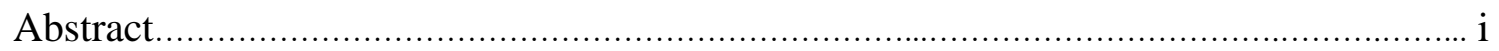

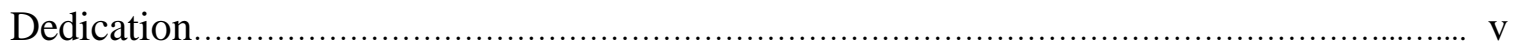

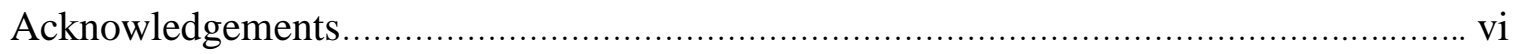

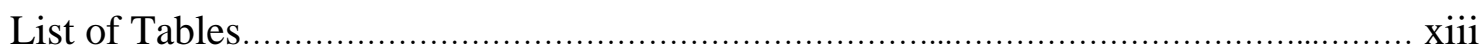

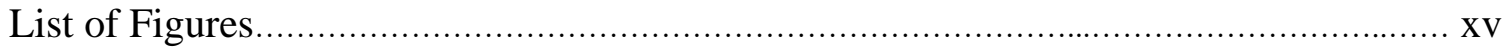

Chapter 1: Introduction........................................................................................ 1

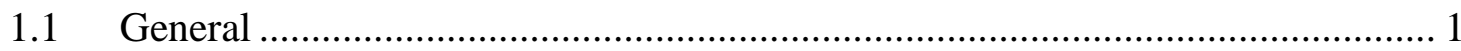

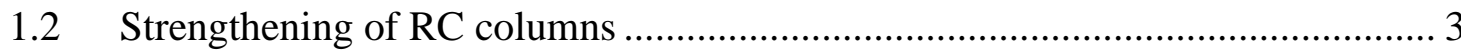

1.3 Post-strengthening repair of damaged RC columns ..................................... 4

1.4 Tensile behavior of FRP anchors ........................................................... 5

1.5 Research significance and objectives ................................................ 7

Chapter 2: Flexural Strengthening of Deficient RC Columns with EB-CFRP Sheets

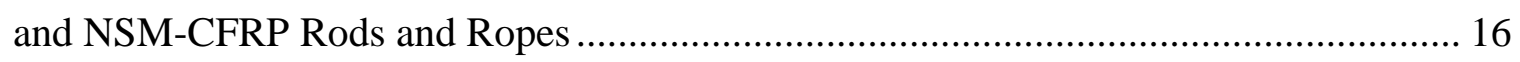

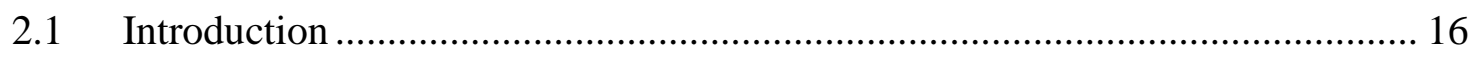

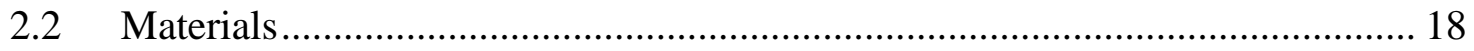

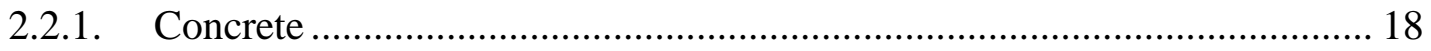

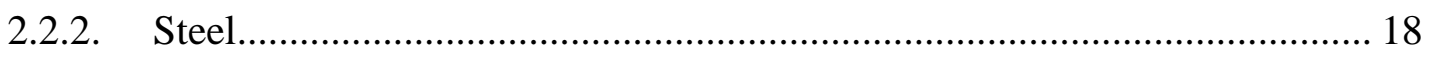

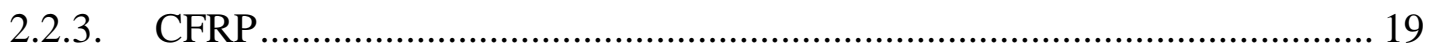




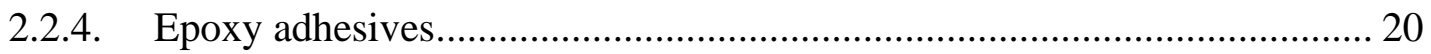

$2.3 \quad$ Test specimens and strengthening methods .......................................... 20

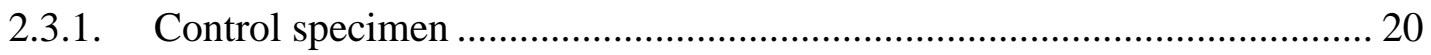

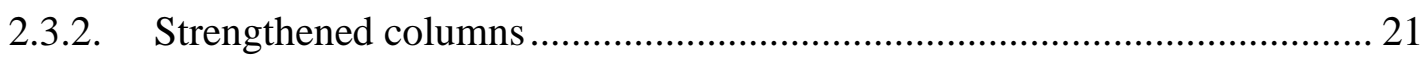

2.3.3. Test setup, instrumentations, and loading protocol ............................... 24

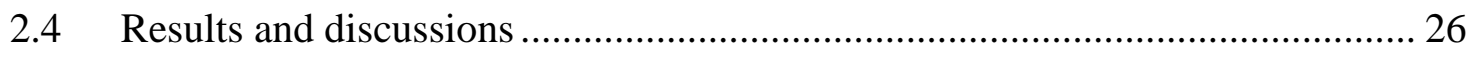

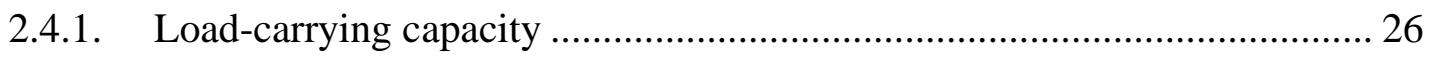

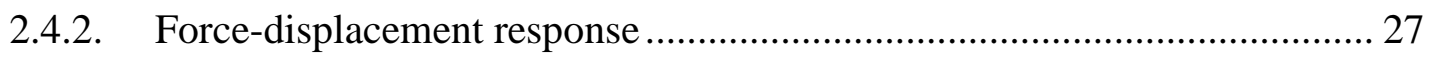

2.4.3. Load-displacement envelopes ....................................................... 30

2.4.4. Stability limit and displacement ductility ........................................ 31

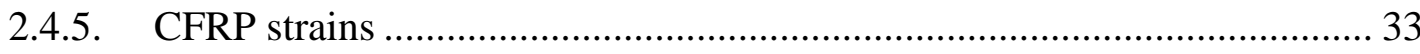

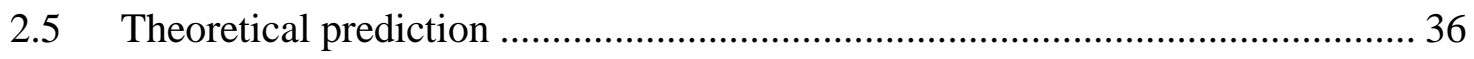

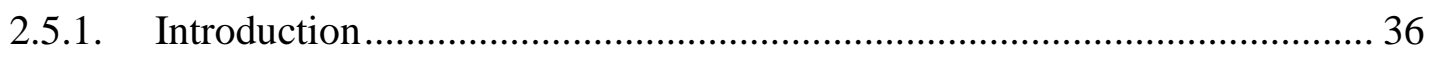

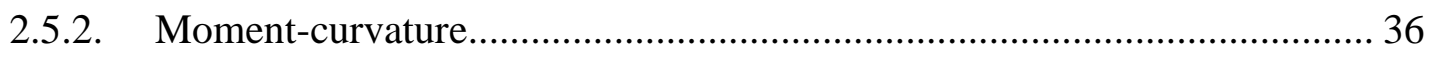

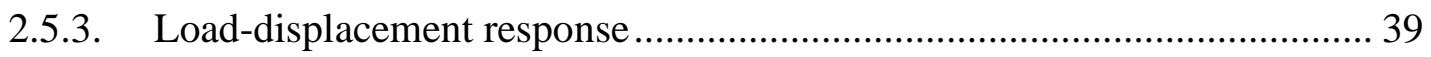

2.5.4. Theoretical-experimental comparison ................................................. 40

2.5.5. Parametric study - Area of CFRP ................................................. 42

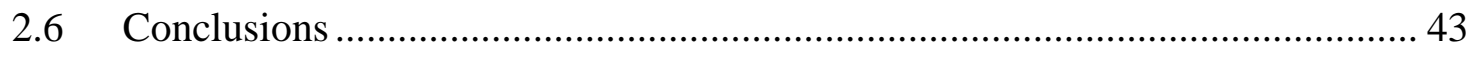

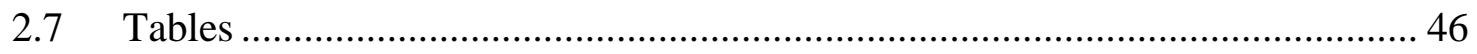


Chapter 3: Post-Strengthening Rapid Repair of Damaged RC Columns Using CFRP Sheets for Confinement and NSM-CFRP Ropes for Flexural Strengthening................. 71

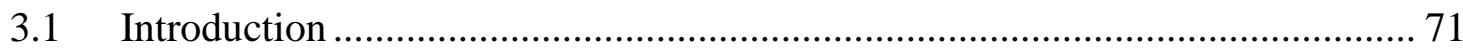

Experimental Program.......................................................................... 74

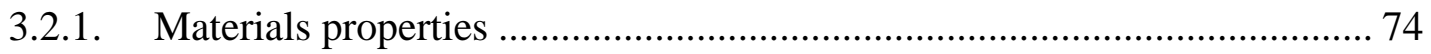

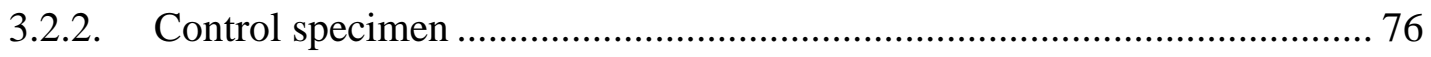

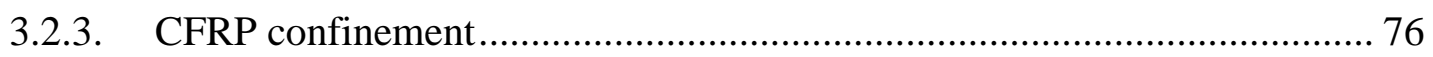

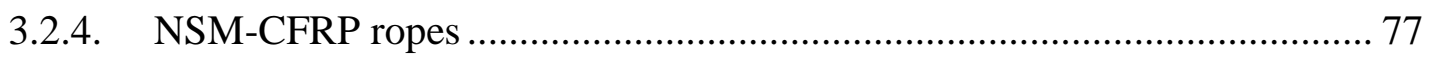

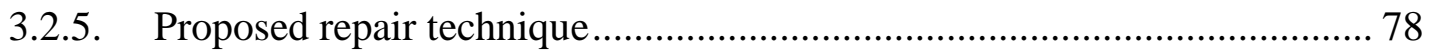

3.2.6. Test setup, instrumentations, and loading protocol ............................... 81

3.3 Experimental results and discussions ................................................. 83

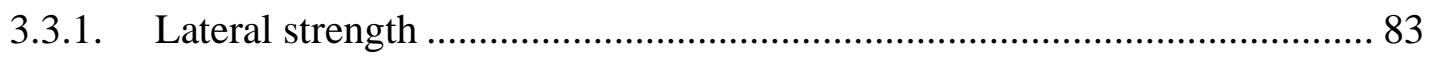

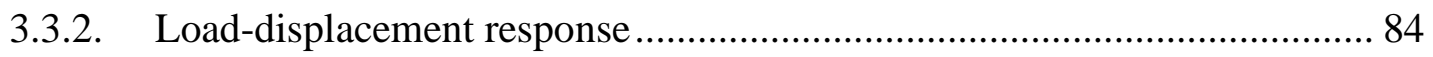

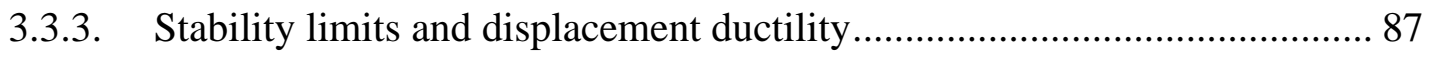

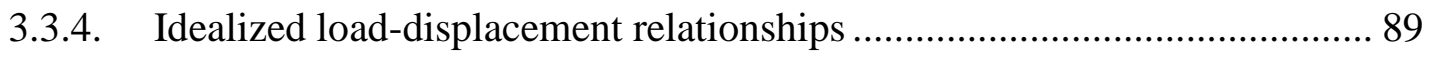

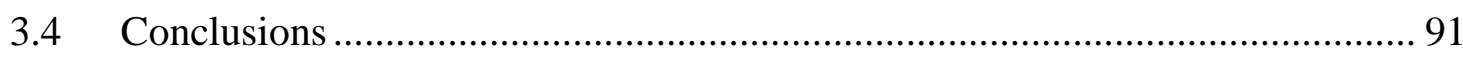

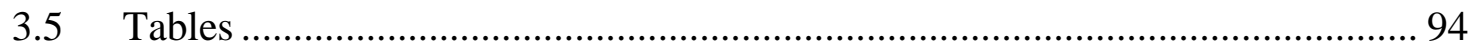

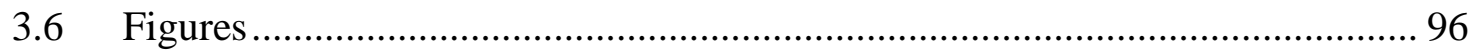


Chapter 4: Tensile Behavior of FRP Anchors Made from CFRP Ropes Epoxy-Bonded to Uncracked Concrete for Flexural Strengthening of RC Columns

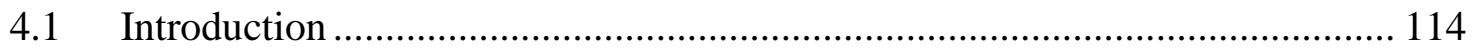

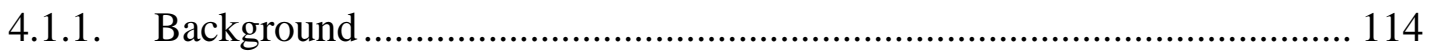

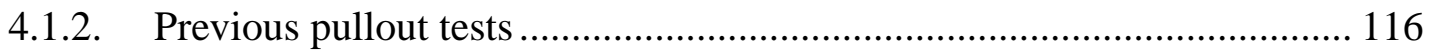

4.1.3. Pullout tests - the present study ...................................................... 120

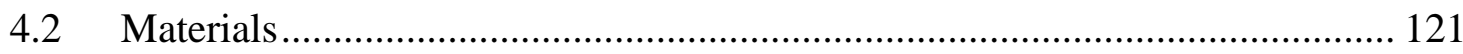

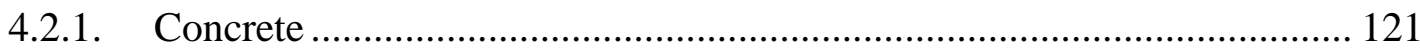

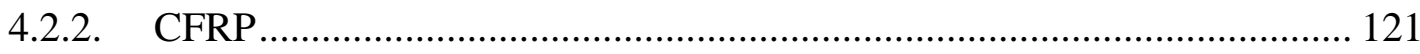

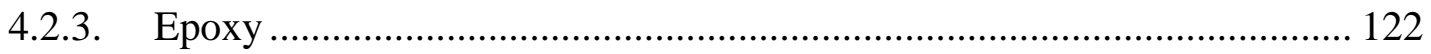

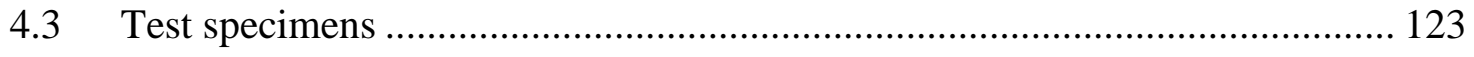

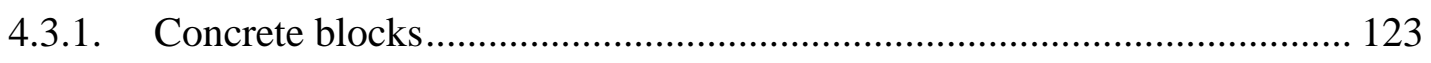

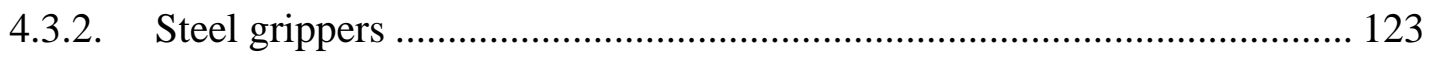

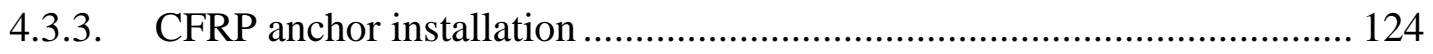

4.3.4. Specimen designation and test matrix............................................. 125

4.3.5. Test setup and instrumentations .................................................. 126

4.4 Experimental results and discussions ................................................... 127

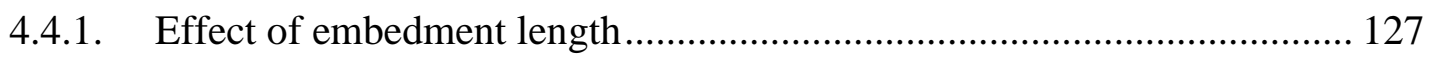

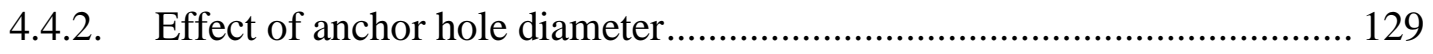


4.4.3. Effect of epoxy type

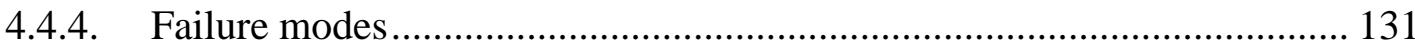

4.4.5. Load-displacement relationships ............................................................ 133

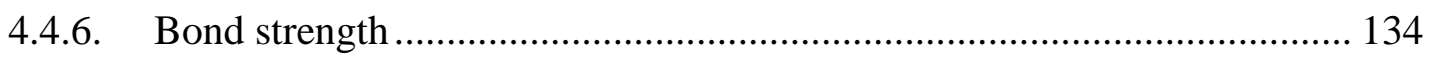

4.5 Available theoretical models ................................................................. 135

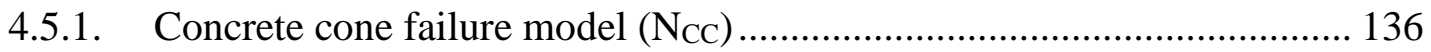

4.5.2. Combined concrete cone-bond failure mode $\left(\mathrm{N}_{\mathrm{CC}}+\mathrm{N}_{\mathrm{CB}}\right) \ldots \ldots \ldots \ldots \ldots \ldots \ldots . . . . .137$

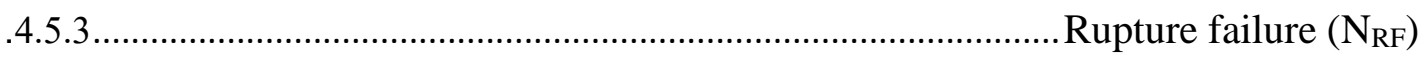
138

4.5.4. Predicted pullout strengths of tested specimens ....................................... 139

4.5.5. Modified model proposed for CFRP rope anchors ................................... 140

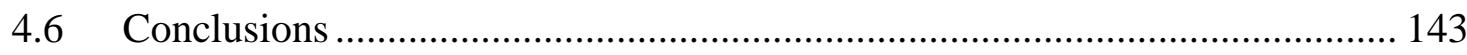

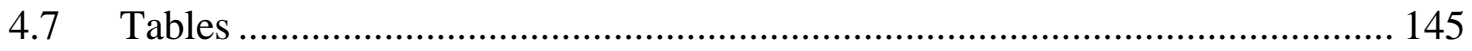

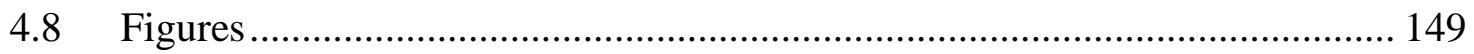

Chapter 5: Conclusions and Recommendations ………………….......................... 167

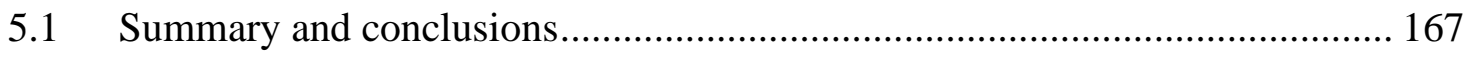

5.2 Recommendations for future work ......................................................... 170 


\section{List of Tables}

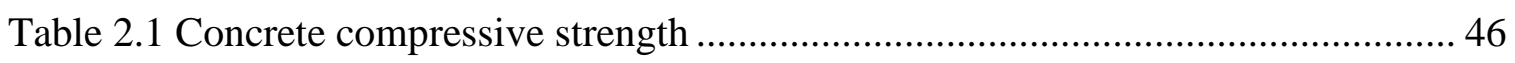

Table 2.2 Mechanical properties of steel bars and wires ......................................... 46

Table 2.3 Mechanical properties of CFRP materials used in flexural strengthening ....... 46

Table 2.4 Test specimens and CFRP strengthening details ..................................... 46

Table 2.5 Maximum measured force for all columns ............................................. 47

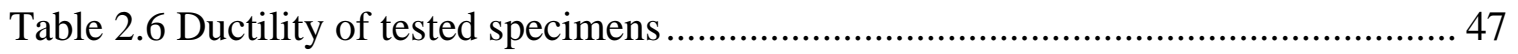

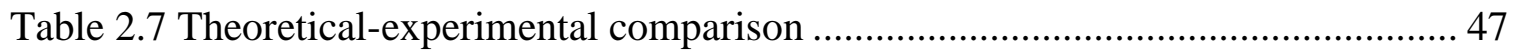

Table 3.1 Test specimens and CFRP strengthening details ...................................... 94

Table 3.2 Experimental results: values recorded during the tests............................... 94

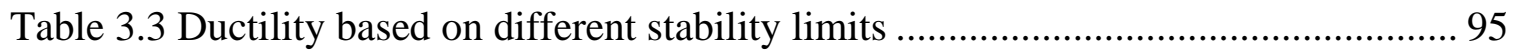

Table 3.4 Results based on idealized relationships................................................ 95

Table 4.1 Specimen details and experimental results ............................................ 145

Table 4.2 Available equations to predict the pullout strength of CFRP anchors........... 146

Table 4.3 Experimental vs. predicted pullout strength of CFRP rope anchors.............. 147 
Table 4.4 Predicted pullout strength based on the modified model proposed in this study 


\section{List of Figures}

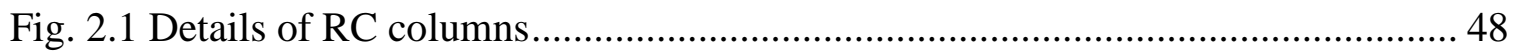

Fig. 2.2 Test specimens and strengthening technique for each column.......................... 49

Fig. 2.3 Photos showing the strengthening process .............................................. 50

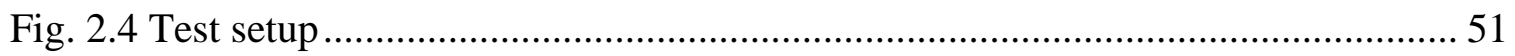

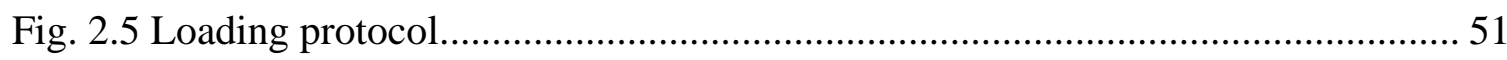

Fig. 2.6 Load-displacement relationships for control and strengthened columns ............ 52

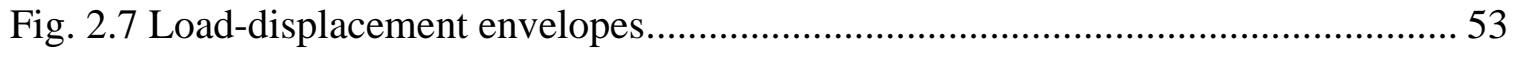

Fig. 2.8 Moment-displacement relationships; ductility and stability limits....................54

Fig. 2.9 Axial strains developed at CFRP sheets in longitudinal direction .................... 56

Fig. 2.10 Axial strains developed at CFRP rods in longitudinal direction ..................... 56

Fig. 2.11 Axial strains developed at CFRP ropes in longitudinal direction ................... 57

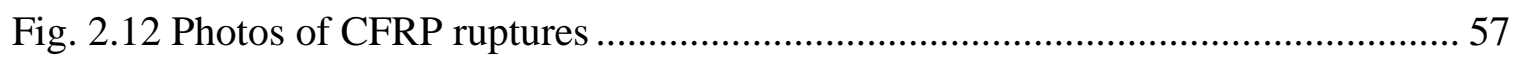

Fig. 2.13 Cross-sectional analysis - strain and stress distributions ............................ 58

Fig. 2.14 Stress-strain curves for unconfined concrete and concrete confined with steel

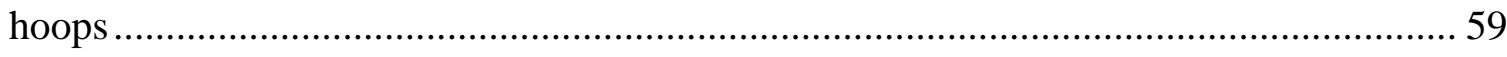


Fig. 2.15 Stress-strain curve for CFRP confined concrete

Fig. 2.16 Stress-strain curve for steel reinforcement 60

Fig. 2.17 Theoretical-experimental comparison 60

Fig. 2.18 Moment-curvature relationships for different CFRP reinforcement ratios ....... 61

Fig. 3.1 Steel reinforcement details of the tested specimens 96

Fig. 3.2 Strengthening and repairing details of the tested columns 96

Fig. 3.3 Cleaning damaged concrete 97

Fig. 3.4 (a) form work, and (b) casting repair mix concrete. 97

Fig. 3.5 (a) concrete grinding, and (b) NSM-CFRP grooves and anchoring holes. 98

Fig. 3.6 Installation of CFRP ropes 98

Fig. 3.7 (a) Concrete surface coated with epoxy, and (b) Application of CFRP confinement. 99

Fig. 3.8 The proposed rapid repairing technique - timeline 99

Fig. 3.9 Test setup 100

Fig. 3.10 Loading protocol. 100

Fig. 3.11 Location of strain gauges attached to CFRP ropes 101 
Fig. 3.12 Load-displacement hysteresis curves 101

Fig. 3.13 Load-displacement envelope 102

Fig. 3.14 Moment-displacement relationships showing the stability limits 103

Fig. 3.15 Idealized load-displacement curves 104

Fig. 3.16 Comparison of the idealized load-displacement envelopes 104

Fig. 3.17 Measured and idealized envelopes for C2-Confined (before repairing) and C7-

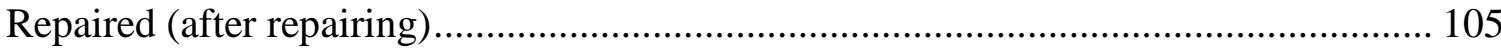

Fig. 4.1 Fabrication of CFRP rope with steel anchors

Fig. 4.2 FRP anchor installation 150

Fig. 4.3 Test setup and instrumentation 151

Fig. 4.4 Effect of the embedment length (present study) 151

Fig. 4.5 Pullout load vs. embedment length; data from present and previous studies.... 152

Fig. 4.6 Average bond stress vs. embedment length; (a) Present study and (b) Previous studies vs. present study

Fig. 4.7 Effect of anchor hole diameter; (a) present study and (b) data from present and previous studies 154 
Fig. 4.8 Average bond stress vs. anchor hole diameter; (a) Present study and (b) data from present and previous studies

Fig. 4.9 Effect of epoxy type on the pullout strength 155

Fig. 4.10 Failure modes; (a) concrete cone failure, (b) combined cone and bond failure, (c) concrete splitting, (d) bond failure, (e) gripper failure, and (f) CFRP rupture failure

Fig. 4.11 Pullout load vs. embedment length characterized by failure modes; (a) Present study, (b) Present study and previous studies 157

Fig. 4.12 Typical pullout load vs. concrete displacement relationships 158

Fig. 4.13 Experimental vs. predicted tensile strength of CFRP rope anchors; (a) Ozdemir, (b) Ozbakkaloglu and Saatcioglu, and (c) Kim and Smith ..... 158

Fig. 4.14 Experimental tests vs. the proposed modified model for CFRP rope anchors; (a) present study and (b) previous studies in addition to the present study..... 159 


\section{Chapter 1: Introduction}

\subsection{General}

In general, the use of fiber reinforced polymer (FRP) materials in reinforcing, strengthening, and repairing concrete structures has been significantly increased in the past two decades [1-4]. FRPs can be made with glass GFRP, aramid AFRP, basalt BFRP, and carbon CFRP materials. CFRP is one of the most commonly used material for strengthening concrete members. CFRP composite materials have extremely high tensile strength (about 4 times stronger than conventional steel reinforcement) and high tensile modulus (about $75 \%$ of steel) compared with other types of FRP materials. Carbon fibers are extremely strong in tension, with tensile strength and modulus of elasticity in the range of 3500-5200 MPa and 260-450 MPa, respectively [5]. However, typical tensile strength of CFRP composites is between 1200 and $2300 \mathrm{MPa}$, and typical tensile modulus between 100 and $150 \mathrm{GPa}[6]$.

There are several forms and products of CFRP composites, namely CFRP sheets, CFRP rods, and CFRP ropes. CFRP sheets are mainly used in strengthening and repairing of RC columns by means of lateral confinement. Previous research has shown that CFRP sheets can be very effective in providing lateral confinement for columns with deficient lateral reinforcement [7-11]. CFRP rods can be used as internal reinforcement instead of steel reinforcement in $\mathrm{RC}$ structures. They can also be used in strengthening and repairing concrete structures by utilizing near-surface-mounted (NSM) technique. Previous studies have used NSM-GFRP rods [12-15] and NSM-BFRP rods [16] in flexural strengthening 
of RC columns. Although CFRP is typically stronger than GFRP and BFRP, NSM-CFRP rods have never been used in flexural strengthening of RC columns.

The last form of CFRP discussed here is a new form of CFRP composites called CFRP ropes. CFRP ropes have the highest flexibility for usage in strengthening and rehabilitation process. Up to date, FRP ropes have mainly been used in lateral confinement of RC columns $[17,18]$ and shear and flexural strengthening of RC beams [19-21]. The use of CFRP ropes in flexural strengthening of RC columns has not been investigated.

In the present study, CFRP sheets, rods, and ropes have been utilized in strengthening and repairing of RC columns. CFRP sheets were used in lateral confinement, while for the first time NSM-CFRP rods and ropes were used in flexural strengthening of RC columns.

This investigation is divided into three main parts:

a) The first part of this investigation discusses the use of externally bonded (EB) CFRP sheet and NSM-CFRP rods and ropes in strengthening deficient RC columns.

b) In the second part, a rapid CFRP-based repairing technique is proposed. The rapid repairing technique aims to allow damaged $\mathrm{RC}$ structures to be repaired within a time span of three days.

c) The third part of the investigation includes twenty-one pullout tests on CFRP anchors made of CFRP ropes 
This document follows the multi-paper format, which is a compilation of papers in a journal article style format. Therefore, the format of this document is divided into three main sections. Each section will have its own introduction, methodology, results, conclusions, tables, figures, and list of references. Further introductory remarks about the three main parts of the investigation are provided below.

\subsection{Strengthening of $\mathrm{RC}$ columns}

Externally bonded EB-FRP and near-surface-mounted NSM-FRP systems have been investigated in the literature in flexural strengthening of reinforced concrete (RC) columns. Regarding the use of NSM-FRP in flexural strengthening of RC columns, only GFRP and BFRP rods have been used, and not CFRP. Research has shown that NSM-FRP systems are preferred in most cases over the use of EB-FRP systems especially in flexural strengthening RC columns against lateral loads [22-25]. However, only limited studies have been conducted to compare the behavior of RC columns that were constructed with the same geometry, concrete mix, and steel reinforcement, but strengthened with EB-FRP or NSM-FRP systems. In this part of the current investigation, the two strengthening systems are compared. To add to the novelty of this investigation, CFRP ropes were used for the first time in flexural strengthening RC columns subjected to cyclic lateral loads. Two of the columns were strengthened with NSM-CFRP ropes, one with NSM-CFRP rods, and one with CFRP lateral confinement only. The lateral cyclic responses of these columns were compared to that of the reference "as-built" column. The results of this study show that strengthening deficient RC columns with NSM-CFRP ropes and rods is promising and 
may be more efficient than strengthening with EB-CFRP composites. Moreover, a theoretical model was created to predict the load-deflection of RC columns strengthened with NSM-CFRP rods and ropes. More details about this investigation is provided in Chapter 2.

\subsection{Post-strengthening repair of damaged $\mathrm{RC}$ columns}

Repairing of concrete structures has become one of the major topics concerning structural engineers globally. It has been stated that the cost of repairing damaged structures has exceeded that spent on constructing new structures [10]. Rapid repair is necessary for essential structures and to prevent the full collapse of damaged structures due to successive strong ground motion. The traditional techniques of concrete and steel jacketing are not efficient methods for rapid or emergency repair because they require intensive labor and time $[7,24,26,27]$. Research has shown that the use of fiber reinforced polymer (FRP) materials in rapid or emergency repair of damaged concrete columns is one of the best alternatives [10]. In the past two decades, many columns have been upgraded with FRP jacketing to meet the seismic demands by the prevailing codes. Therefore, any future repair may include columns that have already been strengthened with FRP jacketing. In this study, a rapid repair technique is proposed to repair damaged $\mathrm{RC}$ columns that have already been strengthened with CFRP jacketing before being damaged. The aim of this investigation is to propose a repair method that allows engineers to repair damaged columns in a matter of days. The repair technique utilizes NSM-CFRP ropes in the axial direction of the columns and CFRP sheets in the transverse direction. This technique was applied to a square RC 
column (150 mm x $150 \mathrm{~mm}$ ) subjected to combined axial and cyclic lateral loads. The loaddeflection response of the repaired column is compared to the original columns, i.e., "asbuilt" column, and the column strengthened with CFRP jacketing only. The results show that the proposed repair technique is promising and may be effective as a rapid repair technique for damaged RC columns. More details about this investigation is provided in Chapter 3.

\subsection{Tensile behavior of FRP anchors}

Premature FRP-to-concrete debonding failure that reduces the efficiency of the strengthening system has often been observed [28-31]. Therefore, researchers have developed anchorage systems to delay or prevent debonding failure and utilize the most of the FRP materials before failure [32-35]. FRP anchors (also called fan anchors or spike anchors) are one of the common types that have been developed to increase the efficiency of EB-FRP system in flexural strengthening of concrete structures [3,36,37]. Depending on the inclination angle and the location where they are installed, FRP anchors can be subjected to shear and/or pullout (tensile) forces.

FRP anchors that are used with EB-FRP strengthening systems for flexural or shear strengthening of RC beams are mostly subjected to shear forces as the angle between FRP anchor and EB-FRP reinforcement is usually between $90^{\circ}$ (perpendicular) and $165^{\circ}$ [37]. On the other hand, FRP anchors used in flexural strengthening of RC columns are often subjected to pullout forces because the angle between FRP anchors and EB-FRP 
reinforcement is usually $180^{\circ}$ [38,39]. In the case of using NSM-FRP technique in flexural strengthening of RC columns, the NSM-FRP rods or laminates must be anchored to transfer the load to the foundation or to the joints. To do that, NSM-FRP materials are inserted in holes predrilled in the foundation and filled with bonding agent $[12,14,16]$. The forces acting on the FRP materials anchored to the holes are similar to the pullout forces acting on the $180^{\circ}$ FRP anchors described earlier. Therefore, FRP anchors subjected to pullout forces are common whether EB-FRP or NSM-FRP systems are used in the strengthening process. Direct pullout test is the simplest and most common way to investigate the bond properties of FRP materials bonded to concrete [40,41].

Previous research on pullout tests on CFRP anchors are limited to three studies [42-44]. In all these studies, CFRP anchors were made from rolling pre-cut CFRP sheets. It has been reported that the quality of work associated with fabricating the anchors by rolling pre-cut CFRP sheets has resulted in scattered data [42-44]. Recently, CFRP ropes have become commercially available. Fabricating CFRP anchors made from ropes is easier than making anchors from pre-cut CFRP sheets. In addition, none of the previous studies tested CFRP anchors with embedment deeper than $100 \mathrm{~mm}$, and none investigated the effects of different epoxy type. In the present study, twenty-one pullout tests were conducted on CFRP anchors made of CFRP ropes, and the effects of embedment length, hole diameter, and epoxy type were investigated. This experimental investigation aims to enhance the current knowledge on CFRP ropes epoxy bonded to uncracked concrete since no similar tests have been conducted previously. More details about this investigation are provided in Chapter 4. 


\subsection{Research significance and objectives}

Recently, the use of fiber reinforced polymer in strengthening and repairing of RC structures have become one of the major topics of investigation. Much research has been conducted to investigate the use of externally bonded FRP systems and near-surfacemounted FRP technique in strengthening and repairing concrete structures. Data collected for columns strengthened in flexure with FRP materials (a total of 45 columns), show that 22 columns were strengthened with NSM-FRP rods, 9 columns were strengthened with EB-FRP sheets or laminates, and 14 columns were strengthened with NSM-FRP strips or laminates. Despite the superior properties of CFRP rods, none of the previous studies used CFRP rods in flexural strengthening RC columns. In addition, the new form of CFRP material, called ropes, have never been used in strengthening or repairing RC columns. In fact, the only study focused on using CFRP ropes in strengthening flexural members (beams in this case) was conducted by Kaya et al. [21].

The presented work is the first of its kind to explore the use of CFRP ropes and rods in flexural strengthening of RC columns subjected to cyclic lateral loads. The results are promising and reveal significant findings for researchers and structural engineers in the field of using advanced composite materials in strengthening and rehabilitation of concrete structures. In addition, a rapid repair technique using NSM-CFRP ropes is proposed in this study. The proposed repair technique focuses on repairing columns that had already been strengthened with CFRP confinement. This topic has not been investigated yet by other investigators and the current study is the first investigation on this topic. Finally, the tensile behavior of CFRP ropes bonded to uncracked concrete using chemical epoxy was 
investigated by conducting twenty-one pullout tests. The results of the pullout tests will help engineers have better understanding of the tensile behavior of CFRP ropes anchored to concrete.

In summary, the main objectives of this study are:

1) Investigate the possible use of CFRP rods and ropes in improving flexural strength and ductility of long RC columns subjected to cyclic lateral loads.

2) Propose a new and rapid repair technique by using a combination of EB-CFRP confinement and NSM-CFRP ropes.

3) Investigate the tensile behavior of CFRP ropes anchored to uncracked concrete using chemical epoxy.

4) For the first time, investigate the effects of deep embedment (larger than $100 \mathrm{~mm}$ ), and the effects of epoxy type, in anchors made of CFRP ropes. 


\section{References - Chapter 1}

[1] Zhou Y, Chen X, Fan Z, Sui L, Li D, Xing F. Bond behaviors of FRP-to-concrete interface under the control of a novel end-anchorage system. Compos Struct 2017;168:130-42. doi:10.1016/j.compstruct.2017.02.056.

[2] Sun W, Jirsa JO, Ghannoum WM. Behavior of anchored carbon fiber-reinforced polymer strips used for strengthening concrete structures. ACI Mater J 2016;113:163-72. doi:10.14359/51688637.

[3] Carozzi FG, Colombi P, Fava G, Poggi C. Mechanical and bond properties of FRP anchor spikes in concrete and masonry blocks. Compos Struct 2018;183:185-98. doi:10.1016/j.compstruct.2017.02.026.

[4] Lingga N, Saeed YM, Yosefani A, Rad F. Concrete beams with fully corroded steel repaired with CFRP laminates. ACI Spec Publ 2019;333:136-58.

[5] Hollaway LC. A review of the present and future utilisation of FRP composites in the civil infrastructure with reference to their important in-service properties. Constr Build Mater 2010;24:2419-45. doi:10.1016/j.conbuildmat.2010.04.062.

[6] Mugahed Amran YH, Alyousef R, Rashid RSM, Alabduljabbar H, Hung CC. Properties and applications of FRP in strengthening RC structures: A review. Structures 2018;16:208-38. doi:10.1016/j.istruc.2018.09.008.

[7] Xiao Y. Applications of FRP composites in concrete columns. Adv Struct Eng 2004;7:335-43. doi:10.1260/1369433041653552. 
[8] Faustino P, Frade P, Chastre C. Lateral cyclic behaviour of RC columns confined with carbon fibres. Structures 2016;5:196-206. doi:10.1016/j.istruc.2015.11.004.

[9] Theodoros C. Rousakis, Theodoros D. Rakitzis and AIK. Design-rriented strength model for FRP-confined concrete members. J Compos Constr 2012;16:615-25. doi:10.1061/(ASCE)CC.1943-5614.

[10] Ma CK, Apandi NM, Sofrie CSY, Ng JH, Lo WH, Awang AZ, et al. Repair and rehabilitation of concrete structures using confinement: A review. Constr Build Mater 2017;133:502-15. doi:10.1016/j.conbuildmat.2016.12.100.

[11] Rocca S, Galati N, Nanni A. Review of design guidelines for FRP confinement of reinforced concrete columns of noncircular cross sections. J Compos Constr 2008;12:8092. doi:10.1061/(ASCE)1090-0268(2008)12:1(80).

[12] Li X, Lv HL, Zhang GC, Sha SY, Zhou SC. Seismic retrofitting of rectangular reinforced concrete columns using fiber composites for enhanced flexural strength. J Reinf Plast Compos 2013;32:619-30. doi:10.1177/0731684413477222.

[13] Esfandi Sarafraz M. Flexural Strengthening of RC Columns with Low Longitudinal Steel Ratio using GFRP Bars. Int J Concr Struct Mater 2019;13. doi:10.1186/s40069-0190354-z.

[14] Bournas DA, Triantafillou TC. Flexural strengthening of reinforced concrete columns with near-surface-mounted FRP or stainless steel. ACI Struct J 2009;106:495505. 
[15] Seifi A, Hosseini A, Marefat MS, Khanmohammadi M. Seismic retrofitting of oldtype RC columns with different lap splices by NSM GFRP and steel bars. Struct Des Tall Spec Build 2018;27:1-21. doi:10.1002/tal.1413.

[16] Ding L, Wu G, Yang S, Wu Z. Performance advancement of RC columns by applying basalt FRP composites with NSM and confinement system. J Earthq Tsunami 2013;07:1350007. doi:10.1142/S1793431113500073.

[17] Rousakis TC. Hybrid confinement of concrete by fiber-reinforced polymer sheets and fiber ropes under cyclic axial compressive loading. J Compos Constr 2013;17:732-43. doi:10.1061/(ASCE)CC.1943-5614.0000374.

[18] Rousakis TC. Reusable and recyclable nonbonded composite tapes and ropes for concrete columns confinement. Compos Part B Eng 2016;103:15-22. doi:10.1016/j.compositesb.2016.08.003.

[19] Chalioris CE, Kosmidou PMK, Papadopoulos NA. Investigation of a new strengthening technique for $\mathrm{RC}$ deep beams using carbon FRP ropes as transverse reinforcements. Fibers 2018;6. doi:10.3390/fib6030052.

[20] Godat A, Ceroni F, Chaallal O, Pecce M. Evaluation of FRP-to-concrete anchored joints designed for FRP shear-strengthened RC T-beams. Compos Struct 2017;176:48195. doi:10.1016/j.compstruct.2017.04.035.

[21] Kaya E, Kutan C, Sheikh S, Ilki A. Flexural retrofit of support regions of reinforced concrete beams with anchored FRP ropes using NSM and ETS methods under reversed cyclic loading. J Compos Constr 2017;21:04016072. 
[22] Noroozieh E, Mansouri A. Lateral strength and ductility of reinforced concrete columns strengthened with NSM FRP rebars and FRP jacket. Int J Adv Struct Eng 2019;11:195-209. doi:10.1007/s40091-019-0225-5.

[23] Sarafraz ME, Danesh F. Flexural enhancement of RC columns with FRP. 14th World Conf. Earthq. Eng., Beijing, China: 2008.

[24] Alkhrdaji T, Nanni A. Flexural strengthening of bridge piers using FRP composites. Struct. Congr. 2000, Philadelphia, Pennsylvania, United States: ASCE - American Society of Civil Engineers; 2012, p. 1-13. doi:10.1061/40492(2000)174.

[25] Yao LZ, Wu G. Fiber-element modeling for seismic performance of square RC bridge columns retrofitted with NSM BFRP bars and/or BFRP sheet confinement. J Compos Constr 2016;20:1-15. doi:10.1061/(ASCE)CC.1943-5614.0000652.

[26] Prota A, Manfredi G, Balsamo A, Nanni A, Cosenza E. Innovative technique for seismic upgrade of RC square columns. Proc. 7th Int. Symp. Fiber Reinf. Polym. Reinf. Concr. Struct. - FRPRCS-7, Farmington Hills, MI.: American Concrete Institute; 2005, p. $1289-304$.

[27] Parvin A, Brighton D. FRP composites strengthening of concrete columns under various loading conditions. Polymers (Basel) 2014;6:1040-56. doi:10.3390/polym6041040.

[28] Bilotta A, Ceroni F, Ludovico ; M Di, Nigro ; E, Pecce ; M, Manfredi G. Bond efficiency of EBR and NSM FRP systems for strengthening concrete members. J Compos Constr 2011;15:757-72. doi:10.1061/(ASCE)CC.1943-5614.0000204. 
[29] Rahimi H, Hutchinson A. Concrete beams strengthened with externally bonded FRP plates. J Compos Constr 2001;5:44-56. doi:10.1061/(ASCE)10900268(2001)5:1(44).

[30] Hiotakis S. Repair and strengthening of reinforced concrete shear walls for earthquake resistance using externally bonded carbon fibre sheets and a novel system. Carleton University, 2004.

[31] Niu H, Wu Z. Effects of FRP-concrete interface bond properties on the performance of RC beams strengthened in flexure with externally bonded FRP sheets. J Mater Civ Eng 2006;18:723-31. doi:10.1061/(ASCE)0899-1561(2006)18:5(723).

[32] Grelle S V., Sneed LH. Review of anchorage systems for externally bonded FRP laminates. Int J Concr Struct Mater 2013;7:17-33. doi:10.1007/s40069-013-0029-0.

[33] Mostafa A, Razaqpur AG. CFRP anchor for preventing premature debonding of externally bonded FRP laminates from concrete. J Compos Constr 2013;17:641-50. doi:10.1061/(ASCE)CC.1943-5614.0000377.

[34] Ozbakkaloglu T, Fang C, Gholampour A. Influence of FRP anchor configuration on the behavior of FRP plates externally bonded on concrete members. Eng Struct 2017;133:133-50. doi:10.1016/j.engstruct.2016.12.005.

[35] Aules W, Saeed YM, Rad FN. A novel anchorage system for strengthening slender RC columns with externally bonded CFRP composite sheets. Constr Build Mater 2020;245:118423. doi:10.1016/j.conbuildmat.2020.118423. 
[36] Kalfat R, Al-Mahaidi R. Development of a hybrid anchor to improve the bond performance of multiple plies of FRP laminates bonded to concrete. Constr Build Mater 2015;94:280-9. doi:10.1016/j.conbuildmat.2015.07.013.

[37] Villanueva Llauradó P, Ibell T, Fernández Gómez J, González Ramos FJ. Pull-out and shear-strength models for FRP spike anchors. Compos Part B Eng 2017;116:239-52. doi:10.1016/j.compositesb.2017.02.029.

[38] Vrettos I, Kefala E, Triantafillou TC. Innovative flexural strengthening of reinforced concrete columns using carbon-fiber anchors. ACI Struct J 2013;110:63-70. doi:10.14359/51684330.

[39] Del Rey Castillo E, Griffith M, Ingham J. Seismic behavior of RC columns flexurally strengthened with FRP sheets and FRP anchors. Compos Struct 2018;203:38295. doi:10.1016/j.compstruct.2018.07.029.

[40] ACI Committee 440 (ACI 440.3R-12). Guide Test Methods for Fiber-Reinforced Polymers (FRPs) for Reinforcing or Strengthening Concrete Structures. Farmington Hills, MI.: American Concrete Institute; 2012.

[41] Rolland A, Quiertant M, Khadour A, Chataigner S, Benzarti K, Argoul P. Experimental investigations on the bond behavior between concrete and FRP reinforcing bars. Constr Build Mater 2018;173:136-48. doi:10.1016/j.conbuildmat.2018.03.169.

[42] Kim SJ, Smith ST. Behaviour of handmade FRP anchors under tensile load in uncracked concrete. Adv Struct Eng 2009;12:845-65. doi:10.1260/136943309790327716. 
[43] Ozbakkaloglu T, Saatcioglu M. Tensile behavior of FRP anchors in concrete. J Compos Constr 2009;13:82-92. doi:10.1061/(ASCE)1090-0268(2009)13:2(82).

[44] Ozdemir G. Mechanical properties of CFRP anchorages. Middle East Technical University, 2005. doi:10.1002/eqe.4290180114. 


\section{Chapter 2: Flexural Strengthening of Deficient RC Columns with EB-CFRP Sheets and NSM-CFRP Rods and Ropes}

\subsection{Introduction}

The conventional methods of strengthening RC structures by using steel or concrete jacketing have proven not to be efficient because they require undesired section enlargement and additional weight, intensive labor, and they commonly encounter construction limitations [1,2]. Additionally, they increase the stiffness of the columns and therefore attract more seismic forces to the strengthened columns [3,4]. On the other hand, fiber reinforced polymers (FRPs) have been used for structural strengthening of reinforced concrete (RC) structures for more than two decades now [5]. FRPs have attractive properties including high tensile strength to weight ratio, high resistance to corrosion, and ease of application and handling [6-8]. FRP jacketing may improve the ductility of strengthened columns, but research has shown that FRP confinement by itself does not improve the flexural strength $[9,10]$.

Externally bonded (EB) FRP sheets or near-surface-mounted (NSM) FRP techniques have been used in flexural strengthening of RC columns or joints [11-14]. Although studies have shown that EB-FRP system is one of the techniques that can be used in flexural strengthening of RC columns [1,15], NSM-FRP technique has been claimed to be more effective and practical for flexural strengthening of RC columns. This is because FRP materials must be anchored to transfer the force between the column element and its 
foundation or joint $[2,16]$, and anchoring FRP materials at the ends of structural elements is more difficult and time-consuming for EB-FRP system than it is for NSM-FRP system.

Although CFRP rods have superior tensile properties compared with GFRP and BFRP bars [5], research on the use of CFRP bars in flexural strengthening of RC columns against seismic loads has not been reported in the literature yet. Therefore, CFRP rods were used in this study to strengthen one of the columns for comparison purposes. In addition, this study presents the only investigation in the use of a new form of CFRP material called "CFRP ropes" in flexural strengthening of RC columns. Up to date, the use of FRP ropes in strengthening RC columns has been limited to lateral confinement only [17-19]. To the best of the authors' knowledge, Kaya et al. [20] is the only investigation in the literature that focused on the use of CFRP ropes in flexural strengthening of RC beams; not columns. The advantage of using CFRP ropes in flexural strengthening of RC columns is that ropes are flexible and can be bent easily at the column-foundation intersection compared to CFRP rods. In using CFRP rods, much more effort is required to make straight holes in the foundation to anchor the rods.

In this study, a total of six column specimens were tested under combined axial and cyclic lateral loads. One specimen was a reference column, one was strengthened with CFRP jacketing only, one was strengthened in flexure with EB CFRP sheets, one was strengthened in flexure using NSM-CFRP rods, and two were strengthened with NSMCFRP ropes. It should be mentioned that each specimen consisted of two "identical" columns (designed and built with the same materials and details) that were connected in the middle by a concrete stub (rigid element). Therefore, the response of each column 
specimen was basically the average response of two columns tested at the same time. More details are available in section 4 (Test setup, instrumentations, and loading protocol). The lateral responses of the columns in terms of hysteresis load-displacement curves, lateral (flexural) strength, stability limits, and ductility are analyzed and discussed. Finally, the observed load-displacement responses of the original and strengthened RC columns were compared to the predicted responses obtained from theoretical calculations.

\subsection{Materials}

\subsubsection{Concrete}

Concrete mix was designed to have a nominal compressive strength of $20 \mathrm{MPa}$ at 28 days. This represents a typical concrete strength for older concrete structures (pre 1970s). Due to equipment and space limitations in the laboratory, each column specimen was cast separately using individual concrete batches. Three concrete cylinders were tested to determine the compressive strength based on ASTM standards [21]. Table 2.1 shows the concrete strength on the day of testing for all column specimens.

\subsubsection{Steel}

Deformed steel reinforcing bars were used in flexural reinforcement of reinforced concrete columns. No. 9 deformed steel bars were used for flexural reinforcement. Steel wires were used for shear reinforcement and ties for the columns. The mechanical properties of steel 
bars and wires were determined experimentally following ASTM Standards [22], and the results were published by Yosefani [23], as shown in Table 2.2.

\subsubsection{CFRP}

Three different forms of CFRP materials were used in this study. Unidirectional CFRP sheets were used mainly for lateral confinement applied to strengthened RC columns. The tensile properties of CFRP sheets were determined in the materials laboratory at Portland State University by Aules et al. [24] following ASTM D7565/ D7565M [25]. The other form of CFRP used in this study was No. $6(6.35 \mathrm{~mm})$ CFRP rods. The rods were tested in the same laboratory following ASTM D7205/ D7205M [26], and the results were published by Al-Obaidi et al. [27,28]. The last form of CFRP used in the present study was CFRP ropes. CFRP ropes were tested under pure tension in the laboratory using grippers devised by Saeed et al. [29]. However, all specimens failed before achieving maximum tensile strength reported by the manufacturer due to difficulties in anchoring CFRP ropes and misalignment of the fibers. The mechanical properties of CFRP sheets, rods, and ropes as reported by the manufacturer and as resulted from the experimental tests are presented in Table 2.3. 


\subsubsection{Epoxy adhesives}

Low viscosity epoxy material (commercially known as MasterBrace SAT 4500) was used as an impregnating resin for CFRP ropes and as a bonding agent for EB CFRP sheets. The tensile strength, elastic modulus, and ultimate strain of the MasterBrace SAT 4500 were $55 \mathrm{MPa}, 3 \mathrm{GPa}$, and $3.5 \%$, respectively. Hilti 500 was used as the bonding agent for NSMCFRP materials and to fill the holes where CFRP rods and ropes were anchored to the foundation. The tensile strength, bond strength, and ultimate strain of Hilti 500 were 44 $\mathrm{MPa}, 12 \mathrm{MPa}$, and $2.0 \%$, respectively.

\subsection{Test specimens and strengthening methods}

\subsubsection{Control specimen}

All specimens are labeled with letter C, representing "Column", followed by a number, 1 through 6: C1-Control, C2-Confined, C3-Sheet, C4-Rod, C5-Rope, C6-Rope-debond. The geometry and details of the control specimen (C1-Control) is shown in Fig. 2.1. Each specimen consisted of two cantilevered columns connected to a stiff member (concrete stub) in the middle. The cross-sectional dimensions of the columns are $150 \times 150 \mathrm{~mm}$. The columns are reinforced longitudinally with four No. 9 steel bars (steel reinforcement ratio $\rho_{\ell}=1.26 \%$ ). Steel ties made of No. 6 smooth wires were placed at $150 \mathrm{~mm}$ on center. The columns were constructed with low concrete strength (20 MPa) and were poorly detailed at the plastic hinge zone representing deficient RC columns designed based on older codes 
(pre 1970s) [30]. The concrete stub (the stiff element at the middle of the specimen) was heavily reinforced (as shown in Fig. 2.1) to act as a fixed end for the columns.

\subsubsection{Strengthened columns}

The strengthened column specimens were constructed the same as the control specimen except that they were strengthened with CFRP materials after they were cured for at least 28 days. Fig. 2.2 shows the test specimens and strengthening techniques for all specimens. Details of strengthened columns are presented in Table 2.4.

\subsubsection{Externally bonded (EB) CFRP sheets}

Specimen C2-Confined was strengthened with lateral CFRP confinement only. The strengthening process for C2-Confined began with concrete surface grinding. The surface of concrete was first cleaned, then ground with a concrete grinder. The corners of the columns were rounded $(\mathrm{R}=25 \mathrm{~mm})$ at the plastic hinge region. The plastic hinge zone, determined based on the definition of ACI 318-14 [31] and ACI 440.2R-17 [32], was equal to $356 \mathrm{~mm}$ from the column base. Then, two layers of epoxy (commercially known as MasterBrace P2000 and MasterBrace P3500) were applied and cured as recommended by the manufacturer before applying CFRP composite sheets. One layer of CFRP composite sheet was applied at the plastic hinge zone of C2-Confined specimen (Fig. 2.3). Details of the strengthening design are shown in Fig. 2.2b and Table 2.4. Fig. 2.2c shows the details 
of the column strengthened with EB-CFRP sheets in longitudinal direction (C3-Sheet). Specimen C3-Sheet is strengthened with one layer of CFRP sheet in the longitudinal direction of the column to upgrade its flexural strength (Fig. 2.2c). The longitudinal CFRP sheet was anchored to the concrete stub using a novel anchorage system proposed by Aules et al. [24]. Then, one layer of CFRP confinement was applied at the plastic hinge zone, and three CFRP strips were distributed along the length of the column between the plastic hinge zone and the hinge support to improve the shear resistance of the column and to prevent debonding of the longitudinal CFRP sheet (Fig. 2.2c and Fig. 2.3).

\subsubsection{NSM CFRP rods}

For specimen C4-Rod, a groove was cut in the longitudinal direction (parallel to steel flexural reinforcement) on each flexural side of the column (Fig. 2.3). The cross-sectional dimensions of the grooves were $13 \mathrm{~mm} \times 13 \mathrm{~mm}$, which were equal to two times the diameter of CFRP rod as recommended by previous studies [32-34]. Previous researchers $[35,36]$ have recommended to use width to depth ratio of the grooves equal to one. Groove details are shown in Fig. 2.2. Straight holes were drilled into the concrete stub to anchor CFRP rods at the base of the column. The diameter of the holes was 1.5 times the rod diameter as recommended by Godat et al. [37], and the anchorage length was $150 \mathrm{~mm}$ [11,37-39]. The grooves and holes were cleaned with compressed air and steel brush, Hilti epoxy was injected into the holes and grooves, and then CFRP rods were inserted. Extra 
amount of epoxy was added, and the surface was leveled. After one day of epoxy curing, CFRP confinement (as described previously) was applied (Fig. 2.2d).

\subsubsection{NSM CFRP ropes}

The last two columns (C5-Rope and C6-Rope-debond) were strengthened in flexure with NSM-CFRP ropes. The design of C6-Rope-debond aimed to increase the ductility of the strengthened column by allowing CFRP rope to deform independent of the concrete. For these two columns, the process of creating the grooves was the same as that of specimen C4-Rod. However, the dimensions of the grooves were different because CFRP ropes were thicker than the rods. The grooves depth had to be $13 \mathrm{~mm}$, equal to the thickness of the concrete cover, and the width of the grooves was $18 \mathrm{~mm}$. The most available sizes of drilling bits that could work were $12.7 \mathrm{~mm}(1 / 2 \mathrm{inch})$ and $19.1 \mathrm{~mm}$ (3/4 inch). The $12.7-$ $\mathrm{mm}$ bit did not work as it was smaller than 1.5 the diameter. Therefore, the diameter of the holes was $19.1 \mathrm{~mm}$. Unlike C4-Rod, where the holes had to be straight, the holes of C5Rope and C6-Rope-debond were drilled at a 7-degree slope (Fig. 2.2). This was one of the advantages of using the flexible CFRP ropes instead of the rigid CFRP rods. Test results of Ozbakkaloglu and Saatcioglu [40] showed that a rope inclination of up to 15-degree had no significant effects on the anchor pullout strength.

The rope was cut by special scissors to the desired lengths $(1.0 \mathrm{~m}$ each). Then, the ropes were impregnated with resin for 30 minutes to 1 hour until the fibers were saturated thoroughly with resin. Next, ropes were inserted into the holes and grooves using a steel 
rod. The CFRP ropes were pressed slightly to make sure that the epoxy went through and around all fibers to fill all the voids. The grooves were filled with more epoxy, the surface was leveled and let to cure for one day. Finally, CFRP confinement jackets were applied following the procedure described earlier. The pictures in Fig. 2.3 show some of the main steps of the strengthening process. The only difference between specimens C5-Rope (Fig. 2.2e) and C6-Rope-debond (Fig. 2.2f) was that CFRP ropes were debonded for $150 \mathrm{~mm}$ at the column base of specimen C6-Rope-debond. At the debonding region, CFRP rope was isolated by a plastic sheet to prevent any bond mechanism between CFRP rope and the surrounding concrete (Fig. 2.3).

\subsubsection{Test setup, instrumentations, and loading protocol}

Fig. 2.4 shows the loading frame used to test the columns under axial and cyclic lateral loads. The specimens were placed horizontally, and each specimen was a combination of two columns connected in the middle by a stiff element (concrete stub $305 \times 450 \times 150$ mm, Fig. 2.1) and supported at the ends by hinge-type supports (Fig. 2.4). The applied lateral load was resisted by the two columns and the recorded response was the average response of the two columns. The axial load was constant, set equal to $0.2 f_{c}^{\prime} A_{g}$ for all specimens. The axial load was monitored manually and continuously during the test using a strain-gauge based load cell connected to a data-logging system. The lateral load was applied using a hydraulic actuator connected to a tension-compression load cell (Fig. 2.4). The lateral loading protocol recommended by ACI 374.2R-13 [41], shown in Fig. 2.5, was 
used in this study. The columns were subjected to four cycles per loading or displacement increment. The first two increments were controlled by $V_{y}$, which was the lateral force required to yield the steel reinforcement in tension. The columns were loaded up to $\mathrm{V}_{\mathrm{y}} / 2$ for the first increment (cycles 1 through cycle 4) and loaded up to $V_{y}$ in the second increment (cycle 5 through cycle 8 ). $\mathrm{V}_{\mathrm{y}}$ was determined when any of the steel strain gauges recorded a strain of 0.0024 .

Displacement-controlled loading protocol was used for the subsequent increments. Yield displacement $(\Delta y)$ was measured from the second increment so that the subsequent displacement increments were $2 \Delta y, 3 \Delta y, 4 \Delta y$, and so on until the specimen failed. Four load cycles per each displacement increment continued until the end of the tests. Displacement was measured using two long LVDTs $(250 \mathrm{~mm})$ instrumented as shown in Fig. 2.4. The test stopped when the drop in lateral strength was more than $50 \%$, or when the loading frame reached its maximum possible displacement $(125 \mathrm{~mm})$. Four strain gauges were used to measure the tensile and compressive strains in the longitudinal steel reinforcing bars in all specimens (Fig. 2.1). To monitor the strains developed in longitudinal CFRP materials, six strain gauges were used for C3-Sheet, thirteen strain gauges for specimen C4-Rod, and nine strain gauges for C5-Rope and C6-Rope-debond, as will be discussed in section 2.4.5. 


\subsection{Results and discussions}

\subsubsection{Load-carrying capacity}

Table 2.5 compares the peak forces and corresponding displacements achieved by each specimen. As shown in Fig. 2.4, the column specimens were tested in a horizontal position. The negative signs in Table 2.5 refer to the values obtained when the force was applied downward (push), and the positive numbers mean that the force was applied upward (pull). As expected, the lateral strength of the control specimen (C1) was the lowest among all specimens. However, strengthening with lateral confinement only (C2-confinemnet) did not have a significant effect on the lateral strength of the column ( $2 \%$ improvement). When CFRP materials were added in the longitudinal direction of the column (flexural strengthening), the enhancement in lateral strength was significant. Strengthening the control column with externally bonded (EB) CFRP sheet (C3-Sheet) and NSM CFRP rods (C4-Rod) improved the lateral strength of columns by $37 \%$ and $44 \%$, respectively (Table 2.5). However, the deflection associated with the peak load for C4-Rod was $28 \%$ larger than that of C3-Sheet (considering the average reported in Table 2.5). Previous studies have shown that the percentage of enhancement for columns strengthened with externally bonded CFRP sheets ranged from $19 \%$ to $87 \%[1,12,42,43]$, and it was $7 \%$ to $86 \%$ for columns strengthened with NSM FRP rods [3,4,14,44-46]. It should be noted that none of the previous studies considered using carbon FRP rods in flexural strengthening of RC columns. Most of the column tests reported in the literature were strengthened in flexure by using glass FRP or basalt FRP rods. 
In the current study, specimen C5-Rope achieved the highest lateral force. The enhancement was $60 \%$ compared to the control specimen. This could be attributed to the larger area of CFRP material in the rope compared to CFRP sheet (C3-Sheet) and rod (C4Rod). C6-Rope-debond was designed to be the same as C5-Rope except that $150 \mathrm{~mm}$ of CFRP rope was debonded at the column base (Fig. 2.2). The design of C6-Rope-debond aimed to increase the ductility of the strengthened column by allowing CFRP rope to deform independent of the concrete. Research in the literature has shown that debonding FRP materials at the base increased the ductility of the strengthened columns [12]. However, in the present study not enough confinement was provided for the CFRP rope to prevent the rope from buckling failure. CFRP ropes in C6-Rope-debond crushed under high compressive stresses as they were not confined adequately. The peak load was 16.02 $\mathrm{kN}$ in the pull direction, but the peak was only $13.45 \mathrm{kN}$ in the push direction since most of the fibers in the rope were crushed in the previous cycle.

\subsubsection{Force-displacement response}

Fig. 2.6 compares the force-displacement hysteresis curves for all specimens. The control column is shown in all graphs of Fig. 2.6 to easily compare the behavior of each column specimen to that of the control column (C1-Control). The load-displacement relationship of C1-Control showed a poor and brittle behavior of the column under axial and cyclic lateral load. The lateral strength started dropping immediately after the column was subjected to the $5^{\text {th }}$ cycle approaching $\mathrm{V}_{\mathrm{y}}\left(1^{\text {st }}\right.$ cycle of the second increment, see section 3.4 
"Test setup, instrumentations, and loading protocol"). The test continued until severe concrete spalling was observed and the force dropped more than $50 \%$ of the peak. However, the data logging system erroneously stopped recording and the data were lost. Confining the columns at the plastic hinge zone with one layer of CFRP sheet (C2Confined) did not noticeably enhance the strength but significantly improved the overall force-displacement response of the column (Fig. 2.6). Because of CFRP confinement, it was not possible to see the failure development and crack patterns during the test. At the end of the test, no significant damage was observed in the CFRP confinement sheets. The test was stopped when the loading frame reached its maximum displacement capacity.

The lateral strength of specimen C3-Sheet was improved by adding EB CFRP sheets in the longitudinal direction (Fig. 2.2). C3-Sheet handled the first two increments (a total of eight cycles) without any strength degradation. EB-CFRP sheet was ruptured when the column was subjected to the $9^{\text {th }}$ cycle; the $1^{\text {st }}$ cycle in increment $3(2 \Delta y)$. CFRP sheet was ruptured on both sides when the displacement approached $2 \Delta y$ in the positive and negative directions. Rupture occurred $38 \mathrm{~mm}$ away from the column-foundation intersection. After CFRP rupture, the column behavior immediately resumed to match the behavior of C2Confined.

The lateral response of specimen C4-Rod was slightly different in terms of strength degradation after the peak load. Unlike C3-Sheet, the lateral force in C4-Rod did not drop rapidly after the peak force as evident in Fig. 2.6. The peak force was obtained during the first cycle of the third displacement increment ( $2 \Delta y$ ), but the force afterward dropped gradually. The gradual drop was most probably caused by limited slippage of CFRP rods, 
which reduced the tensile force in the rod and increased the displacement of the column before CFRP rupture. The same behavior of NSM-FRP rods in flexural strengthening of RC columns was also observed by Yao and $\mathrm{Wu}$ [10]. CFRP rod ruptured at the $4^{\text {th }}$ displacement increment ( $3 \Delta y$ ), and the behavior resumed to that of C2-Confined (Fig. 2.6).

Specimen C5-Rope continued to resist the applied lateral force without strength degradation until most of the fibers in the rope ruptured at the $4^{\text {th }}$ displacement increment (3 $\Delta$ y). It should be noted that C5-Rope is the only specimen that reached a displacement of $3 \Delta y$ (cycle \#13) without strength degradation. Then, the force dropped suddenly to a lower level but not to the point where one could confirm that CFRP rope had completely ruptured. After completing all four cycles of the $4^{\text {th }}$ displacement increment $(3 \Delta y)$, CFRP rope completely ruptured during displacement cycle number $17\left(1^{\text {st }}\right.$ cycle of the $5^{\text {th }}$ displacement increment). The resistance of C5-Rope resumed to that of C2-Confined.

Specimen C6-Rope-debond failed at lower lateral force than specimen C5-Rope. The major difference between the last two columns was that the rope in C6-Rope-debond was debonded for $150 \mathrm{~mm}$ at the base of the column. In retrospect, the area where CFRP was debonded should have been confined well to prevent buckling of CFRP under compression force. At the beginning of the $3^{\text {rd }}$ displacement increment ( $\left.2 \Delta y\right)$, cycle \# 9, CFRP rope in the tension side was healthy, therefore the lateral resistance went all the way up to 16.02 $\mathrm{kN}$. However, when the lateral force reached its maximum in the $9^{\text {th }}$ cycle, CFRP rope in the compression side buckled and most fibers crushed. Therefore, the peak force when the load was applied upward (pull) was higher than the peak force when the load was applied downward (push) as the column was loaded upward first. In the subsequent cycles, strength 
degradation was observed and finally the force-displacement response became similar to the behavior of C2-Confined specimen.

\subsubsection{Load-displacement envelopes}

Fig. 2.7 shows the load-displacement curves for all tested columns. The envelopes were developed from the load-displacement hysteresis curves (Fig. 2.6) by plotting the peaks of all loading increments. Load-displacement envelopes help compare the lateral response of each column to the others. It can be observed that once CFRP ruptured in the columns strengthened in flexure, the load in the columns began to decline somewhat similar to the behavior of the second column (C2-Confined). It can also be observed that the responses were not exactly symmetric. The behavior on the pull side (positive load-displacement) is slightly different from that on the push side (negative load-displacement). The specimens were always loaded in the upward direction first, then followed by applying the load in the downward direction to complete a single cycle. Therefore, when a column was loaded in the downward direction, the compression side of the concrete had already been loaded or cracked in the previous cycle. Another observation is that the strength degradation in externally bonded CFRP technique (C3-Sheet) was more sudden than those observed in NSM-CFRP specimens (C4-Rod, C5-Rope, and C6-debond). Finally, it can be observed that specimen C4-Rod had the best gradual and smooth strength degradation after the peak load. 


\subsubsection{Stability limit and displacement ductility}

Displacement ductility depends mainly on the yield displacement and ultimate displacement. The yield displacement of each specimen was determined experimentally as the displacement recorded when any of the strain gauges attached to steel reinforcement in tension reached a strain of $0.24 \%$. Table 2.6 lists the yield displacements for all specimens. The ultimate displacement is dependent on the structural stability of the member. It is common to associate the ultimate displacement or the displacement capacity with the displacement corresponding to $20 \%$ decay in lateral strength [41]. The " $20 \%$ decay" limit is used as a measure of prevention against lateral instability or collapse. However, for some types of structures, instability may occur before the $20 \%$ decay in lateral strength while other structural members are able to carry axial and lateral loads beyond $20 \%$ decay in lateral strength [41].

For long RC columns, different stability limits have been proposed in the literature. Priestley et al. [47] suggested that the ratio of the secondary moment (P- $\Delta$ effects) to the total moment should not exceed 0.3 . Silva et al. [48] recommend a stability limit of 0.4 , which is less conservative than the limit proposed by Priestley et al. [47]. ACI 318 [31] limits the ratio of the total moment to the primary moment to 1.4. Finally, the stability limit has been defined by Barrera et al. as when the secondary moment is equal to the primary moment $[49,50]$. Based on stability limits described above, the corresponding displacements were measured and the resulting ductility for all specimens were determined, as listed in Table 2.6. In addition, the stability limits are visually shown in Fig. 2.8. The total moment in Fig. 2.8 is the total moment resisted by the column due to the 
applied lateral force and constant axial force. The primary moment is the applied lateral force multiplied by the lever arm, and the secondary moment is the axial load multiplied by the lateral deflection.

As shown in Fig. 2.8 and Table 2.6, the ductility resulting from Barrera's stability limit was the highest compared with the ductility by other limits. Of course, considering the maximum measured displacement as the ultimate displacement resulted in ductility even higher than that based on Barrera's stability limit. It was observed that for specimens with sudden drop in lateral strength (C3-Sheet, C5-Rope, and C6-Rope-debond), the ductility calculated based on $20 \%$ decay, ACI limit [31], and Priestley et al. [47] were very close. However, if there is small and gradual (not sudden) strength degradation after the peak, the ductility based on $20 \%$ decay was higher than those based on ACI and Priestley's limits (Specimens C2-Confined and C4-Rod). In most cases, Silva's limit resulted in higher ductility than those based on $20 \%$ decay, ACI limit and Priestley's. It should be noted that specimen C5-Rope had the highest ductility in all tested specimens regardless of the method used to determine the ductility. This was mainly due to the higher stiffness of C5Rope before reaching yield displacement. As shown in Table 2.6, that the yield displacement for C5-Rope was the smallest.

It has been stated in the literature that considering $20 \%$ decay in lateral strength in calculating the displacement capacity of slender RC columns is conservative $[41,51,52]$. Based on the results of the current study, it is observed that $20 \%$ decay is also conservative for slender RC columns strengthened with CFRP. The tested columns were all stable and able to carry the axial load until the end of tests ( $\Delta \mathrm{u}$ in Table 2.6). Some researchers have 
considered the ultimate displacement obtained from tests as the displacement capacity of strengthened RC columns [53-55]. In the current study, if the measured ultimate displacements are considered in evaluating ductility, all strengthened columns had a ductility equal to or more than 5.0. On the other hand, it may be safer to define the stability limit for columns strengthened with CFRP in lateral and longitudinal directions when the secondary moment is equal to the primary moment $[49,50]$. For strengthened slender RC columns both of the above suggestions in defining the displacement capacity are less conservative, however perhaps more realistic than using ACI stability limit [31], Priestley's limit [47], Silva's limit [48], and 20\% decay in lateral strength. Nevertheless, it is important to recognize that stability limits defined by ACI and Priestley are meant for practical column design, which inherently must contain a prudent level of conservatism to partially take into account the effects of creep, shrinkage, excessive accidental eccentricity, limited support settlement, etc., that may be present but generally not taken into account in routine design practices.

\subsubsection{CFRP strains}

Several strain gauges were attached to CFRP materials in the longitudinal direction as shown in Fig 2.9, Fig. 2.10, and Fig. 2.11. The locations of the strain gauges are labeled using a name code consisting of two letters and one number. The first letter ( $\mathrm{R}$ or $\mathrm{L}$ ) indicates whether the strain gauge is on the right or on the left side of the specimen. The second letter (T or B) indicates whether the strain gauge is on the top or on the bottom side 
of the column. Finally, the number at the end refers to the distance (in inches; 1 in. $=25.4$ $\mathrm{mm}$ ) between a strain gauge and the column-foundation intersection. For example, "RT3" means that the strain gauge is on the right-top side and the distance between the strain gauge and the column-foundation intersection is 3 in. $(76 \mathrm{~mm})$. A negative number (for example, the number " -3 " in RT-3) indicates that a strain gauge is embedded inside the foundation.

Fig. 2.9 shows the change in strains over time developed in the CFRP sheets at different critical locations for specimen C3-Sheet. As shown in Fig. 2.9, the maximum strain was achieved in the first cycle of the third increment $(2 \Delta y)$. Then, CFRP sheets were ruptured and very small strains occurred afterwards. The small strains recorded after the rupture of CFRP sheets were based on the stresses developed between the location of CFRP rupture and the location of the strain gauges. The locations of CFRP rupture ranged from 35 to 40 mm away from the column-foundation intersection. The maximum recorded CFRP strain was 0.0083 recorded by $\mathrm{RB} 3$, which was located $38 \mathrm{~mm}$ away from the observed rupture location.

The behavior was slightly different for NSM-CFRP rods. As shown in Fig. 2.10, CFRP strains did not drop immediately after the maximum CFRP strain or stress was achieved. Instead, CFRP strains continued to drop gradually until the fifth loading or displacement increment $(4 \Delta y)$, at which the recorded strains were very small indicating that CFRP rods were completely ruptured (Fig. 2.12). Therefore, the lateral load was decreasing gradually rather than rapidly. The gradual decrease in the lateral load and in CFRP strains were most likely due to limited slippage of CFRP rods. Fig. 2.12 also shows that there was bond 
failure between CFRP rods and epoxy, which probably resulted in limited slippage. This can be explained by examining the strain change over time of LB1.5 (Fig. 2.10). The displacement increment was increased from $2 \Delta y$ to $4 \Delta y$ (loading protocol; Fig. 2.5), while the peak values of CFRP strains were almost constant. Therefore, there should have been releases in the forces developed at CFRP rods. Since CFRP rods do not yield, the release in the force was most likely due to some slippage. The maximum recorded CFRP strain was 0.012 , recorded by RT0 which was less than $10 \mathrm{~mm}$ away from the observed rupture location.

The behavior of NSM-CFRP ropes (Fig. 2.11) was in between the behavior of EB-CFRP sheet (Fig. 2.9) and NSM-CFRP rods (Fig. 2.10). The tensile strain did not drop suddenly like it did with EB-CFRP sheets nor did the strain keep its peak values for several cycles like it did with NSM-CFRP rods. Fig. 2.11 shows that the peak strain was most likely achieved in the first cycle of the fourth displacement increment $(3 \Delta y)$. Although the strain recording was lost on the left side of the specimen (LT0 and LB0) after the peak strain, it can be observed from RT3 that the strain values dropped about $69 \%$ after the recorded peak strain. This suggests that some of the fibers could have fractured causing the drop in CFRP strain and consequently a reduction in the lateral load (Fig. 2.6). At cycle number seventeen, which was the first cycle in the fifth displacement increment $(4 \Delta y)$, the strain increased slightly and then dropped to small values indicating a complete rupture of the NSM-CFRP ropes, as shown in Fig. 2.12. The maximum CFRP strain was equal to 0.009, which was recorded by LT0 (Fig. 2.11). LT0 was located about $25 \mathrm{~mm}$ away from the observed rupture location. 


\subsection{Theoretical prediction}

\subsubsection{Introduction}

A computer-based model was developed using MATLAB software to predict the momentcurvature and load-displacement response of slender RC columns strengthened with EBCFRP sheets and NSM-CFRP rods and ropes and subjected to combination of lateral and constant axial loads. The theoretical analysis in this study does not provide a new method of calculating the moment-curvature or load-displacement response. Instead, the model utilizes the available equations and methods developed in previous studies and guidelines to predict the response of slender RC columns. The mechanical properties of steel reinforcement, concrete, and CFRP determined in the laboratory were used in the model. Based on the results of the moment-curvature, the lateral displacement due to flexural bending was determined. The additional displacements due to shear deformation, rebar slip, and geometric nonlinearity due to P- $\Delta$ effects were also considered.

\subsubsection{Moment-curvature}

The procedure to determine the moment-curvature relationship was iterative which started by assuming a value for concrete strain $\left(\varepsilon_{c}\right)$ at the extreme compression face of a predefined concrete cross section. Based on the assumed concrete strain and the resulting neutral axis, the equilibrium of the forces acting on the cross section was checked. Strain compatibility and force equilibrium had to be satisfied with an error in the resulting forces 
limited to $2.2 \times 10^{-5} \mathrm{kN}$ before proceeding to the next step. The curvature and corresponding moment were then calculated by repeating the procedure for different concrete strains $\left(\varepsilon_{c}\right)$. The initial concrete strain was 0.0004 and it was increased by strain increments of 0.0001 . Initial concrete strain less than 0.0004 caused an error in the model script as the concrete cross-section would be under compressive stresses only. Based on the distribution of the axial strains along the depth of the cross-section (Fig. 2.13), the axial stresses of concrete, steel reinforcement, and CFRP were determined based on the stress-strain relationship of each material. In this study, two models were used to define the stress-strain relationship of confined and unconfined concrete materials. For unconfined concrete and concrete core confined with steel hoops, the model proposed by Mander et al. [56] was utilized, as shown in Fig. 2.14. Further details on how to calculate the concrete stresses corresponding to the assumed concrete strains can be found in original reference [56]. The ultimate concrete strain $\left(\varepsilon_{\mathrm{cu}}\right)$ for the concrete core confined with steel hoops (Fig. 2.14) was the only parameter that was modified in the present study. The authors [56] suggested that the maximum concrete strain $\left(\varepsilon_{\mathrm{cu}}\right)$ for concrete confined with steel was at first hoop rupture. However, this limit was found to be not reasonable for the columns tested in the present study since the hoops were not ruptured. Therefore, an ultimate concrete strain proposed by Paulay and Priestley [57] was used as shown in the following equation:

$$
\varepsilon_{\mathrm{cu}}=0.004+1.4\left(\rho_{\mathrm{x}}+\rho_{\mathrm{y}}\right) \mathrm{f}_{\mathrm{yh}} \frac{\varepsilon_{\mathrm{sm}}}{\mathrm{f}_{\mathrm{cc}}^{\prime}}
$$


Where, $\rho_{\mathrm{x}}$ and $\rho_{\mathrm{y}}$ are the transverse reinforcement ratios in both directions of the column, $\mathrm{f}_{\mathrm{yh}}$ is the yield strength of the hoops, and $\varepsilon_{\mathrm{sm}}$ is the steel tensile strain at maximum stress. It should be mentioned that the model proposed by Mander et al. [56] (Fig. 2.14) was used for the control specimen only. The other five column-specimens were confined with CFRP sheet, and the stress-strain relationship of CFRP-confined concrete was based on the model proposed by Lam and Teng [58], and adopted by ACI 440 [32]. The maximum concrete strain was limited to 0.01 [32]. The stress-strain relationship of CFRP-confined concrete is shown in Fig. 2.15. The unconfined concrete strength $\left(f_{c}^{\prime}\right)$ was taken from the experimental tests for each specimen, but the rest of the parameters shown in Fig. 2.15 were calculated following the procedure proposed by ACI 440 [32].

The longitudinal steel reinforcement was modeled almost exactly similar to the test results obtained from the laboratory. In the model used in the present study, the equations proposed by Raynor et al. [59] were modified with parameters from the test results to obtain the tensile behavior shown in Fig. 2.16. Finally, the CFRP sheets, rods, and ropes were modeled as linear elastic materials. CFRP materials were modeled with constant moduli of elasticity (Table 2.3), and CFRP stresses at any increment were always equal to the strains multiplied by the constant elastic moduli.

Once the internal forces were in equilibrium and convergence attained, the section curvature and the corresponding moment were determined. Then, the concrete strain was increased by 0.0001 and the process described above was repeated until concrete strain 
reached its ultimate strain, i.e., Eq. 1 for C1-Control and ACI 440 [32] for strengthened specimens.

\subsubsection{Load-displacement response}

The total displacement in a long RC column is the summation of flexural deformation, including the effects of secondary (P- $\Delta$ ) moment, shear deformation, and deformation due to additional column rotation caused by steel rebar slip at the base of the column. Based on the moment and curvature distributions along the length of the column established in the previous section, the second moment-area theorem was applied to find the flexural deformation $\left(\Delta_{\text {flexural }}\right)$ associated with each moment. Then, displacements due to shear deformation $\left(\Delta_{\text {shear }}\right)$ and steel rebar slip $\left(\Delta_{\text {slip }}\right)$ were added. The total moment was then determined by adding the secondary moment (axial load $\mathrm{x}\left[\Delta_{\text {flexural }}+\Delta_{\text {shear }}+\Delta_{\text {slip }}\right]$ ) to the primary moment (lateral load x column length). Based on the calculated total moment, a new displacement was determined using the same procedure. An iteration procedure was followed to check that the new displacement $(\Delta \mathrm{i}+1)$ was very close to the previously calculated displacement $(\Delta \mathrm{i})$ so that the difference was smaller than $0.025 \mathrm{~mm}$ before continuing to the next step. This procedure was followed to account for the deformation resulting from $\mathrm{P}-\Delta$ effects, as the additional displacements due to shear deformation and steel rebar slip were predefined using equations available in the literature. The word "slip" does not refer to an actual slippage of steel reinforcement, but instead, it refers to an additional displacement caused by steel deformation when longitudinal rebar yields. The 
displacement associated with rebar slip was determined using an equation proposed by Sezen and Moehle [60], which depends on the stress and strain developed in the steel rebar, the diameter of the rebar, and the bond strength between steel rebars and concrete. Finally, the shear deformation was calculated by dividing the moment by the effective shear area and by the effective shear modulus [61].

The distribution of the curvature along the column length is approximately linear up to the yielding moment. After yielding, the plastic curvature is concentrated in the plastic hinge length. The plastic hinge was estimated to be formed at a theoretical distance using a wellknown equation proposed by Paulay and Priestley [57]. After establishing the location of the plastic hinge, any increase in the curvature due to increasing the applied load was distributed between the base of the column (concrete stub) and the location of the plastic hinge. The increase in the load after yielding, however, did not affect the distribution of the curvature between the plastic hinge and the hinge support (Fig. 2.4).

\subsubsection{Theoretical-experimental comparison}

Fig. 2.17 compares the predicted load-displacement curves to the experimental results. In general, the results obtained from the theoretical analysis are in good agreement with the experimental results. Up to the yielding point, the theoretical and experimental loaddisplacement relationships were almost identical for all specimens. For C1-Control and C2-Confined, the yield strength was very close to the maximum strength (Table 2.7). Then, the effects of secondary moment caused strength degradation until the end of the test. For 
specimens strengthened in longitudinal direction (C3 through C6), the load increased after the yield point with lower stiffness until CFRP ruptured. The maximum strength for the columns strengthened in flexure was achieved when CFRP rupture occurred. Theoretically, once CFRP sheets, rods, and ropes ruptured, the behavior of the columns resumed to match the behavior of C2-Confined. For specimen C4-Rod, the theoretical behavior after rupture was different from the experimental behavior because the theoretical model did not consider the effects of CFRP rod slippage. Theoretically, the analyses could be terminated at the strain limits labeled in Fig. 2.17 (based on [32,57]). However, the theoretical loaddisplacement curves were extended to end at theoretical displacements close to those obtained experimentally for comparison purposes.

Table 2.7 compares the theoretical and experimental results in terms of yield strength, maximum strength, and displacements at yield and at maximum strength. The theoretical procedure well predicted the yield strength and the maximum strength. The predicted yield strengths and maximum strengths ranged from $88 \%$ to $109 \%$ and from $91 \%$ to $107 \%$ of those obtained from the experimental results, respectively. The prediction of the displacements was less accurate but still close to the actual displacements. The predicted yield displacements were always less than the actual displacements except for specimen C5-Rope, for which the predicted and actual displacements were almost equal. The predicted displacements at maximum strength varied from $65 \%$ to $146 \%$ of those obtained from experimental results. Fig. 2.17 and Table 2.7 show that the best prediction was for specimen C5-Rope. Since no previous studies on the use of CFRP ropes in flexural strengthening of RC columns are currently available, engineers may wish to use the 
equations available in the literature and follow the procedure presented in the present study to predict the load-displacement relationship for RC columns strengthened in flexure with CFRP ropes. More data in this area are needed.

\subsubsection{Parametric study - Area of CFRP}

Using the theoretical model proposed in this study, a parametric study was conducted to investigate the effects of CFRP reinforcement ratio on the behavior of strengthened RC columns. Columns strengthened with NSM-CFRP ropes were chosen for this study. All structural materials and design features were the same as specimen C5-Rope. The only variable was the amount of CFRP used in flexural strengthening. Specimen C5-Rope had one NSM-CFRP rope on each flexural side. The reinforcement ratio of CFRP $\left(\rho_{\text {frp }}\right)$ for one rope on each side was $0.57 \%$ (the total area of CFRP ropes on both sides divided by the gross area of the column). The amount of CFRP investigated in this parametric study was half a rope $\left(\rho_{\text {frp }}=0.29 \%\right)$, one rope $\left(\rho_{\text {frp }}=0.57 \%\right)$, one and a half ropes $\left(\rho_{\text {frp }}=0.86 \%\right)$, two ropes $\left(\rho_{\text {frp }}=1.15 \%\right)$, and three ropes $\left(\rho_{\text {frp }}=1.72 \%\right)$. Fig. 2.18 compares the momentcurvature responses for the tested specimens. It can be observed that using more CFRP in flexure increases the lateral capacity of the strengthened columns, as expected. However, the curvature capacity of the strengthened columns reduces with increasing FRP materials. Using CFRP reinforcement ratio more than $0.57 \%$ changes the failure mode from CFRP rupture to concrete compressive failure. In this study, the concrete in compression was considered failed if the concrete compressive strain exceeds 0.01 (ACI 440.2R). Fig. 2.18 shows that for CFRP reinforcement ratios more than $0.57 \%$, the expected failure mode is 
concrete compression. On the other hand, reducing the reinforcement ratio to less than $0.57 \%$ reduces the lateral strength but does not increase the curvature capacity of the strengthened columns. Whether one rope of CFRP $\left(\rho_{\text {frp }}=0.57 \%\right)$ or half a rope $\left(\rho_{\text {frp }}=0.29\right.$ $\%$ ) is used for flexural strengthening, the compression failure of concrete (axial strain = 0.01) occurs after CFRP rupture at about the same curvature capacity. Therefore, it is recommended to limit the CFRP reinforcement ratio to about $0.60 \%$, similar to specimen C5-Rope.

The behavior demonstrated by this parametric study is analogous to the behavior of steel reinforced concrete beams where a large amount of steel (more than $\rho_{\max }$ ) results in primary compression failure of concrete, and less than desirable ductility.

\subsection{Conclusions}

Externally bonded CFRP and NSM-CFRP techniques for flexural strengthening of RC columns were investigated by experimentally testing six square RC column specimens. NSM-CFRP ropes were used for the first time in flexural strengthening of RC columns. Based on the results of this study, the following conclusions can be drawn:

1. Both techniques, EB-CFRP and NSM-CFRP, can effectively be used to improve the flexural strength of deficient RC columns. The lateral strength of columns strengthened with EB-CFRP sheets and NSM-CFRP rods were increased by $37 \%$ and $44 \%$, respectively. 
2. The force-displacement response of columns strengthened with NSM-CFRP rods was more desirable than that of the columns strengthened with EB-CFRP sheets because the strength degradation after the peak lateral load was more gradual for NSM-CFRP rods compared with EB-CFRP sheets.

3. Strengthening a column with NSM-CFRP ropes can improve the lateral strength significantly; the percentage of enhancement was $60 \%$. However, the forcedisplacement response was not ductile and sudden strength degradation was observed.

4. Debonding of NSM-CFRP materials at the base of a column aiming to allow CFRP ropes to deform independent of the concrete to increase column deformability was not successful. Debonding CFRP ropes may require more confinement and probably a different debonding technique to prevent buckling of CFRP ropes under high compressive forces. This observation needs to be further investigated as it was based on testing one column with debonded NSM-CFRP rope.

5. The yield displacement for C5-Rope was the smallest and the ductility was the highest compared to all other tested columns regardless of the method used to calculate the ductility.

6. Considering $20 \%$ decay in lateral strength as the stability limit resulted in displacement ductility that ranged from 1.74 to 3.39. However, all strengthened specimens achieved displacement ductility equal or higher than 5.0 when the ultimate recorded displacement was considered. 
7. The theoretical procedure followed in this study well predicted the loaddisplacement of RC columns strengthened with EB-CFRP sheets and NSM-CFRP rods and ropes. The predicted maximum strengths varied from $91 \%$ to $107 \%$ of the experimental values.

8. Among all specimens, the best prediction of the load-displacement behavior was for specimen C5-Rope (strengthened with NSM-CFRP ropes).

9. To preserve adequate ductility, it is recommended to limit the CFRP reinforcement ratio to about $0.6 \%$, similar to specimen C5-Rope. 


\subsection{Tables}

Table 2.1 Concrete compressive strength

\begin{tabular}{lcccccc}
\hline Specimen & C1-Control & C2-Confined & C3-Sheet & C4-Rod & C5-Rope & $\begin{array}{c}\text { C6-Rope- } \\
\text { debond }\end{array}$ \\
\hline $\begin{array}{l}\text { Strength, } \\
\text { MPa }\end{array}$ & 23.8 & 22.2 & 23.2 & 19.0 & 20.5 & 19.2 \\
\hline
\end{tabular}

Table 2.2 Mechanical properties of steel bars and wires

\begin{tabular}{lccccccc}
\hline Label & $\begin{array}{c}\text { Diameter, } \\
\mathrm{mm}\end{array}$ & $\begin{array}{c}\text { Area, } \\
\mathrm{mm}^{2}\end{array}$ & $\begin{array}{c}\text { Yield } \\
\text { strength, } \\
\mathrm{MPa}\end{array}$ & $\begin{array}{c}\text { Yield } \\
\text { strain }\end{array}$ & $\begin{array}{c}\text { Elastic } \\
\text { modulus, } \\
\text { GPa }\end{array}$ & $\begin{array}{c}\text { Ultimate } \\
\text { strength, MPa }\end{array}$ & $\begin{array}{c}\text { Ultimate } \\
\text { strain, MPa }\end{array}$ \\
\hline $\begin{array}{l}\text { No. 9, deformed } \\
\text { bar }\end{array}$ & 9.5 & 71 & 493 & 0.0024 & 200 & 765 & 0.05 \\
$\begin{array}{l}\text { No. 6, smooth } \\
\text { wire }\end{array}$ & 6.4 & 32 & 393 & 0.0022 & 180 & 514 & 0.05 \\
\hline
\end{tabular}

\section{Table 2.3 Mechanical properties of CFRP materials used in flexural strengthening}

\begin{tabular}{lccccc}
\hline \multicolumn{7}{l}{ Nominal properties of CFRP materials (from technical data sheet) } \\
\hline $\begin{array}{c}\text { Tensile strength, } \\
\mathrm{MPa}\end{array}$ & $\begin{array}{c}\text { Cross-sectional } \\
\text { area, } \mathrm{mm}^{2}\end{array}$ & $\begin{array}{c}\text { Max. force, } \\
\mathrm{kN}\end{array}$ & $\begin{array}{c}\text { Tensile modulus, } \\
\mathrm{GPa}\end{array}$ & $\begin{array}{c}\text { Tensile } \\
\text { strain, \% }\end{array}$ \\
\hline CFRP sheet & 3,530 & 16.95 & 60 & 233 & 1.50 \\
CFRP rod & 2,241 & 31.67 & 71 & 124 & 1.81 \\
CFRP rope & 2,100 & 64.5 & 135 & 230 & 0.91 \\
\hline Experimental properties of CFRP & materials & & & \\
CFRP sheet & 3,123 & 16.95 & 53 & 233 & 1.34 \\
CFRP rod & 2,509 & 31.67 & 79 & 156 & 1.61 \\
CFRP rope & 1,180 & 64.50 & 76 & 140 & 0.84 \\
\hline
\end{tabular}

Table 2.4 Test specimens and CFRP strengthening details

\begin{tabular}{cccccc}
\hline Label & $\rho_{\ell}$ & $\begin{array}{c}\text { Flexural strengthening } \\
\text { method }\end{array}$ & $\begin{array}{c}\text { A FRP per } \\
\text { flexural side }\end{array}$ & $\begin{array}{c}\rho_{\text {frp }} \\
\%\end{array}$ & Confinement \\
\hline C1-Control & 1.26 & None & 0.00 & 0.00 & None \\
C2-Confined & 1.26 & None & 0.00 & 0.00 & 1 layer of CFRP sheet \\
C3-Sheet & 1.26 & 100-mm wide EB-CFRP sheet & $16.95 \mathrm{~mm}^{2}$ & 0.15 & 1 layer of CFRP sheet \\
C4-Rod & 1.26 & No. 6 NSM-CFRP rod & $31.67 \mathrm{~mm}^{2}$ & 0.28 & 1 layer of CFRP sheet \\
C5-Rope & 1.26 & NSM-CFRP rope & $64.50 \mathrm{~mm}^{2}$ & 0.57 & 1 layer of CFRP sheet \\
C6-Rope- & 1.26 & NSM-CFRP rope debonded at & $64.50 \mathrm{~mm}^{2}$ & 0.57 & 1 layer of CFRP sheet \\
debond & & the column base & & \\
\hline
\end{tabular}


Table 2.5 Maximum measured force for all columns

\begin{tabular}{lccc|ccc|c}
\hline Specimen & \multicolumn{3}{c|}{$\begin{array}{c}\text { Peak force, } \\
\text { kN }\end{array}$} & \multicolumn{2}{c|}{$\begin{array}{c}\text { Deflection at peak force, } \\
\text { mm }\end{array}$} & $\begin{array}{c}\text { Percentage of } \\
\text { enhancement in lateral } \\
\text { strength }\end{array}$ \\
\hline & Pull & Push & Average & Pull & Push & Average & \\
C1-Control & 10.87 & -10.90 & 10.88 & 28.72 & -29.58 & 29.15 & 1.00 \\
C2-Confined & 11.19 & -10.96 & 11.08 & 29.06 & -30.80 & 29.93 & 1.02 \\
C3-Sheet & 15.03 & -14.83 & 14.93 & 32.59 & -32.15 & 32.37 & 1.37 \\
C4-Rod & 15.98 & -15.26 & 15.62 & 41.52 & -41.30 & 41.41 & 1.44 \\
C5-Rope & 17.33 & -17.54 & 17.43 & 45.95 & -30.29 & 38.12 & 1.60 \\
C6-Rope-debond & 16.02 & -13.45 & 14.74 & 35.57 & -35.09 & 35.33 & 1.35 \\
\hline
\end{tabular}

Table 2.6 Ductility of tested specimens

\begin{tabular}{|c|c|c|c|c|c|c|c|c|}
\hline \multicolumn{3}{|c|}{ Category } & $C 1$ & $C 2$ & C3 & C4 & C5 & C6 \\
\hline \multirow{2}{*}{\multicolumn{2}{|c|}{$\begin{array}{l}\text { Yield displacement } \Delta y, \\
\mathrm{~mm}\end{array}$}} & $(+)$ & 23.37 & 24.13 & 21.59 & 24.56 & 17.71 & 22.99 \\
\hline & & $(-)$ & -25.15 & -24.64 & -22.10 & -24.56 & -16.63 & -23.07 \\
\hline \multirow{6}{*}{ 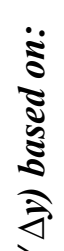 } & \multirow{2}{*}{$\begin{array}{l}20 \% \text { decay in lateral } \\
\text { strength }\end{array}$} & $(+)$ & 2.31 & 2.98 & 1.83 & 3.14 & 3.39 & 2.24 \\
\hline & & $(-)$ & 2.45 & 3.27 & 1.74 & 2.85 & 3.07 & 2.34 \\
\hline & \multirow[t]{2}{*}{ ACI limit [31] } & $(+)$ & 1.88 & 1.95 & 2.32 & 2.61 & 3.27 & 2.30 \\
\hline & & $(-)$ & 1.59 & 1.54 & 1.95 & 2.20 & 3.13 & 1.95 \\
\hline & \multirow[t]{2}{*}{ Priestley et al. [47] } & $(+)$ & 1.97 & 2.03 & 2.36 & 2.53 & 3.39 & 2.35 \\
\hline & & $(-)$ & 1.75 & 1.87 & 2.13 & 2.36 & 3.37 & 2.17 \\
\hline \multirow{6}{*}{ 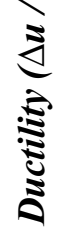 } & \multirow[t]{2}{*}{ Silva et al. [48] } & $(+)$ & 2.48 & 2.74 & 3.15 & 3.34 & 3.95 & 2.91 \\
\hline & & $(-)$ & 2.47 & 2.72 & 2.99 & 3.18 & 4.39 & 2.90 \\
\hline & \multirow[t]{2}{*}{ Barrera et al. [49] } & $(+)$ & N/A & 3.69 & 4.26 & 3.91 & 4.52 & 3.48 \\
\hline & & $(-)$ & N/A & 3.57 & 4.07 & 3.83 & 5.59 & 3.64 \\
\hline & \multirow[t]{2}{*}{ Max. measured $\Delta \mathrm{u}$} & $(+)$ & 2.78 & 5.17 & 6.34 & 5.08 & 6.88 & 5.41 \\
\hline & & $(-)$ & 2.56 & 4.99 & 6.39 & 5.04 & 7.89 & 5.45 \\
\hline
\end{tabular}

Table 2.7 Theoretical-experimental comparison

\begin{tabular}{|c|c|c|c|c|c|c|c|c|c|c|c|c|}
\hline \multirow[t]{2}{*}{ Label } & \multicolumn{3}{|c|}{ Yield strength, kN } & \multicolumn{3}{|c|}{$\Delta$ at yield, $\mathrm{mm}$} & \multicolumn{3}{|c|}{$\begin{array}{c}\text { Maximum strength, } \\
\mathrm{kN}\end{array}$} & \multicolumn{3}{|c|}{$\Delta$ at maximum, $\mathrm{mm}$} \\
\hline & Expt. $^{1}$ & Theo. $^{2}$ & $(2) /(1)$ & Expt. $^{1}$ & Theo. $^{2}$ & $(2) /(1)$ & Expt. $^{1}$ & Theo. $^{2}$ & $(2) /(1)$ & Expt. $^{1}$ & Theo. $^{2}$ & $(2) /(1)$ \\
\hline C1 & 10.50 & 10.05 & 0.96 & 23.37 & 18.29 & 0.78 & 10.87 & 10.10 & \begin{tabular}{c|}
0.93 \\
\end{tabular} & 28.72 & 18.79 & 0.65 \\
\hline $\mathrm{C} 2$ & 10 & 10 & 0. & 24.13 & 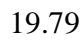 & & 9 & 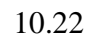 & & 6 & & \\
\hline C3 & 13.17 & 11.56 & 0.88 & 21.59 & 17.84 & 0.8 & 15.03 & 14.28 & 0.95 & 32.59 & 35.18 & 1.08 \\
\hline C4 & 13.12 & 11.8 & 0.9 & 24.56 & 17.84 & 0. & 15.98 & 17 & 1.07 & 41 & 49.75 & 1.20 \\
\hline C5 & 11.08 & 12. & 1.09 & 17.71 & 17.76 & 1.00 & 17.33 & 17.58 & 1.01 & 45.95 & 51.96 & 1.13 \\
\hline C6 & 13.21 & 12.10 & 0.92 & 22.99 & 17.76 & 0.77 & 16.02 & 17.58 & 1.10 & 35.57 & 51.96 & 1.46 \\
\hline
\end{tabular}

Notes:

${ }^{1}$ The results were obtained from experimental tests

${ }^{2}$ The results were obtained from theoretical analysis 


\subsection{Figures}

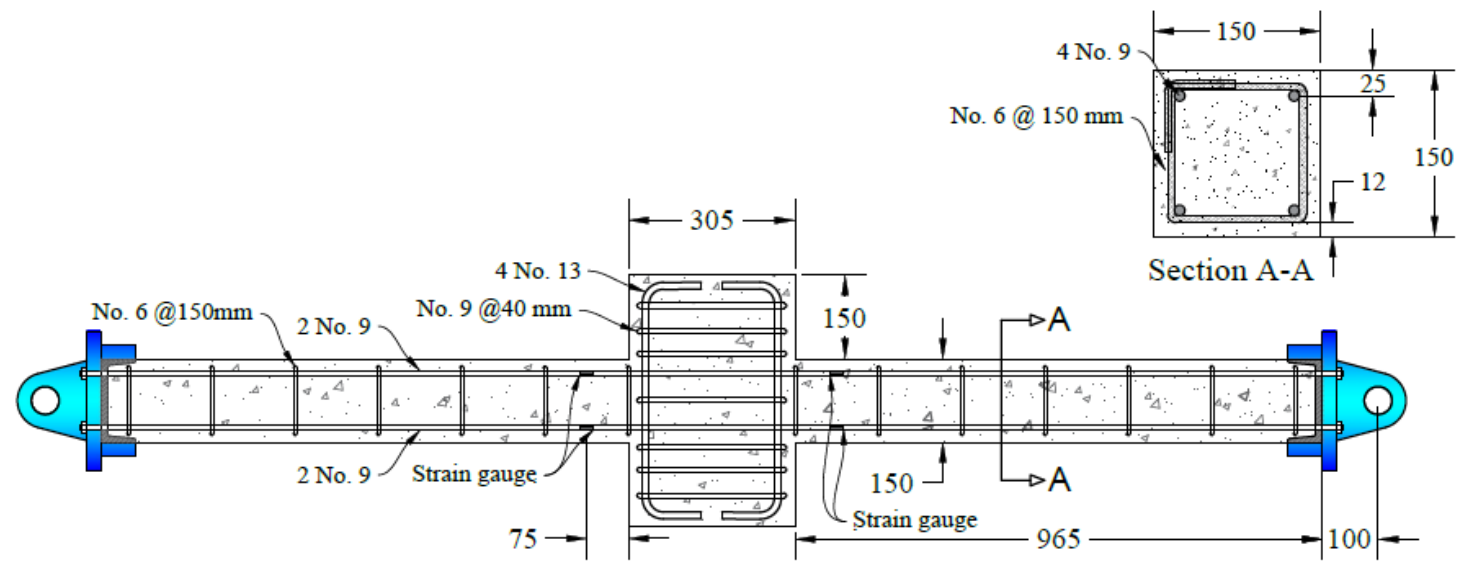

Fig. 2.1 Details of RC columns 


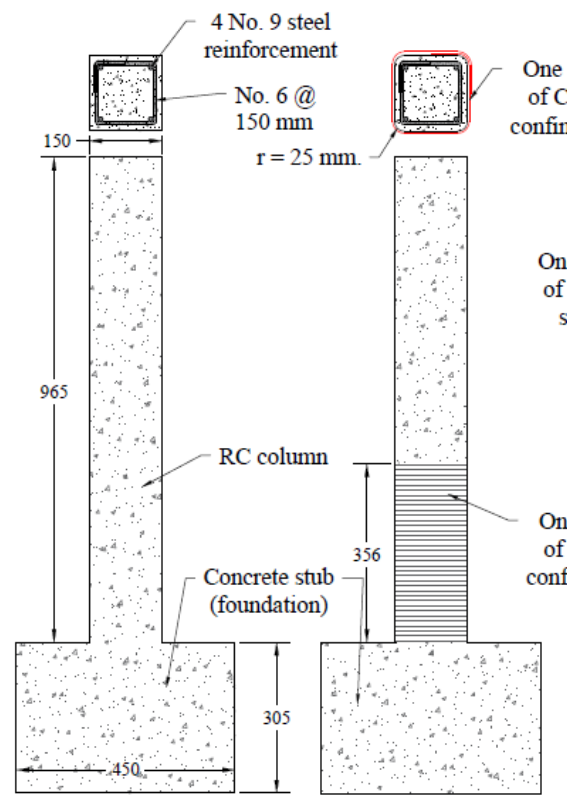

$\begin{array}{ll}\text { (a) C1-Control } & \text { (b) C2-Confined }\end{array}$

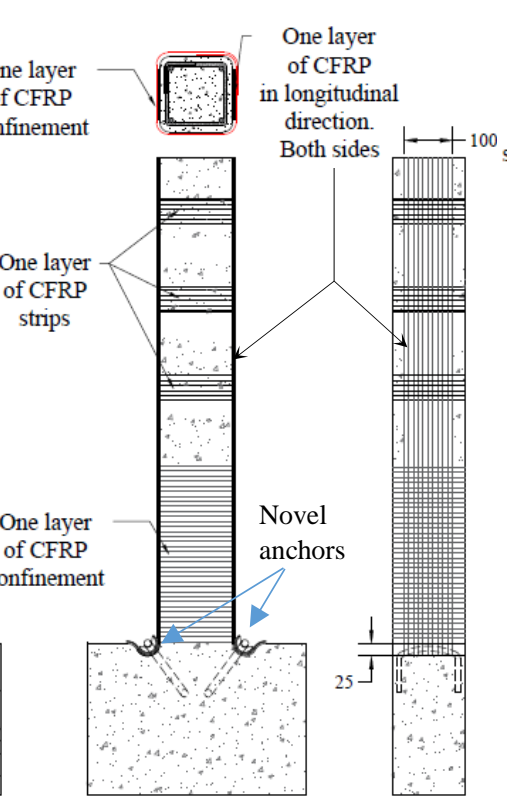

(c) C3-Sheet

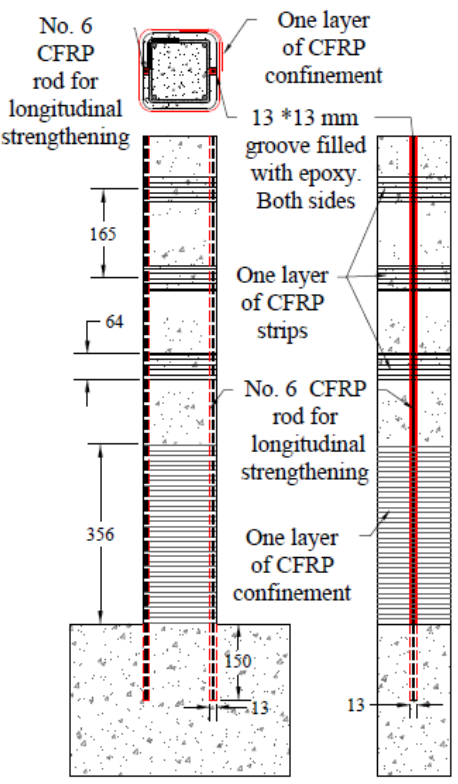

(d) C4-Rod

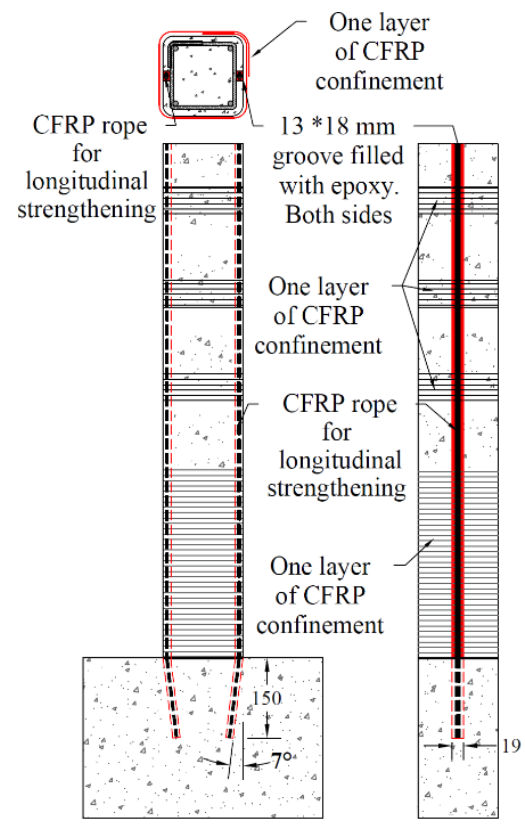

(e) C5-Rope

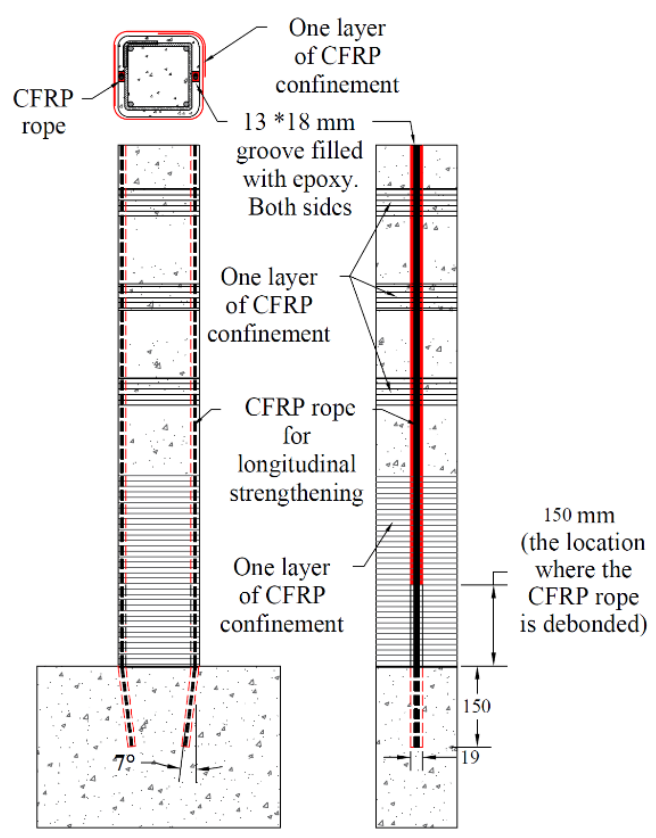

(f) C6-Rope-debond

Fig. 2.2 Test specimens and strengthening technique for each column 


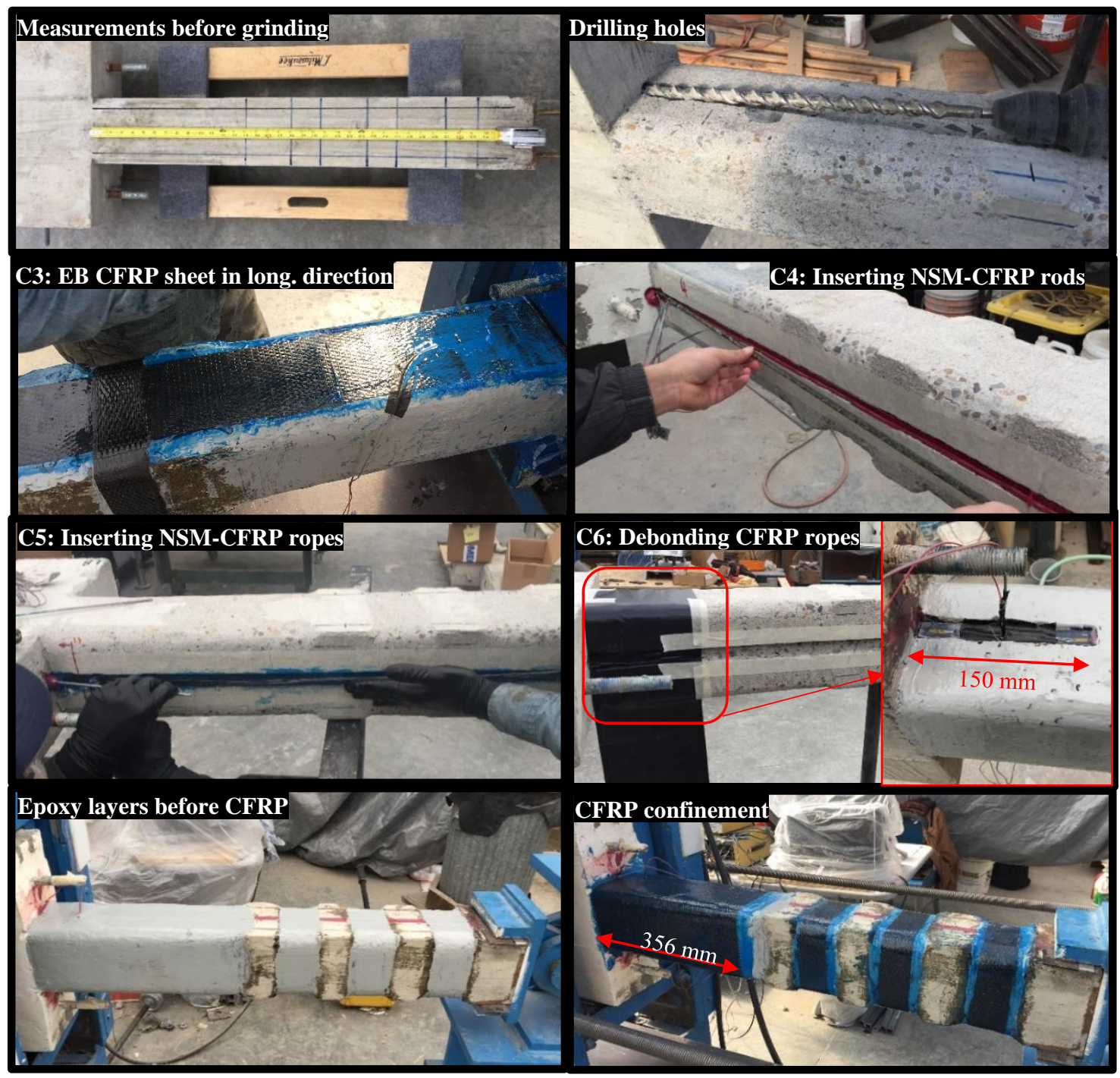

Fig. 2.3 Photos showing the strengthening process 


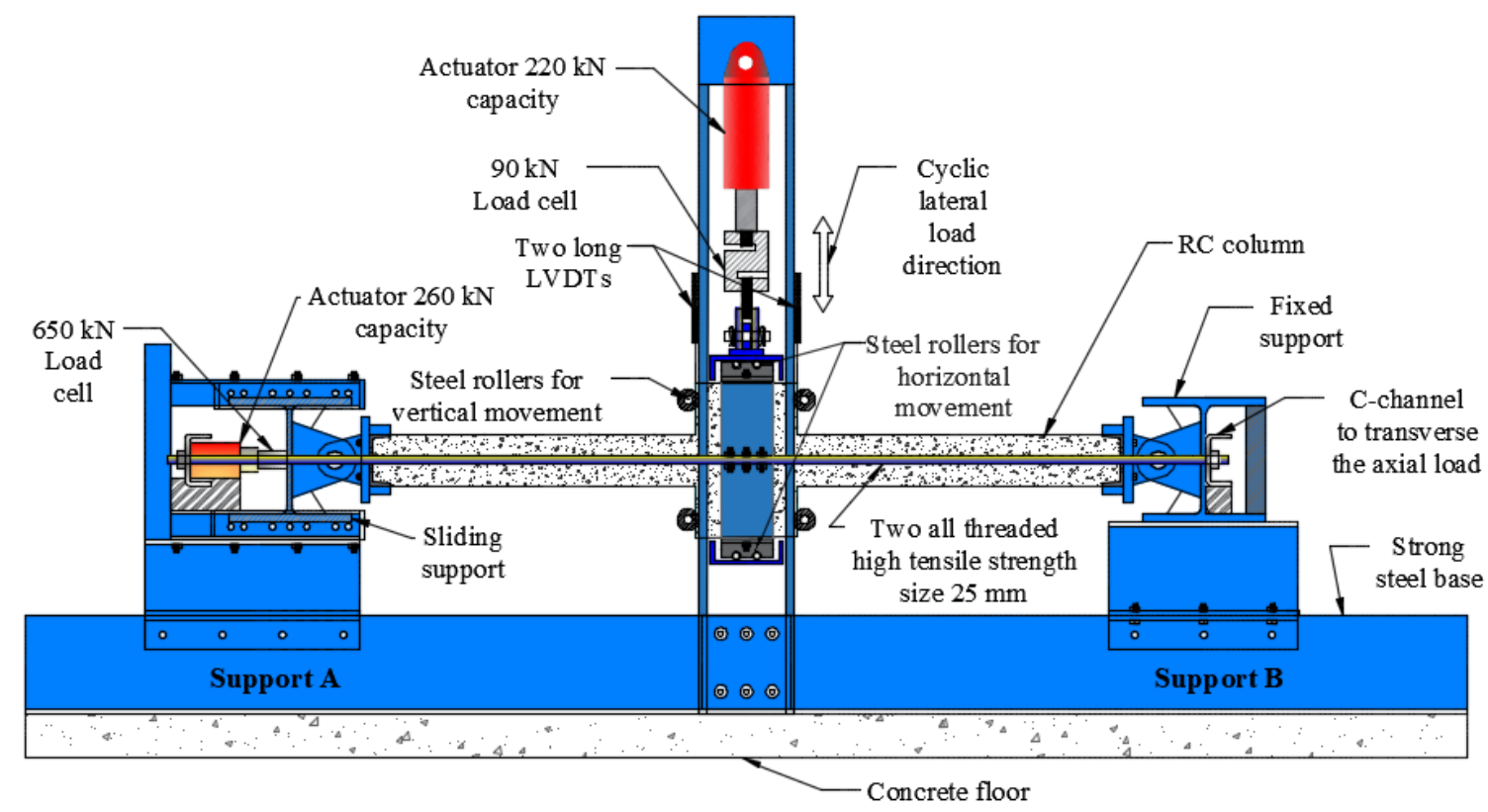

Fig. 2.4 Test setup

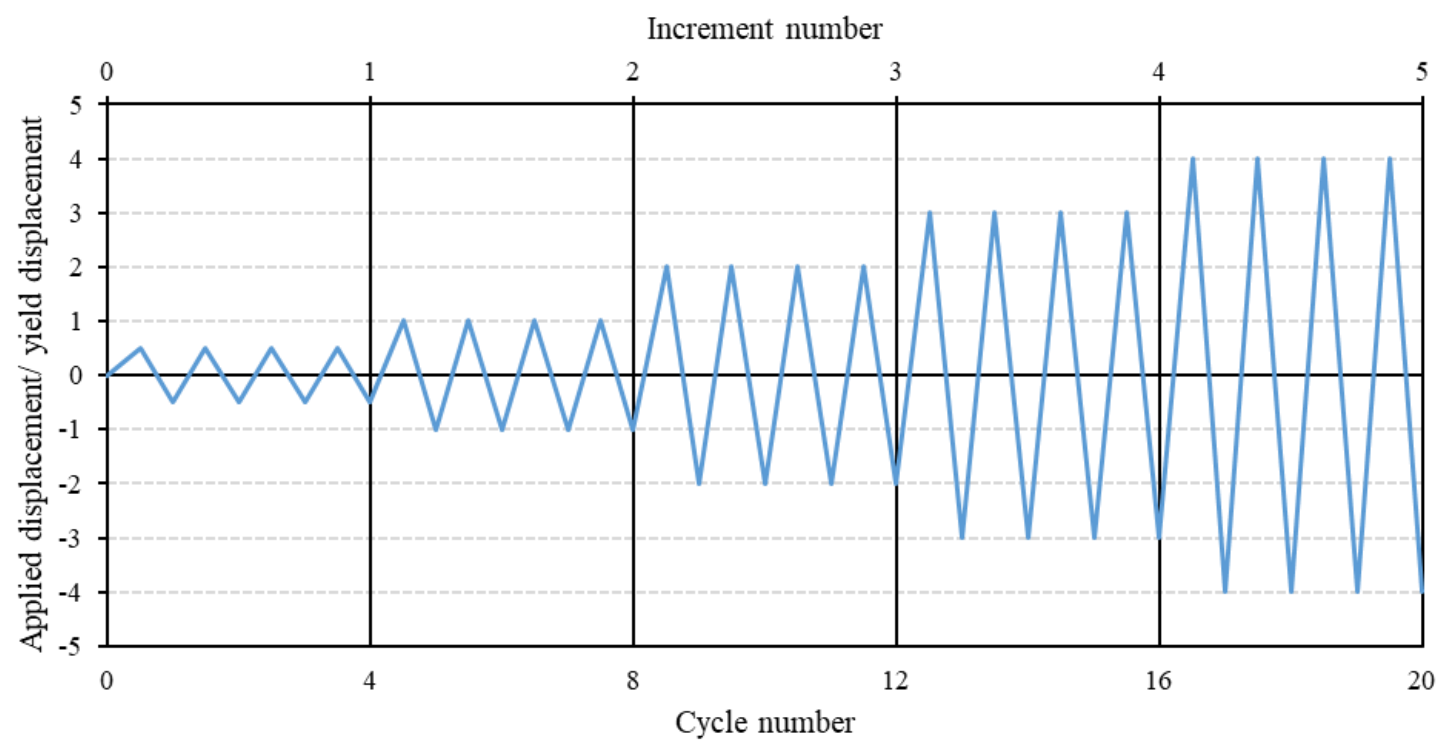

Fig. 2.5 Loading protocol 

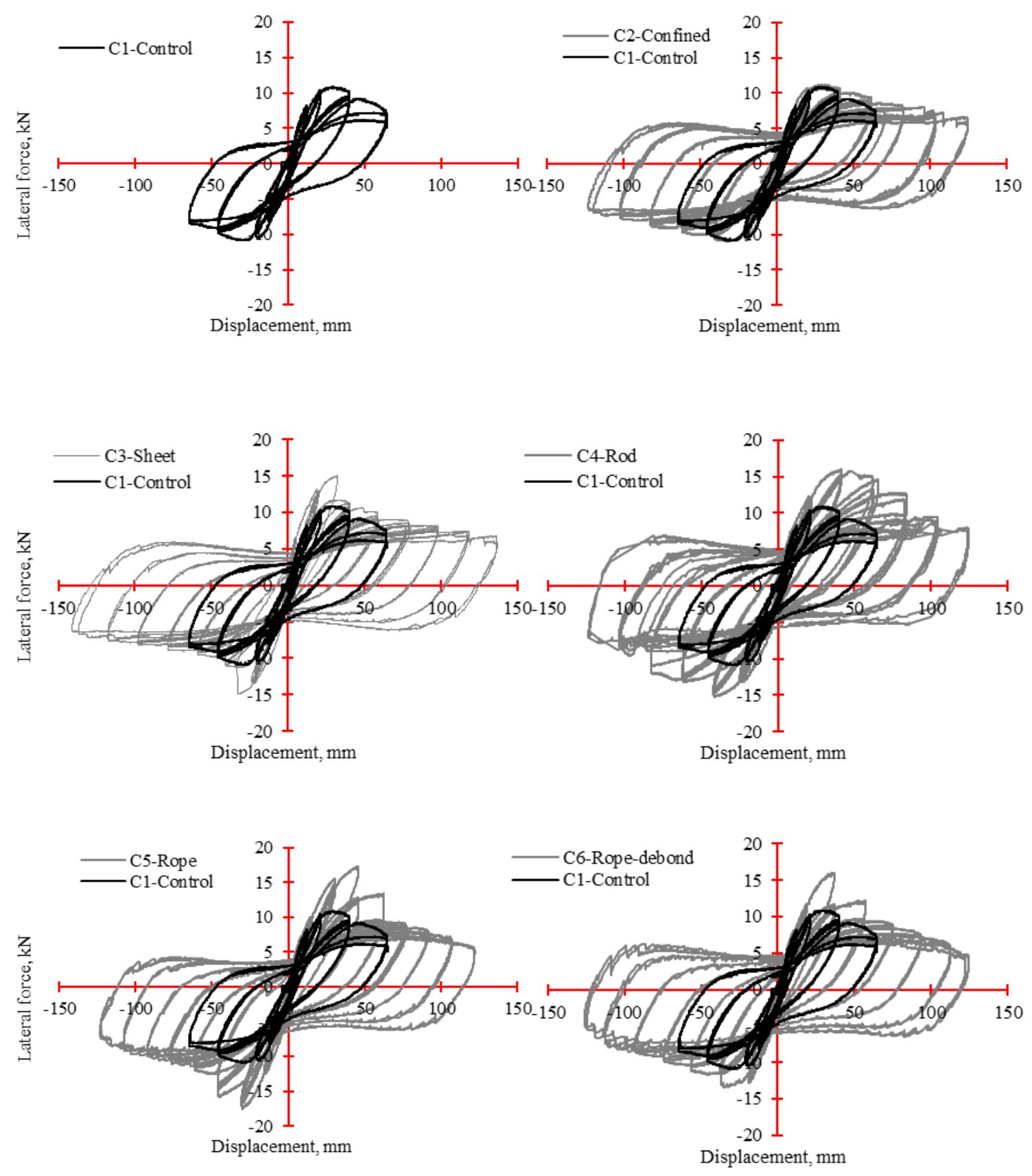

Fig. 2.6 Load-displacement relationships for control and strengthened columns 


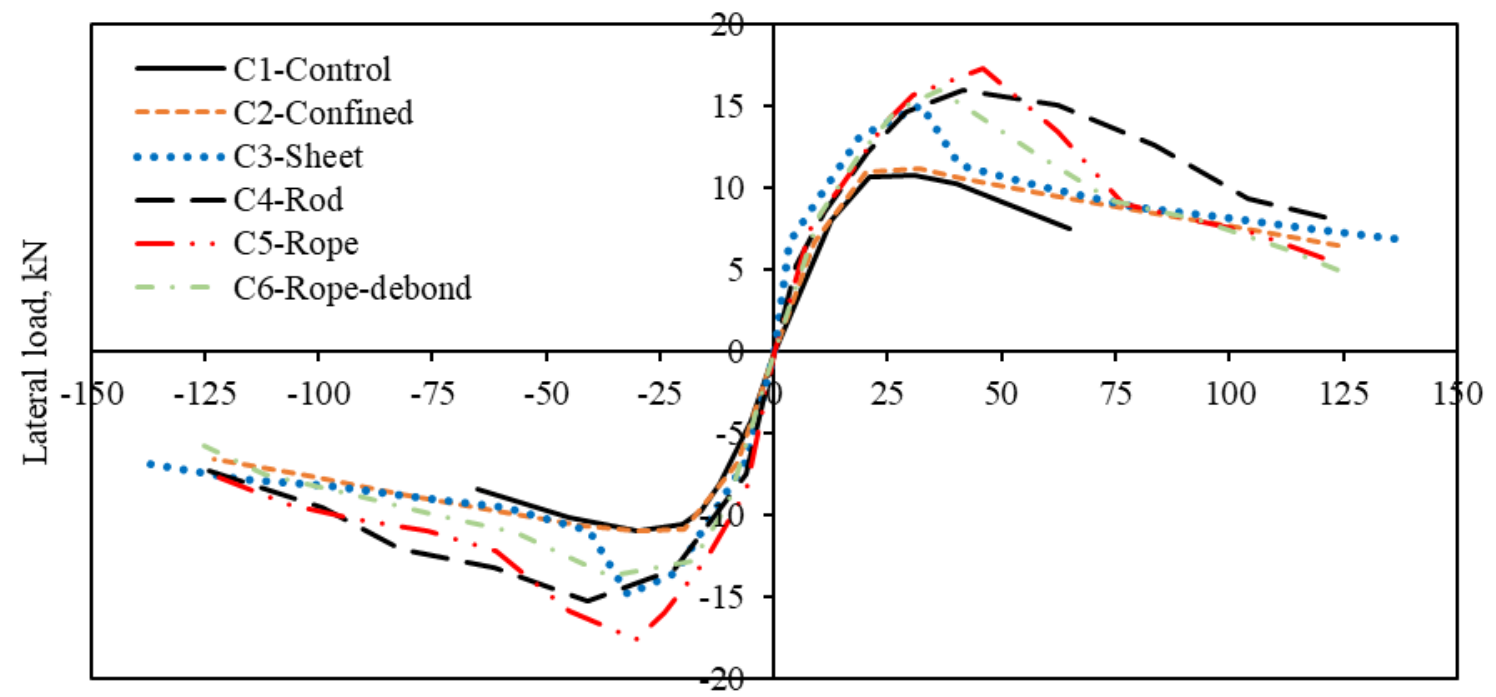

Lateral displacement, $\mathrm{mm}$

Fig. 2.7 Load-displacement envelopes 

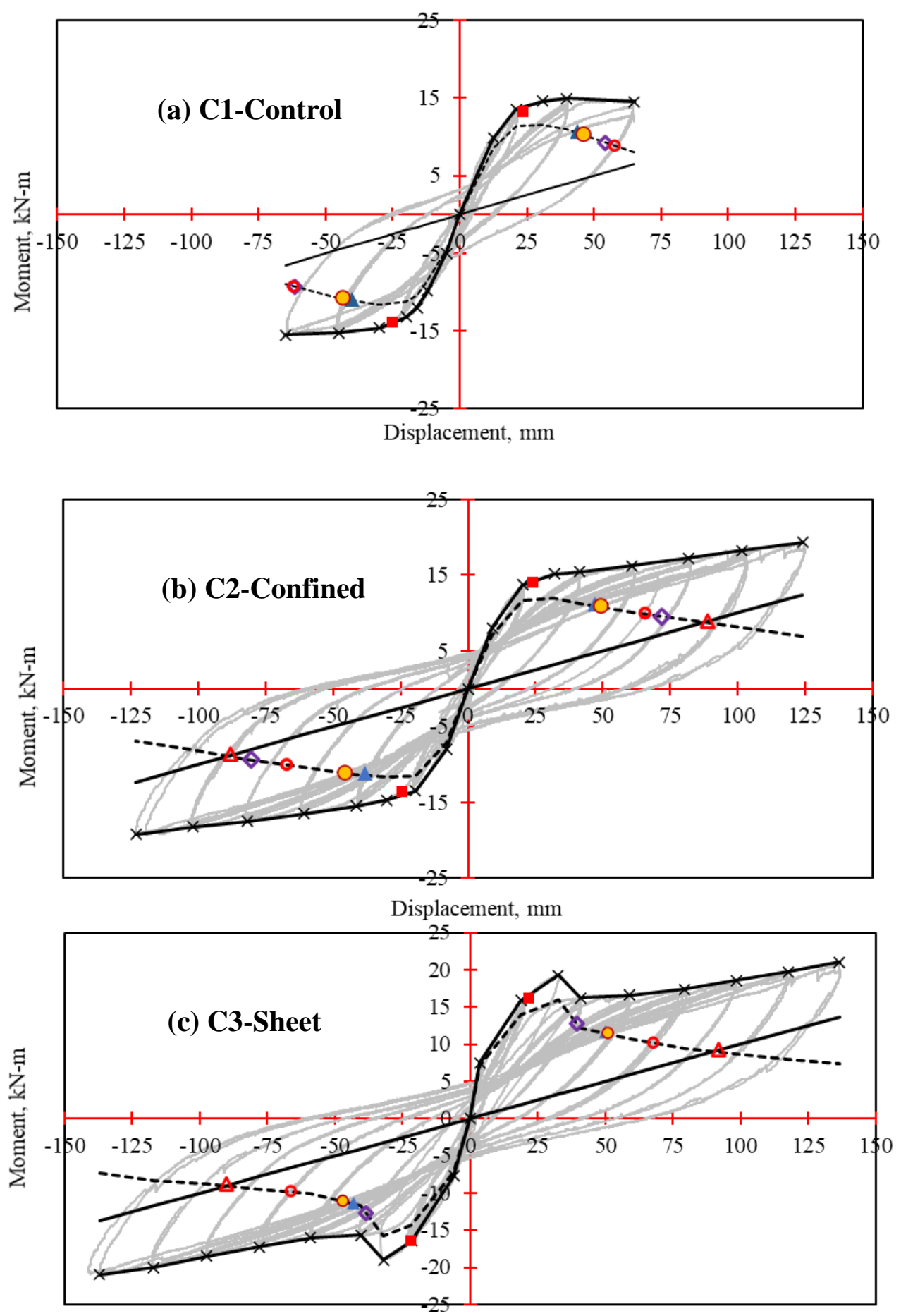

Displacement, $\mathrm{mm}$

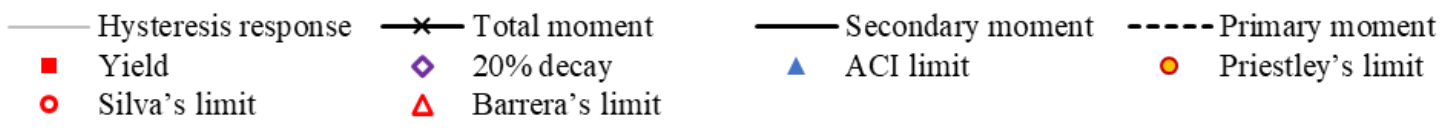

Fig. 2.8 Moment-displacement relationships; ductility and stability limits 


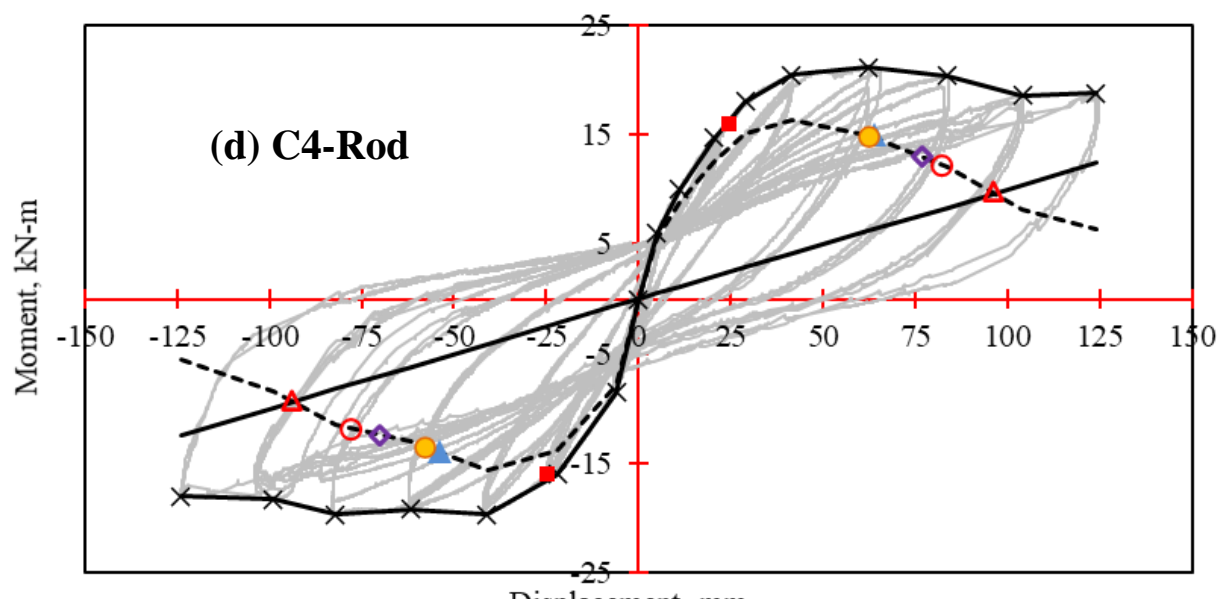

Displacement, $\mathrm{mm}$

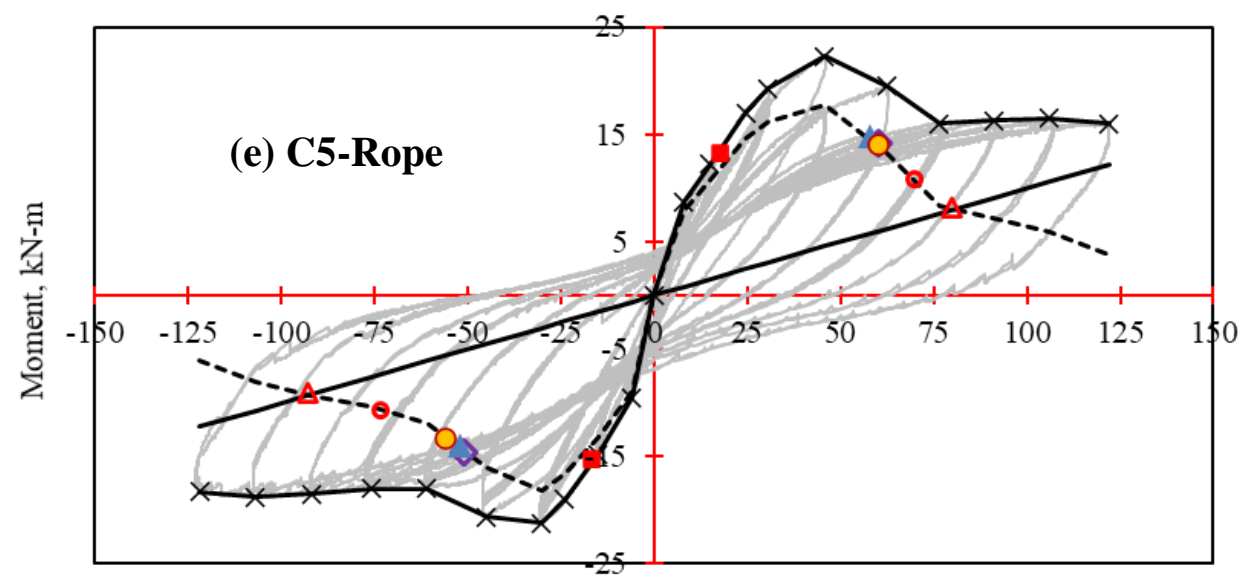

Displacement, $\mathrm{mm}$

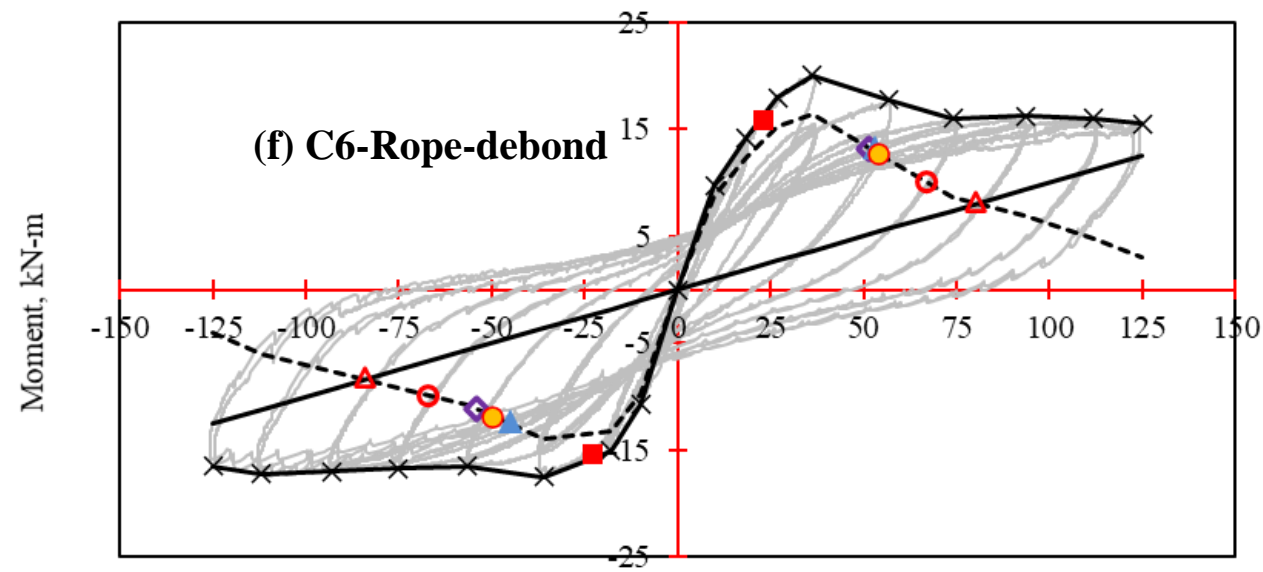

Displacement, $\mathrm{mm}$

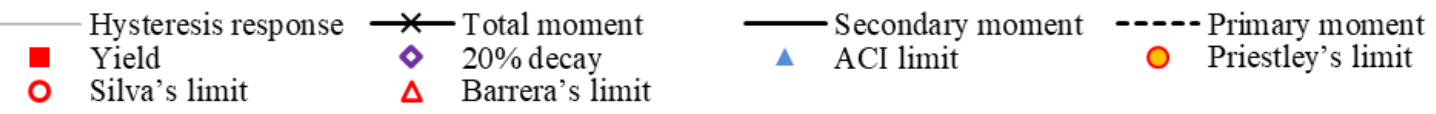

Fig. 2.8 Moment-displacement relationships; ductility and stability limits (continued) 


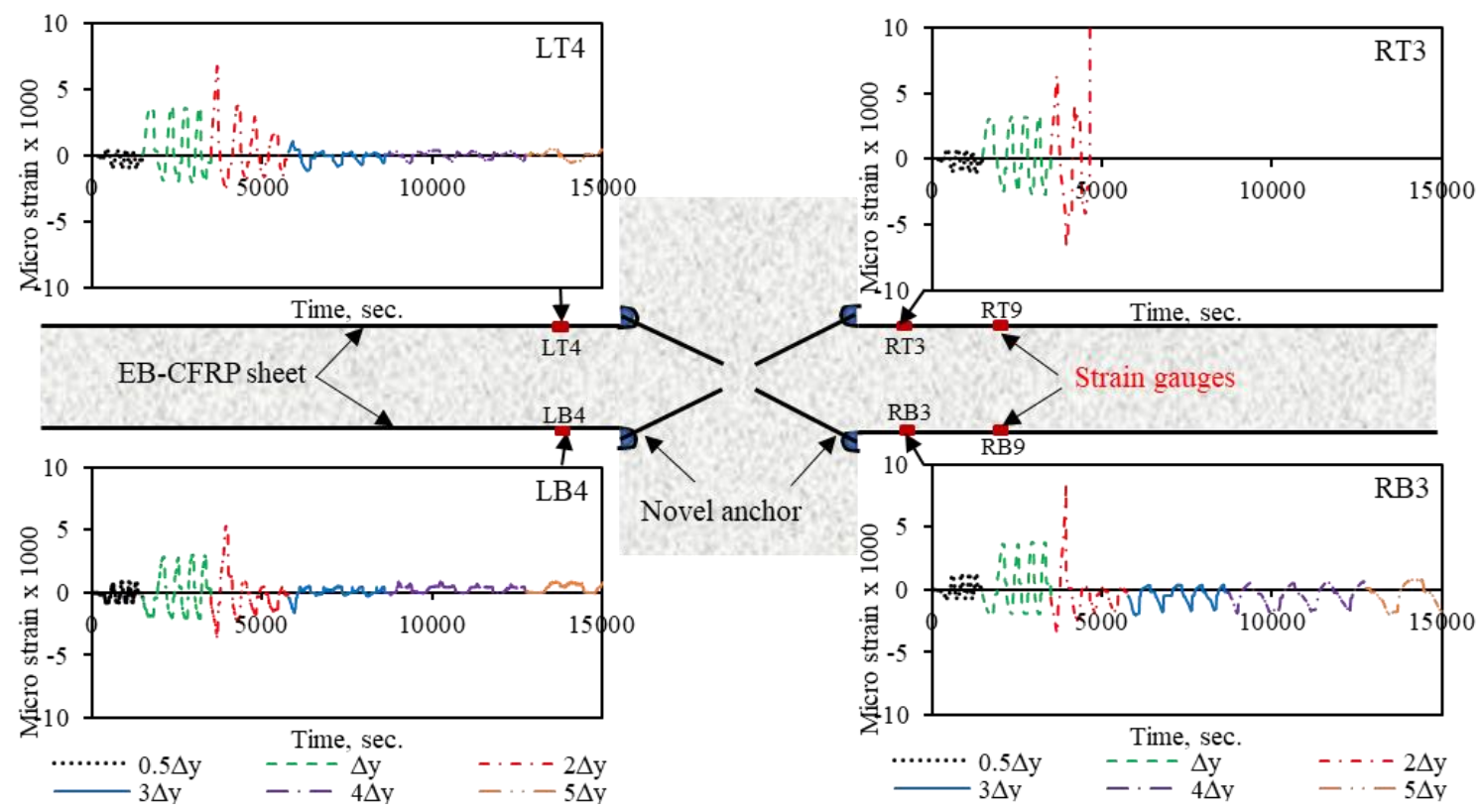

Fig. 2.9 Axial strains developed at CFRP sheets in longitudinal direction

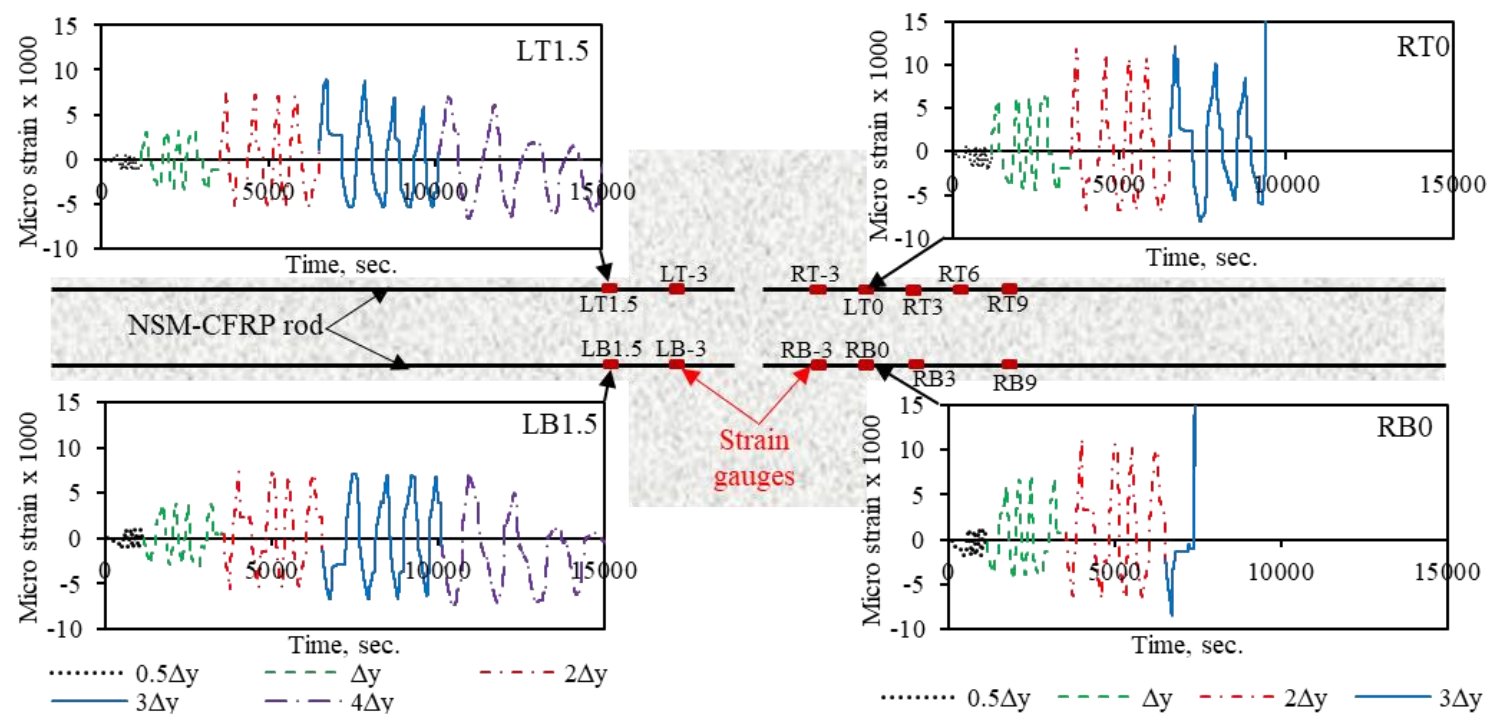

Fig. 2.10 Axial strains developed at CFRP rods in longitudinal direction 

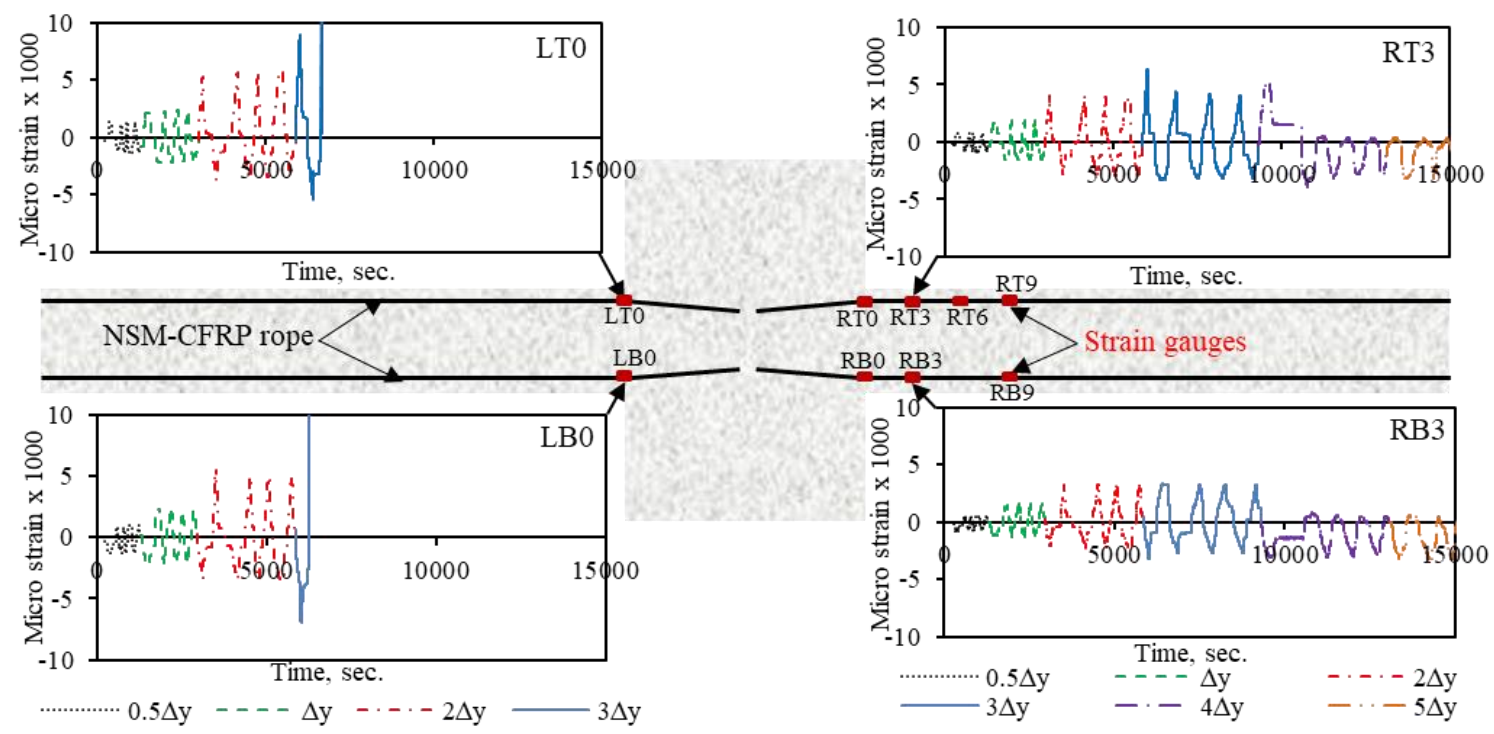

Fig. 2.11 Axial strains developed at CFRP ropes in longitudinal direction

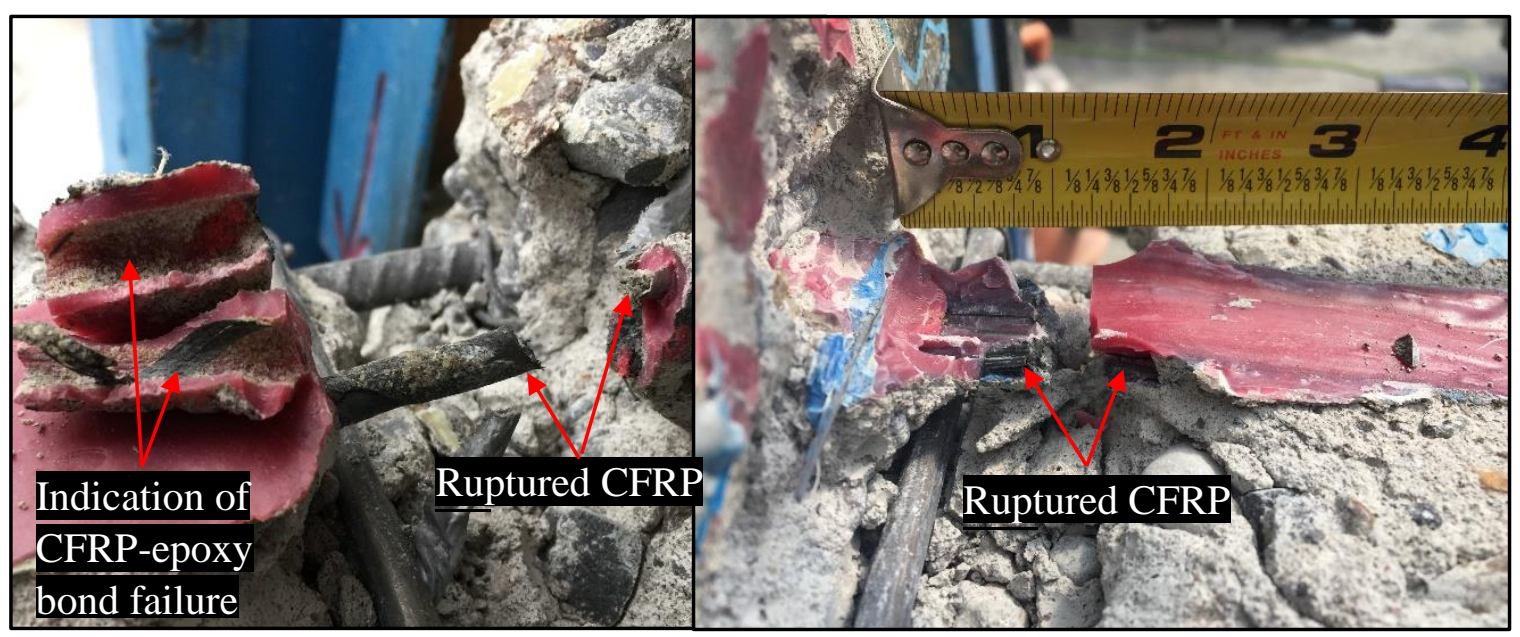

Fig. 2.12 Photos of CFRP ruptures 


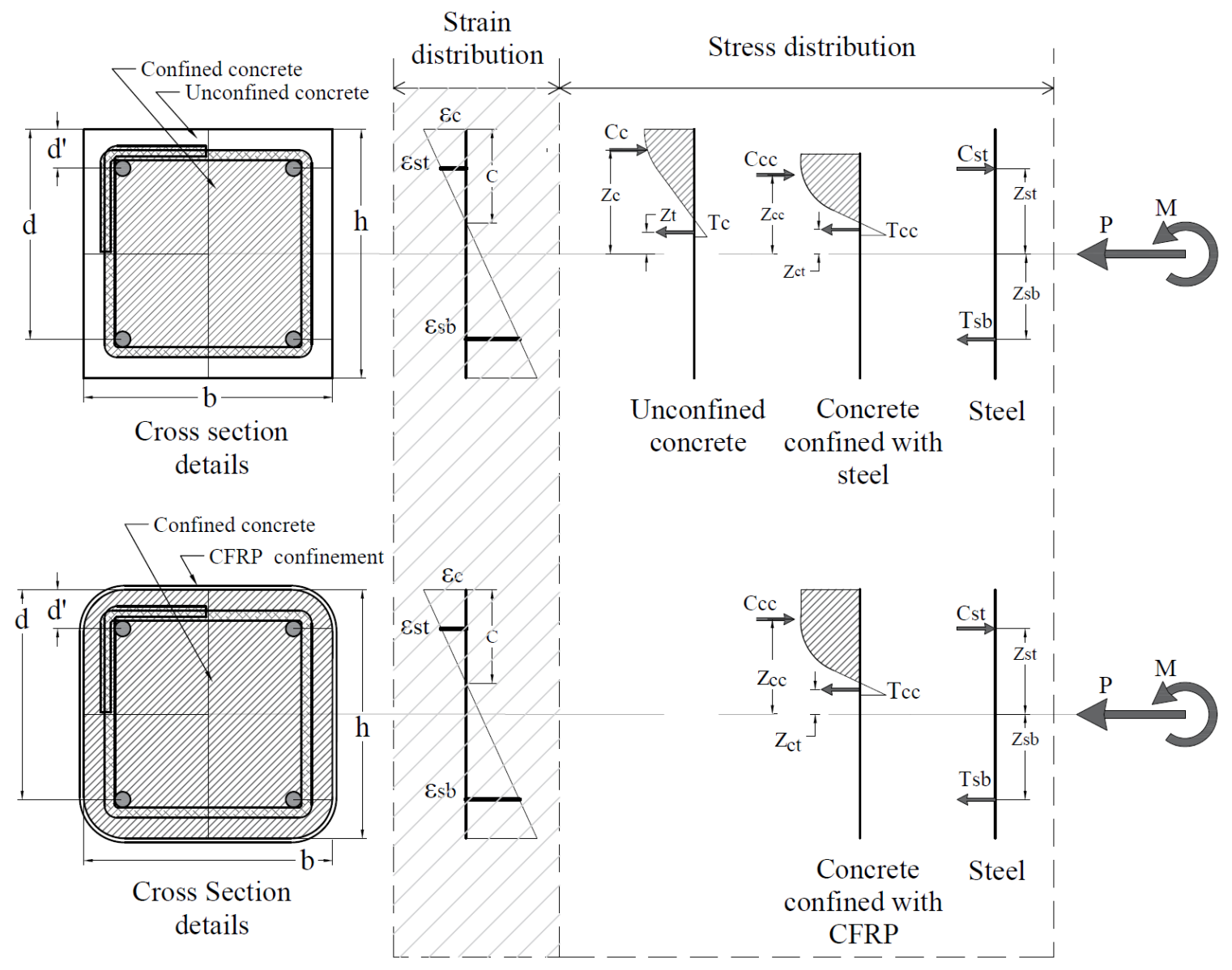

Fig. 2.13 Cross-sectional analysis - strain and stress distributions 


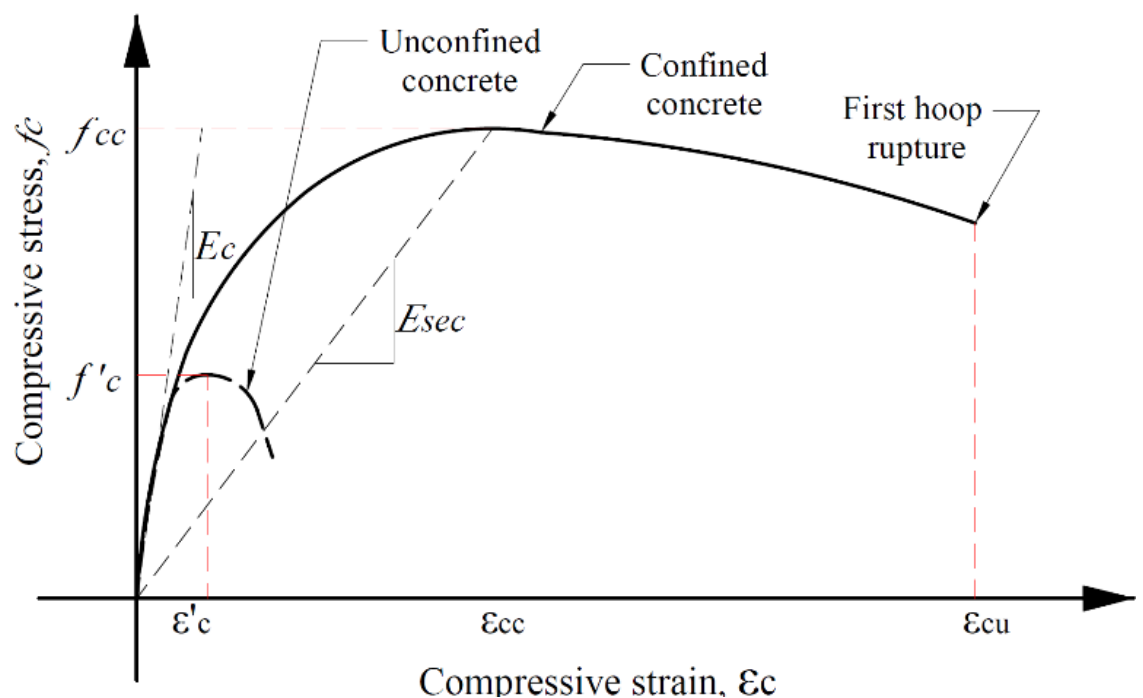

Fig. 2.14 Stress-strain curves for unconfined concrete and concrete confined with steel hoops

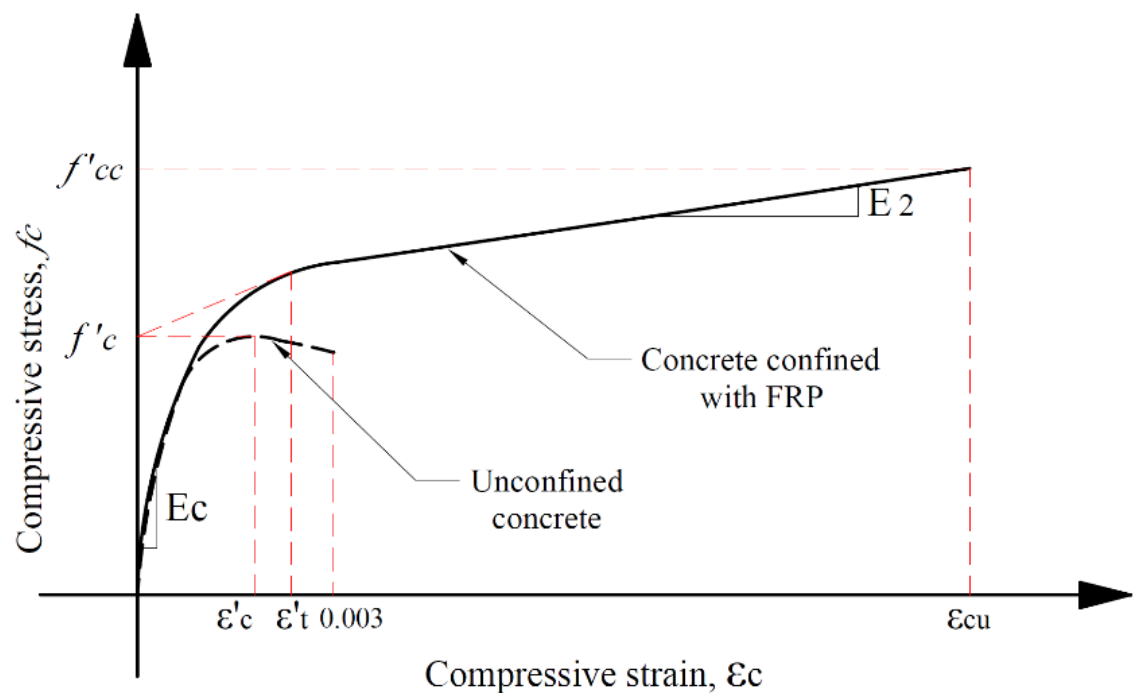

Fig. 2.15 Stress-strain curve for CFRP confined concrete 


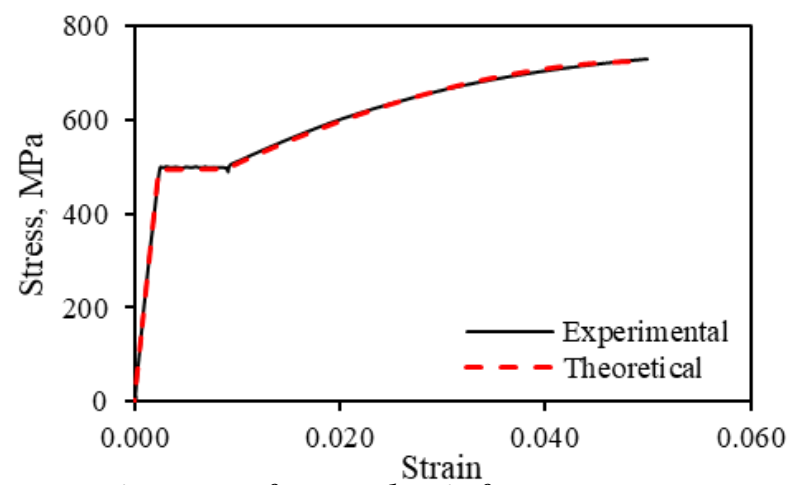

Fig. 2.16 Stress-strain curve for steel reinforcement
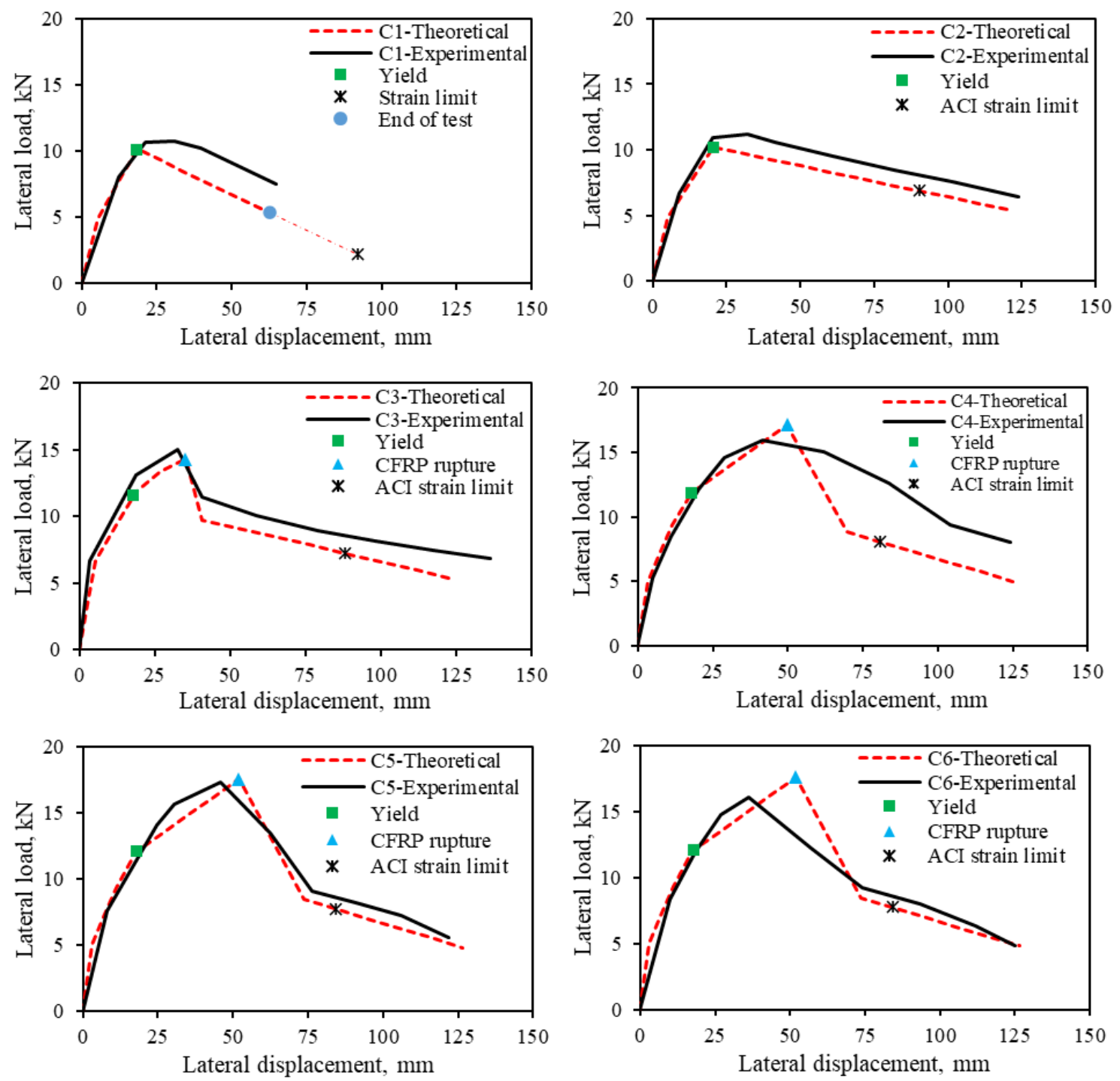

Fig. 2.17 Theoretical-experimental comparison 


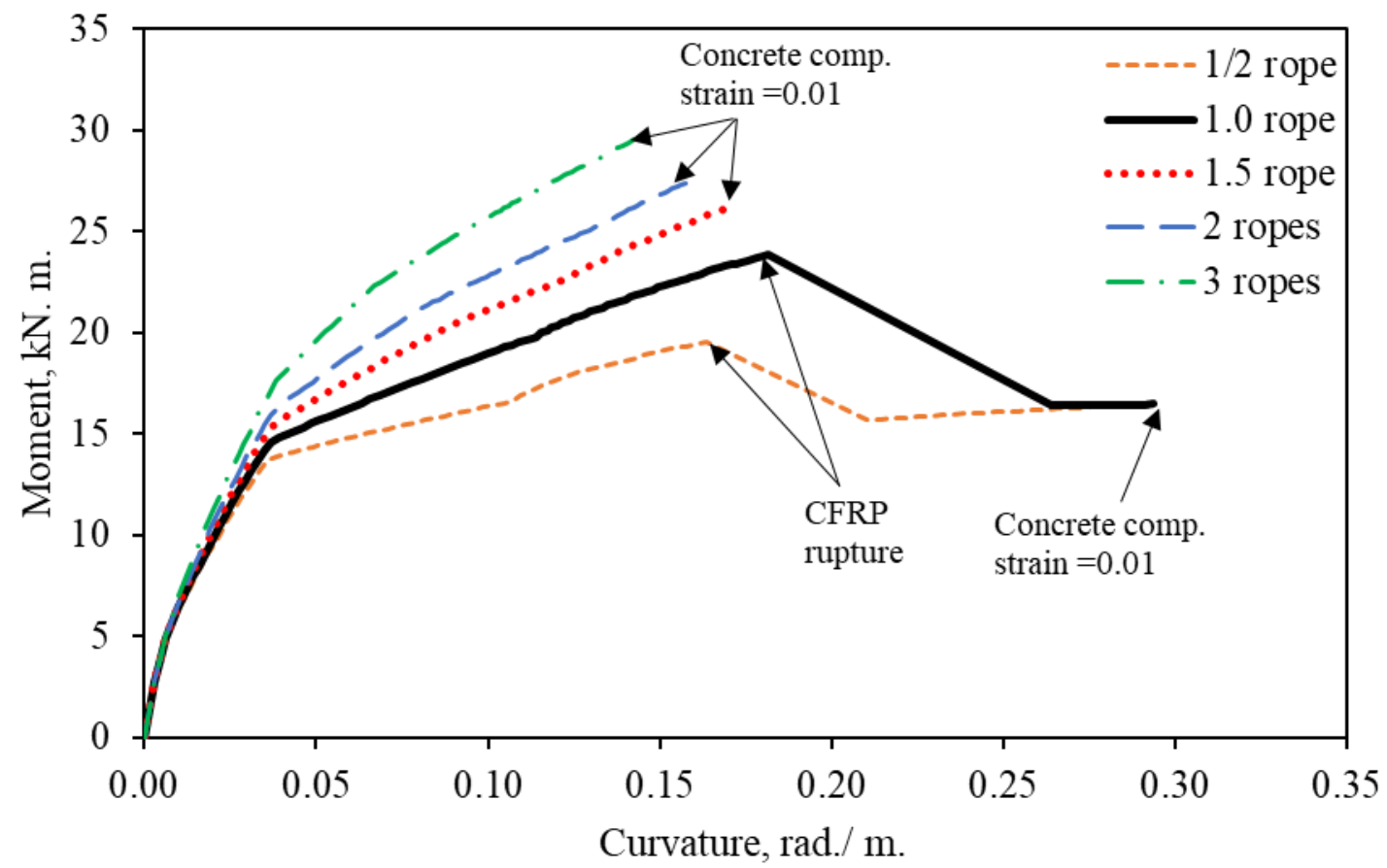

Fig. 2.18 Moment-curvature relationships for different CFRP reinforcement ratios 


\section{References - Chapter 2}

[1] Vrettos I, Kefala E, Triantafillou TC. Innovative flexural strengthening of reinforced concrete columns using carbon-fiber anchors. ACI Struct J 2013;110:63-70. doi:10.14359/51684330.

[2] Alkhrdaji T, Nanni A. Flexural strengthening of bridge piers using FRP composites. Struct. Congr. 2000, Philadelphia, Pennsylvania, United States: ASCE - American Society of Civil Engineers; 2012, p. 1-13. doi:10.1061/40492(2000)174.

[3] Li X, Lv HL, Zhang GC, Sha SY, Zhou SC. Seismic retrofitting of rectangular reinforced concrete columns using fiber composites for enhanced flexural strength. J Reinf Plast Compos 2013;32:619-30. doi:10.1177/0731684413477222.

[4] Seifi A, Hosseini A, Marefat MS, Khanmohammadi M. Seismic retrofitting of oldtype RC columns with different lap splices by NSM GFRP and steel bars. Struct Des Tall Spec Build 2018;27:1-21. doi:10.1002/tal.1413.

[5] Mugahed Amran YH, Alyousef R, Rashid RSM, Alabduljabbar H, Hung CC. Properties and applications of FRP in strengthening RC structures: A review. Structures 2018;16:208-38. doi:10.1016/j.istruc.2018.09.008.

[6] Hollaway LC. A review of the present and future utilisation of FRP composites in the civil infrastructure with reference to their important in-service properties. Constr Build Mater 2010;24:2419-45. doi:10.1016/j.conbuildmat.2010.04.062. 
[7] Yang Y, Sneed L, Saiidi MS, Belarbi A, Ehsani M, He R. Emergency repair of an RC bridge column with fractured bars using externally bonded prefabricated thin CFRP laminates and CFRP strips. Compos Struct 2015;133:727-38. doi:10.1016/j.compstruct.2015.07.045.

[8] Xiao Y. Applications of FRP composites in concrete columns. Adv Struct Eng 2004;7:335-43. doi:10.1260/1369433041653552.

[9] Noroozieh E, Mansouri A. Lateral strength and ductility of reinforced concrete columns strengthened with NSM FRP rebars and FRP jacket. Int J Adv Struct Eng 2019;11:195-209. doi:10.1007/s40091-019-0225-5.

[10] Yao LZ, Wu G. Fiber-element modeling for seismic performance of square RC bridge columns retrofitted with NSM BFRP bars and/or BFRP sheet confinement. J Compos Constr 2016;20:1-15. doi:10.1061/(ASCE)CC.1943-5614.0000652.

[11] Perrone M, Barros JAO, Aprile A. CFRP-based strengthening technique to increase the flexural and energy dissipation capacities of RC Columns. J Compos Constr 2009;13:372-83. doi:10.1061/(ASCE)CC.1943-5614.0000031.

[12] Del Rey Castillo E, Griffith M, Ingham J. Seismic behavior of RC columns flexurally strengthened with FRP sheets and FRP anchors. Compos Struct 2018;203:382-95. doi:10.1016/j.compstruct.2018.07.029.

[13] Zerkane ASH, Saeed YM, Rad FN. Cyclic loading behavior of CFRP-wrapped non-ductile beam-column joints. ACI Spec Publ 2019;331:34-54. 
[14] Bournas DA, Triantafillou TC. Flexural strengthening of reinforced concrete columns with near-surface-mounted FRP or stainless steel. ACI Struct J 2009;106:495-505.

[15] Bank LC. Composites for construction: structural design with FRP materials. New Jersey, USA: John Wiley \& Sons Inc.; 2006.

[16] Sarafraz ME, Danesh F. Flexural enhancement of RC columns with FRP. 14th World Conf. Earthq. Eng., Beijing, China: 2008.

[17] Rousakis TC, Tourtouras IS. RC columns of square section - Passive and active confinement with composite ropes. Compos Part B Eng 2014;58:573-81. doi:10.1016/j.compositesb.2013.11.011.

[18] Rousakis TC. Reusable and recyclable nonbonded composite tapes and ropes for concrete columns confinement. Compos Part B Eng 2016;103:15-22. doi:10.1016/j.compositesb.2016.08.003.

[19] Rousakis TC. Hybrid confinement of concrete by fiber-reinforced polymer sheets and fiber ropes under cyclic axial compressive loading. J Compos Constr 2013;17:732-43. doi:10.1061/(ASCE)CC.1943-5614.0000374.

[20] Kaya E, Kutan C, Sheikh S, Ilki A. Flexural retrofit of support regions of reinforced concrete beams with anchored FRP ropes using NSM and ETS methods under reversed cyclic loading. J Compos Constr 2017;21:04016072.

[21] ASTM C39 / C39M-18. Standard Test Method for Compressive Strength of 
Cylindrical Concrete Specimens. West Conshohocken, PA.: 2018. doi:10.1520/C0039_C0039M-18.

[22] ASTM E8 / E8M - 16ae1. Standard Test Methods for Tension Testing of Metallic Materials. West Conshohocken, PA.: 2016. doi:10.1520/E0008_E0008M-16AE01.

[23] Yosefani A. Flexural Strength, Ductility, and Serviceability of Beams that Contain High-Strength Steel Reinforcement and High-Grade Concrete. Portland State University, 2018. doi:10.15760/etd.6286.

[24] Aules W, Saeed YM, Rad FN. A novel anchorage system for strengthening slender RC columns with externally bonded CFRP composite sheets. Constr Build Mater 2020;245:118423. doi:10.1016/j.conbuildmat.2020.118423.

[25] ASTM D7565 / D7565M-10(2017). Standard Test Method for Determining Tensile Properties of Fiber Reinforced Polymer Matrix Composites Used for Strengthening of Civil Structures. West Conshohocken, PA.: 2017. doi:10.1520/D7565_D7565M-10R17.

[26] ASTM D7205 / D7205M-06(2016). Standard Test Method for Tensile Properties of Fiber Reinforced Polymer Matrix Composite Bars. West Conshohocken, PA.: 2016. doi:10.1520/D7205_D7205M-06R16.

[27] Al-Obaidi SM, Saeed YM, Rad FN. Pullout tests on near-surface-mounted CFRP rods with and without lateral grooves. Int J Eng Technol 2018;7:72-8. doi:10.14419/ijet.v7i4.20.25855. 
[28] Al-Obaidi S, Saeed YM, Rad FN. Flexural strengthening of reinforced concrete beams with NSM-CFRP bars using mechanical interlocking. J Build Eng 2020;31:101422. doi:10.1016/j.jobe.2020.101422.

[29] Saeed YM, Al-Obaidi SM, Al-hasany EG, Rad FN. Evaluation of a new bond-type anchorage system with expansive grout for a single FRP rod. Constr Build Mater 2020;261:120004. doi:10.1016/j.conbuildmat.2020.120004.

[30] ACI Committee 318 (ACI 318-63). Building Code Requirements for Reinforced Concrete. Farmington Hills, MI.: 1963.

[31] ACI Committee 318 (ACI 318-14). Building Code Requirements for Structural Concrete and Commentary. Farmington Hills, MI.: 2014.

[32] ACI Committee 440 (ACI 440.2R-17). Guide for the Design and Construction of Externally Bonded FRP Systems for Strengthening Concrete Structures. Farmington Hills, MI.: 2017.

[33] Jiang SF, Zeng X, Shen S, Xu X. Experimental studies on the seismic behavior of earthquake-damaged circular bridge columns repaired by using combination of near-surface-mounted BFRP bars with external BFRP sheets jacketing. Eng Struct 2016;106:317-31. doi:10.1016/j.engstruct.2015.10.037.

[34] De Lorenzis L, Teng JG. Near-surface mounted FRP reinforcement: An emerging technique for strengthening structures. Compos Part B Eng 2007;38:119-43. doi:10.1016/j.compositesb.2006.08.003. 
[35] Galati D, De Lorenzis L. Effect of Construction Details on the Bond Performance of NSM FRP Bars in Concrete. Adv Struct Eng 2009;12:683-700. doi:10.1260/136943309789867836.

[36] Soliman SM, El-Salakawy E, Benmokrane B. Bond performance of near-surfacemounted FRP bars. J Compos Constr 2011;15:103-11. doi:10.1061/ASCECC.1943-5614.0000150.

[37] Godat A, L'Hady A, Chaallal O, Neale KW. Bond behavior of the ETS FRP bar shear-strengthening method. J Compos Constr 2012;16:529-39. doi:10.1061/(ASCE)CC.1943-5614.0000280.

[38] Ozdemir G. Mechanical properties of CFRP anchorages. Middle East Technical University, 2005. doi:10.1002/eqe.4290180114.

[39] Olivova K, Bilcik J. Strengthening of Concrete Columns With CFRP. Slovak J Civ Eng 2009;1:1-9.

[40] Ozbakkaloglu T, Saatcioglu M. Tensile behavior of FRP anchors in concrete. J Compos Constr 2009;13:82-92. doi:10.1061/(ASCE)1090-0268(2009)13:2(82).

[41] ACI Committee 374 (ACI 374.2R-13). Guide for Testing Reinforced Concrete Structural Elements under Slowly Applied Simulated Seismic Loads. Farmington Hills, MI.: 2013.

[42] Faustino P, Frade P, Chastre C. Lateral cyclic behaviour of RC columns confined with carbon fibres. Structures 2016;5:196-206. doi:10.1016/j.istruc.2015.11.004. 
[43] Faustino P, Chastre C. Flexural strengthening of columns with CFRP composites and stainless steel: Cyclic behavior. J Struct Eng 2016;142:1-15. doi:10.1061/(ASCE)ST.1943-541X.0001400.

[44] Esfandi Sarafraz M. Flexural Strengthening of RC Columns with Low Longitudinal Steel Ratio using GFRP Bars. Int J Concr Struct Mater 2019;13. doi:10.1186/s40069-019-0354-z.

[45] Ding L, Wu G, Yang S, Wu Z. Performance advancement of RC columns by applying basalt FRP composites with NSM and confinement system. J Earthq Tsunami 2013;07:1350007. doi:10.1142/S1793431113500073.

[46] Sarafraz ME, Danesh F. New technique for flexural strengthening of RC columns with NSM FRP bars. Mag Concr Res 2012;64:151-61. doi:10.1680/macr.10.00139.

[47] Priestley MJN, Seible F, Calvi GM. Seismic design and retrofit of bridges. John Wiley \& Sons, Inc.; 1996.

[48] Silva PF, Sangtarashha A, Burgueño R. P-Delta Effects in Limit State Design of Slender RC Bridge Columns. 15th World Conf. Earthq. Eng., vol. LISBOA, Lisbon Portugal: 2012.

[49] Barrera AC, Bonet JL, Romero ML, Miguel PF. Experimental tests of slender reinforced concrete columns under combined axial load and lateral force. Eng Struct 2011;33:3676-89. doi:10.1016/j.engstruct.2011.08.003. 
[50] Burgueño R, Babazadeh A, Fedak LK, Silva PF. Second-order effects on seismic response of slender bridge columns. ACI Struct J 2016;113:735-46. doi:10.14359/51688751.

[51] Saatcioglu M. Deformability of reinforced concrete columns. Earthquake-Resistant Struct. Response Des., Detroit, MI.: American Concrete Institute; 1991, p. 421452.

[52] Saatcioglu M, Baingo D. Circular high-strength concrete columns under simulated seismic loading. J Struct Eng 1999;125:272-80. doi:10.1061/(ASCE)07339445(1999)125:3(272).

[53] Fahmy MFM, Wu Z, Wu G. Seismic performance assessment of damagecontrolled FRP-retrofitted RC Bridge Columns using residual deformations. J Compos Constr 2009;13:498-513. doi:10.1061/(ASCE)CC.1943-5614.0000046.

[54] Li B, Harries KA. Seismic performance assessment of flexure-dominate FRPconfined RC columns using plastic rotation angle. Eng Struct 2018;172:453-71. doi:10.1016/j.engstruct.2018.06.046.

[55] Alvarez JC, Breña SF, Arwade SR. Nonlinear backbone modeling of concrete columns retrofitted with fiber-reinforced polymer or steel jackets. ACI Struct J 2018;115:53-64.

[56] Mander JB, Priestley MJN, Park P. Theoretical Stress-Srain Model for Confined Concrete. J Struct Eng 1988;114:1804-26. doi:10.1061/(ASCE)07339445(1988)114:8(1804). 
[57] Paulay T, Priestley MJN. Seismic Design of Reinforced Concrete and Masonry Buildings. John Wiley \& Sons, Inc.; 1992.

[58] Lam L, Teng JG. Design-oriented stress-strain model for FRP-confined concrete. Constr Build Mater 2003;17:471-89. doi:10.1016/S0950-0618(03)00045-X.

[59] Raynor DJ, Lehman DE, Stanton JF. Bond-slip response of reinforcing bars grouted in ducts. ACI Struct J 2002;99:568-76. doi:10.14359/12296.

[60] Sezen H, Moehle JP. Strength and deformation capacity of reinforced concrete columns with limited ductility. Proc. 13th World Conf. Earthq. Eng., Vancouver, Canada: 2004.

[61] Popov EP. Engineering Mechanics of Solids. 2nd ed. Pearson; 1998. 


\section{Chapter 3: Post-Strengthening Rapid Repair of Damaged RC Columns Using CFRP Sheets for Confinement and NSM-CFRP Ropes for Flexural Strengthening}

\subsection{Introduction}

Repairing concrete structures has become one of the major topics for structural engineers globally. It has been stated that money spent on repairing damaged structures has exceeded that spent on constructing new structures [1]. The major difference between conventional and rapid repair techniques is the that rapid repair aims (1) to rapidly repair the areas damaged by earthquake to quickly reopen bridges and essential structures, and (2) to prevent full collapse of damaged structures during the subsequent aftershocks [2]. It has been reported that in various earthquake events many structures were damaged during the mainshock but collapsed during the aftershocks [3]. Therefore, rapid repair is necessary for essential structures to prevent full collapse and to reopen quickly. During seismic events, some essential structures and key bridges must be repaired and reopened in a matter of days $[2,4]$. However, the time required to complete the repair has not been a major consideration in most of the repair techniques available in the literature.

The traditional techniques of concrete and steel jacketing are not efficient methods for rapid or emergency repair because they require intensive labor over an extended period of time [5-9]. Research has shown that the use of fiber reinforced polymer (FRP) materials in rapid or emergency repair of damaged concrete columns is one of the best alternatives [10-13]. FRP composites require short time, are relatively easy to install compared with 
conventional repair techniques, and can rapidly achieve high strength [14-16]. FRP confinement has been proven to be effective in repairing concrete structures $[1,9,17,18]$. However, it may be difficult to restore the strength of severely damaged columns by FRP confinement only without additional flexural reinforcement [3,15]. Therefore, it is important to develop a rapid repair technique that can effectively restore or improve the flexural capacity of damaged columns.

Few ideas have been proposed for rapid repair of damaged $\mathrm{RC}$ columns using externally bonded (EB) CFRP in the longitudinal (flexural) direction of columns. Using EB-CFRP system in flexural repair of RC columns against lateral loads must involve complicated anchorage systems at the column-foundation intersection [14,19]. Therefore, near-surfacemounted (NSM)-FRP systems are less complicated in terms of transferring the load from columns to their foundations. FRP rods are the common materials used in NSM-FRP repair techniques. The challenge in such cases is to make straight holes in the foundation to insert FRP rods as they are not flexible against bending. Therefore, straight holes sometimes are made outside the perimeter of damaged columns [20], and the cross section of repaired columns must be increased. Otherwise, significant effort is needed to make straight holes inside the perimeter of damaged columns [3]. As an alternative to overcome these challenges, CFRP ropes have the highest flexibility to be used in such repair techniques. CFRP ropes are flexible and can be bent and inserted in inclined holes made at the edge of column-foundation intersection. Research has shown that bending CFRP anchors up to $15^{\circ}$ has negligible effects on the pullout strength of CFRP [21]. Although CFRP ropes have the advantages mentioned above, their use in flexural strengthening or repairing of $\mathrm{RC}$ 
columns has not been investigated yet. Another area that has not been investigated is the repairing of columns that had already been strengthened before being damaged with earthquake forces. In the past two decades, many columns all around the globe have been upgraded and strengthened with FRP jacketing to meet the current seismic demands. Therefore, future repairs are likely to include columns that have already been strengthened with FRP jacketing.

In this study, a rapid repair technique is proposed to repair damaged RC columns that had already been strengthened with CFRP jacketing before being damaged. The repair technique utilizes NSM-CFRP ropes in the axial direction of the columns and CFRP sheets in the transverse direction. All columns in this study were designed based on pre-1971 ACI code [22]. Each specimen consisted of two identical columns connected in the middle by a concrete stub. The first specimen called the control specimen (C1-Control) was constructed based on pre-1971 ACI code and tested. The second specimen (C2-Confined) was the same as C1-Control, except that it was strengthened with CFRP confinement before it was tested. Specimen C5-Strengthened was the same as C1-Control except that it was strengthened with CFRP confinement and NSM-CFRP ropes before it was tested. C5-Strengthened was tested to check the applicability of the proposed technique in strengthening and repairing of RC columns. After C2-Confined was tested under combined axial and lateral cyclic loads, the damaged specimen was then repaired with the proposed rapid repair technique. The repaired C2-Confined was named C7-Repaired.

The main aim of this investigation was to investigate the feasibility of a repair method that may allow engineers to repair damaged columns within a short span of time, e.g., three 
days [4]. The following sections describe the proposed technique. The results of the tested columns are then presented and discussed.

\subsection{Experimental Program}

\subsubsection{Materials properties}

A concrete strength on the order of $20 \mathrm{MPa}$ is common for older RC columns. The $20 \mathrm{MPa}$ is a relatively low strength, hence represents a more conservative assumption for concrete strength to be used in this investigation. Therefore, the nominal strength of the concrete used in constructing the column specimens in this study was selected as $20 \mathrm{MPa}$ at 28 days. Three concrete cylinders $(150 \times 300 \mathrm{~mm})$ were tested to determine the compressive strength based on ASTM standards [23]. The average concrete strength at 28 days was 22.4 MPa. Concrete strengths on the day of testing for C1-Control, C2-Confined, C5Strengthened, and C7-Repaired were 23.8, 22.2, 20.5, and 22.2 MPa, respectively.

Columns were reinforced in the longitudinal direction with No. $10(9.52 \mathrm{~mm})$ deformed steel bars. The yield strength, yield strain, modulus of elasticity and ultimate strength were determined experimentally in the Concrete Laboratory at Portland State University by Yosefani [24] and were equal to $493 \mathrm{MPa}, 0.24 \%$, $200 \mathrm{GPa}$, and $765 \mathrm{MPa}$, respectively. Steel ties were made using No. $6(6.35 \mathrm{~mm})$ smooth steel wires. The yield strength, yield strain, modulus of elasticity and ultimate strength were $393 \mathrm{MPa}, 0.22 \%, 180 \mathrm{GPa}$, and $514 \mathrm{MPa}$, respectively [24]. 
Two different forms of CFRP materials were used in this study. Unidirectional CFRP sheet was used mainly for lateral confinement applied to the strengthened and repaired RC columns. The tensile mechanical properties of CFRP sheets were determined in the same laboratory by Aules et al. [19] following ASTM D7565 [25]. The tensile strength, ultimate strain, modulus of elasticity of CFRP composite sheets are 3,123 $\mathrm{MPa}, 1.50 \%$, and 233 GPa. The thickness of the CFRP sheets is $0.167 \mathrm{~mm}$. The other form of CFRP used in the present study was CFRP ropes. CFRP ropes were tested under pure tension in the laboratory, but all specimens failed before achieving maximum tensile strength due to difficulties in anchoring CFRP ropes. To the best of authors' knowledge, an accepted experimental methodology to determine tensile properties of CFRP ropes is not available. Therefore, properties reported by the manufacturer were used for CFRP ropes. The reported tensile strength, ultimate strain, modulus of elasticity of CFRP composite ropes are $2,100 \mathrm{MPa}, 0.91 \%$, and $230 \mathrm{GPa}$, and the reported cross-sectional area of the rope is $64.5 \mathrm{~mm}^{2}$

Low viscosity epoxy material (MasterBrace SAT 4500) was used as an impregnating resin for CFRP ropes and as a bonding agent for CFRP sheets. The tensile strength, elastic modulus, and ultimate strain of the MasterBrace SAT 4500 were $55 \mathrm{MPa}, 3 \mathrm{GPa}$, and 3.5\%, respectively. Hilti 500 was used as the bonding agent for NSM-CFRP materials and to fill the holes where CFRP ropes were anchored to the foundation. The tensile strength, bond strength, and ultimate strain of Hilti 500 were $44 \mathrm{MPa}, 12 \mathrm{MPa}$, and 2.0\%, respectively. 


\subsubsection{Control specimen}

The geometry and details of the control specimen (C1-Control) is shown in Fig. 3.1. The specimen consisted of two cantilevered columns connected to a stiff member (concrete stub) in the middle. So, in effect, each specimen contained two columns tested at the same time. The cross-sectional dimensions of the columns are $150 \times 150 \mathrm{~mm}^{2}$. The columns were reinforced longitudinally with four No. 10 steel bars (steel reinforcement ratio $\rho_{\ell}=$ $1.26 \%$ ). Steel stirrups made of No. 6 smooth wires were placed at $150 \mathrm{~mm}$ on center. The columns were constructed with low concrete strength and were poorly detailed at the plastic hinge zone representing deficient RC columns designed based on older (pre 1970s) codes. The concrete stub (the stiff element at the middle of the specimen) was heavily reinforced (as shown in Fig. 3.1) to act as a fixed end for the columns.

\subsubsection{CFRP confinement}

The first step in CFRP confinement was concrete surface grinding. A typical concrete grinder was used to remove loose particles from the top surface of concrete. Additionally, the corners of the columns were rounded $(\mathrm{R}=25 \mathrm{~mm})$ at the plastic hinge region or wherever CFRP confinement was applied. The plastic hinge zone, determined based on the definition of ACI codes [26,27], was equal to $356 \mathrm{~mm}$ from the column base. After grinding, concrete surface was cleaned with compressed air and washed with water to remove any dust or loose particles. Then, concrete surface was prepared with two layers of epoxy materials, commercially named MasterBrace P 2000 and MasterBrace P 3500. One 
layer of CFRP composite sheet was applied. MasterBrace SAT 4500 was used to bond CFRP composite sheets to pretreated concrete surface. Fig. 3.2 shows the details of all specimens tested in this study. C2-Confined was constructed similar to the control specimen (C1-Control) except that it was strengthened with CFRP confinement before it was tested. One layer of CFRP confinement was applied at the plastic hinge zone of all strengthened and repaired columns.

\subsubsection{NSM-CFRP ropes}

Near-surface-mounted CFRP technique started with cutting a groove in the longitudinal direction (parallel to steel flexural reinforcement) on each flexural side of the strengthened and repaired columns. The dimensions of the grooves for NSM-CFRP rods are recommended to be two time the rod diameter $[3,27,28]$. Although the width of the grooves in this study was about two times CFRP rope diameter $(18 \mathrm{~mm})$, the depth of the grooves had to be $13 \mathrm{~mm}$ as that was the thickness of the concrete cover. Since NSM-CFRP ropes had to be anchored at the base of the columns, holes were drilled into the foundation (concrete stub). The diameter of the holes was $19 \mathrm{~mm}$, and they were $150 \mathrm{~mm}$ deep based on previous studies [29-32]. The holes were drilled at a 7-degree slope (Fig. 3.2). This was one of the advantages of using the flexible CFRP ropes instead of the rigid CFRP rods. Test results of Ozbakkaloglu and Saatcioglu [21] showed that an inclination of up to 15degree had no significant effects on the pullout strength of CFRP anchors. The grooves and holes were cleaned with compressed air and steel brush. The rope was cut by special 
scissors to the desired lengths $(1.0 \mathrm{~m}$ each). Then, the ropes were impregnated for 30 minutes to 1 hour until the fibers were saturated thoroughly with the impregnating resin. Next, ropes were inserted into the holes (using a steel stick) and grooves. The CFRP ropes were pressed slightly to make sure that the epoxy went through and around all fibers and to fill all the voids. The grooves were filled with more epoxy, and the surface was leveled and let to cure until the day of testing.

Fig. 3.2 shows that specimen C5-Strengthened was strengthened with NSM-CFRP ropes and with CFRP confinement. After one day of curing for NSM-CFRP ropes, CFRP confinement (as described in section 2.3) was applied to specimen C5-Strengthened. Table 3.1 presents the design details for the specimens of this study. Only C5-strengthend and C7-Repaired were strengthened/repaired with NSM-CFRP ropes. NSM-CFRP reinforcing ratio ( $\left.\rho_{\text {frp }}\right)$ was $0.57 \%$.

\subsubsection{Proposed repair technique}

\subsubsection{Cleaning damaged concrete}

One of the issues in repairing columns that were previously strengthened with CFRP confinement is that cracks and damage to the concrete are not visible before cleaning and peeling off CFRP sheets. As shown in Fig. 3.3 (a), the damaged column appeared healthy. However, Fig. 3.3 (b) shows that the concrete under CFRP sheets was completely damaged. The concrete under CFRP sheets was more like loose aggregates wrapped with CFRP. Therefore, it was decided to remove all loose concrete, as shown in Fig. 3.3 (c). The 
strengthened column (C2-Confined) underwent large deformation (maximum drift ratio of 11.7\%) when it was tested under combined axial and lateral cyclic loads. The steel reinforcement had already yielded under tension and buckled under compression. Special efforts were made to straighten the steel reinforcement and the specimen overall as much as possible.

\subsubsection{Casting repair concrete}

Fig. 3.4 (a) shows the formwork of the column being repaired before casting. A commercially available concrete bonding adhesive (SikaLatex® R Concrete Fortifier) was used to help bond the existing concrete to the new concrete. Since the aim was to develop a rapid repair technique, the repair concrete mix was selected to achieve the design strength (25 MPa) in the first three hours after casting. Based on the manufacturer, the concrete strength in one day and seven days are $31 \mathrm{MPa}$ and $38 \mathrm{MPa}$, respectively. Fig. 3.4 (b) shows the column sections after the concrete mix was cast. At the same time, concrete cylinders $(75 \mathrm{~mm} \times 150 \mathrm{~mm})$ were prepared, and tests showed that the concrete strength was $30 \mathrm{MPa}$ after 24 hours, and $40 \mathrm{MPa}$ on the day of testing the column specimen (C7Repaired). Fig. 3.5 (a) shows the cured repaired concrete section next to the old (original) concrete ready for CFRP application. 


\subsubsection{Surface preparation, grooves, and holes}

Concrete surface at the plastic hinge zone was ground to be ready for CFRP confinement. As shown in Fig. 3.5 (a), the corners of the column were rounded with a 25 -mm radius ( $R$ $=25 \mathrm{~mm}$ ). Grooves were cut in the longitudinal direction on each flexural side of the column as described in section 2.4. Because CFRP ropes are flexible, the anchor holes did not have to be exactly parallel to the column axis. Therefore, inclined holes at an angle of $7^{\circ}$ (Fig. 3.2) were drilled at the column-foundation intersection (Fig. 3.5b). Finally, grooves and holes were cleaned with compressed air and steel brush.

\subsubsection{CFRP application}

Four pieces of CFRP ropes, 1.0-meter-long each, were prepared and impregnated to be used for specimen C7-Repaired. As shown in Fig. 3.6, CFRP ropes were inserted in the holes and placed inside the grooves. The same procedure described in section 2.4 was followed. After six hours of curing time for Hilti 500 (NSM-CFRP), the application of CFRP confinement started by applying MasterBrace P 2000 at the plastic hinge zone (Fig.

3.7). Six hours later, MasterBrace P 3500 was applied. Then, concrete column was confined with one layer of CFRP sheet in the plastic hinge zone using MasterBrace SAT 4500 (Fig. 3.7b). 


\subsubsection{Timeline of the repair technique}

Since this is a rapid repair technique, time is of essence. The timeline presented in Fig. 3.8 shows that the proposed rapid repair technique can be completed within three days. One of the main steps was using the rapid set concrete mix. Because concrete strength of $25 \mathrm{MPa}$ could be achieved in three hours, concrete surface preparation could be started three hours after the concrete was cast. All physical work of the proposed rapid repair technique was completed in 40 hours. Then, the repaired column was left for curing in room temperature. After 12 hours of curing, test instrumentations and setup started, and the repaired column became ready for test. It should be noted that in real-life projects columns are larger, so repair is likely to take a longer time to complete. However, columns in real projects do not need complicated instrumentation (strain gauges, LVDTs, load cells, data logging system, etc.) and do not need setups for tests. Even if the time of repairing full scale columns is twice as long as it was for specimen C7-Repaired, 80 hours can still be considered "rapid" for repairing a damaged $\mathrm{RC}$ column.

\subsubsection{Test setup, instrumentations, and loading protocol}

Fig. 3.9 shows the loading frame used to test the columns under axial and cyclic lateral loads. Each specimen consisted of two columns, and the obtained results were the average response of the two columns. The axial load was consistent and was equal to $0.2 f_{c}^{\prime} A_{g}$ for all specimens. The axial load was monitored continuously during the test using a straingauge based load cell connected to the data logging system. The lateral load was applied 
using a hydraulic actuator connected to a tension-compression load cell (Fig. 3.9). The lateral loading protocol recommended by ACI 374.2R-13 (2013) was used in this study, as shown in Fig. 3.10. The columns were subjected to four cycles per loading or displacement increment. The first two increments were controlled by $V_{y}$, which was the lateral force required to yield the steel reinforcement in tension. The columns were loaded up to $V_{y} / 2$ for the first increment (cycles 1 through cycle 4) and loaded up to $\mathrm{V}_{\mathrm{y}}$ in the second increment (cycle 5 through cycle 8 ). $\mathrm{V}_{\mathrm{y}}$ was determined when any of the steel strain gauges (Fig. 3.1) reached a strain of 0.0024 .

Displacement-controlled loading protocol was used for the subsequent increments. Yield displacement $(\Delta y)$ was measured from the second increment so that the subsequent displacement increments were $2 \Delta y, 3 \Delta y, 4 \Delta y$, and so on until the specimen failed (Fig. 3.10). Displacement was measured using two long LVDTs $(250 \mathrm{~mm})$ instrumented as shown in Fig. 3.9. The test stopped when the drop in lateral strength was more than 50\%, or when the loading frame reached its maximum possible displacement $(125 \mathrm{~mm})$.

Four strain gauges were used to measure the tensile and compressive strains in the longitudinal steel reinforcing bars in all specimens (Fig. 3.1). Fig. 3.11 shows the distribution of strain gauges that were attached to CFRP ropes for specimens C5Strengthened and C7-Repaired. The locations of the strain gauges are labeled using a name code consisting of two letters and one number. The first letter ( $\mathrm{R}$ or $\mathrm{L})$ indicates whether a strain gauge is on the right or on the left side of the specimen. The second letter (T or B) indicates whether a strain gauge is located on the top or on the bottom side of the column. Finally, the number at the end refers to the distance (in inches; 1 in. $=25.4 \mathrm{~mm}$ ) between 
a strain gauge and the column-foundation intersection. For example, "RT3" means that RT3 strain gauge is on the right-top side and the distance between RT3 and the columnfoundation intersection is $3 \mathrm{in} .(76 \mathrm{~mm})$.

\subsection{Experimental results and discussions}

\subsubsection{Lateral strength}

The main goal of an emergency repair is to restore the original strength $[2,11]$. The philosophy of the proposed repair technique is to design the repaired column such that its reinforcing steel yields under a lateral force equal to the target lateral strength, and to behave similar to the column before it was damaged, under cyclic loading. The target strength in this case was the lateral strength of the original column. Table 3.2 shows the yield and maximum strengths and displacements for all specimens. The forces and displacements in both directions of the load cycles are listed. The difference was reasonably small, so the average of the two values (Pull and Push directions, Table 3.2) were considered for comparison purposes. Table 3.2 shows that the proposed repair technique improved the flexural strength significantly. The percentage of enhancement in lateral strength for specimen C7-Repaired $(18.31 \mathrm{kN})$ was $68 \%$ compared to C1-Control $(10.89 \mathrm{kN})$ and $65 \%$ compared to $\mathrm{C} 2$-Confined $(11.08 \mathrm{kN})$. In fact, the strength improvement of C7-Repaired based on the theoretical (moment-curvature) analyses and based on the result of specimen C5-Strengthened was expected to be at least $60 \%$. The prediction of $60 \%$ came from the results of column C5-Strengthened $(17.44 \mathrm{kN})$ which was 
strengthened with the same amount of CFRP materials in flexure and same amount of CFRP confinement. The difference between C5-Strengthened and C7-Repaired was that C5-Strengthened was strengthened before testing, while C7-Repaired was the damaged column C2 which was repaired, and then tested. The higher strength of the repair concrete mix used in the plastic hinge zone of C7-Repaired specimen probably contributed to the slightly higher strength of C7-Repaired. The concrete strength of the original concrete was 22.2 $\mathrm{MPa}$, while the strength of the repair mix was $40 \mathrm{MPa}$ on the day of testing. In conclusion, this observation indicates that the results are promising, and the repair technique is effective in restoring and improving the lateral strength of damaged $\mathrm{RC}$ columns.

\subsubsection{Load-displacement response}

Fig. 3.12 presents the hysteresis load-displacement relationships for all columns. Except for specimen C7-Repaired, the responses of the specimens in both directions (positive and negative) were approximately symmetrical. The load-displacement response of C1-Control showed a poor and brittle behavior of the column under axial and cyclic lateral load. The lateral strength started dropping immediately after the column was subjected to the 5th cycle approaching Vy (1st cycle of the second increment, see section 2.6). The test continued until severe concrete spalling was observed and the force dropped to a level less than $50 \%$ of the peak. However, the data logging system erroneously stopped recording and some of the data were lost. The observed behavior of C1-Control was expected because 
it was originally designed as a deficient column. Confining the columns at the plastic hinge zone with one layer of CFRP sheet (C2-Confined) did not noticeably enhance the strength but significantly improved the overall force-displacement response of the column (Fig. 3.12). The ultimate displacement increased significantly. This observation is in alignment with the results of previous studies [5,34-36] which showed that confinement could improve the displacement capacity of strengthened columns but was not effective for flexural strengthening. Because of CFRP confinement, it was not possible to see the failure development and crack patterns during the test. At the end of the test, no significant damage was observed in the CFRP confinement sheets. The test was stopped when the loading frame reached its maximum displacement capacity.

Specimen C5-Strengthened continued to resist the applied lateral force without strength degradation until most of the fibers in the rope ruptured at the 4th displacement increment (3 $\Delta y$ ). Then, the force dropped suddenly to a lower level but not to the point where one could confirm that CFRP rope had completely ruptured. After completing all four cycles of the 4th displacement increment ( $3 \Delta y$ ), CFRP rope completely ruptured during displacement cycle number 17 ( 1 st cycle of the 5 th displacement increment). The resistance of C5-Strengthened resumed to that of C2-Confined.

The unsymmetrical response of C7-Repaired was expected because the original concrete in both flexural sides had cracks, and the damaged concrete was removed and replaced with a new concrete mix. In addition, this could be attributed to the unsymmetrical straining of the steel reinforcement in the damaged column. Before repairing, the damaged column (C2-Confined) underwent full 28 cycles, and it experienced a drift ratio of $11.7 \%$. 
Therefore, the steel reinforcement bars were far from symmetrical-elastic response. The overall response of C7-Repaired was not much different from C5-Strengthened. Once rupture of CFRP rope initiated, the load capacity started to drop rapidly to match that of C2-Confined. The cycles continued until the maximum capacity of the loading frame was reached.

Fig. 3.13 shows the load-displacement envelopes for the four columns. The envelopes were developed from the load-displacement hysteresis curves (Fig. 3.12) by simply plotting the peaks of all loading increments. Load-displacement envelopes help compare the lateral response of each column to the others. It can be observed that once CFRP ruptured in the columns strengthened in flexure, the load in the columns began to decline somewhat similar to the behavior of the second column (C2-Confined). It can also be observed that the responses were not exactly symmetric. The behavior on the pull side (positive loaddisplacement) is slightly different from that on the push side (negative load-displacement). The specimens were always loaded in the upward direction first, then followed by applying the load in the downward direction to complete a single cycle. Therefore, when a column was loaded in the downward direction, the compression side of the concrete had already been loaded or cracked in the previous cycle. It can be observed that specimens C1-Control and C2-Confined had similar strengths but different ultimate deflections. Fig. 3.13 shows the strength improvement of the strengthened column (C5) and repaired column (C7) compared to specimens $\mathrm{C} 1$ and $\mathrm{C} 2$. Although specimens $\mathrm{C} 5$ and $\mathrm{C} 7$ had similar responses, Fig. 3.13 shows the slight difference between the lateral responses of each specimen. 


\subsubsection{Stability limits and displacement ductility}

Displacement ductility depends mainly on the yield displacement and ultimate displacement. The yield displacement of each specimen was determined experimentally as the displacement recorded when any of the strain gauges attached to the steel reinforcement in tension reached a strain of $0.24 \%$. Table 3.3 lists the yield displacements for all specimens. For the repaired column (C7), it was impossible to record the yield displacement because the steel rebars were in plastic condition (have already yielded before the test). Therefore, the yield displacements in the positive and negative directions were based on the author's best estimates from the load-displacement curves. The ultimate displacement is dependent on the structural stability of the member. It is common to associate the ultimate displacement or the displacement capacity with the displacement corresponding to $20 \%$ decay in lateral strength [33]. The " $20 \%$ decay" limit is used as a measure of prevention against lateral instability or collapse. However, for some types of structures, instability may occur before the $20 \%$ decay in lateral strength while other structural members are able to carry axial and lateral loads well beyond 20\% decay [33].

For long RC columns, a number of stability limits have been proposed in the literature. Priestley et al. [37] suggested that the ratio of the secondary moment (P- $\Delta$ effects) to the total moment should not exceed 0.3 . Silva et al. [38] recommend a stability limit of 0.4 , which is less conservative than the limit proposed by Priestley et al. [37]. ACI 318 [26] limits the ratio of the total moment to the primary moment to 1.4 . Finally, the stability limit has been defined by Barrera et al. as when the secondary moment is equal to the primary moment $[39,40]$. Based on stability limits described above, the corresponding 
displacements were measured and the resulting ductility for all specimens were determined, as listed in Table 3.3. In addition, the stability limits are visually shown in Fig. 3.14. The total moment in Fig. 3.14 is the total moment resisted by the column due to the applied lateral force and constant axial force. The primary moment is the applied lateral force multiplied by the lever arm, and the secondary moment is the axial load multiplied by the lateral deflection.

As shown in Fig. 3.14 and Table 3.3, the ductility resulting from Barrera's stability limit was the highest compared to ductility by other limits. Considering the maximum measured displacement as the ultimate displacement resulted in ductility even higher than that based on Barrera's stability limit. In most cases, Silva's limit resulted in higher value than ductility based on 20\% decay, ACI limit and Priestley's. It has been stated in the literature that considering $20 \%$ decay in lateral strength in calculating the displacement capacity of slender RC columns is conservative $[33,41,42]$. Based on the results of the current study, it is also observed that $20 \%$ decay is conservative for slender RC columns strengthened with CFRP. The tested columns were all stable and able to carry the axial load until the end of tests ( $\Delta \mathrm{u}$ in Table 3.3). Some researchers have considered the ultimate displacement obtained from tests as the displacement capacity of strengthened RC columns [43-45]. In the current study, if the measured ultimate displacements are considered in evaluating ductility, all strengthened and repaired columns had a ductility equal to or more than 5.0, which is a desired value of ductility based on Caltrans guidelines [46]. On the other hand, it may be safer to define the stability limit for columns strengthened or repaired with CFRP in lateral and longitudinal directions when the secondary moment is equal to the primary 
moment $[39,40]$. For strengthened slender RC columns both of the above suggestions in defining the displacement capacity are less conservative, however perhaps more realistic than using ACI stability limit [26], Priestley's limit [37], Silva's limit [38], and 20\% decay in lateral strength.

Table 3.3 suggests that the proposed repair technique is not only effective in improving the strength (Table 3.2), but also effective in improving the ductility. Therefore, the proposed emergency repair technique may be considered as a viable repair technique in areas of moderate seismicity since the ductility of the repaired column appears to be satisfactory $[2,46]$. As a reminder, the design philosophy of the proposed technique assumes that the strength of the repaired column is the yield strength. In this case, the $68 \%$ overstrength is ignored for more safety. It should be noted that this observation is based on limited tests conducted in this study. Therefore, more tests are required to confirm the results.

\subsubsection{Idealized load-displacement relationships}

To better compare the results and to accurately evaluate the load-displacement response of the repaired column compared to the other columns, idealized load-displacement envelopes were constructed. Fig. 3.15 shows the hysteresis responses and the experimental (measured) and idealized load-displacement envelopes for all tested specimens. The idealized envelopes were constructed as bilinear relationships. The initial slope of the idealized envelopes is the slope between the origin and the point on the measured curve at which the lateral strength is equal to half of the maximum measured strength. The plastic 
portion or the yield level of the idealized envelope was defined by equalizing the area under the two curves: the measured and idealized curves. This procedure was adopted from previous experimental studies $[3,14,15]$.

Fig. 3.16 compares the idealized envelopes of the four specimens. Similar to the observation made when measured envelopes were compared (Fig. 3.13), Fig. 3.16 shows that specimens $\mathrm{C} 1$ and $\mathrm{C} 2$ had nearly the same idealized strength, as well as specimens $\mathrm{C} 5$ and C7. The lateral strength of $\mathrm{C} 7$ in the positive direction was slightly higher than the strength of C5. However, C5 and C7 had almost similar strengths in the negative direction. The idealized yield displacements and strengths reported in Table 3.4 are the average between the positive and negative values. The ductility ratios were obtained by dividing the ultimate displacement by the idealized yield displacement. Based on the idealized envelopes, the ductility of the repaired column (C7) was 79\% of the ductility of the column before repairing $(\mathrm{C} 2)$. On the other hand, the stiffness (the slope of the elastic portion of the idealized envelope) of the repaired column (C7) was higher than that of $\mathrm{C} 2$.

Fig. 3.17 compares the measured and idealized envelopes of the columns before and after repair. Fig. 3.17 confirms that the proposed repair technique significantly improved the column strength with an acceptable level of ductility. Based on Table 3.4, the ductility of the repaired column (8.49) is $70 \%$ higher than the desired ductility (5.0) reported in previous studies and guidelines $[2,46]$. Few examples of repair techniques presented in previous studies are summarized in the following. Yang et al. [15] repaired a circular RC column with EB-CFRP laminates and CFRP jacketing, and the ductility of the repaired column was 4.0 based on the idealized load-displacement envelope. He et al. [14] proposed 
a rapid repair technique for square $\mathrm{RC}$ columns using EB-CFRP sheets and novel steel anchors, and they tested three large-scale columns. Based on the idealized curves, the ductility of the repaired columns did not exceed 4.9. Jiang et al. [3] repaired four circular RC columns with NSM-BFRP bars in longitudinal direction and BFRP jacketing in transverse direction. The ductility calculated from the idealized envelopes of the repaired columns ranged from 3.82 to 4.53 . Saiidi and Cheng [11] repaired four large scale RC flared columns with CFRP and GFRP fabrics with fibers running in longitudinal and transverse directions of the columns. The ductility obtained from experimental results did not exceed 4.4. Based on the results of the current study as compared to previous experimental investigations, the proposed repair technique may be considered as a permanent repair, especially in low and moderate seismic areas.

\subsection{Conclusions}

A proposed rapid repair technique using CFRP sheets and ropes is proposed in this experimental investigation. A total of four specimens were fabricated and tested under a combination of axial and cyclic lateral loads. Each specimen consisted of two columns connected in the middle by a stiff element (concrete stub). C1-Control was an as-built specimen, C2-Confined was strengthened with CFRP confinement in the plastic hinge zone only, C5-Strengthened was strengthened with CFRP confinement in the plastic hinge zone and with NSM-CFRP ropes in longitudinal direction, and specimen C7-Repaired was the repaired version of $\mathrm{C} 2$-Confined. The rapid repairing technique involves replacing the 
damaged concrete with rapid high strength concrete mix, confining the column with one layer of CFRP confinement in the plastic hinge zone, and strengthening the column in flexure using NSM-CFRP ropes. The conclusions stated below are made based on the results of limited tests. Testing more specimens may affect the conclusions reported in this study, given the fact that the response of each specimen depended on the behavior of concrete (a non-homogenous material), steel, CFRP, and epoxy. However, the results of each specimen were the average of testing two columns, which is expected to increase the reliability of the results. In addition, the experimental results of $\mathrm{C} 1, \mathrm{C} 2, \mathrm{C} 5$, and $\mathrm{C} 7$ were reasonably close to the results predicted by the theoretical analysis, which may point to more reliability. Finally, what may give rise to the level of confidence in the results is that the response of C7-Repaired was close to that of C5-Strengthened. Comparable responses were expected because both specimens had experienced the same strengthening/repairing procedure with same amount of CFRP reinforcement.

The following conclusions can be drawn based on the results of the tested columns which were presented and discussed in previous sections:

1. The proposed rapid repair technique can be applied and completed in less than three days.

2. The rapid repair technique increased the lateral strength by $68 \%$ compared to the as-built column (C1-Control) and 65\% compared to the column strengthened by confinement only (C2-Confined). 
3. By considering most of the known stability limits reported in the literature to determine the ultimate displacement, the ductility of the repaired column was higher than the ductility of C1-Control and C2-Confined.

4. Based on the idealized envelopes, the repaired column had higher strength and stiffness compared to C1-Control and C2-Confined. However, the ductility of the repaired column (C7-Repaired) was reduced by $21 \%$ compared with C2-Confined.

5. The ductility ratio of the repaired column was 6.12 based on the ultimate measured displacement and 8.49 based on the idealized load-displacement envelopes. This observation combined with the significant improvement in strength leads to the possibility of considering the proposed rapid repair technique as a viable technique in areas of moderate seismicity. 


\subsection{Tables}

Table 3.1 Test specimens and CFRP strengthening details

\begin{tabular}{|c|c|c|c|c|c|}
\hline Label & $\begin{array}{l}\rho_{\ell} \\
\%\end{array}$ & $\begin{array}{l}\text { Strengthening/repairing } \\
\text { method }\end{array}$ & $\begin{array}{c}\text { A }_{\text {FRP per }} \\
\text { flexural side }\end{array}$ & $\begin{array}{c}\rho_{\text {frp }} \\
\%\end{array}$ & Confinement \\
\hline C1-Control & 1.26 & None & 0.00 & 0.00 & None \\
\hline C2-Confined & 1.26 & Confinement & 0.00 & 0.00 & $\begin{array}{c}1 \text { layer of CFRP } \\
\text { sheet }\end{array}$ \\
\hline C5-Strengthened & 1.26 & $\begin{array}{c}\text { Confinement+NSM-CFRP } \\
\text { rope }\end{array}$ & $64.5 \mathrm{~mm}^{2}$ & 0.57 & $\begin{array}{c}1 \text { layer of CFRP } \\
\text { sheet }\end{array}$ \\
\hline C7-Repaired & 1.26 & $\begin{array}{c}\text { Confinement + NSM-CFRP } \\
\text { rope + Replacing damaged } \\
\text { concrete with concrete repair } \\
\text { mix }\end{array}$ & $64.5 \mathrm{~mm}^{2}$ & 0.57 & $\begin{array}{c}1 \text { layer of CFRP } \\
\text { sheet }\end{array}$ \\
\hline
\end{tabular}

Table 3.2 Experimental results: values recorded during the tests

\begin{tabular}{|c|c|c|c|c|c|c|c|c|c|c|c|c|}
\hline Label & \multicolumn{3}{|c|}{$\begin{array}{l}\text { Yield strength, } \\
\text { kN }\end{array}$} & \multicolumn{3}{|c|}{$\begin{array}{l}\Delta \text { at yield, } \\
\mathrm{mm}\end{array}$} & \multicolumn{3}{|c|}{$\begin{array}{c}\text { Maximum strength, } \\
\mathrm{kN}\end{array}$} & \multicolumn{3}{|c|}{$\begin{array}{l}\Delta \text { at max. strength, } \\
\mathrm{mm}\end{array}$} \\
\hline & Pull $^{1}$ & $\mathrm{Push}^{2}$ & Avg. ${ }^{3}$ & Pull $^{1}$ & $\mathrm{Push}^{2}$ & Avg. ${ }^{3}$ & Pull $^{1}$ & $\mathrm{Push}^{2}$ & Avg. ${ }^{3}$ & Pull $^{1}$ & Push $^{2}$ & Avg. $^{3}$ \\
\hline C1 & 10.50 & -10.58 & 10.54 & 23.37 & -25.15 & 24.26 & 10.87 & -10.90 & 10.89 & 28.72 & -29.58 & 29.15 \\
\hline $\mathrm{C} 2$ & 10.85 & -10.45 & 10.65 & 24.13 & -24.64 & 24.39 & 11.19 & -10.96 & 11.08 & 29.06 & -30.80 & 29.93 \\
\hline C5 & 11.08 & -12.96 & 12.02 & 17.71 & -16.63 & 17.17 & 17.33 & -17.54 & 17.44 & 45.95 & -30.29 & 38.12 \\
\hline $\mathbf{C} 7^{*}$ & 12.51 & -13.99 & 13.25 & 20.00 & -19.00 & 19.50 & 17.53 & -19.09 & 18.31 & 40.67 & -40.22 & 40.44 \\
\hline
\end{tabular}

Notes:

${ }^{1}$ The direction of the applied load was upward (positive)

${ }^{2}$ The direction of the applied load was downward (negative)

${ }^{3}$ Avg. means the average of the two values

* It was impossible to record the yield strength or yield displacement because the steel rebars were in plastic condition (have already yielded before the test). Therefore, the yield information was based on the authors' best estimates from the load-displacement curves. 
Table 3.3 Ductility based on different stability limits

\begin{tabular}{|c|c|c|c|c|c|c|c|c|c|c|}
\hline \multicolumn{3}{|c|}{ Category } & \multicolumn{2}{|c|}{ C1 } & \multicolumn{2}{|c|}{$C 2$} & \multicolumn{2}{|c|}{ C5 } & \multicolumn{2}{|c|}{$C 7$} \\
\hline \multicolumn{2}{|c|}{$\begin{array}{l}\text { Yield displacement } \Delta y \text {, } \\
\mathrm{mm}\end{array}$} & $\begin{array}{l}(+) \\
(-)\end{array}$ & $\begin{array}{r}23.37 \\
-25.15\end{array}$ & Avg. & $\begin{array}{c}24.13 \\
-24.64\end{array}$ & Avg. & $\begin{array}{c}17.71 \\
-16.63\end{array}$ & Avg & $\begin{array}{c}20.00 \\
-19.00\end{array}$ & Avg. \\
\hline \multirow{6}{*}{ 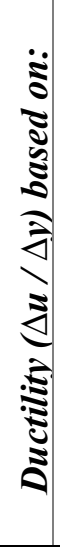 } & $\begin{array}{l}20 \% \text { decay in lateral } \\
\text { strength }\end{array}$ & $\begin{array}{l}(+) \\
(-)\end{array}$ & $\begin{array}{l}2.31 \\
2.45\end{array}$ & 2.38 & $\begin{array}{l}2.98 \\
3.27\end{array}$ & 3.13 & $\begin{array}{l}3.39 \\
3.07\end{array}$ & 3.23 & $\begin{array}{l}2.68 \\
2.76\end{array}$ & 2.72 \\
\hline & ACI limit [26] & $\begin{array}{l}(+) \\
(-)\end{array}$ & $\begin{array}{l}1.88 \\
1.59\end{array}$ & 1.74 & $\begin{array}{l}1.95 \\
1.54\end{array}$ & 1.75 & $\begin{array}{l}3.27 \\
3.13\end{array}$ & 3.20 & $\begin{array}{l}2.85 \\
2.87\end{array}$ & 2.86 \\
\hline & Priestley et al. [37] & $\begin{array}{l}(+) \\
(-)\end{array}$ & $\begin{array}{l}1.97 \\
1.75\end{array}$ & 1.86 & $\begin{array}{l}2.03 \\
1.87\end{array}$ & 1.95 & $\begin{array}{l}3.39 \\
3.37\end{array}$ & 3.38 & $\begin{array}{l}2.95 \\
3.05\end{array}$ & 3.00 \\
\hline & Silva et al. [38] & $\begin{array}{l}(+) \\
(-)\end{array}$ & $\begin{array}{l}2.48 \\
2.47\end{array}$ & 2.48 & $\begin{array}{l}2.74 \\
2.72\end{array}$ & 2.73 & $\begin{array}{l}3.95 \\
4.39\end{array}$ & 4.17 & $\begin{array}{l}3.68 \\
4.00\end{array}$ & 3.84 \\
\hline & Barrera et al. [39] & $\begin{array}{l}(+) \\
(-)\end{array}$ & $\begin{array}{l}\text { N/A }{ }^{1} \\
\text { N/A }^{1}\end{array}$ & N/A ${ }^{1}$ & $\begin{array}{l}3.69 \\
3.57\end{array}$ & 3.63 & $\begin{array}{l}4.52 \\
5.59\end{array}$ & 5.06 & $\begin{array}{l}4.53 \\
4.89\end{array}$ & 4.71 \\
\hline & Max. measured $\Delta \mathrm{u}$ & $\begin{array}{l}(+) \\
(-)\end{array}$ & $\begin{array}{l}2.78 \\
2.56\end{array}$ & 2.67 & $\begin{array}{l}5.17 \\
4.99 \\
\end{array}$ & 5.08 & $\begin{array}{l}6.88 \\
7.89\end{array}$ & 7.39 & $\begin{array}{l}6.74 \\
5.50 \\
\end{array}$ & 6.12 \\
\hline
\end{tabular}

${ }^{1}$ N/A means not available.

Table 3.4 Results based on idealized relationships

\begin{tabular}{lccccc}
\hline Label & $\begin{array}{c}\text { Idealized yield } \\
\text { displacement, } \\
\mathrm{mm}\end{array}$ & $\begin{array}{c}\text { Idealized yield } \\
(\mathrm{max}) \text { strength, } \\
\mathrm{kN}\end{array}$ & $\begin{array}{c}\text { Ultimate } \\
\text { displacement, } \\
\mathrm{mm}\end{array}$ & $\begin{array}{c}\text { Ductility } \\
\text { ratio }\end{array}$ & $\begin{array}{c}\text { Stiffness, } \\
\mathrm{kN} / \mathrm{mm}\end{array}$ \\
\hline C1-Control & 14.07 & 9.75 & 65.00 & 4.62 & 0.69 \\
C2-Confined & 11.48 & 9.05 & 123.50 & 10.76 & 0.79 \\
C5-Strengthened & 11.76 & 11.82 & 122.00 & 10.37 & 1.01 \\
C7-Repaired & 14.02 & 12.49 & 119.00 & 8.49 & 0.89 \\
\hline
\end{tabular}




\subsection{Figures}

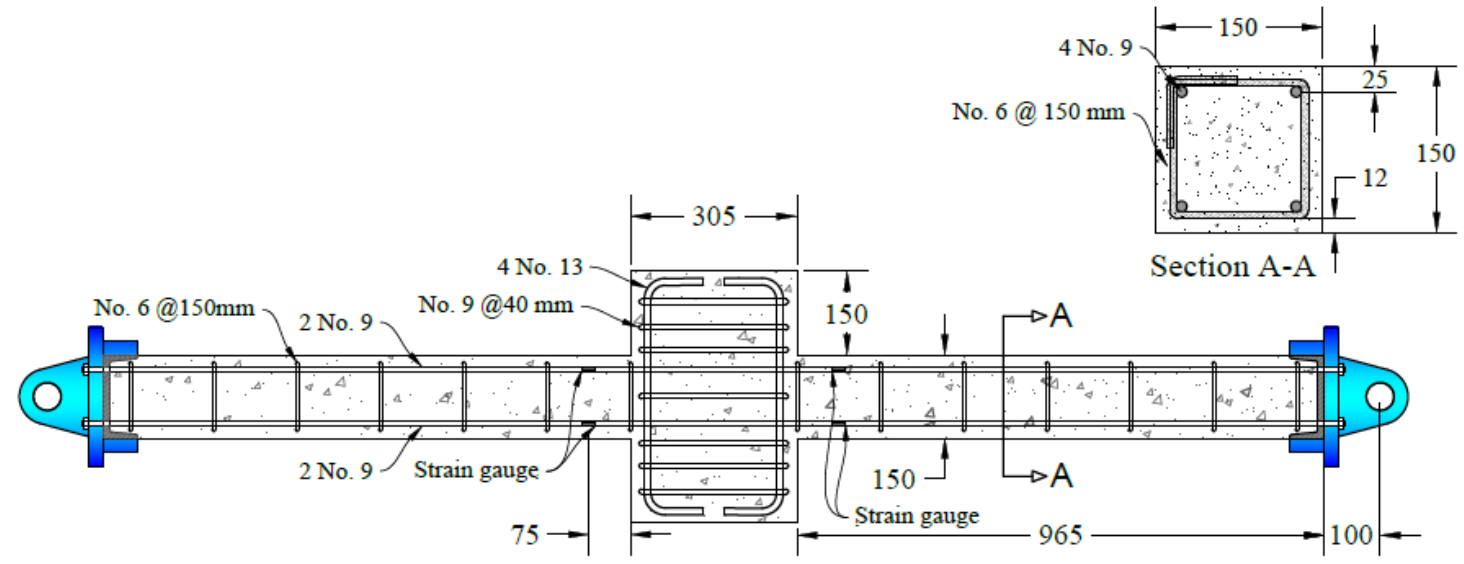

Fig. 3.1 Steel reinforcement details of the tested specimens

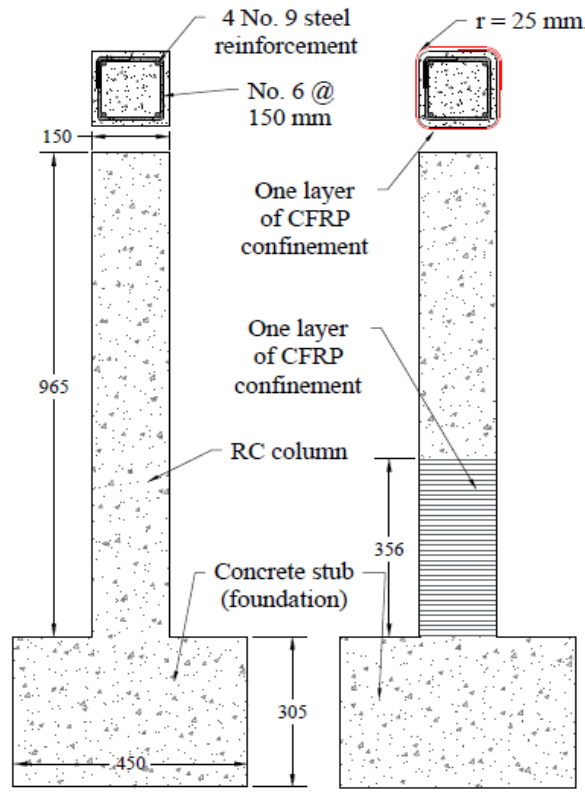

(a) C1-Control

(b) C2-Confined

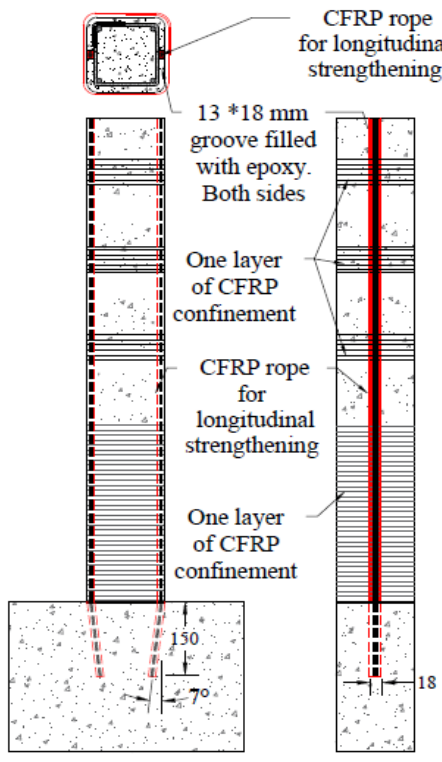

(c) C5-Strengthened

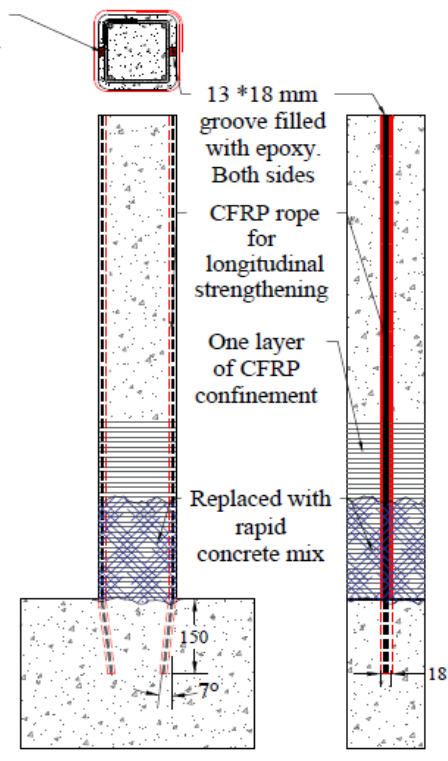

(d) C7-Repaired

Fig. 3.2 Strengthening and repairing details of the tested columns 


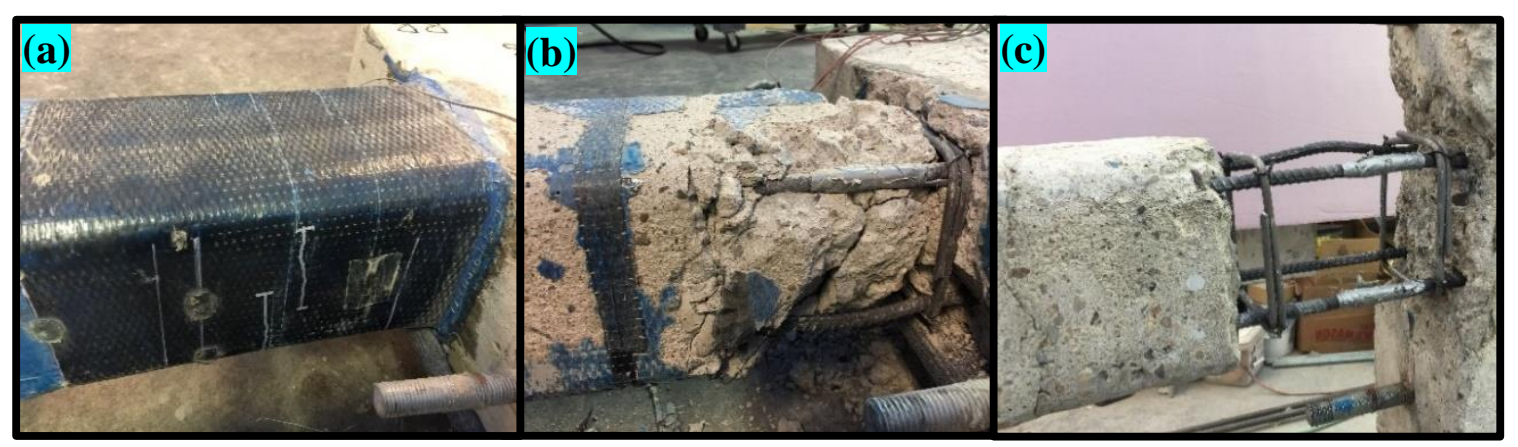

Fig. 3.3 Cleaning damaged concrete

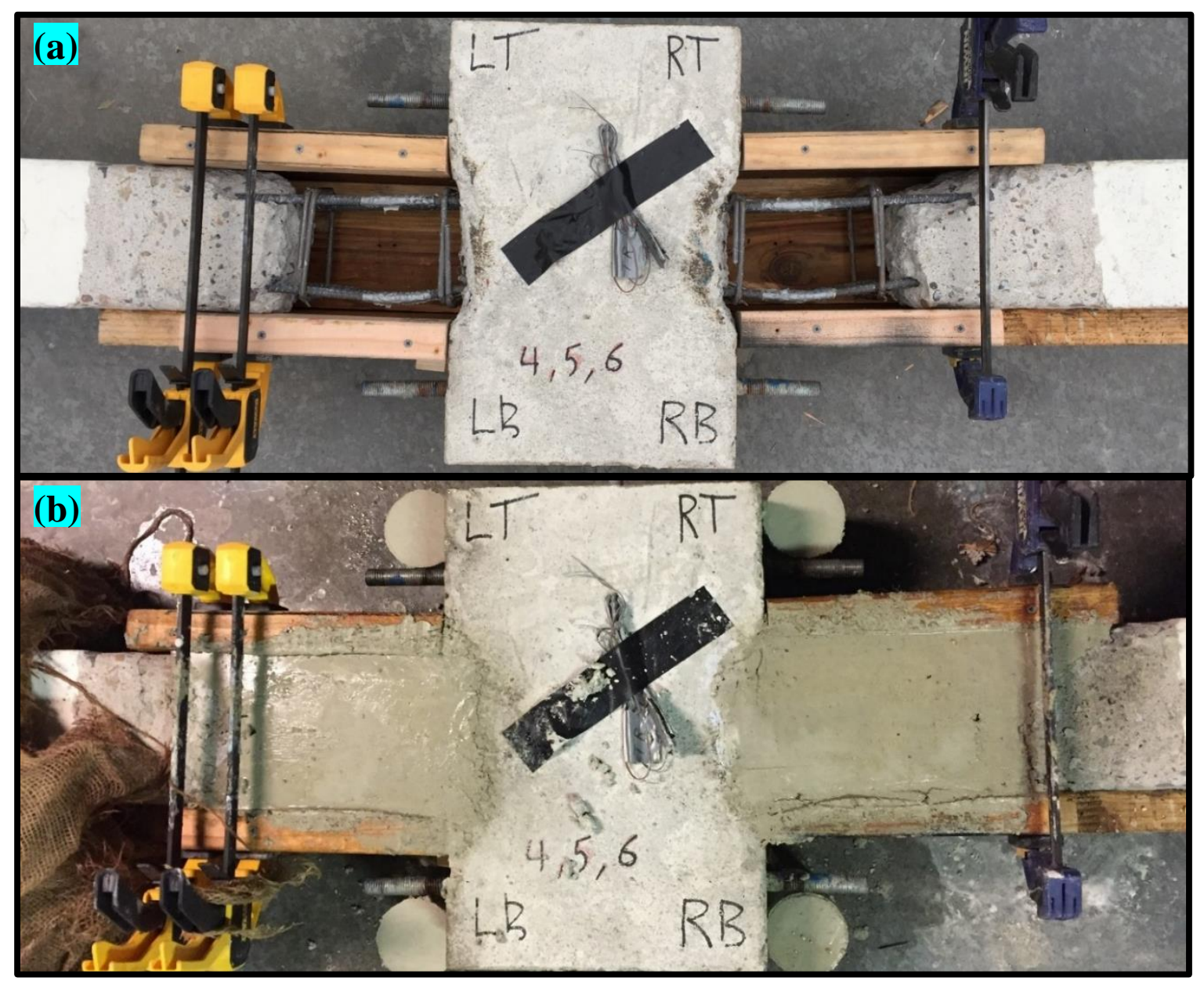

Fig. 3.4 (a) form work, and (b) casting repair mix concrete 


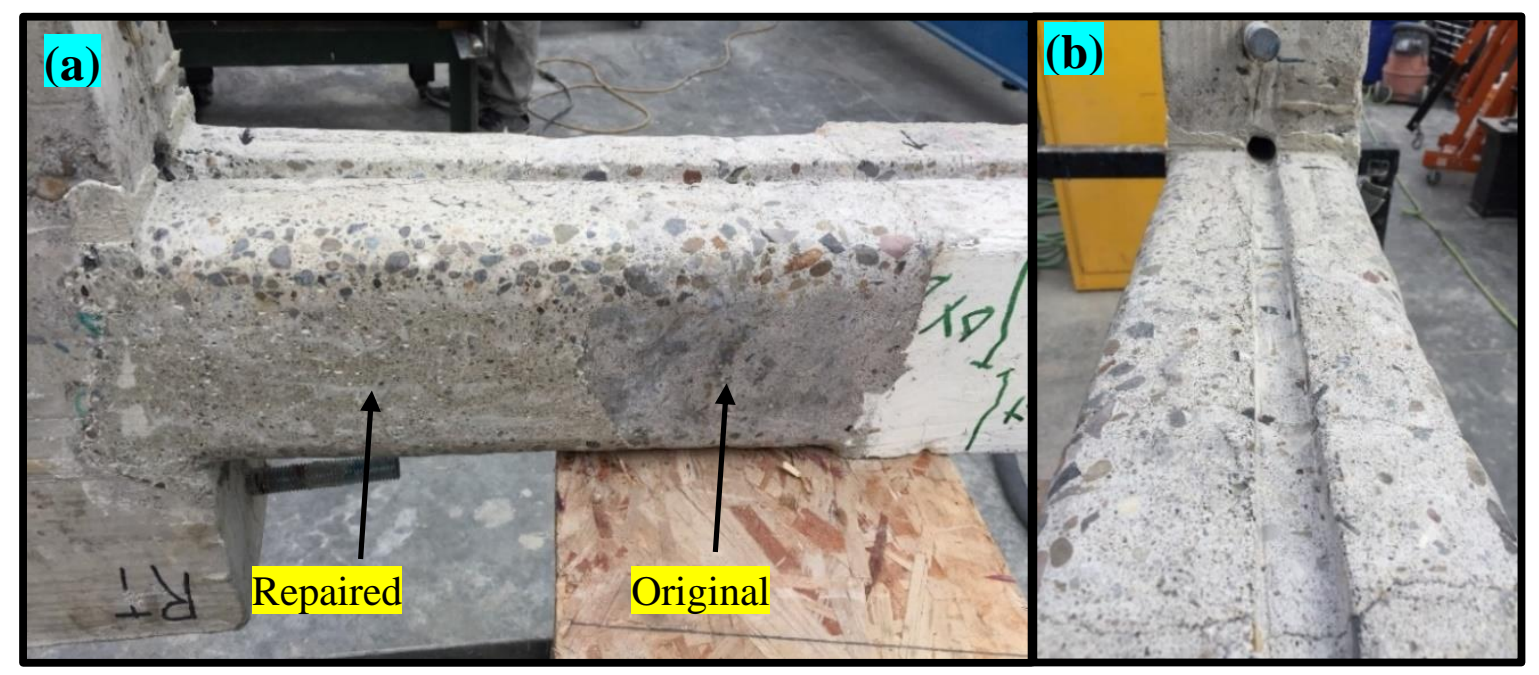

Fig. 3.5 (a) concrete grinding, and (b) NSM-CFRP grooves and anchoring holes
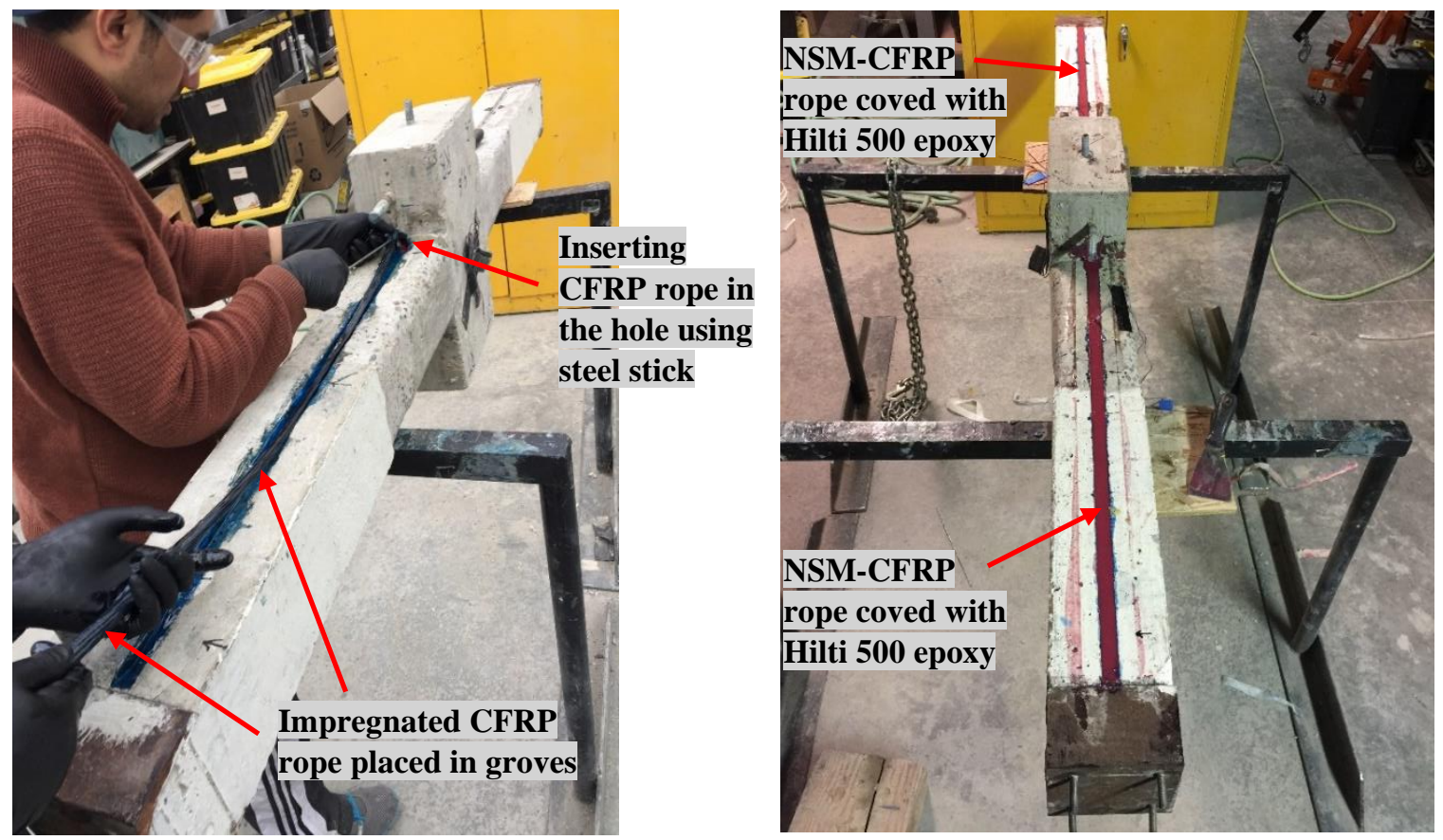

Fig. 3.6 Installation of CFRP ropes 


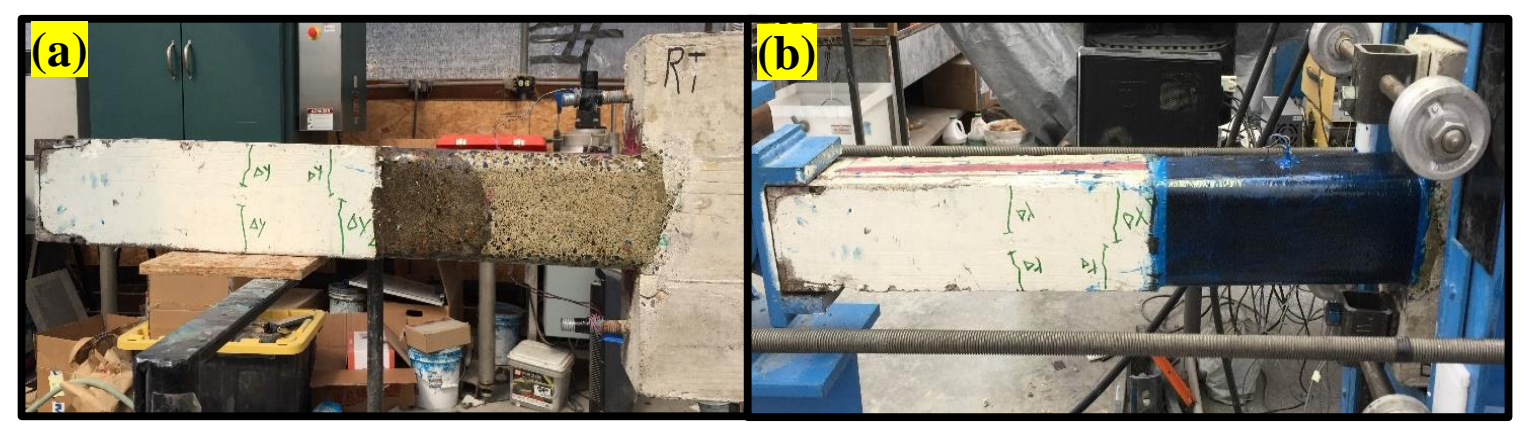

Fig. 3.7 (a) Concrete surface coated with epoxy, and (b) Application of CFRP confinement

\begin{tabular}{|c|c|c|c|c|c|c|c|c|c|c|c|c|}
\hline & 1/4 Day1 & 1/2 Day1 & 3/4 Day1 & End Day 1 & 1/4 Day2 & 1/2 Day2 & 3/4 Day2 & End Day 2 & 1/4 Day3 & 1/2 Day3 & 3/4 Day3 & End Day 3 \\
\hline TASK & 123456 & & 2 hrs & & 4 hrs & & 5 hrs & 48 & & $60 \mathrm{~h}$ & & $72 \mathrm{hrs}$ \\
\hline Straightening/cleaning & & & & & & & & & & & & \\
\hline Form work & & & & & & & & & & & & \\
\hline Repair mix casting & & & & & & & & & & & & \\
\hline Repair mix curing & & & & & & & & & & & & \\
\hline Concrete grinding & & & & & & & & & & & & \\
\hline Make grooves/holes & & & & & & & & $40 \mathrm{r}$ & & & & \\
\hline Rope installation & & & & & & & $\leftarrow$ & $\operatorname{Rep}$ & air was co & mpleted & & \\
\hline Hilti 500 Epoxy curing & & & & & & & & & & & & \\
\hline MasterBrace P 2000 & & & & & & & & & & & & \\
\hline P 2000 curing & & & & & & & & & & & & \\
\hline MasterBrace P 3500 & & & & & & & & & & & & \\
\hline P 3500 curing & & & & & & & & & & & & \\
\hline CFRP confinement & & & & & & & & & & & & \\
\hline MasterBrace curing & & & & & & & & & & & & \\
\hline Setup/instrumentation & & & & & & & & & & & & \\
\hline Ready for test & & & & & & & & & & & & \\
\hline
\end{tabular}

Fig. 3.8 The proposed rapid repairing technique - timeline 


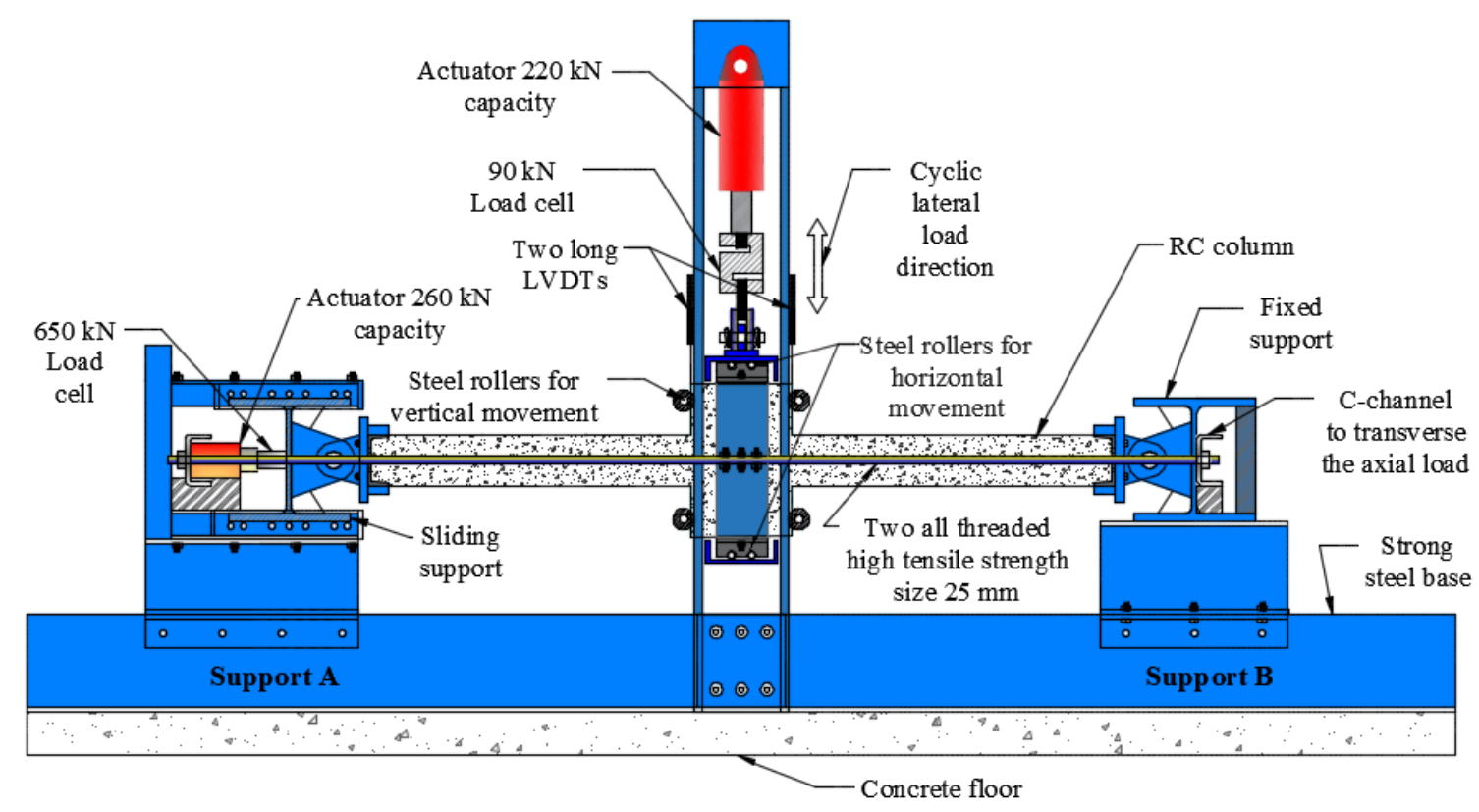

Fig. 3.9 Test setup

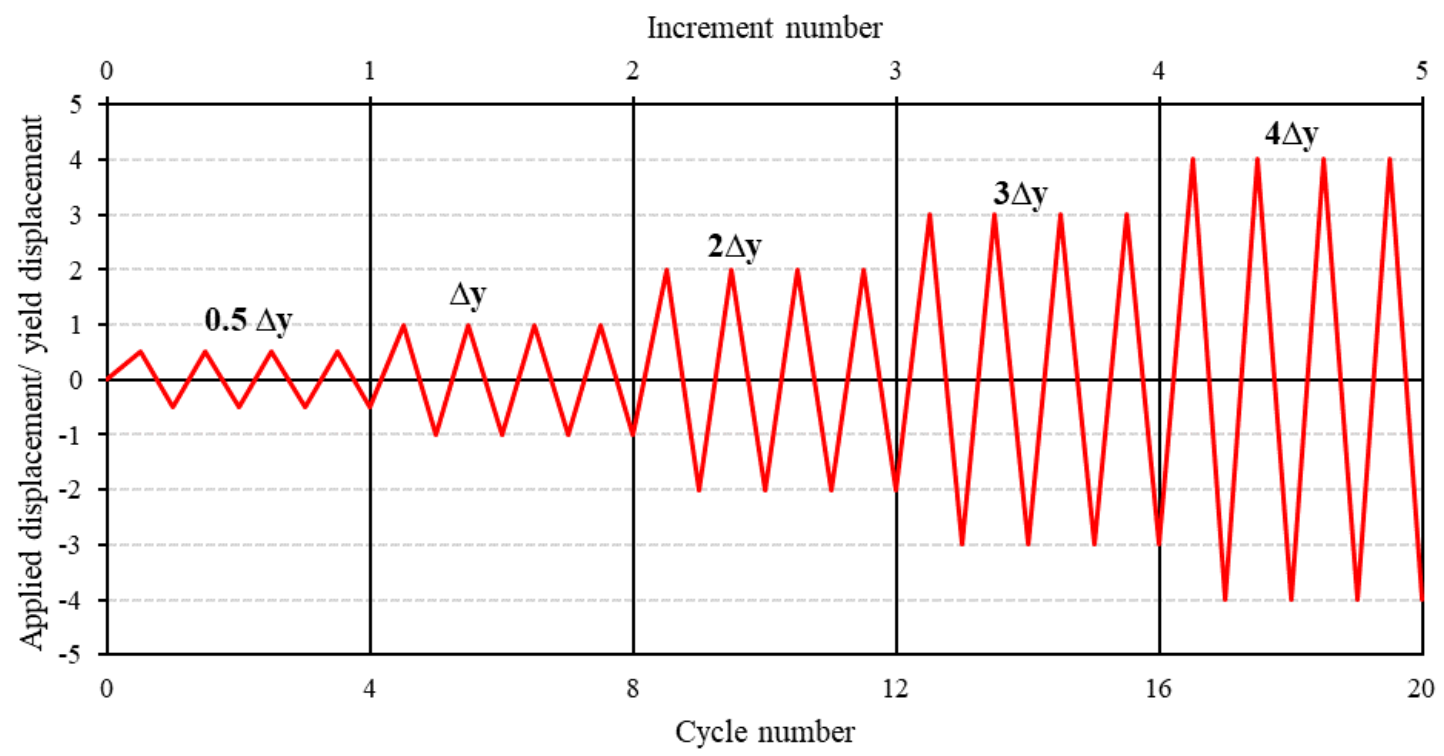

Fig. 3.10 Loading protocol 


\section{C5-Strengthened}

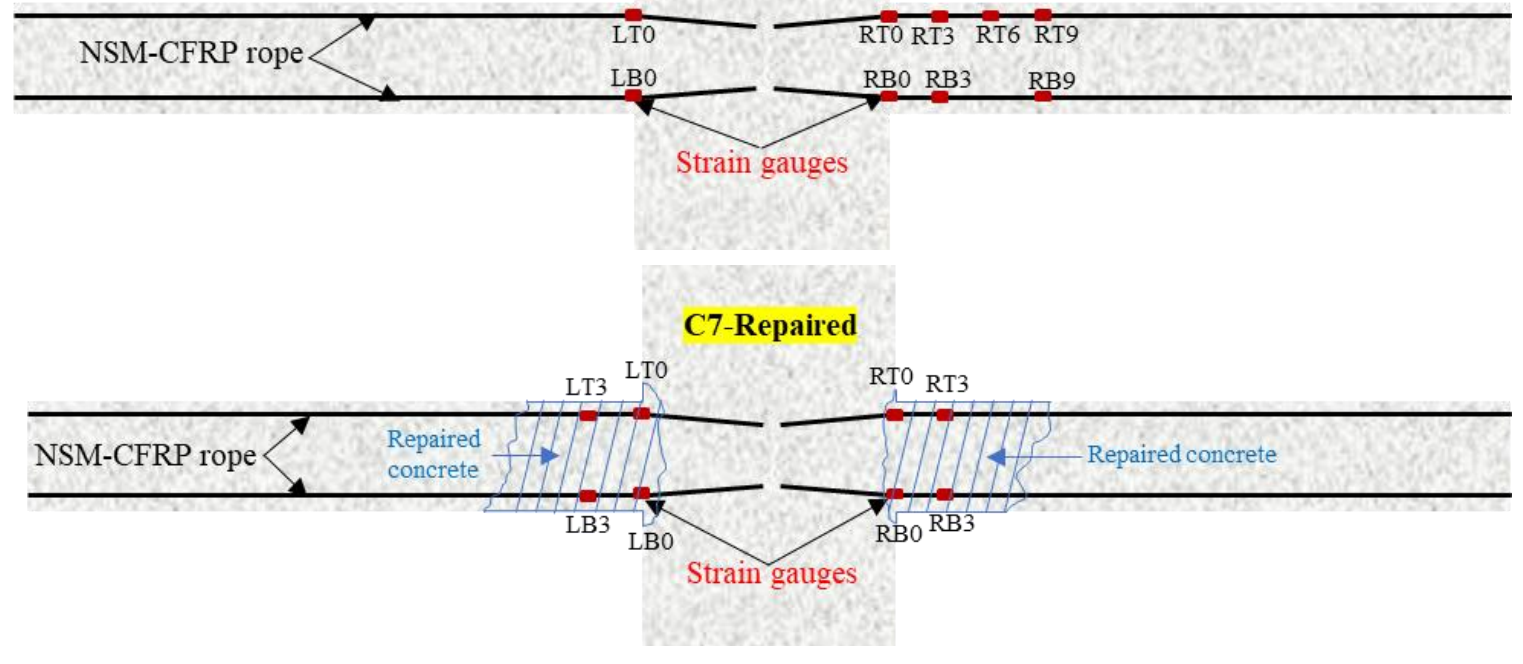

Fig. 3.11 Location of strain gauges attached to CFRP ropes
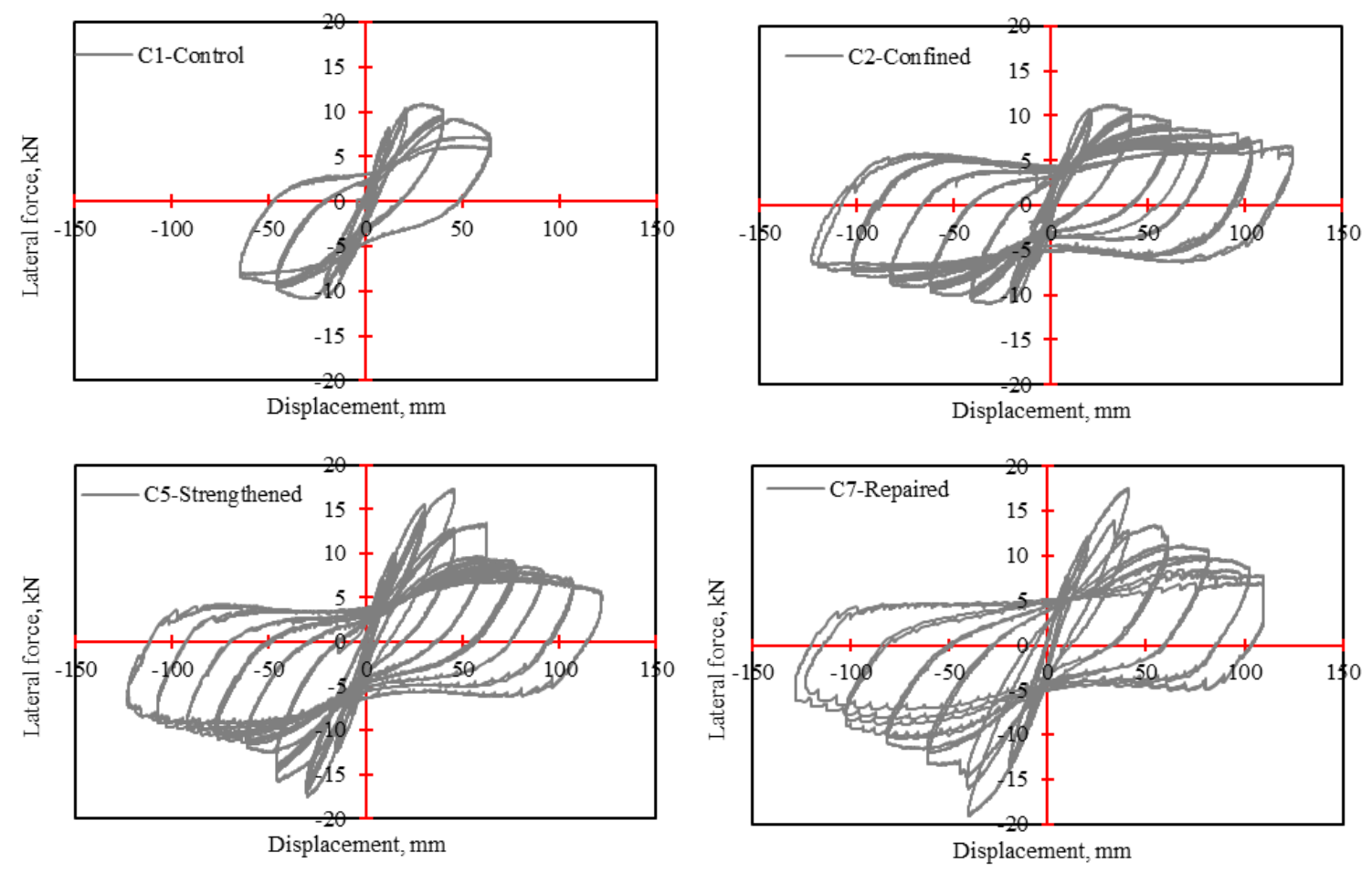

Fig. 3.12 Load-displacement hysteresis curves 


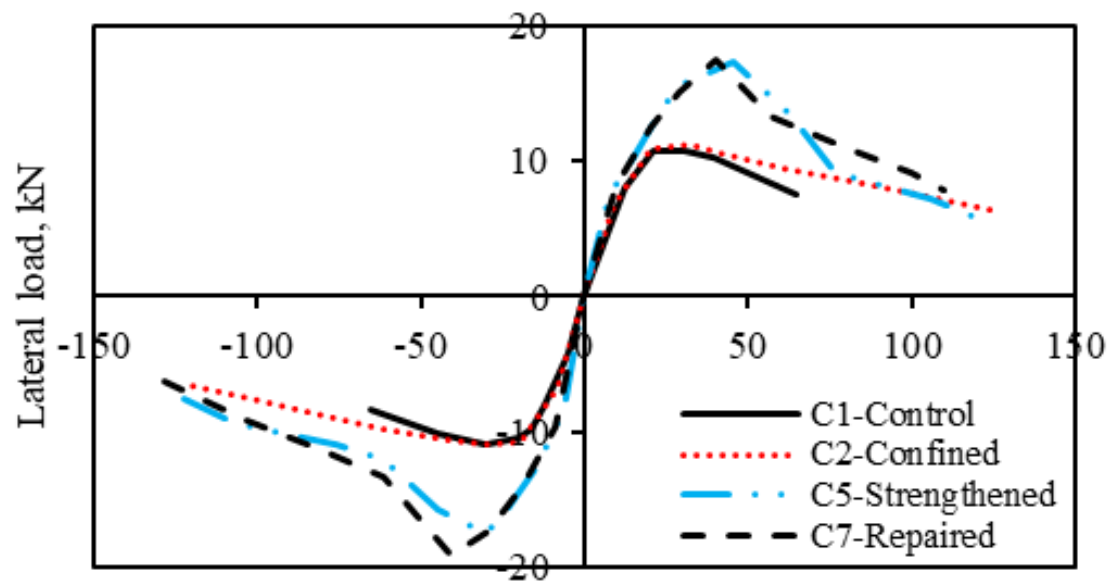

Lateral displacement, $\mathrm{mm}$

Fig. 3.13 Load-displacement envelope 


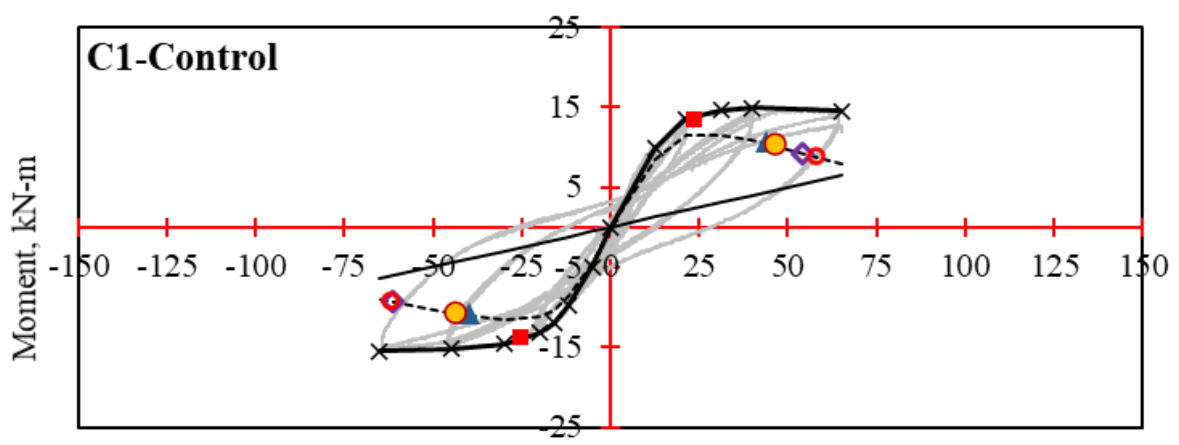

Displacement, $\mathrm{mm}$
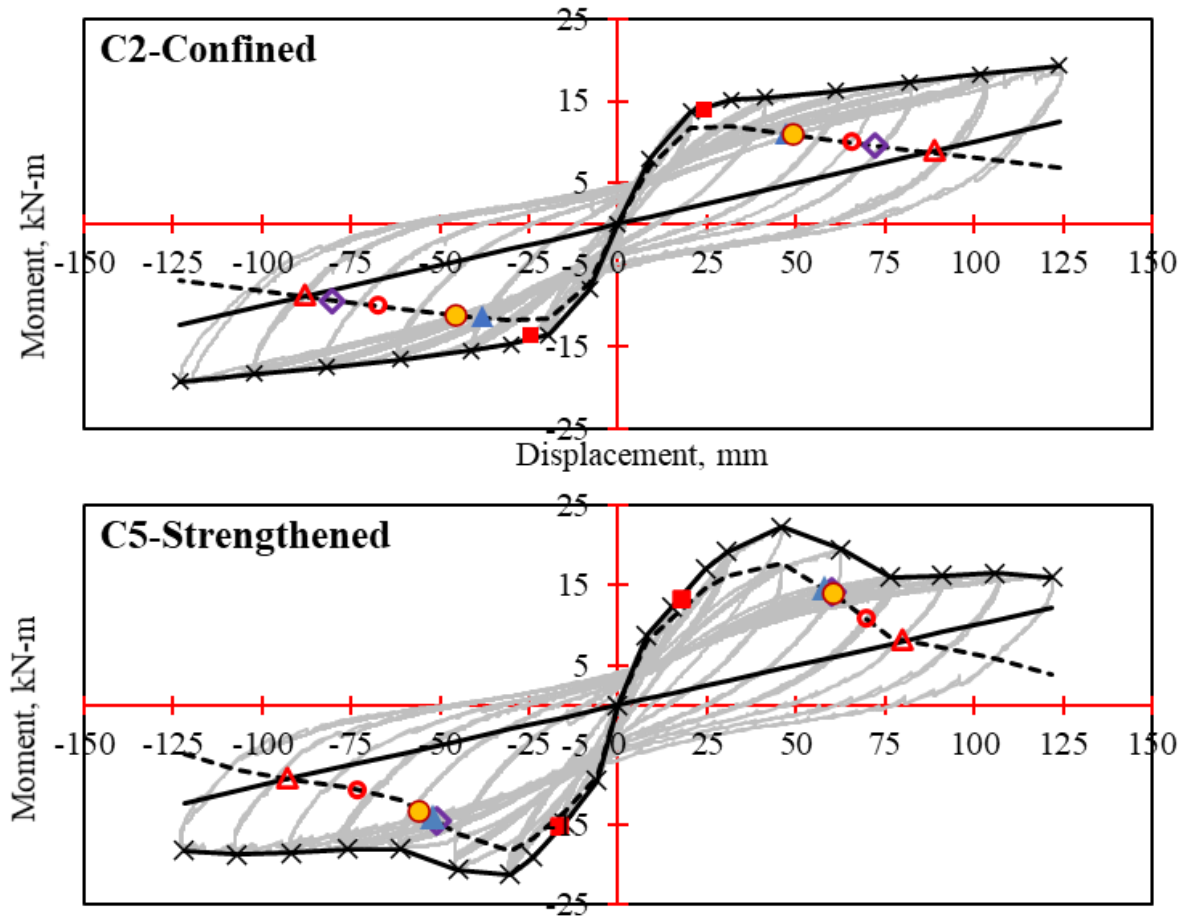

Displacement, $\mathrm{mm}$

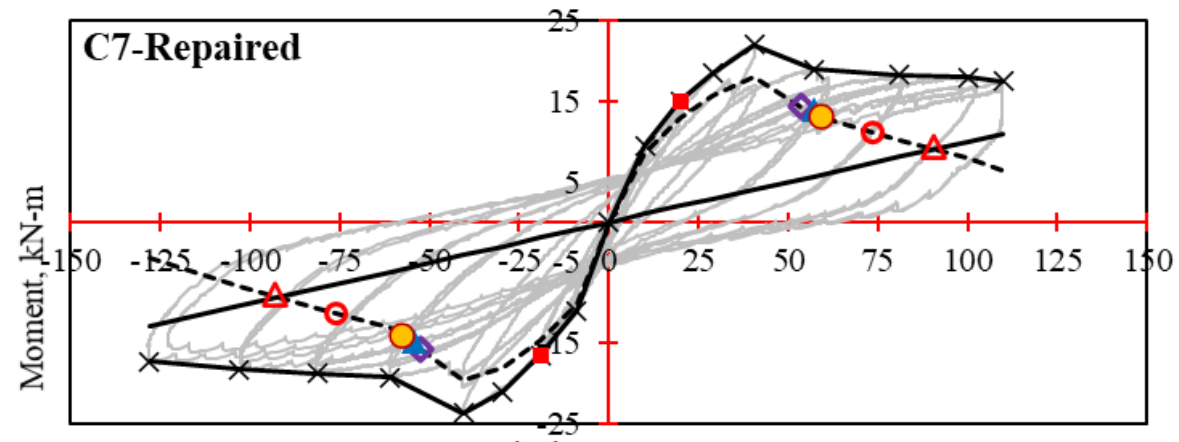

Displacement, $\mathrm{mm}$

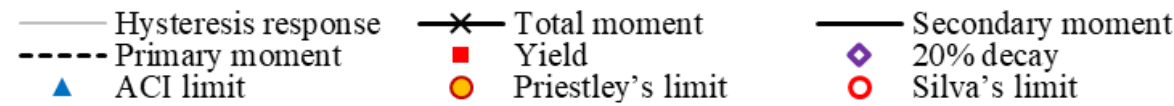

Fig. 3.14 Moment-displacement relationships showing the stability limits 


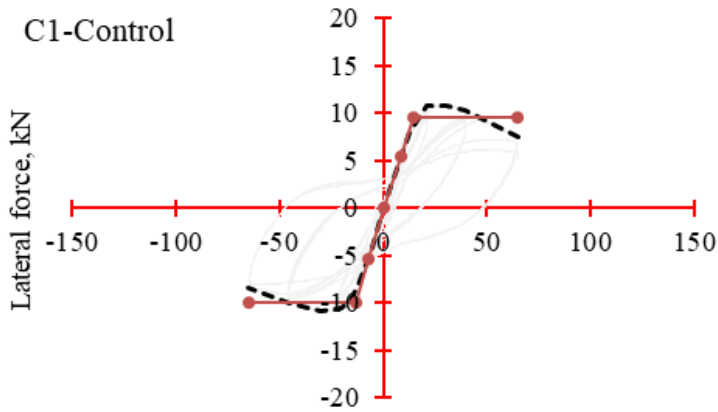

Displacement, $\mathrm{mm}$

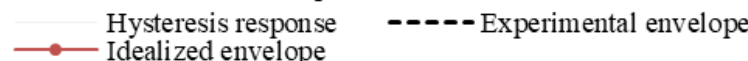
Idealized envelope

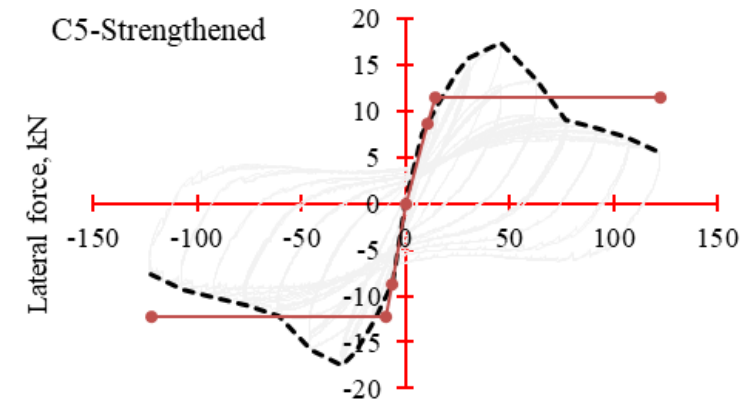

Displacement, $\mathrm{mm}$

Hysteresis response - - - Experimental envelope $\longrightarrow$ Idealized envelope

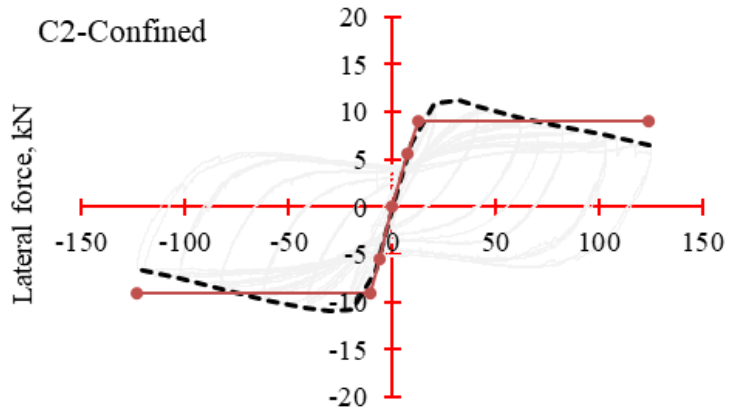

Displacement, $\mathrm{mm}$

Hysteresis response - - - Experimental envelope $\longrightarrow$ Idealized envelope

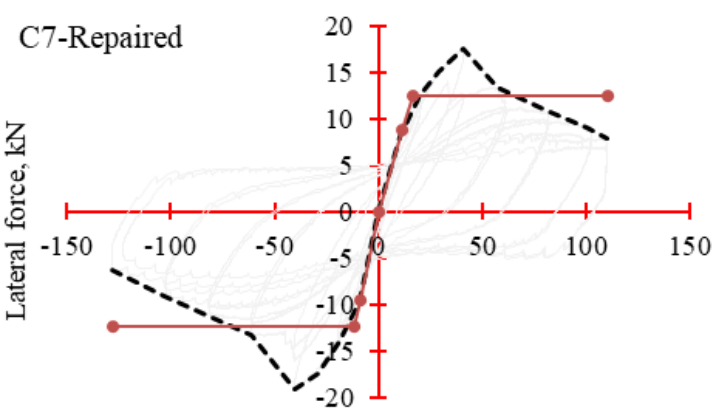

Displacement, $\mathrm{mm}$

Hysteresis response - - - Experimental envelope - Idealized envelope

Fig. 3.15 Idealized load-displacement curves

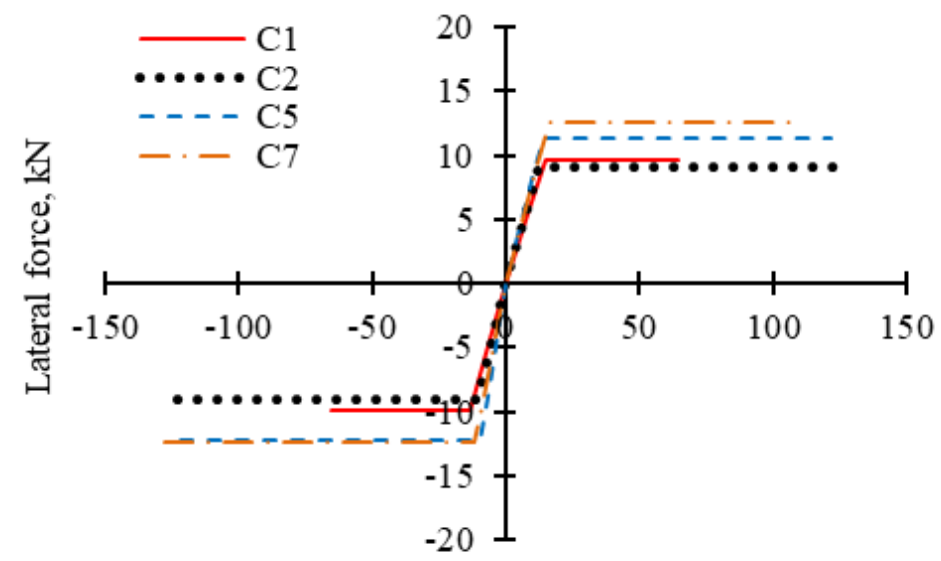

Displacement, $\mathrm{mm}$

Fig. 3.16 Comparison of the idealized load-displacement envelopes 


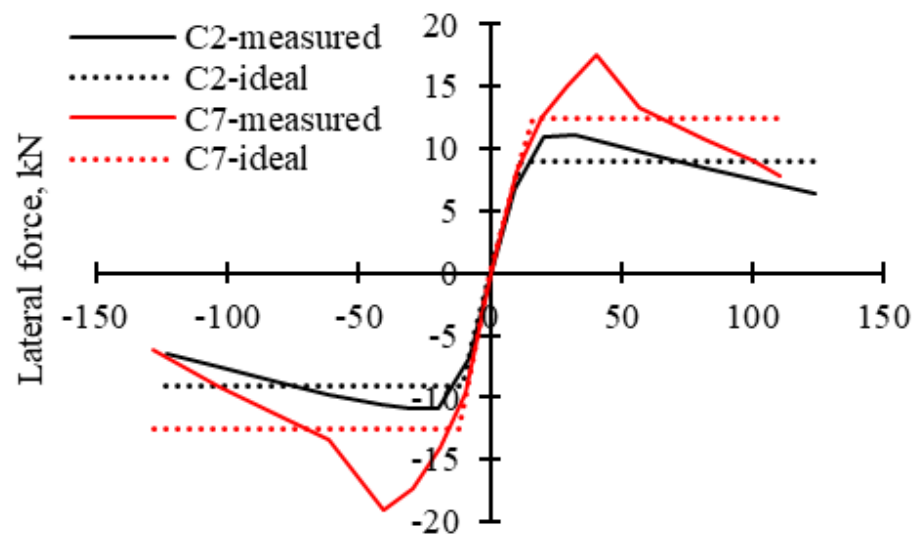

Displacement, $\mathrm{mm}$

Fig. 3.17 Measured and idealized envelopes for C2-Confined (before repairing) and C7Repaired (after repairing) 


\section{References - Chapter 3}

[1] C.K. Ma, N.M. Apandi, C.S.Y. Sofrie, J.H. Ng, W.H. Lo, A.Z. Awang, W. Omar, Repair and rehabilitation of concrete structures using confinement: A review, Constr. Build. Mater. 133 (2017) 502-515. https://doi.org/10.1016/j.conbuildmat.2016.12.100.

[2] A. Vosooghi, M.S. Saiidi, Design guidelines for rapid repair of earthquakedamaged circular RC bridge columns using CFRP, J. Bridg. Eng. 18 (2013) $827-$ 836. https://doi.org/10.1061/(ASCE)BE.1943-5592.0000426.

[3] S.F. Jiang, X. Zeng, S. Shen, X. Xu, Experimental studies on the seismic behavior of earthquake-damaged circular bridge columns repaired by using combination of near-surface-mounted BFRP bars with external BFRP sheets jacketing, Eng. Struct. 106 (2016) 317-331. https://doi.org/10.1016/j.engstruct.2015.10.037.

[4] Applied Technology Council (ATC), Seismic Design Criteria for Bridges and Other Highway Structures: Current and Future, National Center for Earthquake Engineering research, Redwood City, California, 1997. http://hdl.handle.net/10477/845.

[5] T. Alkhrdaji, A. Nanni, Flexural strengthening of bridge piers using FRP composites, in: Struct. Congr. 2000, ASCE - American Society of Civil Engineers, Philadelphia, Pennsylvania, United States, 2012: pp. 1-13. https://doi.org/10.1061/40492(2000)174.

[6] A. Prota, G. Manfredi, A. Balsamo, A. Nanni, E. Cosenza, Innovative technique 
for seismic upgrade of RC square columns, in: Proc. 7th Int. Symp. Fiber Reinf. Polym. Reinf. Concr. Struct. - FRPRCS-7, American Concrete Institute, Farmington Hills, MI., 2005: pp. 1289-1304. http://www.quakewrap.com/frp papers/InnovativetechniqueforSeismicUpgradeofRCSquareColumns.pdf.

[7] A. Parvin, D. Brighton, FRP composites strengthening of concrete columns under various loading conditions, Polymers (Basel). 6 (2014) 1040-1056. https://doi.org/10.3390/polym6041040.

[8] Y. Xiao, Applications of FRP composites in concrete columns, Adv. Struct. Eng. 7 (2004) 335-343. https://doi.org/10.1260/1369433041653552.

[9] C. Lee, J.F. Bonacci, M.D.A. Thomas, M. Maalej, S. Khajehpour, N. Hearn, S. Pantazopoulou, S. Sheikh, Accelerated corrosion and repair of reinforced concrete columns using carbon fibre reinforced polymer sheets, Can. J. Civ. Eng. 27 (2000) 941-948. https://doi.org/10.1139/100-030.

[10] R. He, Rapid repair of severely damaged RC columns under combined loading of flexure, shear, and torsion with externally bonded CFRP, Missouri University of Science and Technology, 2014. http://scholarsmine.mst.edu/doctoral_dissertations.

[11] M.S. Saiidi, Z. Cheng, Effectiveness of composites in earthquake damage repair of reinforced concrete flared columns, J. Compos. Constr. 8 (2004) 306-314. https://doi.org/10.1061/(ASCE)1090-0268(2004)8:4(306).

[12] M. Shin, B. Andrawes, Emergency repair of severely damaged reinforced concrete columns using active confinement with shape memory alloys., Smart Mater. 
Struct. 20 (2011) 065018. https://doi.org/10.1088/0964-1726/20/6/065018.

[13] R. He, L.H. Sneed, A. Belarbi, Rapid repair of severely damaged RC columns with different damage conditions - an experimental study, Int. J. Concr. Struct. Mater. 7 (2013) 35-50. https://doi.org/10.1007/s40069-013-0030-7.

[14] R. He, S. V. Grelle, L.H. Sneed, A. Belarbi, Rapid repair of a severely damaged RC column having fractured bars using externally bonded CFRP, Compos. Struct. 101 (2013) 225-242. https://doi.org/10.1016/j.compstruct.2013.02.012.

[15] Y. Yang, L. Sneed, M.S. Saiidi, A. Belarbi, M. Ehsani, R. He, Emergency repair of an RC bridge column with fractured bars using externally bonded prefabricated thin CFRP laminates and CFRP strips, Compos. Struct. 133 (2015) 727-738. https://doi.org/10.1016/j.compstruct.2015.07.045.

[16] F. Capani, A. D’Ambrisi, M. De Stefano, F. Focacci, R. Luciano, R. Nudo, R. Penna, Experimental investigation on cyclic response of RC elements repaired by CFRP external reinforcing systems, Compos. Part B Eng. 112 (2017) 290-299. https://doi.org/10.1016/j.compositesb.2016.12.053.

[17] I.S. Kim, J.O. Jirsa, O. Bayrak, Use of carbon fiber-reinforced polymer anchors to repair and strengthen lap splices of reinforced concrete columns, ACI Struct. J. 108 (2011) 630-640. https://doi.org/10.14359/51683220.

[18] T. El Maaddawy, Post-repair performance of eccentrically loaded RC columns wrapped with CFRP composites, Cem. Concr. Compos. 30 (2008) 822-830. https://doi.org/10.1016/j.cemconcomp.2008.06.009. 
[19] W. Aules, Y.M. Saeed, F.N. Rad, A novel anchorage system for strengthening slender RC columns with externally bonded CFRP composite sheets, Constr. Build. Mater. 245 (2020) 118423. https://doi.org/10.1016/j.conbuildmat.2020.118423.

[20] S.T. Rutledge, M.J. Kowalsky, R. Seracino, J.M. Nau, Repair of reinforced concrete bridge columns containing buckled and fractured reinforcement by plastic hinge relocation, J. Bridg. Eng. 19 (2014) 1-10. https://doi.org/10.1061/(ASCE)BE.1943-5592.0000492.

[21] T. Ozbakkaloglu, M. Saatcioglu, Tensile behavior of FRP anchors in concrete, J. Compos. Constr. 13 (2009) 82-92. https://doi.org/10.1061/(ASCE)10900268(2009)13:2(82).

[22] ACI Committee 318 (ACI 318-63), Building Code Requirements for Reinforced Concrete, Farmington Hills, MI., 1963.

[23] ASTM C39 / C39M-18, Standard Test Method for Compressive Strength of Cylindrical Concrete Specimens, West Conshohocken, PA., 2018. https://doi.org/10.1520/C0039_C0039M-18.

[24] A. Yosefani, Flexural Strength, Ductility, and Serviceability of Beams that Contain High-Strength Steel Reinforcement and High-Grade Concrete, Portland State University, 2018. https://doi.org/10.15760/etd.6286.

[25] ASTM D7565 / D7565M-10(2017), Standard Test Method for Determining Tensile Properties of Fiber Reinforced Polymer Matrix Composites Used for 
Strengthening of Civil Structures, West Conshohocken, PA., 2017.

https://doi.org/10.1520/D7565_D7565M-10R17.

[26] ACI Committee 318 (ACI 318-14), Building Code Requirements for Structural Concrete and Commentary, Farmington Hills, MI., 2014.

[27] ACI Committee 440 (ACI 440.2R-17), Guide for the Design and Construction of Externally Bonded FRP Systems for Strengthening Concrete Structures, Farmington Hills, MI., 2017.

[28] L. De Lorenzis, J.G. Teng, Near-surface mounted FRP reinforcement: An emerging technique for strengthening structures, Compos. Part B Eng. 38 (2007) 119-143. https://doi.org/10.1016/j.compositesb.2006.08.003.

[29] A. Godat, A. L'Hady, O. Chaallal, K.W. Neale, Bond behavior of the ETS FRP bar shear-strengthening method, J. Compos. Constr. 16 (2012) 529-539. https://doi.org/10.1061/(ASCE)CC.1943-5614.0000280.

[30] G. Ozdemir, Mechanical properties of CFRP anchorages, Middle East Technical University, 2005. https://doi.org/10.1002/eqe.4290180114.

[31] K. Olivova, J. Bilcik, Strengthening of Concrete Columns With CFRP, Slovak J. Civ. Eng. 1 (2009) 1-9.

[32] M. Perrone, J.A.O. Barros, A. Aprile, CFRP-based strengthening technique to increase the flexural and energy dissipation capacities of RC Columns, J. Compos. Constr. 13 (2009) 372-383. https://doi.org/10.1061/(ASCE)CC.1943- 
5614.0000031.

[33] ACI Committee 374 (ACI 374.2R-13), Guide for Testing Reinforced Concrete Structural Elements under Slowly Applied Simulated Seismic Loads, Farmington Hills, MI., 2013.

[34] S.N. Bousias, T.C. Triantafillou, M.N. Fardis, L. Spathis, B.A. O'Regan, Fiberreinforced polymer retrofitting of rectangular reinforced concrete columns with or without corrosion, ACI Struct. J. 101 (2004) 512-520. https://doi.org/10.14359/13337.

[35] L.Z. Yao, G. Wu, Fiber-element modeling for seismic performance of square RC bridge columns retrofitted with NSM BFRP bars and/or BFRP sheet confinement, J. Compos. Constr. 20 (2016) 1-15. https://doi.org/10.1061/(ASCE)CC.19435614.0000652.

[36] E. Noroozieh, A. Mansouri, Lateral strength and ductility of reinforced concrete columns strengthened with NSM FRP rebars and FRP jacket, Int. J. Adv. Struct. Eng. 11 (2019) 195-209. https://doi.org/10.1007/s40091-019-0225-5.

[37] M.J.N. Priestley, F. Seible, G.M. Calvi, Seismic design and retrofit of bridges, John Wiley \& Sons, Inc., 1996.

[38] P.F. Silva, A. Sangtarashha, R. Burgueño, P-Delta Effects in Limit State Design of Slender RC Bridge Columns, in: 15th World Conf. Earthq. Eng., Lisbon Portugal, 2012. 
[39] A.C. Barrera, J.L. Bonet, M.L. Romero, P.F. Miguel, Experimental tests of slender reinforced concrete columns under combined axial load and lateral force, Eng. Struct. 33 (2011) 3676-3689. https://doi.org/10.1016/j.engstruct.2011.08.003.

[40] R. Burgueño, A. Babazadeh, L.K. Fedak, P.F. Silva, Second-order effects on seismic response of slender bridge columns, ACI Struct. J. 113 (2016) 735-746. https://doi.org/10.14359/51688751.

[41] M. Saatcioglu, Deformability of reinforced concrete columns, in: EarthquakeResistant Struct. Response Des., American Concrete Institute, Detroit, MI., 1991: pp. $421-452$.

[42] M. Saatcioglu, D. Baingo, Circular high-strength concrete columns under simulated seismic loading, J. Struct. Eng. 125 (1999) 272-280. https://doi.org/10.1061/(ASCE)0733-9445(1999)125:3(272).

[43] M.F.M. Fahmy, Z. Wu, G. Wu, Seismic performance assessment of damagecontrolled FRP-retrofitted RC Bridge Columns using residual deformations, J. Compos. Constr. 13 (2009) 498-513. https://doi.org/10.1061/(ASCE)CC.19435614.0000046.

[44] B. Li, K.A. Harries, Seismic performance assessment of flexure-dominate FRPconfined RC columns using plastic rotation angle, Eng. Struct. 172 (2018) $453-$ 471. https://doi.org/10.1016/j.engstruct.2018.06.046.

[45] J.C. Alvarez, S.F. Breña, S.R. Arwade, Nonlinear backbone modeling of concrete columns retrofitted with fiber-reinforced polymer or steel jackets, ACI Struct. J. 
115 (2018) 53-64.

[46] Caltrans, Caltrans Seismic Design Criteria, Version 2.0, Sacramento, CA, 2019. 


\title{
Chapter 4: Tensile Behavior of FRP Anchors Made from CFRP Ropes Epoxy- Bonded to Uncracked Concrete for Flexural Strengthening of RC Columns
}

This part of the dissertation (Chapter 4) has already been published by Elsevier Journal “Case Studies in Construction Materials.”

\author{
Full citation of the paper: \\ Y.M. Saeed, W.A. Aules, F.N. Rad, A.M. Raad, Tensile behavior of FRP anchors \\ made from CFRP ropes epoxy-bonded to uncracked concrete for flexural \\ strengthening of RC columns, Case Stud. Constr. Mater. 13 (2020) e00435. \\ https://doi.org/10.1016/j.cscm.2020.e00435.
}

\subsection{Introduction}

\subsubsection{Background}

Fiber reinforced polymer (FRP) materials have become the material of choice for strengthening and repairing reinforced concrete (RC) structures. FRP composites have been used successfully in strengthening RC beams $[1,2]$, slabs $[3,4]$, columns $[5,6]$ beamcolumn joints $[7,8]$, and walls $[9,10]$. The way of strengthening RC structures can mainly be done by either externally bonded EB-FRP system or near-surface-mounted NSM-FRP technique. Previous studies have reported that EB-FRP technique can effectively be used in strengthening RC structures. However, premature FRP-to-concrete debonding failure 
that reduces the efficiency of the strengthening system has often been observed [11-14]. Therefore, researchers have developed anchorage systems to delay or prevent debonding failure and utilize the most of the FRP materials before failure [15-18]. FRP anchors (also called fan anchors or spike anchors) are one of the common types that have been developed to increase the efficiency of EB-FRP system in flexural strengthening of concrete structures [19-21]. Depending on the inclination angle and the location where they are installed, FRP anchors can be subjected to shear and/or pullout (tensile) forces.

FRP anchors that are used with EB-FRP strengthening systems for flexural or shear strengthening of RC beams are mostly subjected to shear forces as the angle between FRP anchor and EB-FRP reinforcement is usually between $90^{\circ}$ (perpendicular) and $165^{\circ}$ [21]. On the other hand, FRP anchors used in flexural strengthening of RC columns are often subjected to pullout forces because the angle between FRP anchors and EB-FRP reinforcement is usually $180^{\circ}$ [22,23]. In the case of using NSM-FRP technique in flexural strengthening of RC columns, the NSM-FRP rods or laminates must be anchored to transfer the load to the foundation or to the joints. To do that, NSM-FRP materials are inserted in holes predrilled in the foundation and filled with bonding agent [24-26]. The forces acting on the FRP materials anchored to the holes are similar to the pullout forces acting on the $180^{\circ} \mathrm{FRP}$ anchors described earlier. Therefore, FRP anchors subjected to pullout forces are common whether EB-FRP or NSM-FRP systems are used in the strengthening process. Direct pullout test is the simplest and most common way to investigate the bond properties of FRP materials bonded to concrete $[27,28]$. 


\subsubsection{Previous pullout tests}

Much research has been carried out to investigate the bond properties of FRP rods epoxybonded to concrete and subjected to pullout forces [29-32]. However, information about the tensile properties of FRP anchors is mainly limited to the experimental tests of three studies [33-35]. Kim and Smith [33] tested a total of 27 FRP anchors under pure tension loading. The parameters were the embedment length $(20,40$ and $60 \mathrm{~mm})$, the hole (anchor) diameter $(12,14$ and $16 \mathrm{~mm}$ ), and the amount of CFRP (width of rolled CFRP sheet $=60$, 110 and $130 \mathrm{~mm}$ ). The observed failure modes were concrete cone failure, combined concrete cone and bond failure, FRP rupture failure, and bond failure. Concrete cone failure was observed for all FRP anchors with $20 \mathrm{~mm}$ embedment. All other failure modes mentioned earlier were observed for anchors with embedment length of $40 \mathrm{~mm}$ or larger. With significant variation in the test results, it was observed that anchors with $14 \mathrm{~mm}$ anchor hole diameter had higher pullout strength than those with $16 \mathrm{~mm}$ hole diameter. FRP rupture failure was seen in most of the anchors with $60 \mathrm{~mm}$ embedment. The pullout strength clearly increased with the increase of the embedment length. Compared to the nominal strength of FRP stated by the manufacturer, the maximum pullout force achieved by FRP anchors with 20, 40, and $60 \mathrm{~mm}$ embedment lengths were 34\%, 47\%, and 60\%, respectively. However, the authors stated that more tests were required to verify their conclusions. It was claimed that the variation of the results was mainly due to the challenge associated with the manufacturing process of FRP anchors.

Ozbakkaloglu and Saatcioglu [34] tested 81 FRP anchors under pure tension (pullout). The parameters were the embedment length $(25,50,75$, and $100 \mathrm{~mm})$, the hole diameter $(12.7$, 
15.9, and $19.1 \mathrm{~mm}$ ), concrete strength (25 and $50 \mathrm{MPa}$ ), and the angle of anchor inclination $\left(0^{\circ}, 15^{\circ}, 30^{\circ}\right.$, and $\left.45^{\circ}\right)$. It was observed that $84 \%$ of the tested anchors failed by either cone failure or combined cone and bond failure, $10 \%$ failed by FRP rupture, and $6 \%$ failed by concrete splitting. Cone failure mode was observed for all FRP anchors with $25 \mathrm{~mm}$ embedment length, and the depth of the concrete cone was $25 \mathrm{~mm}$ as well. However, it was found that the depth of the concrete cone reduced when the embedment length increased. The average bond stress decreased when increasing the embedment length, suggesting that the stress distribution along the length of the anchor was not uniform. The average bond strength also decreased with increasing the anchor diameter. The authors related this observation to the effects of Poisson's ratio. Concrete strength did not have a significant effect on the bond strength. Data from all the 81 tested anchors including those that failed in FRP rupture revealed that the maximum achieved pullout force did not exceed 50\% of the nominal FRP strength. This was judged to be significantly related to the quality of the manufacturing process of FRP anchors. Therefore, the authors recommended a reduction factor of 0.33 when calculating the tensile strength of handmade FRP anchors.

For the first set of tests, Ozdemir [35] tested a total of 153 pullout specimens. However, only 127 tests were considered because the quality of 26 tests were not as desired, and therefore they were excluded. The study parameters were the embedment length $(70,100$, and $150 \mathrm{~mm}$ ), the hole diameter (12, 14, and $16 \mathrm{~mm}$ ), CFRP amount (width of pre-cut CFRP sheet $=80,120$, and $160 \mathrm{~mm})$, and concrete compressive strength (10, 16, and 20 MPa). The author stated that it was hard to make any conclusions out of the test results as the results had no clear correlation. It was observed, though, that the optimum embedment 
depth was $100 \mathrm{~mm}$. Seventeen additional tests were carried out in the second series of the pullout tests. All seventeen specimens were made of the same width of pre-cut CFRP sheet $(120 \mathrm{~mm})$ and had a hole diameter of $20 \mathrm{~mm}$. The varied parameters were the embedment depth $(50,70,100,150 \mathrm{~mm})$ and concrete strength (10 and $16 \mathrm{MPa})$. Ozdemir confirmed from the second set of pullout tests that the optimum embedment length for FRP anchors was $100 \mathrm{~mm}$. However, by reviewing the row raw data published by the same author [35], it can be observed that many of the specimens with embedment length of $150 \mathrm{~mm}$ achieved higher pullout strengths than those with $100 \mathrm{~mm}$ embedment. In fact, the ratio of the maximum achieved pullout force to the nominal ultimate capacity of CFRP was at its maximum (66\%) when the embedment length was $150 \mathrm{~mm}$. Therefore, it appears that the tensile behavior of CFRP anchors with deeper embedment lengths should be further investigated.

In all previous studies [33-35], CFRP anchors were made by rolling pre-cut CFRP sheets to form rope-like anchors. A common conclusion was that the results were scattered, and large variation in pullout strength was observed because of the challenges associated with the fabrication process of the anchors. Twisting and "poor alignment" of the fibers while fabricating CFRP anchors were the main reasons of this challenge [33]. However, readymade CFRP ropes have recently become available in the market. Using CFRP ropes to produce CFRP anchors is easier than rolling pre-cut CFRP sheets to fabricate CFRP anchors. Since none of the previous studies used CFRP ropes as anchors, it is unsafe to assume that the tensile behavior of CFRP anchors made of rolling pre-cut CFRP sheets is the same as that of anchors made from CFRP ropes. Moreover, the maximum embedment 
length considered in the previous studies was $100 \mathrm{~mm}$, except for Ozdemir [35] who tested a few samples with $150 \mathrm{~mm}$ embedment. However, Ozdemir was not successful to obtain useful conclusions for anchors with an embedment length larger than $100 \mathrm{~mm}$. One might argue that longer embedment may be required if FRP anchors are used in flexural strengthening of RC columns because the anchors are installed where the maximum load transfer occurs. However, all these studies [33-35] focused on using the anchors to delay or prevent debonding failure for RC beams strengthened with EB-FRP composite sheets. Kim and Smith [36] proposed a model to predict the pullout strength of FRP anchors. They concluded that more tests are required to improve the accuracy of the model. The model considered embedment lengths of up to $100 \mathrm{~mm}$ because there was no reliable data with larger embedment lengths. A more recent theoretical model has been proposed by Villanueva Llauradó [21]. However, for pullout strength (anchors subjected to pure tension), Villanueva Llauradó used the same model proposed by Kim and Smith [36] because there were no reliable experimental data other than the tests considered in the model proposed by Kim and Smith. Finally, even though the properties of the bonding agent (epoxy adhesive in this case) is expected to affect the tensile behavior of FRP anchors [34], to the best of the author's knowledge epoxy type has not been considered as a parameter in any of the previous studies focusing on pullout strength of FRP anchors. 


\subsubsection{Pullout tests - the present study}

In the present study, a total of twenty-one pullout tests were carried out on CFRP anchors made from ready-made CFRP ropes. The nominal embedment lengths were 45, 90, 135, 180,270 , and $315 \mathrm{~mm}$. This study is the first to consider an embedment length larger than $150 \mathrm{~mm}$. The hole diameters were $12.7,19.1$, and $25.4 \mathrm{~mm}$. Since none of the previous studies considered varying the epoxy type, two types of epoxy adhesives available in the market were considered in this study. The results of previous tests [33-35] show that concrete compressive strength did not have significant effects on the pullout strength of FRP anchors, especially for anchors with deep embedment. Therefore, a nominal concrete strength of $20 \mathrm{MPa}$ was selected for all test specimens in the present study. The main aim of this investigation was to provide additional experimental data on the tensile behavior of FRP anchors made from CFRP ropes. In addition, the tests carried out in this study was part of an investigation on using CFRP ropes in flexural strengthening of RC columns. As mentioned earlier, CFRP ropes epoxy-bonded to concrete has not been tested to examine their tensile behavior. It is expected that the results of this investigation may provide useful information for developing and calibrating future theoretical models to predict the tensile behavior of FRP anchors made of CFRP ropes. The available models in the literature have been utilized to predict the pullout strengths of the teste specimens, and the results were compared with the experimental data of this study. Finally, a modified model was proposed to better predict the tensile strength of CFRP rope anchors. 


\subsection{Materials}

\subsubsection{Concrete}

The concrete strength was not one of the parameters considered in this study. Therefore, it was aimed to consider one concrete strength for all test specimens. A ready-mixed concrete of $20 \mathrm{MPa}$ was ordered from a local provider. All test specimens were cast on the same day. However, the pullout tests were conducted in different days. The time period between the first test and the last test was 15 days. The average concrete strength at 28 days was 19.1 MPa determined based on testing three concrete cylinders $(150 \mathrm{~mm}$ x $300 \mathrm{~mm})$ following ASTM Standards [37]. The concrete strength for each pullout specimen was also determined by testing three concrete cylinders on the day of pullout test. The concrete strengths for all pullout specimens will be presented later.

\subsubsection{CFRP}

A new form of CFRP material called "CFRP rope" was used in the present study. It is a unidirectional carbon fiber string that comes from the manufacturer (Sika Corporation) as a 25-meter string encased in a plastic envelope and rolled on plastic reel dispenser. One of the advantages of using CFRP rope is that it is a flexible-multifunctional string that can be used in different shapes and angles in structural strengthening and rehabilitation of concrete structures. Based on the manufacturer data sheet, the dry fiber tensile strength, modulus of elasticity, and ultimate strain are $4000 \mathrm{MPa}, 240 \mathrm{GPa}$, and 1.67\%, respectively. However, 
the rope composite tensile strength, modulus of elasticity, and ultimate strain are 2100 $\mathrm{MPa}, 230 \mathrm{GPa}$, and $0.91 \%$, respectively. Depending on the manufacturer's technical data sheet, the strength of CFRP fibers (4000 MPa) was reduced significantly (48\%) when mixed with epoxy and tested as a composite material (2100 MPa).

\subsubsection{Epoxy}

Two types of commercially available epoxy adhesives were considered and used in this study. One type of epoxy was a high viscosity, high strength, two-part epoxy adhesive that was used as an anchoring resin (commercially known as Hilti 500 and referred to as epoxy Type A in this study). As specified by the manufacturer, the tensile strength, bond strength, and ultimate strain of the anchoring resin Type A were $43.4 \mathrm{MPa}, 12.4 \mathrm{MPa}$, and 2.0\%, respectively. Epoxy Type A is a red epoxy usually used in practice as a chemical adhesive for fastening steel bars/bolts into concrete. The epoxy type was one of the parameters considered in this investigation. A low viscosity epoxy material that consisted of two parts was used as an impregnating resin (commercially known as MasterBrace SAT 4500 and referred to as epoxy Type B in this study). Epoxy Type B is a blue color epoxy usually used in practice to encapsulate FRP fabrics. As specified by the manufacturer, the tensile strength, modulus of elasticity, and the ultimate strain of the impregnating resin were 55.2 $\mathrm{MPa}, 3 \mathrm{GPa}$, and 3.5\%, respectively. All CFRP anchors were impregnated with epoxy Type B. However, specimens were anchored to the concrete by using either Type A or Type B epoxy adhesives. 


\subsection{Test specimens}

\subsubsection{Concrete blocks}

A total of nine plain concrete blocks were fabricated in the laboratory. Concrete blocks \#1, $\# 2$, and \#3 were designed for short CFRP rope anchors (embedment $=5 \mathrm{D}$ and 10D) and were $200 \mathrm{~mm}$ (width) x $900 \mathrm{~mm}$ (length) x $150 \mathrm{~mm}$ (thickness). The letter " $\mathrm{D}$ " here represents the diameter of CFRP rope, which was assumed to be $9 \mathrm{~mm}$. For longer CFRP anchors (15D and 20D), the dimensions of the concrete blocks (blocks \#4 and \#5) were $400 \mathrm{~mm}$ (width) x $800 \mathrm{~mm}$ (length) x $250 \mathrm{~mm}$ (thickness). For the longest CFRP anchors (20D, 30D, and 35D), the dimensions of the concrete blocks (blocks \#6 through \#9) were $600 \mathrm{~mm}$ (width) x $600 \mathrm{~mm}$ (length) x $400 \mathrm{~mm}$ (thickness). The compressive strengths for all concrete blocks on the day of testing are listed in Table 4.1.

\subsubsection{Steel grippers}

One of the challenges with FRP composite materials is the fact that they are extremely weak in the transverse direction. This fact makes it a challenge to hold FRP materials during pullout or tensile tests. In this study, the anchoring technique proposed by Saeed and $\operatorname{Rad}[38,39]$ were modified and used to hold one of the ends of CFRP ropes during the pullout tests. The gripping technique consisted of a steel tube continuously threaded from the outside and smooth from the inside. In the present study, the inside smooth surface of the tube was roughened slightly by a hand threading tap to increase the friction between 
the bonding agent and the steel surface (Fig. 4.1a). From the outside, a hex nut was placed and fixed at one of the tube ends. As shown in Fig. 4.1 (a), the outside surface of the nut was also roughened slightly using a steel grinding tool. The edges at the end of the steel tube, where the nut was attached, was curved to minimize stress concentration when the fibers of CFRP rope bend over it. The length of the steel tube ranged between $65 \mathrm{~mm}$ to $125 \mathrm{~mm}$ depending on the anticipated maximum force and the dimensional requirements

of the test setup. CFRP rope was cut by special scissors to the desired lengths (Fig. 4.1b). The steel tube was held vertically on a wood frame as shown in Fig. 4.1 (c), and the lower opening was closed by a duct tape to prevent epoxy from spalling out. The steel tube was then filled with epoxy. After being impregnated, CFRP rope was inserted inside the steel tube from top to bottom (Fig. 4.1c). The extra length of CFRP fibers on the top were separated like a fan and bent $180^{\circ}$ to be attached to the outside surface of the nut as shown in Fig. 4.1 (d). The other end (bottom end) of CFRP rope was embedded into the concrete as described in the following section. The samples were left undisturbed for at least 48 hours.

\subsubsection{CFRP anchor installation}

The procedure started with drilling holes in the concrete blocks using a commercially available concrete drill (Fig. 4.2a). New drill pits were used to avoid local cracks and damages to the concrete specimens. The holes were cleaned using compressed air and steel brush, then filled with epoxy. As described in the previous section, each steel tube was 
placed vertically on a wood frame and centered on top of a hole that was already cleaned and filled with epoxy (Fig. 4.2b). CFRP rope was then inserted vertically from the top all the way through the steel tube to the concrete surface. The bottom end of CFRP rope was tied with a plastic zipper and pushed to the bottom of the hole by a steel rod. Since the holes were filled with epoxy before inserting the ropes, extra epoxy spilled out of the holes. The extra epoxy was leveled, and special efforts were made to make the fibers of the CFRP rope straight with good alignment (Fig. 4.2c). An example of cured CFRP anchors ready for pullout test is shown in Fig. 4.2 (d).

\subsubsection{Specimen designation and test matrix}

Specimens' labels were associated with the assumed diameter of CFRP rope. Because impregnated CFRP rope does not have a clear diameter, the diameter was assumed to be 9 mm based on the authors' best estimation. The letter " $\mathrm{D}$ " in a specimen label refers to the diameter of the rope. Epoxy type was also considered in naming the specimens. Specimens starting with the letter "A" mean that epoxy Type A was used as the anchoring resin, and specimens starting with the letter "B" indicate that epoxy Type B was used. For example, A-5D-1.5D refers to a specimen with epoxy Type A, nominal embedment length of 5D (5 $\mathrm{x} 9=45 \mathrm{~mm})$, and a nominal hole diameter of $1.5 \mathrm{D}(1.5 \times 9=13.5 \mathrm{~mm})$. It should be noted that the hole diameters in this study were selected based on the most available sizes of drilling bits in the United States $(12.7,19.1$, and $25.4 \mathrm{~mm})$. Table 4.1 provides a list of pullout test specimens. Specimens' labels, concrete strength, epoxy type, embedment 
length, and hole diameter are listed in Table 4.1. Two specimens (A-5D-2D-R and A-20D2D-R) had the letter "R" at the end meaning that these specimens were repeated because similar previous specimens (A-5D-2D and A-20D-2D) failed in concrete splitting.

\subsubsection{Test setup and instrumentations}

Fig. 4.3 shows the test setup and instrumentation. The head of the anchor was hooked as shown in the figure and pulled up using an all-thread high-strength steel rod and a hydraulic ram. The strain in the CFRP rope was measured by a strain gauge attached to the free length of the rope as shown in Fig. 4.3. Two linear variable differential transformers (LVDTs) were used to measure the slippage between CFRP rope and concrete. The load was measured using a hollow strain-gauge based load cell. The all-thread steel rod went through the load cell and the hydraulic ram, and it was locked by a nut on top of the ram. The load cell, strain gauge, and the two LVDTs were all connected to a data logging system that measured the applied load, CFRP strain, and displacements at a rate of 20 readings per second. The loading rate was based on the recommendations of ACI [27] and ASTM [40]. ACI recommends that the loading rate should not be more than $20 \mathrm{kN} / \mathrm{min}$. ASTM suggests that the test should be done between one and three minutes. In this study, the anticipated maximum anchor capacity was divided by 2 and was applied in one minute, aiming to finish the test within two minutes. The loading rate used in this study fulfilled both above guidelines. 


\subsection{Experimental results and discussions}

Table 4.1 shows the pullout load capacities for all tested specimens. The pullout strengths ranged from about $12 \mathrm{kN}$ for shallow embedment to $76 \mathrm{kN}$ for deep embedment of CFRP anchors. The largest pullout load $(76 \mathrm{kN})$ achieved in this study is the maximum pullout strength among all data reported in the literature so far. The largest load recorded for CFRP anchors tested by Ozbakkaloglu and Saatcioglu [34] was $61 \mathrm{kN}$. In the present study, although the results were scattered similar to most previous studies [33-35], the effects of embedment length, hole diameter, and epoxy type on the pullout capacity of CFRP anchors are discussed in the following sections. Discussion about the observed failure modes is also provided. First, the results of this investigation are presented. Then, data from previous tests on comparable CFRP anchors [33-35] are included in the discussion.

\subsubsection{Effect of embedment length}

It has been reported in the literature that higher pullout capacity is expected for longer embedment length whether the FRP is in a form of bars [29-31] or anchors made of rolling pre-cut CFRP sheets [33-35]. However, no reliable tests are available for FRP anchors with embedment length larger than $100 \mathrm{~mm}$. Fig. 4.4 (a) shows the relationship between the embedment length and pullout capacity of CFRP rope anchors, and Fig. 4.4 (b) shows the relationship between the pullout capacity of CFRP rope anchor and the embedment length/hole diameter. The results of the present study confirm that pullout strength increases with the increase of the embedment length. Considering the trend of the results 
presented in Fig. 4.4 (a), this observation is generally true for all anchors with embedment lengths up to $270 \mathrm{~mm}$. One specimen (A-35D-2D) was tested with $315 \mathrm{~mm}$ embedment, and it achieved lower pullout strength than anchors with $270 \mathrm{~mm}$ embedment. In addition, the pullout strength of anchors with $180 \mathrm{~mm}$ was slightly lower than that of $270-\mathrm{mm}$ anchors. Therefore, it can be stated that the optimum embedment length for CFRP rope anchor lays between $180 \mathrm{~mm}$ and $270 \mathrm{~mm}$. Ozdemir [35] concluded that the optimum embedment length for CFRP anchors was $100 \mathrm{~mm}$. However, all Ozdemir's specimens with 150-mm embedment failed by CFRP rupture, which means that the CFRP amount used in fabricating the anchors was not adequate. If more CFRP amount had been used, anchors with $150-\mathrm{mm}$ embedment potentially could have achieved higher pullout loads than those with 100-mm embedment. The results of the present study confirm that anchors longer than 100-mm embedment achieved higher pullout strength.

Fig. 4.4 (b) shows that the pullout strength increases with increasing the embedment/ hole diameter ratio. The maximum achieved pullout strengths were for CFRP rope anchors with embedment/ hole diameter between 9.5 and 14.5. Fig. 4.5 compares the results of the present study to the data available in the literature. It can be observed that information about CFRP anchors longer than $100 \mathrm{~mm}$ relies solely on the tests performed in the present study. Although more tests are required to have statistically meaningful data, the increase of the pullout strength with increasing embedment length can be clearly observed. Fig. 4.6 (a) shows the average bond stress vs. embedment length. The average bond stress was calculated by dividing the maximum achieved pullout force $(\mathrm{kN})$ by the bonded area of CFRP rope anchor. As shown in Fig. 4.6 (a), it can be observed that the average bond stress 
decreased with the increase in embedment length, Moreover, for the same embedment length, smaller anchor hole diameters achieved higher bond strength than larger diameters. Fig. 4.6 (b) compares the results of this study with the average bond stresses achieved by other investigators in previous tests. Although the data points are scattered, it can be noted that generally the bond stress decreases as embedment length increases. This observation stands against the simplifying assumption that the bond stress is evenly distributed along the length of the anchor.

\subsubsection{Effect of anchor hole diameter}

The effects of anchor hole diameter on pullout load and average bond stress are presented in Fig. 4.7 and Fig. 4.8, respectively. The relationship between pullout load $(\mathrm{kN})$ and anchor hole diameter is shown in Fig. 4.7 (a). It can be observed that hole diameter does not have a significant effect on the pullout strength of CFRP rope anchors. For a constant embedment length ( $45 \mathrm{~mm}$ or $90 \mathrm{~mm}$ ), changing hole diameter from $12.7 \mathrm{~mm}$ to $25.4 \mathrm{~mm}$ did not increase the pullout load more than 5\%. The pullout load decreased $1 \%$ when the hole diameter increased from $12.7 \mathrm{~mm}$ to $19.1 \mathrm{~mm}$ for anchors with 135 -mm embedment. On the other hand, the pullout load increased by $9 \%$ when the anchor hole diameter increased from $19.1 \mathrm{~mm}$ to $25.4 \mathrm{~mm}$ for anchors with embedment length of $270 \mathrm{~mm}$. Based

on the limited range of tested specimens and observed results, the effect of hole diameter on the pullout strength of CFRP rope anchor does not appear to be significant. By considering more data from previous tests [33-35], as shown in Fig. 4.7 (b), no clear pattern 
of behavior can be observed about the effect of anchor hole diameter on the pullout load. However, the maximum pullout load was achieved when the hole diameter was $19.1 \mathrm{~mm}$ for all embedment lengths ranged between $25 \mathrm{~mm}$ and $100 \mathrm{~mm}$. Depending on the data of previous results (Fig. 4.7b; embedment is equal to or less than $100 \mathrm{~mm}$ ), a hole diameter of $19.1 \mathrm{~mm}(2 \mathrm{D})$ might be the optimum hole diameter for CFRP anchors. However, Fig. 4.7 (a) shows that this observation is not necessarily true, especially for embedment larger than $100 \mathrm{~mm}$.

Fig. 4.8 shows that the average bond stress decreases with the increase of anchor hole diameter. This observation can be made based on the results of this study (Fig. 4.8a) and based on the results of previous tests [33-35] (Fig. 4.8b). For all embedment lengths considered in Fig. 4.8 (a) (45 $\mathrm{mm}$ to $270 \mathrm{~mm})$, the maximum bond stress was achieved when the hole diameter was $12.7 \mathrm{~mm}$, which was the smallest diameter considered in this study. Fig. 4.8 (b) also shows that smaller anchor hole diameters achieved higher bond stresses than larger diameters. Ozbakkaloglu and Saatcioglu [34] explained this phenomenon by the effect of CFRP Poisson's ratio. Anchors with larger hole diameter experience larger lateral deformation when subjected to pullout load, and therefore larger diameters would have less confinement and less frictional resistance between CFRP anchor and surrounding concrete. In addition, previous studies on pullout strength of FRP bars bonded to concrete with chemical epoxy have recommended an optimum ratio of hole diameter to bar diameter of 1.5 [30]. In the present study, anchor hole diameter of $12.7 \mathrm{~mm}$ is approximately 1.5 time the diameter of CFRP ropes. 


\subsubsection{Effect of epoxy type}

The effect of epoxy type on the pullout strength of CFRP anchors has not been investigated before. In this study, a total of twelve specimens can be used to compare the influence of two different types of epoxy on the tensile behavior of CFRP rope anchors. All twelve specimens had the same embedment length, same hole diameter, and same amount of CFRP. Two commercially available epoxy types were compared. As described in section 2.3, epoxy referred to as Type A is commercially known as Hilti 500, and epoxy referred to as Type B is known as MasterBrace SAT 4500. Fig. 4.9 shows that CFRP anchors constructed with epoxy Type A achieved higher pullout strengths than those with epoxy Type B, except specimens with 45-mm embedment and 12.7-mm anchor holes (A-5D-1.5d vs. B-5D-1.5D). The tensile strength of CFRP rope anchors using epoxy Type A was at least $9 \%$ and at most $29 \%$ higher when using epoxy Type B. Based on this observation, the rest of the specimens were constructed with epoxy Type A.

\subsubsection{Failure modes}

Five main failure modes were observed in this study: concrete cone failure (CC), combined cone-bond failure (CB), CFRP-to-epoxy bond failure (BF), concrete splitting (SF), and CFRP rupture failure (RF). In addition, CFRP rope slipped from the steel gripper for two specimens (A-20D-2D-R and A-30D-2D). This failure mode is called gripper failure (GF) in this study. The observed failure modes are listed in Table 4.1. Concrete cone failure mode was observed in most specimens with 45-mm embedment (Fig. 4.10a). This is similar 
to results reported in previous studies [33]. The cone depth was equal to the embedment length. Only one specimen (A-5D-2D) of 45-mm embedment failed in concrete splitting, therefore the test was repeated (A-5D-2D-R). Another specimen (B-5D-2D) failed in combined cone and bond failure. All specimens with embedment of $90-\mathrm{mm}$ and $135 \mathrm{~mm}$ failed in combined cone and bond failure (Fig. 4.10b). The cone depth was smaller than that of $45-\mathrm{mm}$ anchors. It is interesting to note that the relationship between embedment length and failure modes observed in this study was similar to the failure modes observed in testing metal anchors [41].

Unfortunately, two of the 180-mm anchors (A-20D-2D and A-20D-2.8D) failed by concrete splitting (Fig. 4.10c). Concrete splitting failure indicated that the concrete block was too small to resist the pullout force. The results of these two specimens were excluded from the analysis. Bond failure (Fig. 4.10d) was observed by only one specimen (A-30D2.8D), which had an embedment of $270 \mathrm{~mm}$. The bond failure was between CFRP rope and epoxy. This type of failure is new and was not observed in any of the previous studies. Gripper failure (GF) was observed in specimens A-20D-2D-R and A-30D-2D (Fig. 4.10e). The failure was caused by low construction quality of the steel grippers for these two specimens. Finally, one specimen only (A-35D-2D) failed in FRP rupture (Fig. 4.10f). Although A-35D-2D reached CFRP rupture, the maximum pullout load was $13 \%$ lower than the maximum pullout strength achieved by A-30D-2.8D, which failed by CFRP-toepoxy bond failure (BF). This indicates that the CFRP fibers in A-35D-2D were not aligned well. The issue of fiber misalignment was also observed by previous investigations [3335]. 
Fig. 4.11 shows the relationship between the maximum pullout load and embedment length characterized by failure modes based on the present and previous studies [33-35]. It can be observed from Fig. 4.11(a) and (b) that for anchor embedment between $40 \mathrm{~mm}$ and 50 $\mathrm{mm}$ the failure mode changed from concrete cone failure $(\mathrm{CC})$ to combined cone and bond failure (CB). However, no clear observation could be made about the rupture failure (RF). The main reason for specimens that failed by CFRP rupture in previous studies was due to inadequate amount of CFRP used to make the anchors. If larger amount of CFRP had been used, the rupture failure could have been avoided. In the present study CFRP rupture did not occur for anchors with embedment less than $318 \mathrm{~mm}$ because the amount of CFRP was large enough to prevent the rupture of the ropes. This observation is in agreement with previous studies $[33,36]$.

\subsubsection{Load-displacement relationships}

Fig. 4.12 shows typical load-displacement relationships for some of the tested specimens. Two small LVDTs were attached to the CFRP rope and concrete surface to measure the displacement, as shown in Fig. 4.3. Because of the test setup and the nature of the CFRP rope anchor, it was difficult to distinguish between the slippage and concrete displacement. Therefore, the displacement in Fig. 4.12 is the total displacement including slippage, if occurred. It was not expected to see any significant slippage for short anchors $(45-\mathrm{mm}$ embedment), most of which failed in concrete cone failure mode. Longer anchors may have experienced some slippage, but slippage was not measured separately. Only one specimen 
(A-30D-2.8D) in this study failed mainly by slippage that occurred between CFRP rope and epoxy. A-30D-2.8D had 270-mm embedment and 25.4-mm hole diameter. The loaddisplacement response of A-30D-2.8D is labeled in Fig. 4.12 as " 270 mm" or "slip-270 mm." The reason the response of this specimen was divided into two stages in Fig. 4.12 was because it was the only specimen to show a ductile post-peak response. Slippage was the main reason for the post-peak ductile response of A-30D-2.8D. All other specimens failed in a brittle manner as shown in Fig. 4.12.

\subsubsection{Bond strength}

It can be observed in Fig. 4.6 and Fig. 4.8 that the average bond stress decreases with the increase of embedment length and hole diameter. The average bond stress for all eighteen specimens tested in this study (excluding specimens with concrete splitting failure mode) was 5.8 MPa. By considering a total of 76 pullout tests on CFRP anchors analyzed by Kim and Smith [33], the average bond stress was 8.8 MPa. There are no guidelines specifying what to assume as the average bond stress for CFRP anchors. ACI 440 [42] recommends that 6.9 MPa can be assumed as the average bond stress for NSM-FRP bars. However, that assumption was based on tests conducted on FRP bars; not FRP anchors or ropes. Because no data were available on the tensile behavior of CFRP rope anchors, Kaya et al. [43], which is the only study in the literature that used CFRP rope in strengthening flexural members, proposed that an average bond stress of $5 \mathrm{MPa}$ could "conservatively" be assumed for CFRP ropes chemically bonded to concrete. Based on the test results of the 
present study and previous studies [33-35], as shown in Fig. 4.6b, an average bond stress lower than that suggested by ACI $440(6.9 \mathrm{MPa})$ should be recommended for FRP anchors. The average bond stress should be reduced even more for FRP anchors with deep embedment (larger than $100 \mathrm{~mm}$ ).

\subsection{Available theoretical models}

In this section, the results of the pullout tests were compared with existing theoretical models. The only available model up to date is the one proposed by Kim and Smith [36]. The model was developed based on the pullout tests conducted on FRP anchors by three experimental studies [33-35]. All data gathered to create the model [36] were based on CFRP anchors made from rolling pre-cut CFRP sheets. The pullout strength of CFRP anchors were predicted based on three main failure modes, namely concrete cone failure, combined cone-bond failure, and CFRP rupture. Table 4.2 presents the equations used to calculate the pullout strength of CFRP anchors based on the failure modes. In the following sections, the equations available for each failure mode are discussed. Then, the equations presented in Table 4.2 are used to predict the pullout strength of the specimens tested in the present study. 


\subsubsection{Concrete cone failure model $\left(\mathrm{N}_{\mathrm{CC}}\right)$}

This type of failure commonly occurs in anchors with shallow embedment. The pullout capacity in this type of failure mode depends mostly on concrete tensile strength. The embedment length at which FRP anchor fails due to concrete cone failure varies and affects by the mechanical properties of the concrete. Ozdemir [35] used Eq. 1 to calculate concrete cone capacity of FRP anchors. The equation was originally developed by ACI 349-85 [44] for metallic anchors. Concrete cone pullout capacity in Eq. 1 is determined by multiplying concrete tensile strength $\left(0.33 \sqrt{f_{c}^{\prime}}\right)$ by the projected area of the failure cone assuming an angle of $45^{\circ}[\pi h(d+h)]$. Ozdemir [35] assumed that all FRP anchors with embedment (h) less than $50 \mathrm{~mm}$ fail by concrete cone failure mode (CC), as shown in Eq. 1. Ozbakkaloglu and Saatcioglu [34] stated that ACI equation of concrete tensile strength, $0.33 \sqrt{f_{c}^{\prime}}$, underestimate the actual tensile strength, so they modified Eq. 1 by replacing the tensile strength of concrete, $0.33 \sqrt{f_{c}^{\prime}}$, with experimentally-recorded tensile strengths, $\left(f_{c t}^{\prime}\right)_{\exp }$. Kim and Smith [36] used the concrete capacity design (CCD) approach proposed by Fuchs et al. [45] to calculate the concrete breakout strength, or concrete cone capacity of FRP anchors. Eq. 3 assumes that the angle of failure cone is about $35^{\circ}$. For metallic anchors, the value of the $\alpha$ is recommended to be 13.5 [45]. Kim and Smith [36] analyzed the experimental data of FRP anchors [33-35] and recommended to use a value of 9.68 for $\alpha$. 


\subsubsection{Combined concrete cone-bond failure mode $\left(\mathrm{N}_{\mathrm{CC}}+\mathrm{N}_{\mathrm{CB}}\right)$}

Combined concrete cone-bond failure mode is a combination of concrete cone strength $\left(\mathrm{N}_{\mathrm{CC}}\right)$ and anchor bond strength $\left(\mathrm{N}_{\mathrm{CB}}\right)$. Cook et al. [46] proposed an approach to determine the pullout capacity of metallic adhesive anchors by adding concrete cone capacity to anchor bond capacity $\left(\mathrm{N}_{\mathrm{U}}=\mathrm{N}_{\mathrm{CC}}+\mathrm{N}_{\mathrm{CB}}\right)$. Ozdemir [35] used the same approach proposed by Cook et al. [46] but assumed that cone depth $\left(h_{c}\right)$ is always equal to $50 \mathrm{~mm}$, as shown in Eq. 4 (Table 4.2). In Eq. 4, the average bond strength $\left(\tau_{\text {ave }}\right)$ was assumed to be 9.0, 7.2, and 4.5 MPa for concrete strengths of 20,16, and $10 \mathrm{MPa}$, respectively. On the other hand, Ozbakkaloglu and Saatcioglu [34] determined the cone depths $\left(\mathrm{h}_{\mathrm{c}}\right)$ and bond depths $\left(\mathrm{h}_{\mathrm{b}}=\right.$ $h-h_{c}$ ) experimentally for each specimen and used them to develop a relationship between embedment length, hole diameter and bond strength $\left(\mathrm{F}_{\mathrm{b}}\right)$. The average bond strength ( $\left.\tau_{\text {bond }}, \mathrm{MPa}\right)$ used in Eq. 5 is calculated by dividing the bond strength $\left(\mathrm{F}_{\mathrm{b}}, \mathrm{kN}\right)$ by the contact area along the bond depth $\left(\mathrm{h}-\mathrm{h}_{\mathrm{c}}\right)$.

Kim and Smith [36] stated that it was difficult to accurately predict of the concrete cone depth. Ozdemir [35] assumed that the cone depth was constant, equal to $50 \mathrm{~mm}$. Ozbakkaloglu and Saatcioglu [34] used the observed cone depths without providing an expression for calculating the cone depth. In addition, the contribution of the concrete cone resistance to the pullout strength was found to be minimal for metallic anchors [47]. Kim and Smith [36] found that the best model to efficiently predict the pullout strength of FRP anchors was by assuming an average bond stress $\left(\tau_{\text {ave }}\right)$ acting along the total embedment length. Based on the analysis conducted on available FRP pullout tests [33-35], Kim and Smith [36] proposed an equation (Eq. 6) to predict the combined concrete cone-bond 
failure capacity without the need to know the depth of the concrete cone. The average bond strength $\left(\tau_{\text {ave }}\right)$ could be taken as $4.62 \mathrm{MPa}$ for concrete strength less than $20 \mathrm{MPa}$, and it could be taken as $9.07 \mathrm{MPa}$ for concrete strength equal or higher than $20 \mathrm{MPa}$. It should be noted, however, that the large difference between the two values of the assumed bond strength significantly affect the results. Therefore, it is probably not straightforward to choose one of the values for bond strength (4.62 or $9.07 \mathrm{MPa}$ ) to predict the tensile capacity of FRP anchors with a concrete strength close to $20 \mathrm{MPa}$.

\subsubsection{Rupture failure $(\mathrm{NRF})$}

This type of failure occurs when the tensile capacity of FRP anchor is less than the bond strength between FRP anchor and concrete. The available experimental pullout tests were conducted on handmade CFRP anchors made by rolling pre-cut CFRP sheets. According to previous test results [33-35], misalignment and consequently uneven distribution in the axial strain across the cross-section of the anchor resulted in low tensile capacity of CFRP anchors compared to the theoretical tensile strength of CFRP materials used to fabricate the anchors. The maximum achieved tensile strength of CFRP anchors were $61 \%, 56 \%$, and 60\% compared to the theoretical tensile strength of CFRP materials based on Ozdemir [35], Ozbakkaloglu and Saatcioglu [34], and, Kim and Smith [33], respectively. Although Ozdemir did not consider any reduction for anchor rupture failure (Eq. 7), Ozbakkaloglu and Saatcioglu recommended to divide the tensile strength of FRP anchors by 3 to account for rupture failure (Eq. 8). The design model proposed by Kim and Smith [36] reduced the 
tensile capacity of FRP anchors to 59\% (Eq. 9). It should be noted that the tensile strength $\left(f_{\mathrm{FRP}}\right)$ in Eq. 9 is not the theoretical tensile strength reported by the manufacturer, but it is the tensile strength of experimentally tested flat coupons of FRP materials. The study by Kim and Smith [33] is the only one that tested equivalent flat coupons for FRP anchors. It was reported that the tensile strength of flat coupons was $72 \%$ of the theoretical tensile strength of FRP reported by the manufacturer. Therefore, the rupture failure occurs at $42 \%$ $(59 \% \times 72 \%=42 \%)$ of the theoretical tensile strength of FRP based on the design model proposed by Kim and Smith [36].

\subsubsection{Predicted pullout strengths of tested specimens}

In general, the minimum force resulting from the above three failure modes is considered as the predicted tensile strength of FRP anchors. As mentioned before, the models presented in Table 4.2 were based on CFRP anchors made from pre-cut CFRP sheets. In the present study, these models were used because none of the previous studies have included tests or investigation on CFRP anchors made from CFRP ropes. Table 4.3 compares the experimental results with the predicted tensile strengths as well as the predicted failure modes. It should be noted that CFRP anchors with embedment deeper than $100 \mathrm{~mm}$ were not considered in the previous models presented in Table 4.3. All three models underestimated the pullout strength of specimens with 45-mm embedment, except for one specimen (B-5D-2.8D) . This is mainly because the failure mode for most specimens with 45-mm embedment was concrete cone failure. For longer embedment 
lengths, Ozdemir [35] overestimated the pullout strength for almost all specimens with embedment length larger than $45 \mathrm{~mm}$ (Fig. 4.13 a). This was expected since Ozdemir (1) did not reduce the rupture strength of CFRP and (2) used a high bond strength (9.0 MPa) regardless of the hole diameter and embedment length. Ozbakkaloglu and Saatcioglu [34] overestimated the strength of all specimens with $90-\mathrm{mm}$ embedment. However, it seems that the recommended rupture strength $\left(0.33 \mathrm{f}_{\mathrm{FRP}}\right)$ was very conservative. The pullout strength resulted from this method [34] did not exceed one-third of the theoretical strength of CFRP rope (44.7 kN), as shown in Fig. 4.13 (b). The model proposed by Kim and Smith [36] overestimated the tensile strength of CFRP rope anchors, but it was the best out of the three models used in this study as shown in Fig. 4.13 (c). This could be attributed to the assumed average bond strength suggested by Kim and Smith. The model suggested to use either an average bond strength of $9.07 \mathrm{MPa}$ for concrete strengths equal or higher than 20 MPa or 4.62 MPa for concrete strengths less than 20 MPa. In this study, an average bond strength of 9.07 was used, and it seemed to be more than the actual bond strength of the tested specimens. In summary, none of the models used in this study had a consistently good agreement with the experimental results, therefore a modified or new model for CFRP ropes epoxy-bonded to uncracked concrete is needed.

\subsubsection{Modified model proposed for CFRP rope anchors}

The modified model proposed in the current study for CFRP rope anchors is basically the same as the model proposed by Kim and Smith [36] with some modifications. The equation 
used for concrete cone strength (Eq. 3) was found to be reasonable. However, the modifications were mostly related to the reduction factor used for FRP rupture strength and the average bond strength $\left(\tau_{\text {ave }}\right)$ used for combined concrete cone-bond failure. The reduction factor of 0.59 used in Eq. 9 was proposed based on the tensile strength of CFRP flat coupons determined by Kim and Smith [33]. It is more reasonable to use the theoretical tensile strength of CFRP ( $\left.F_{F R P}\right)$ instead of the tensile strength of flat coupons ( $\left.f_{F R P}\right)$, which were based on limited tests conducted on handmade CFRP anchors. In order to use the theoretical tensile strength of CFRP $\left(\mathrm{F}_{\mathrm{FRP}}\right)$ in Eq. 9, the factor of 0.59 must be reduced. In the present study, only one specimen failed due to CFRP rupture after achieving $49 \%$ of the theoretical tensile strength of CFRP rope. Therefore, it is recommended to reduce the factor of 0.59 in Eq. 9 to 0.49 and replace $f_{F R P}$ with $F_{F R P}$ since values for $f_{F R P}$ are not always available. Although this suggestion is based on very limited data, it is safer to reduce the rupture failure of CFRP rope anchors until more data becomes available.

Moreover, Kim and Smith [36] suggested to use the same value of bond strength for different hole diameters and embedment lengths. However, it was observed from tests in the present study as well as previous tests on CFRP anchors $[33,34]$ that the average bond strength decreases with the increase of hole diameter and embedment length. In addition, the model presented by Kim and Smith [36] allows the user to choose either an average bond strength of 9.07 MPa or 4.62 MPa based on concrete compressive strength. Choosing a reliable value is crucial as the difference between the two values is significant. Although embedment length and hole dimeter have been proven in the past to affect the bond strength, a reliable expression to predict the bond strength has not been proposed yet. Test 
results of the present study showed that the bond strength was influenced by epoxy type as well. In the modified model proposed in this study for CFRP rope anchors, a multiple linear regression analysis was performed to quantify the influence of each parameter on the average bond strength. The parameters were the embedment length, hole diameter, and epoxy type. The regression analyses showed that the bond strength of CFRP rope anchors can be expressed using the following equation:

Avg. bond stress, $\tau_{\text {ave }}=14.056+\alpha L_{b}+\beta d+\gamma$

where $\alpha=\left(\frac{-1}{96.644}\right), \beta=\left(\frac{-1}{3.274}\right), \gamma=-0.897$ for epoxy Type A and $\gamma=-1.795$ for epoxy Type B. The regression analysis was performed to gain a better estimation of the average bond strength proposed by Kim and Smith [36]. It showed that the influence of the epoxy type was statistically not significant. However, including the influence of epoxy type as one of the independent variables (x-axis) better explained the dependent variable (yaxis), which was the average bond strength, and improved the model.

Table 4.4 summarizes the results of the proposed model and shows the steps of calculating the pullout strength of CFRP rope anchors. Comparison between the predicted strength and the experimental results are presented in the table as well. Fig. 4.14 (a) shows that the predicted values have a good agreement with the experimental results of the present study. 
The results of the modified model proposed in this study (Fig. 4.14 a) have a better agreement with the experimental results than the predicted values using all previous models (Fig. 4.13). In addition, the results of the proposed model showed a good agreement with the test results of previous studies [33-35], as shown in Fig. 4.14 (b). Based on the limited data available currently in the literature, more tests are required to develop a more reliable mode for CFRP rope anchors.

\subsection{Conclusions}

The following conclusions can be drawn based on the test results reported in this study, published by Saeed et al. [48]:

- CFRP ropes can be used to fabricate FRP anchors without having to cut and roll CFRP sheets to make the anchors.

- Based on the limited tests conducted in this study, the increase of pullout strength with increasing the embedment length continued until an embedment of $270 \mathrm{~mm}$. However, the increase of strength between an embedment of $180 \mathrm{~mm}$ and $270 \mathrm{~mm}$ was not significant. Therefore, the optimum embedment length to maximize the pullout strength of CFRP rope anchor appears to be between $180 \mathrm{~mm}$ and $270 \mathrm{~mm}$.

- Test results from the present study and previous studies on FRP anchors showed that there is no clear relationship between anchor hole diameter and pullout strength. 
- The average bond strength decreased with the increase of anchor hole diameter and embedment length.

- For CFRP rope anchors, resin close to the properties of epoxy Type A is recommended.

- The available models used to predict the tensile strength of CFRP anchors did not show good agreement with the test results of this study.

- It is recommended to use the modified model for CFRP rope anchors proposed in this study until a more reliable model becomes available. 


\subsection{Tables}

Table 4.1 Specimen details and experimental results

\begin{tabular}{lcccccccc}
\hline Specimen & $\begin{array}{c}\text { Concrete } \\
\text { block }\end{array}$ & $\begin{array}{c}\text { Concrete } \\
\text { strength }^{2}, \\
\text { MPa }\end{array}$ & $\begin{array}{c}\text { Epoxy } \\
\text { type }^{3}\end{array}$ & $\begin{array}{c}\text { Nominal } \\
\text { embedment } \\
\text { mm }\end{array}$ & $\begin{array}{c}\text { Measured } \\
\text { embedment } \\
\text { mm }\end{array}$ & $\begin{array}{c}\text { Hole } \\
\text { diamete } \\
\text {, mm }\end{array}$ & $\begin{array}{c}\text { Max. } \\
\text { pullout } \\
\text { kN }\end{array}$ & $\begin{array}{c}\text { Failure } \\
\text { mode }^{4}\end{array}$ \\
\hline A-5D-1.5D & Block\#1 & 22.4 & A & 45 & 46 & 12.70 & 15.70 & CC \\
B-5D-1.5D & Block\#1 & 22.4 & B & 45 & 47 & 12.70 & 17.97 & CC \\
A-5D-2D & Block\#1 & 22.4 & A & 45 & 45 & 19.10 & 11.92 & SF \\
A-5D-2D-R & Block\#2 & 22.1 & A & 45 & 45 & 19.10 & 20.46 & CC \\
B-5D-2D & Block\#1 & 22.4 & B & 45 & 43 & 19.10 & 16.64 & CB \\
A-5D-2.8D & Block\#3 & 22.1 & A & 45 & 48 & 25.40 & 20.19 & CC \\
B-5D-2.8D & Block\#3 & 22.1 & B & 45 & 46 & 25.40 & 15.70 & CC \\
A-10D-1.5D & Block\#1 & 22.4 & A & 90 & 93 & 12.70 & 25.67 & CB \\
B-10D-1.5D & Block\#2 & 22.1 & B & 90 & 92 & 12.70 & 23.44 & CB \\
A-10D-2D & Block\#2 & 22.1 & A & 90 & 90 & 19.10 & 26.11 & CB \\
B-10D-2D & Block\#2 & 22.1 & B & 90 & 91 & 19.10 & 24.15 & CB \\
A-10D-2.8D & Block\#3 & 22.1 & A & 90 & 92 & 25.40 & 27.58 & CB \\
B-10D-2.8D & Block\#3 & 22.1 & B & 90 & 93 & 25.40 & 23.98 & CB \\
A-15D-1.5D & Block\#5 & 22.6 & A & 135 & 136 & 12.70 & 51.02 & CB \\
A-15D-2D & Block\#4 & 22.6 & A & 135 & 134 & 19.10 & 50.75 & CB \\
A-20D-2D & Block\#4 & 22.6 & A & 180 & 180 & 19.10 & 46.35 & SF \\
A-20D-2D-R & Block\#6 & 21.9 & A & 180 & 182 & 19.10 & 67.52 & GF \\
A-20D-2.8D & Block\#5 & 22.6 & A & 180 & 183 & 25.40 & 48.57 & SF \\
A-30D-2.8D & Block\#9 & 21.9 & A & 270 & 269 & 25.40 & 76.11 & BF \\
A-30D-2D & Block\#7 & 21.9 & A & 270 & 270 & 19.10 & 69.93 & GF \\
A-35D-2D & Block\#8 & 21.9 & A & 315 & 318 & 19.10 & 66.01 & RF \\
\hline
\end{tabular}

1 The letter " $R$ " means that this specimen was a repeated specimen.

2 Based on the average of testing three concrete cylinders on the day of testing

3 Epoxy Type A is Hilti 500 and Epoxy Type B is MasterBrace SAT 4500.

4 Failure modes; concrete cone failure (CC), combined concrete cone-bond failure (CB), CFRP-to-epoxy bond failure $(B F)$, concrete splitting $(S F)$, CFRP rupture failure $(R F)$, and gripper failure $(G F)$. 
Table 4.2 Available equations to predict the pullout strength of CFRP anchors

\begin{tabular}{|c|c|c|c|}
\hline \multicolumn{4}{|c|}{ Concrete cone failure (CC) } \\
\hline Equation & Reference & $\mathrm{N}_{\mathrm{CC}}$ & Condition \\
\hline Eq. 1 & Ozdemir [35] & $0.33 \sqrt{f_{c}^{\prime}} h(d+h) \pi$ & $\mathrm{h}<50 \mathrm{~mm}$ \\
\hline Eq. 2 & Ozbakkaloglu and Saatcioglu [34] & $\left(f_{c t}^{\prime}\right)_{\exp } h(d+h) \pi$ & \\
\hline Eq. 3 & Kim and Smith [36] & $\alpha \mathrm{h}^{1.5} \sqrt{\mathrm{f}_{\mathrm{c}}^{\prime}}$ & \\
\hline \multicolumn{4}{|c|}{ Combined cone-bond failure (CB) } \\
\hline & & $\mathrm{N}_{\mathrm{CC}}+\mathrm{N}_{\mathrm{CB}}$ & Condition \\
\hline Eq. 4 & Ozdemir [35] & $\begin{array}{c}0.33 \sqrt{\mathrm{f}_{\mathrm{c}}^{\prime}} 50(\mathrm{~d}+50) \pi+\tau_{\mathrm{ave}} \pi \mathrm{d}(\mathrm{h} \\
-50)\end{array}$ & $h>50$ \\
\hline Eq. 5 & Ozbakkaloglu and Saatcioglu [34] & $\begin{array}{c}\left(\mathrm{f}_{\mathrm{ct}}^{\prime}\right)_{\exp } \mathrm{h}_{c}\left(\mathrm{~d}+\mathrm{h}_{c}\right) \pi+\tau_{\text {bond }} \pi \mathrm{d}(\mathrm{h} \\
\left.-\mathrm{h}_{\mathrm{c}}\right)\end{array}$ & \\
\hline Eq. 6 & Kim and Smith [36] & $\tau_{\text {ave }} \pi \mathrm{dh}$ & \\
\hline \multicolumn{4}{|c|}{ Rupture failure (RF) } \\
\hline & & $\mathrm{N}_{\mathrm{RF}}$ & \\
\hline Eq. 7 & Ozdemir [35] & $\mathrm{w}_{\mathrm{FRP}} \mathrm{t}_{\mathrm{FRP}} F_{\mathrm{FRP}}$ & \\
\hline Eq. 8 & Ozbakkaloglu and Saatcioglu [34] & $0.33 \mathrm{w}_{\mathrm{FRP}} \mathrm{t}_{\mathrm{FRP}} F_{\mathrm{FRP}}$ & \\
\hline Eq. 9 & Kim \& Smith [36] & $0.59 \mathrm{w}_{\mathrm{FRP}} \mathrm{t}_{\mathrm{FRP}} \mathrm{f}_{\mathrm{FRP}}$ & \\
\hline
\end{tabular}

Note: $\mathrm{N}_{\mathrm{CC}}=$ concrete cone tensile capacity; $\mathrm{N}_{\mathrm{CB}}=$ combined cone-bond tensile capacity; $\mathrm{N}_{\mathrm{RF}}=$ FRP rupture capacity; $h=$ embedment length; $h_{c}=$ concrete cone failure depth; $d=$ anchor hole diameter; $\tau_{\text {ave }}=$ average bond stress along the length of the embedment $(\mathrm{h}) ; \tau_{\text {bond }}=$ average bond stress along the bond length $\left(h_{b}=\mathrm{h}-\mathrm{h}_{\mathrm{c}}\right) ;\left(\mathrm{f}_{\mathrm{ct}}^{\prime}\right)_{\exp }=$ splitting tensile strength at 28 days based on test results; $\alpha=$ coefficient for calculating concrete breakout strength based on CCD approach [45] (modified by Kim and Smith [36]); $\mathrm{w}_{\mathrm{FRP}}=$ width of FRP sheet used to fabricate FRP anchors; $\mathrm{t}_{\mathrm{FRP}}=$ thickness of FRP sheet used to fabricate FRP anchors; $F_{\mathrm{FRP}}=$ maximum theoretical tensile strength of $\mathrm{FRP}$, and $\mathrm{f}_{\mathrm{FRP}}=$ tensile rupture strength of tested FRP flat coupons. 
Table 4.3 Experimental vs. predicted pullout strength of CFRP rope anchors

\begin{tabular}{|c|c|c|c|c|c|c|c|c|c|}
\hline \multirow{2}{*}{ Specimen } & \multirow{2}{*}{$\begin{array}{l}\text { Embedment } \\
\text { length, mm }\end{array}$} & \multirow{2}{*}{$\begin{array}{c}\mathrm{Nu}_{\text {-EXP }} \\
\mathrm{kN}\end{array}$} & \multirow{2}{*}{$\begin{array}{l}\text { Failure } \\
\text { mode }\end{array}$} & \multicolumn{2}{|c|}{ Ozdemir } & \multicolumn{2}{|c|}{$\begin{array}{l}\text { Ozbakkaloglu } \\
\text { and Saatcioglu }\end{array}$} & \multicolumn{2}{|c|}{ Kim \& Smith } \\
\hline & & & & $\begin{array}{l}\mathrm{Nu}, \\
\mathrm{kN}\end{array}$ & $\begin{array}{c}\text { Failure } \\
\text { mode }\end{array}$ & $\begin{array}{l}\mathrm{Nu}, \\
\mathrm{kN}\end{array}$ & $\begin{array}{c}\text { Failure } \\
\text { mode }\end{array}$ & $\begin{array}{l}\mathrm{Nu} \\
\mathrm{kN}\end{array}$ & $\begin{array}{c}\text { Failure } \\
\text { mode }\end{array}$ \\
\hline A-5D-1.5D & 46 & 15.70 & $\mathrm{CC}$ & 13.25 & $\mathrm{CC}$ & 13.25 & $\mathrm{CC}$ & 14.29 & $\mathrm{CC}$ \\
\hline B-5D-1.5D & 47 & 17.97 & $\mathrm{CC}$ & 13.77 & $\mathrm{CC}$ & 13.77 & $\mathrm{CC}$ & 14.76 & $\mathrm{CC}$ \\
\hline A-5D-2D & 45 & 11.92 & SF & 14.16 & $\mathrm{CC}$ & 14.16 & $\mathrm{CC}$ & 13.83 & $\mathrm{CC}$ \\
\hline A-5D-2D-R & 45 & 20.46 & $\mathrm{CC}$ & 14.06 & $\mathrm{CC}$ & 14.06 & $\mathrm{CC}$ & 13.74 & $\mathrm{CC}$ \\
\hline B-5D-2D & 43 & 16.64 & $\mathrm{CB}$ & 13.11 & $\mathrm{CC}$ & 14.64 & $\mathrm{CB}$ & 12.92 & $\mathrm{CC}$ \\
\hline A-5D-2.8D & 48 & 20.19 & $\mathrm{CC}$ & 17.18 & $\mathrm{CC}$ & 17.18 & $\mathrm{CC}$ & 15.13 & $\mathrm{CC}$ \\
\hline B-5D-2.8D & 46 & 15.70 & $\mathrm{CC}$ & 16.01 & $\mathrm{CC}$ & 16.01 & $\mathrm{CC}$ & 14.20 & $\mathrm{CC}$ \\
\hline A-10D-1.5D & 93 & 25.67 & $\mathrm{CB}$ & 30.83 & $\mathrm{CB}$ & 37.43 & $\mathrm{CB}$ & 33.67 & CB \\
\hline B-10D-1.5D & 92 & 23.44 & $\mathrm{CB}$ & 30.37 & $\mathrm{CB}$ & 37.30 & $\mathrm{CB}$ & 33.31 & $\mathrm{CB}$ \\
\hline A-10D-2D & 90 & 26.11 & $\mathrm{CB}$ & 38.46 & $\mathrm{CB}$ & 44.70 & $\mathrm{RF}$ & 38.85 & $\mathrm{CC}$ \\
\hline B-10D-2D & 91 & 24.15 & $\mathrm{CB}$ & 39.00 & $\mathrm{CB}$ & 44.70 & $\mathrm{RF}$ & 39.50 & $\mathrm{CC}$ \\
\hline A-10D-2.8D & 92 & 27.58 & $\mathrm{CB}$ & 48.56 & CB & 44.70 & $\mathrm{RF}$ & 40.16 & $\mathrm{CC}$ \\
\hline B-10D-2.8D & 93 & 23.98 & $\mathrm{CB}$ & 49.27 & $\mathrm{CB}$ & 44.70 & $\mathrm{RF}$ & 40.81 & $\mathrm{CC}$ \\
\hline A-15D-1.5D & 136 & 51.02 & CB & 46.35 & CB & 44.70 & $\mathrm{RF}$ & 49.24 & $\mathrm{CB}$ \\
\hline A-15D-2D & 134 & 50.75 & $\mathrm{CB}$ & 62.42 & CB & 44.70 & $\mathrm{RF}$ & 71.38 & $\mathrm{CC}$ \\
\hline A-20D-2D & 180 & 46.35 & SF & 87.27 & CB & 44.70 & $\mathrm{RF}$ & 79.92 & RF \\
\hline A-20D-2D-R & 182 & 67.52 & GF & 88.08 & CB & 44.70 & $\mathrm{RF}$ & 79.92 & RF \\
\hline A-20D-2.8D & 183 & 48.57 & SF & 114.14 & CB & 44.70 & RF & 79.92 & RF \\
\hline A-30D-2.8D & 269 & 76.11 & $\mathrm{BF}$ & 135.45 & $\mathrm{RF}$ & 44.70 & $\mathrm{RF}$ & 79.92 & $\mathrm{RF}$ \\
\hline A-30D-2D & 270 & 69.93 & GF & 135.45 & $\mathrm{RF}$ & 44.70 & $\mathrm{RF}$ & 79.92 & RF \\
\hline A-35D-2D & 318 & 66.01 & $\mathrm{RF}$ & 135.45 & $\mathrm{RF}$ & 44.70 & $\mathrm{RF}$ & 79.92 & $\mathrm{RF}$ \\
\hline
\end{tabular}


Table 4.4 Predicted pullout strength based on the modified model proposed in this study

\begin{tabular}{|c|c|c|c|c|c|c|c|c|}
\hline Specimen & $\begin{array}{c}\mathrm{Nu}_{\mathrm{EXXP}}, \\
\mathrm{kN}\end{array}$ & $\begin{array}{c}\text { Failure } \\
\text { mode }\end{array}$ & $\begin{array}{l}\mathbf{N}_{\mathrm{CC}} \\
=\underset{\mathbf{9} .68 \mathbf{h}^{1.5} \sqrt{1}}{\mathrm{kN}}\end{array}$ & $\begin{array}{c}\mathrm{N}_{\mathrm{CB}}=(14.056+ \\
\boldsymbol{\alpha} \mathrm{L}_{\mathbf{b}}+\boldsymbol{\beta d}+ \\
\boldsymbol{\gamma}) \boldsymbol{\pi d h} \\
\mathrm{kN} \\
\end{array}$ & $\begin{array}{c}\mathrm{N}_{\mathrm{RF}}= \\
0.49 \mathrm{~F}_{\mathrm{FRP}} \mathrm{A}_{\mathrm{FRI}} \\
, \mathrm{kN}\end{array}$ & $\begin{array}{c}\mathrm{Nu}=\mathrm{Min} \\
\text { of } \mathbf{N}_{\mathrm{CC}}, \\
\mathbf{N}_{\mathrm{CB}}, \mathbf{N}_{\mathrm{RF}}, \\
\mathrm{kN}\end{array}$ & $\begin{array}{l}\text { Control } \\
\text { failure } \\
\text { mode }\end{array}$ & $\begin{array}{c}\mathrm{Nu} / \\
\mathrm{Nu}_{\text {-EXP }},\end{array}$ \\
\hline $\mathrm{A}-5 \mathrm{D}-1.5 \mathrm{D}$ & 15.70 & $\mathrm{CC}$ & 14.29 & 16.16 & 66.37 & 14.29 & $\mathrm{CC}$ & $91 \%$ \\
\hline B-5D-1.5D & 17.97 & $\mathrm{CC}$ & 14.76 & 14.81 & 66.37 & 14.76 & $\mathrm{CC}$ & $82 \%$ \\
\hline$A-5 D-2 D$ & 11.92 & SF & 13.83 & 18.53 & 66.37 & 13.83 & $\mathrm{CC}$ & $116 \%$ \\
\hline A-5D-2D-R & 20.46 & $\mathrm{CC}$ & 13.74 & 18.53 & 66.37 & 13.74 & $\mathrm{CC}$ & $67 \%$ \\
\hline B-5D-2D & 16.64 & $\mathrm{CB}$ & 12.92 & 15.44 & 66.37 & 12.92 & $\mathrm{CC}$ & $78 \%$ \\
\hline A-5D-2.8D & 20.19 & $\mathrm{CC}$ & 15.13 & 18.79 & 66.37 & 15.13 & $\mathrm{CC}$ & $75 \%$ \\
\hline B-5D-2.8D & 15.70 & $\mathrm{CC}$ & 14.20 & 14.79 & 66.37 & 14.20 & $\mathrm{CC}$ & $90 \%$ \\
\hline A-10D-1.5D & 25.67 & $\mathrm{CB}$ & 41.09 & 30.88 & 66.37 & 30.88 & $\mathrm{CB}$ & $120 \%$ \\
\hline B-10D-1.5D & 23.44 & $\mathrm{CB}$ & 40.16 & 27.29 & 66.37 & 27.29 & $\mathrm{CB}$ & $116 \%$ \\
\hline A-10D-2D & 26.11 & $\mathrm{CB}$ & 38.85 & 34.54 & 66.37 & 34.54 & $\mathrm{CB}$ & $132 \%$ \\
\hline B-10D-2D & 24.15 & $\mathrm{CB}$ & 39.50 & 29.97 & 66.37 & 29.97 & $\mathrm{CB}$ & $124 \%$ \\
\hline A-10D-2.8D & 27.58 & $\mathrm{CB}$ & 40.16 & 32.68 & 66.37 & 32.68 & $\mathrm{CB}$ & $118 \%$ \\
\hline B-10D-2.8D & 23.98 & $\mathrm{CB}$ & 40.81 & 26.29 & 66.37 & 26.29 & $\mathrm{CB}$ & $110 \%$ \\
\hline A-15D-1.5D & 51.02 & $\mathrm{CB}$ & 72.99 & 42.74 & 66.37 & 42.74 & $\mathrm{CB}$ & $84 \%$ \\
\hline$A-15 D-2 D$ & 50.75 & $\mathrm{CB}$ & 71.38 & 47.77 & 66.37 & 47.77 & $\mathrm{CB}$ & $94 \%$ \\
\hline$A-20 D-2 D$ & 46.35 & SF & 111.13 & 59.03 & 66.37 & 59.03 & $\mathrm{CB}$ & $127 \%$ \\
\hline A-20D-2D-R & 67.52 & GF & 111.23 & 59.46 & 66.37 & 59.46 & $\mathrm{CB}$ & $88 \%$ \\
\hline A-20D-2.8D & 48.57 & SF & 113.92 & 51.24 & 66.37 & 51.24 & $\mathrm{CB}$ & $105 \%$ \\
\hline A-30D-2.8D & 76.11 & $\mathrm{BF}$ & 199.86 & 56.21 & 66.37 & 56.21 & $\mathrm{CB}$ & $74 \%$ \\
\hline A-30D-2D & 69.93 & GF & 200.98 & 73.45 & 66.37 & 66.37 & $\mathrm{RF}$ & $95 \%$ \\
\hline A-35D-2D & 66.01 & $\mathrm{RF}$ & 256.88 & 77.02 & 66.37 & 66.37 & RF & $101 \%$ \\
\hline
\end{tabular}




\subsection{Figures}

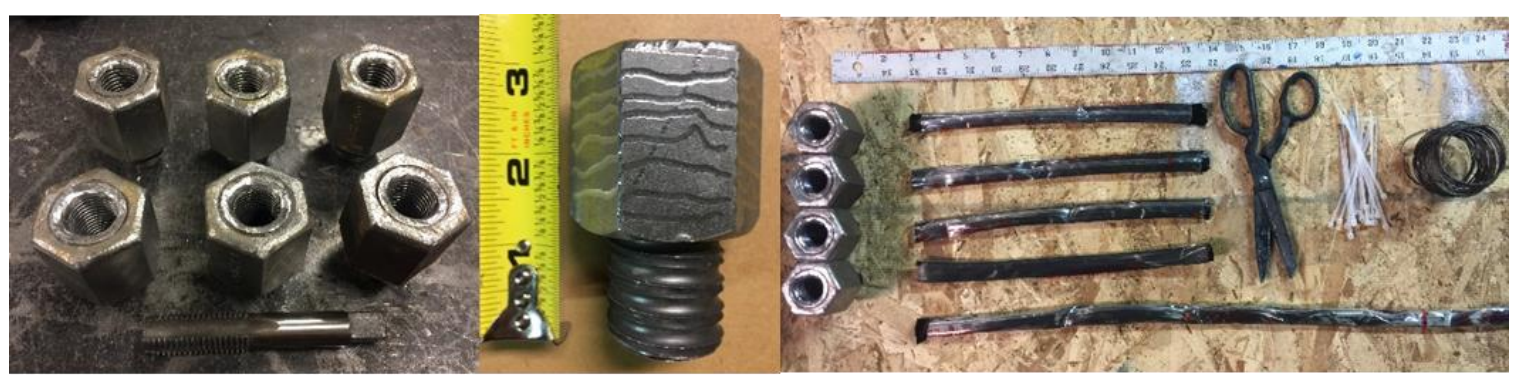

a) Steel tube

b) CFRP rope and tools

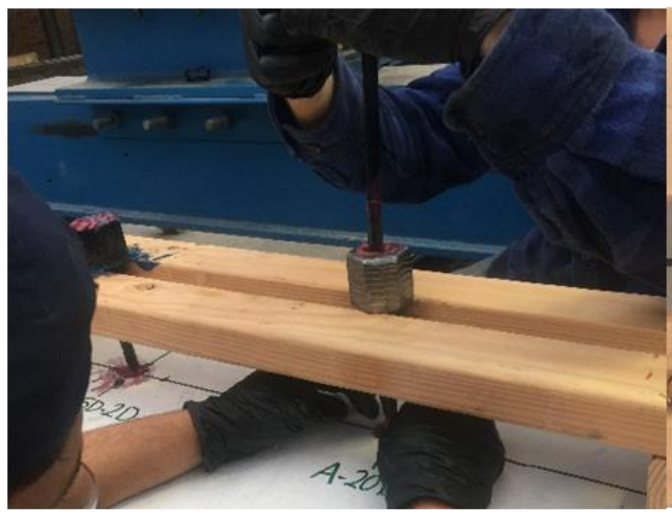

c) Inserting CFRP rope in steel tube

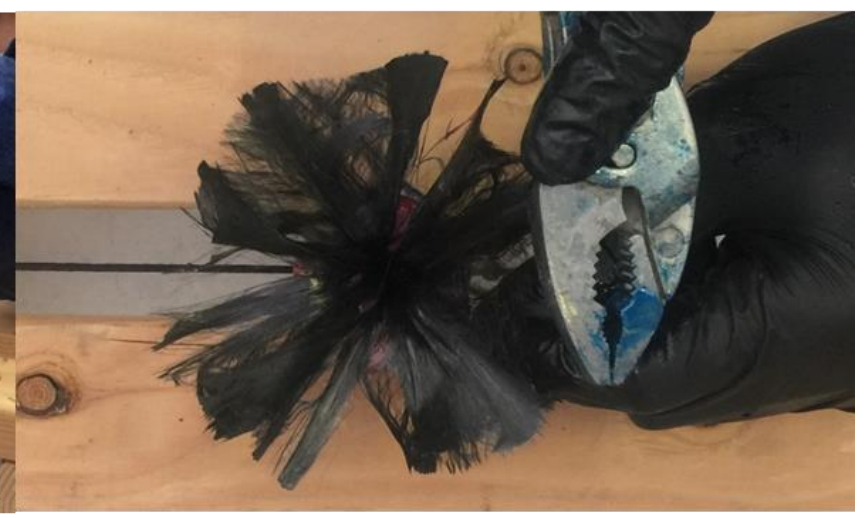

d) Fan-shaped CFRP fibers before attaching them to the hex nut.

Fig. 4.1 Fabrication of CFRP rope with steel anchors 


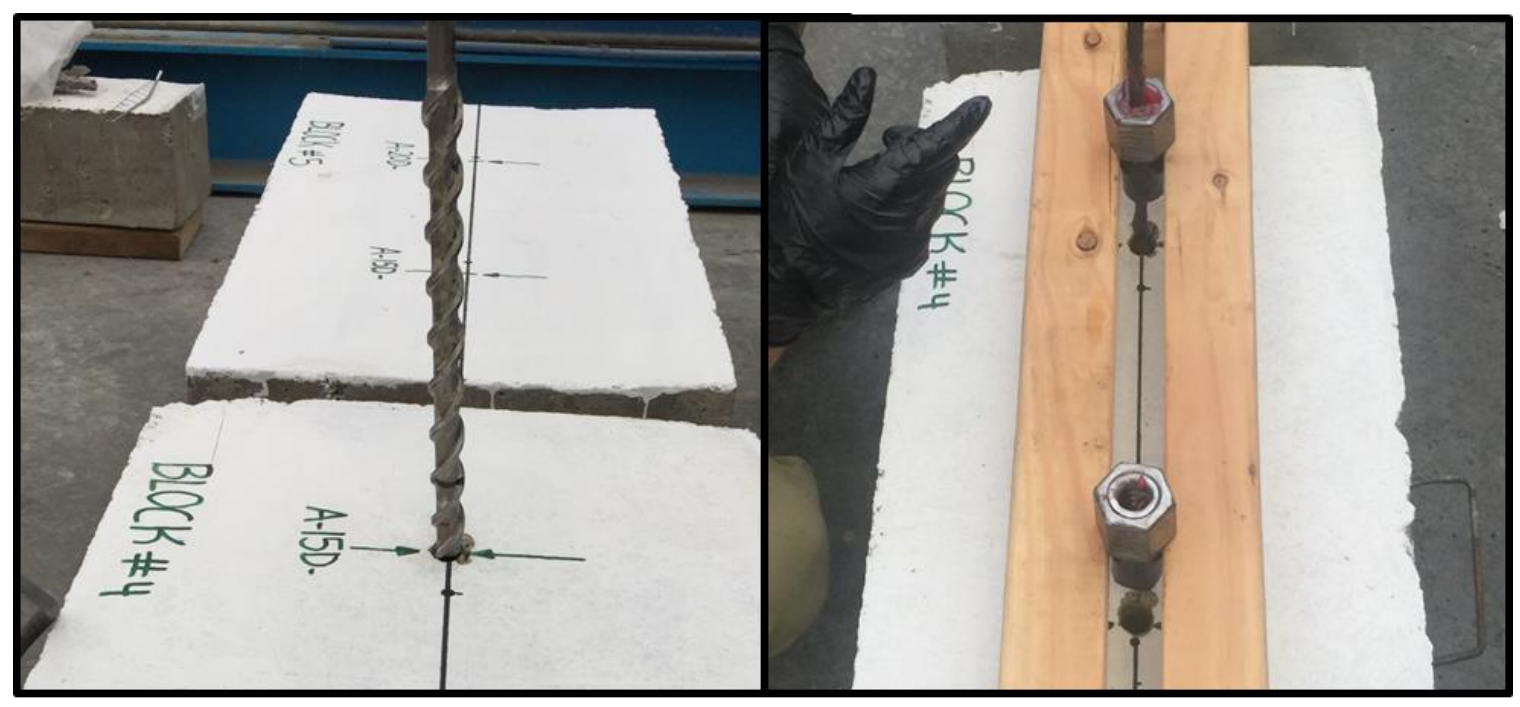

a) Drilling the holes

b) Steel tubes on a wood frame on top of the holes

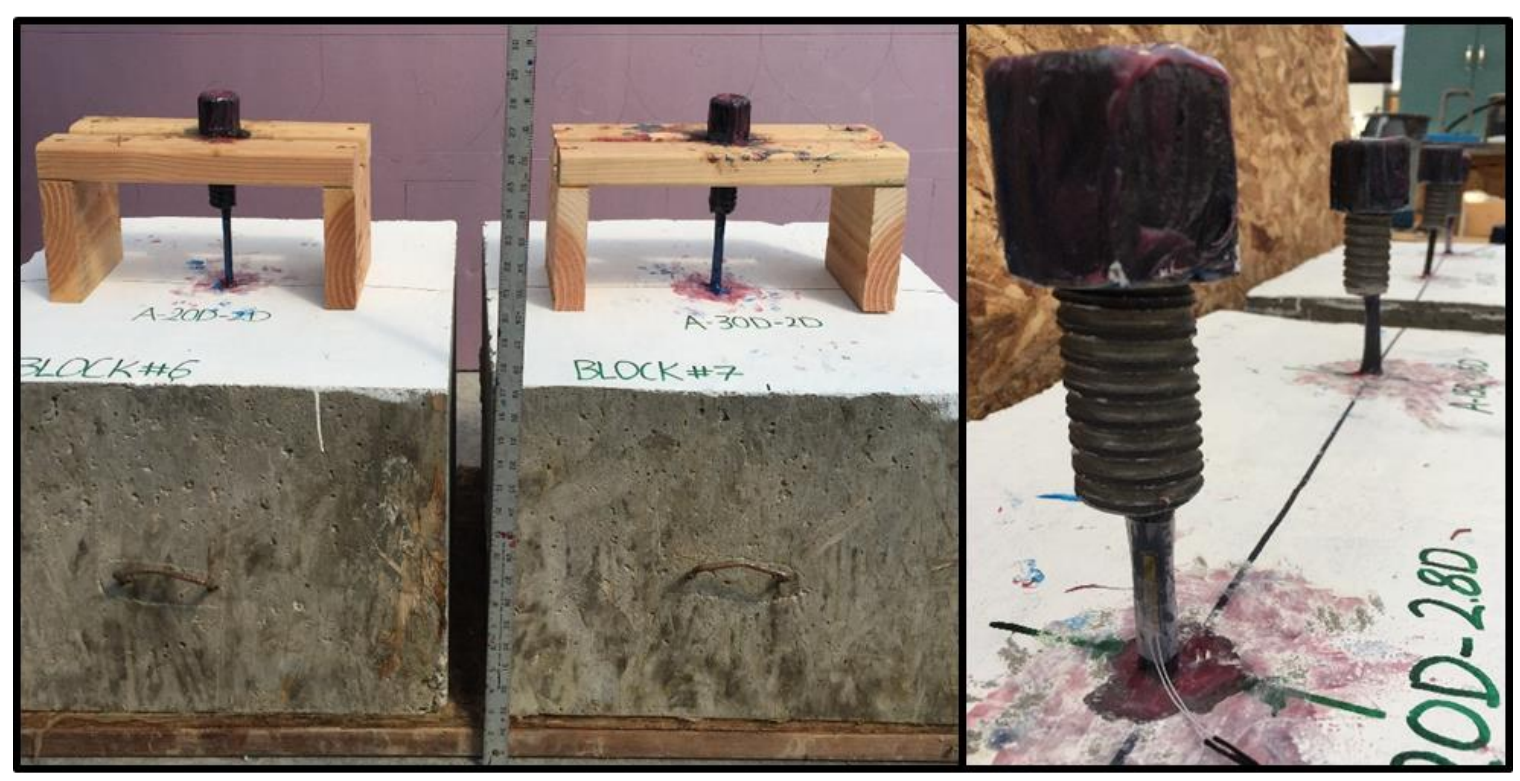

c) Installed anchors set for curing

d) Cured anchors ready for testing

Fig. 4.2 FRP anchor installation 


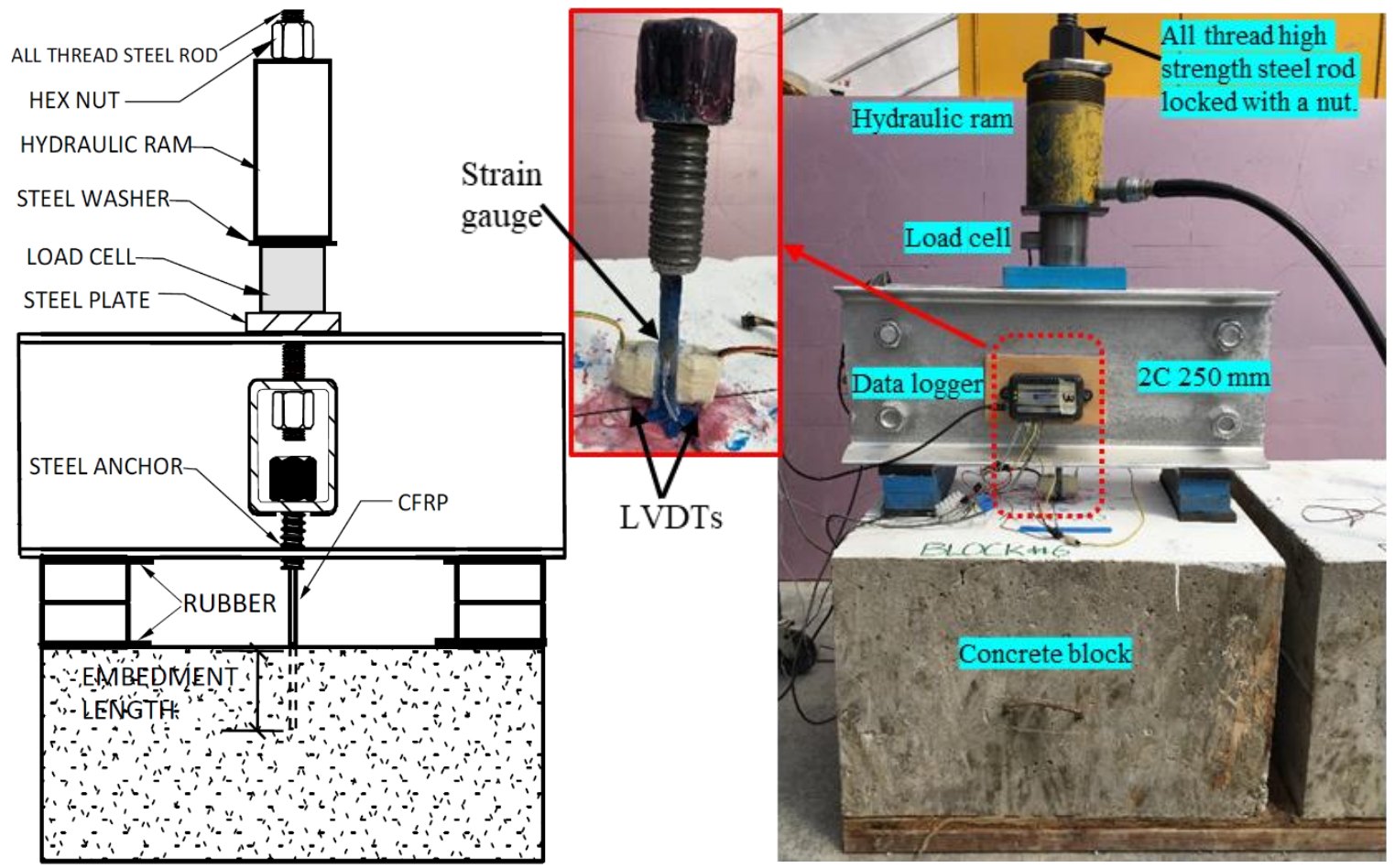

Fig. 4.3 Test setup and instrumentation

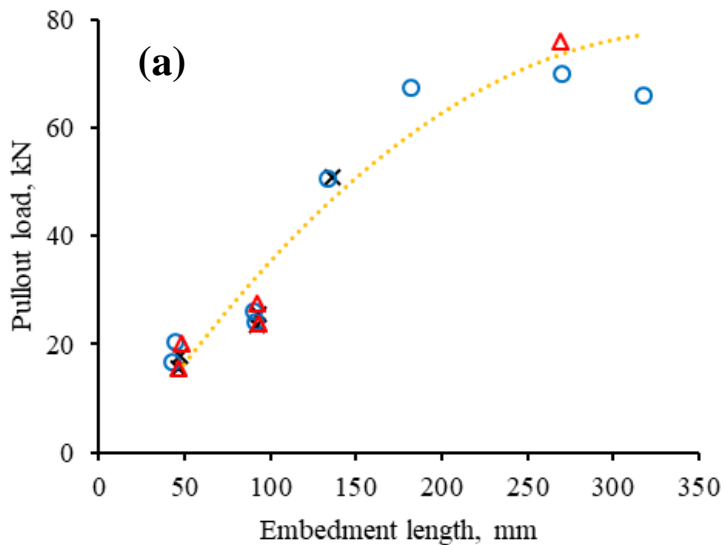

$\times$ Hole dia. $12.7 \mathrm{~mm}$

$019.1 \mathrm{~mm}$

$\Delta 25.4 \mathrm{~mm}$

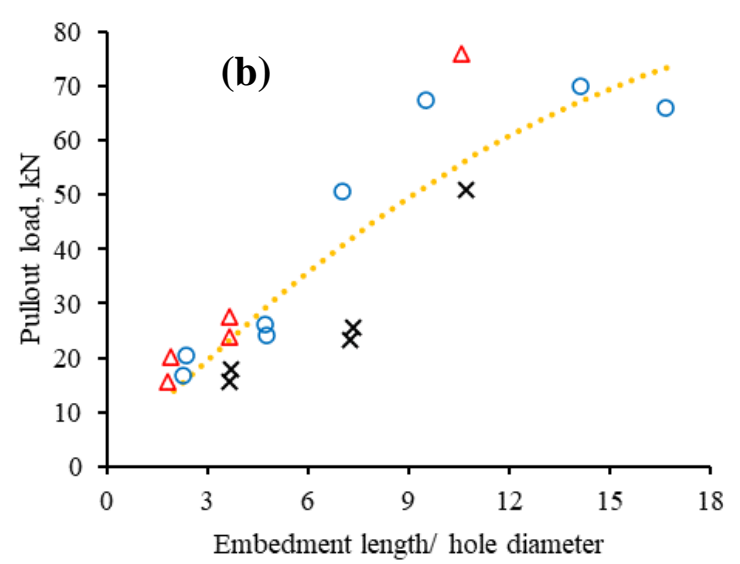

$\times$ Hole dia. $12.7 \mathrm{~mm}$

$019.1 \mathrm{~mm}$

$\triangle 25.4 \mathrm{~mm}$

Fig. 4.4 Effect of the embedment length (present study) 


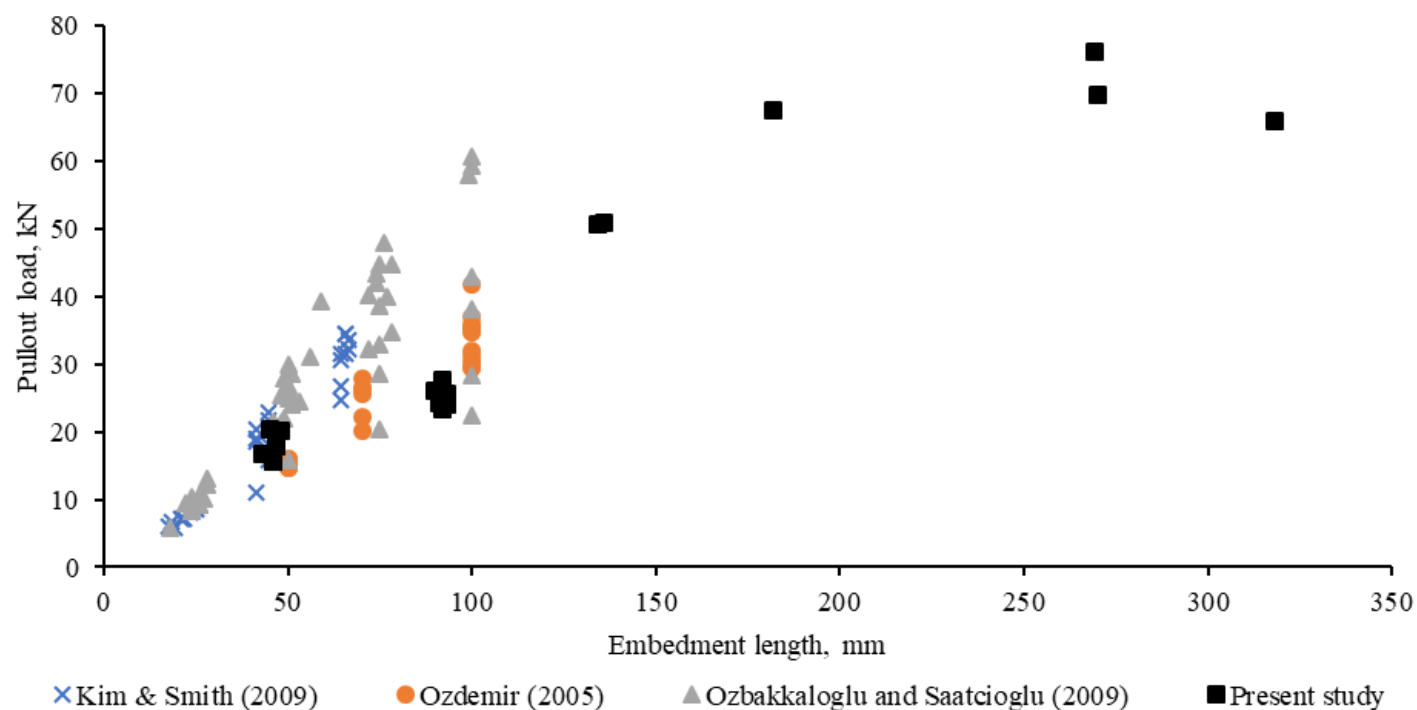

Fig. 4.5 Pullout load vs. embedment length; data from present and previous studies 


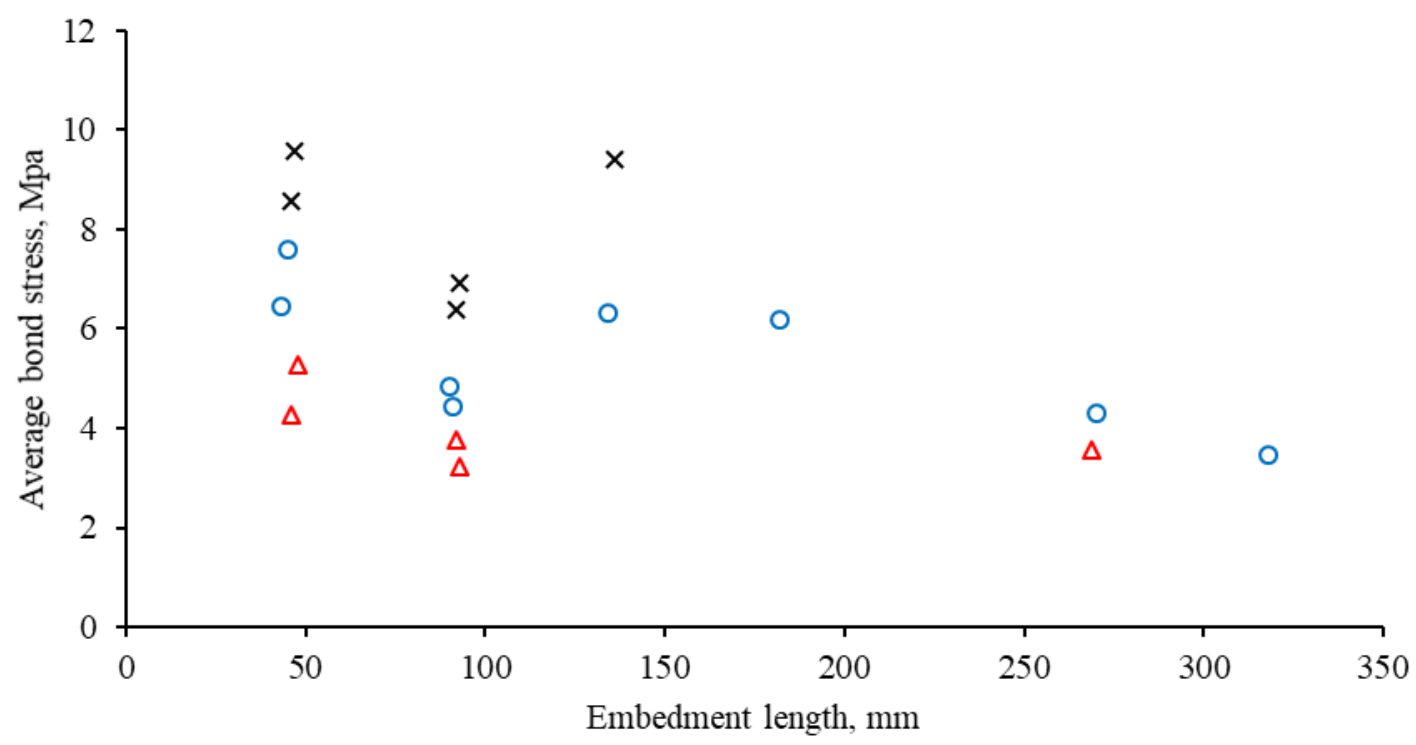
$\times$ Hole dia. $12.7 \mathrm{~mm}$
$019.1 \mathrm{~mm}$
$\Delta 25.4 \mathrm{~mm}$

(a)

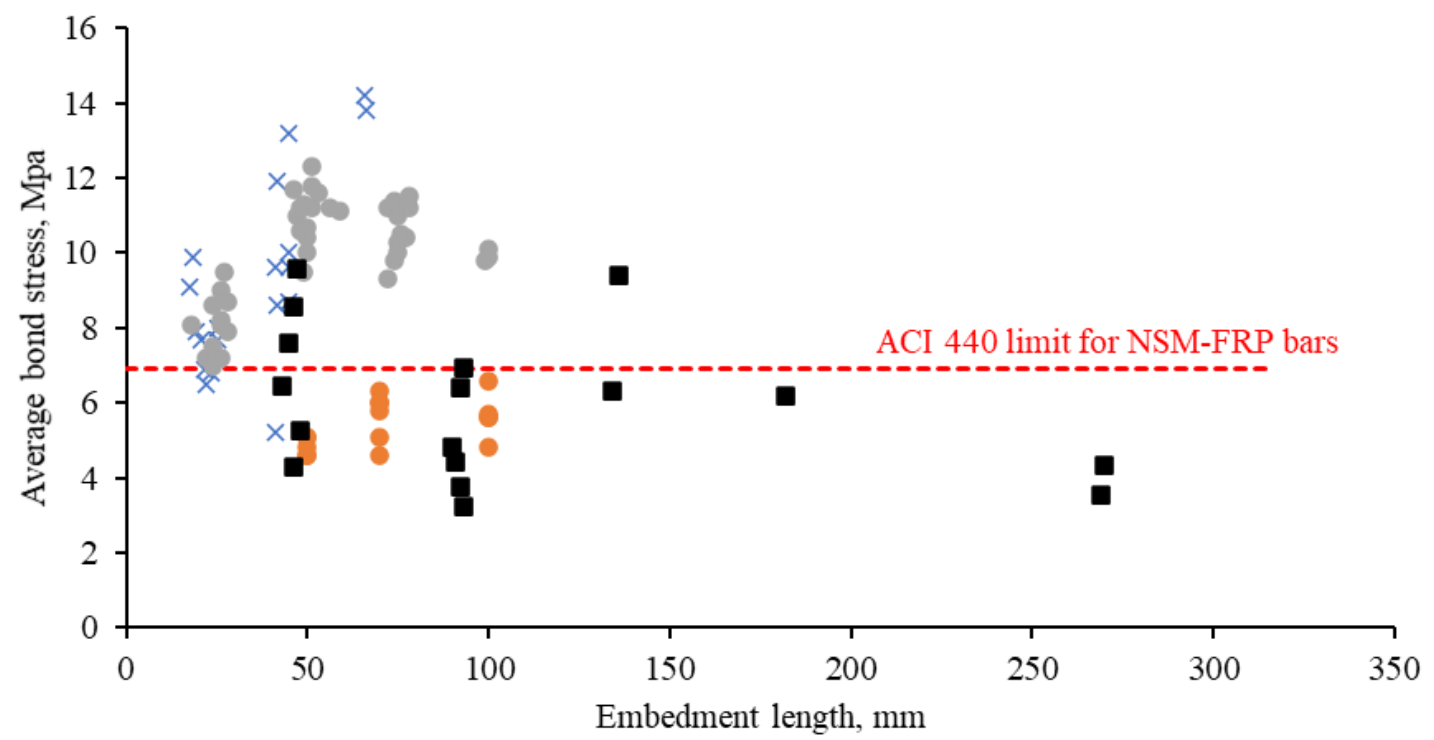

$\times$ Kim and Smith (2009) • Ozdemir (2005) - Ozbakkaloglu and Saatcioglu (2009) - Present study

(b)

Fig. 4.6 Average bond stress vs. embedment length; (a) Present study and (b) Previous studies vs. present study 


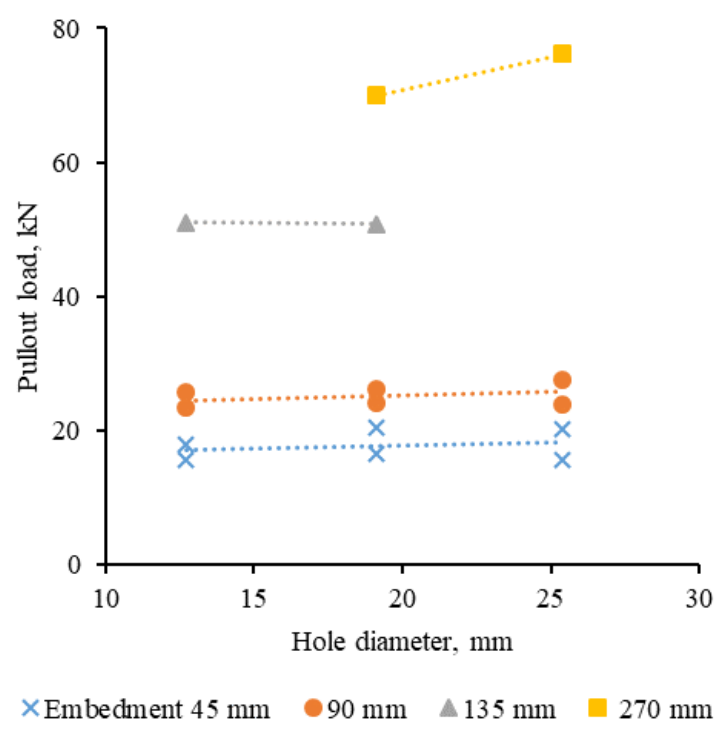

(a)

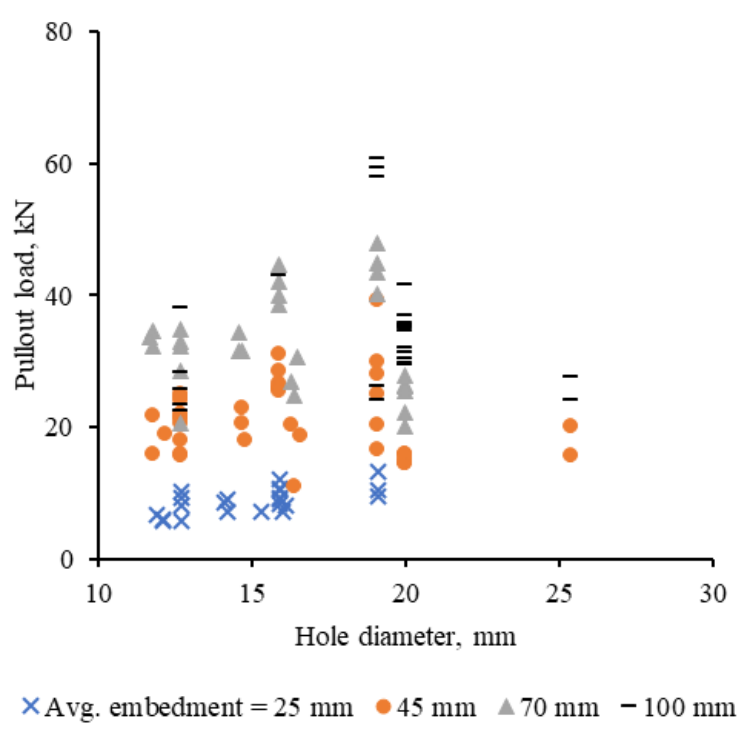

(b)

Fig. 4.7 Effect of anchor hole diameter; (a) present study and (b) data from present and previous studies

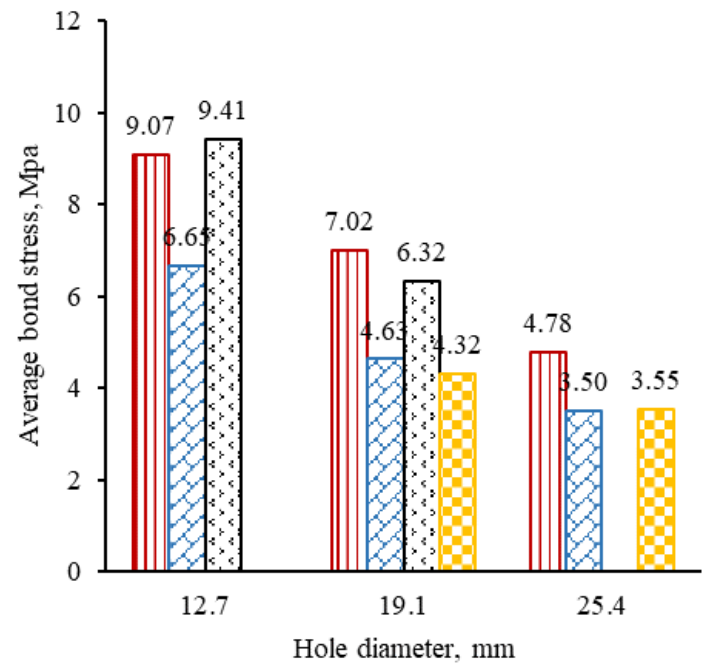

पEmbedment length $=45 \mathrm{~mm} \otimes 90 \mathrm{~mm} \square 135 \mathrm{~mm} \square 270 \mathrm{~mm}$

(a)

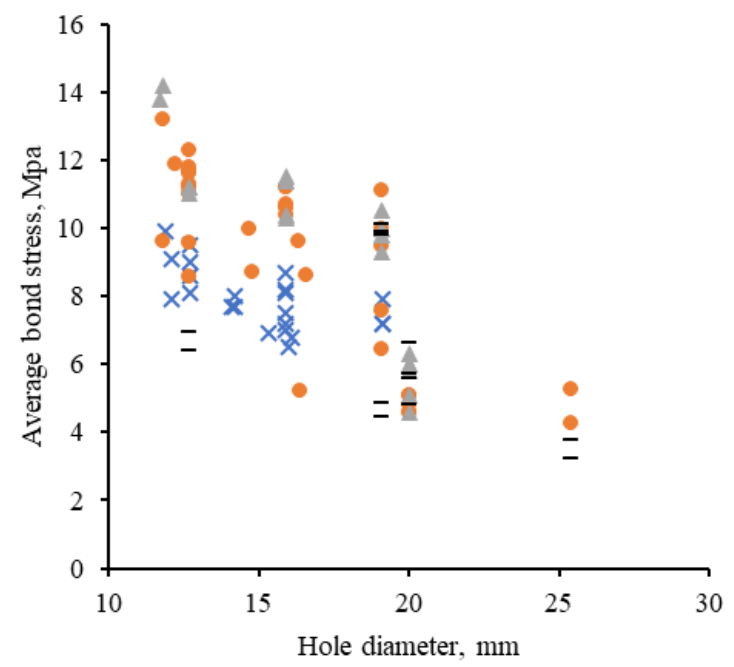

(b)

Fig. 4.8 Average bond stress vs. anchor hole diameter; (a) Present study and (b) data from present and previous studies 


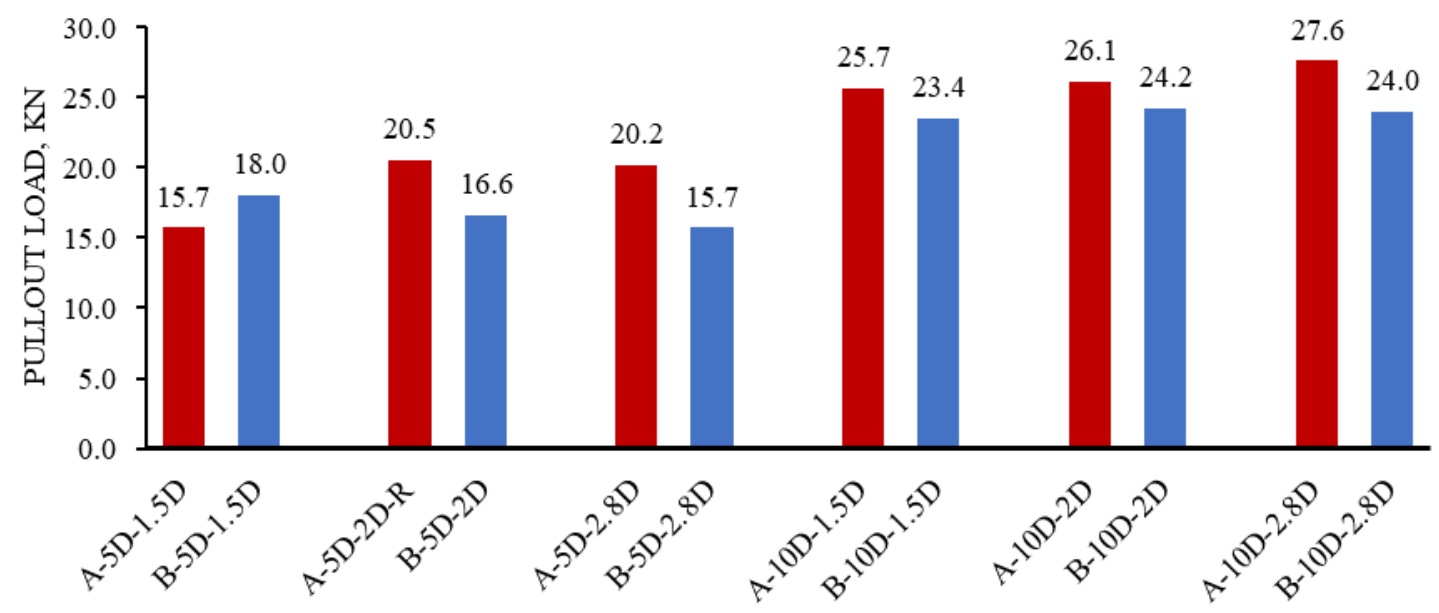

Fig. 4.9 Effect of epoxy type on the pullout strength 


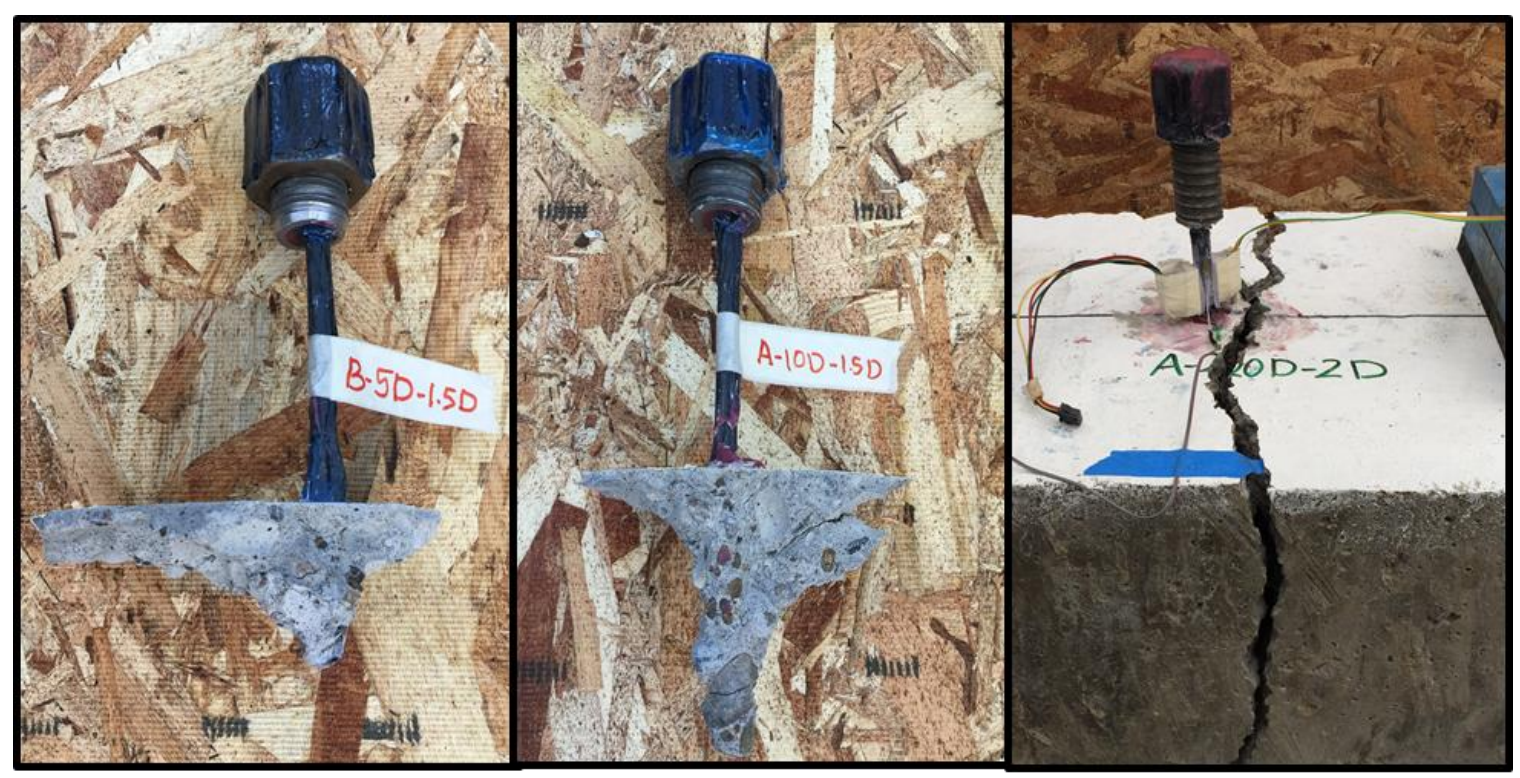

(a)

(b)

(c)

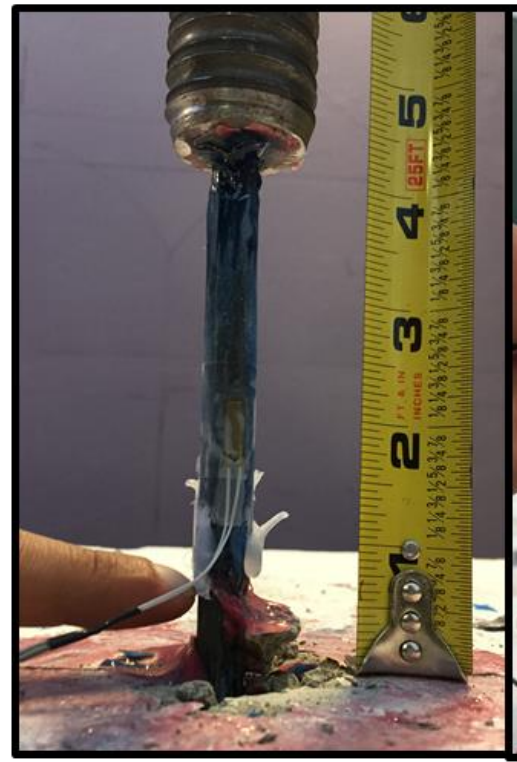

(d)

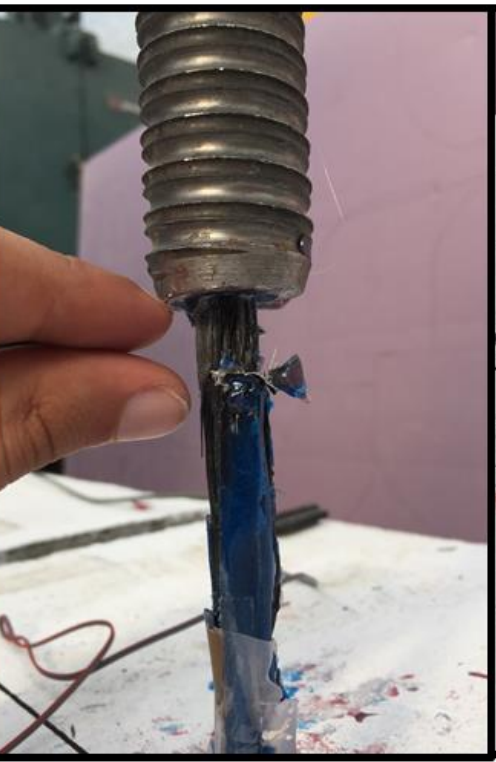

(e)

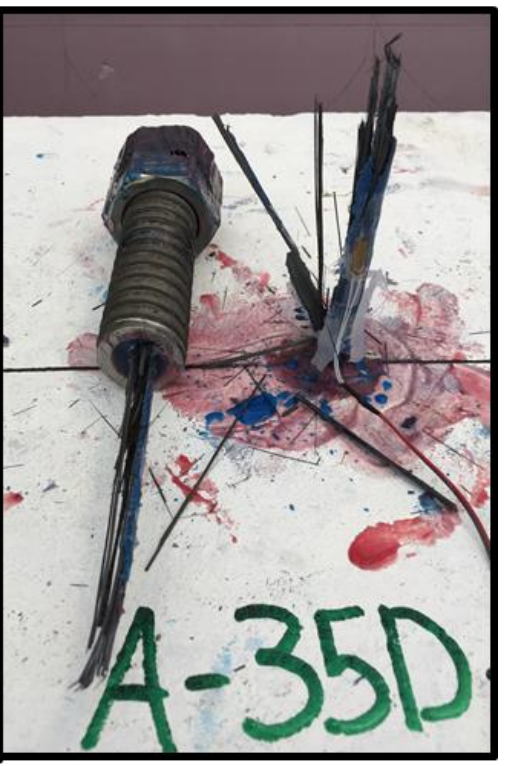

(f)

Fig. 4.10 Failure modes; (a) concrete cone failure, (b) combined cone and bond failure, $(c)$ concrete splitting, $(d)$ bond failure, $(e)$ gripper failure, and $(f) C F R P$ rupture failure 


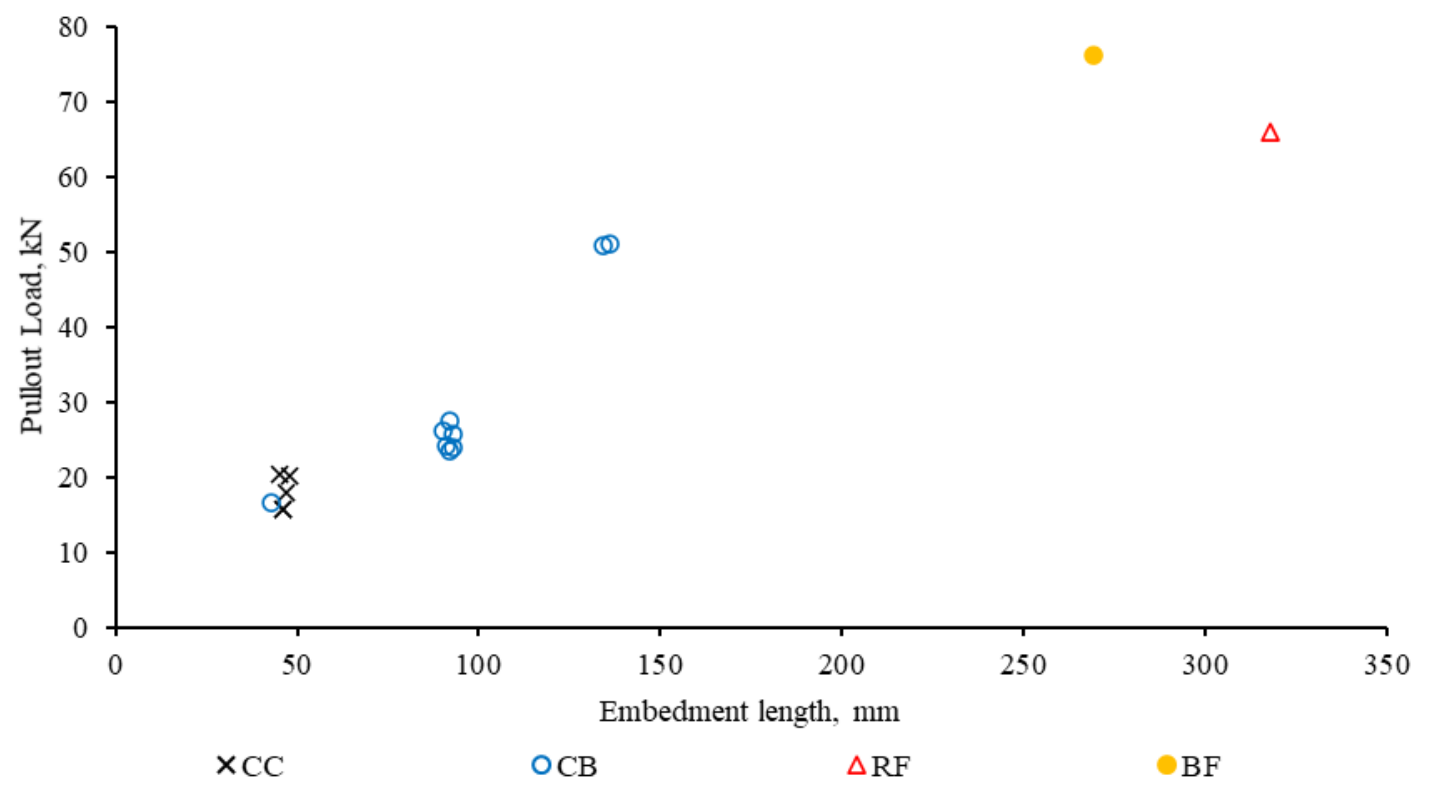

(a)

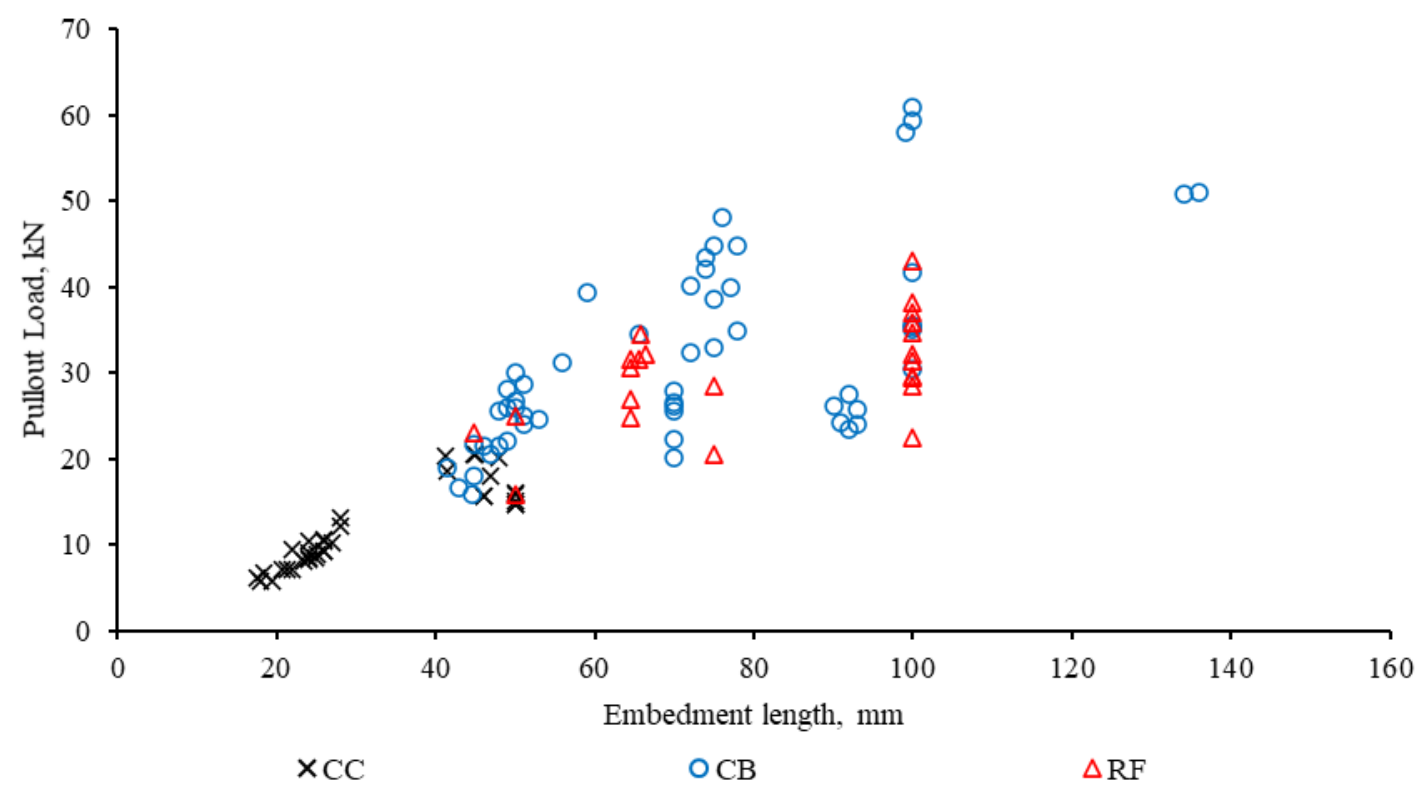

(b)

Fig. 4.11 Pullout load vs. embedment length characterized by failure modes; (a) Present study, (b) Present study and previous studies 


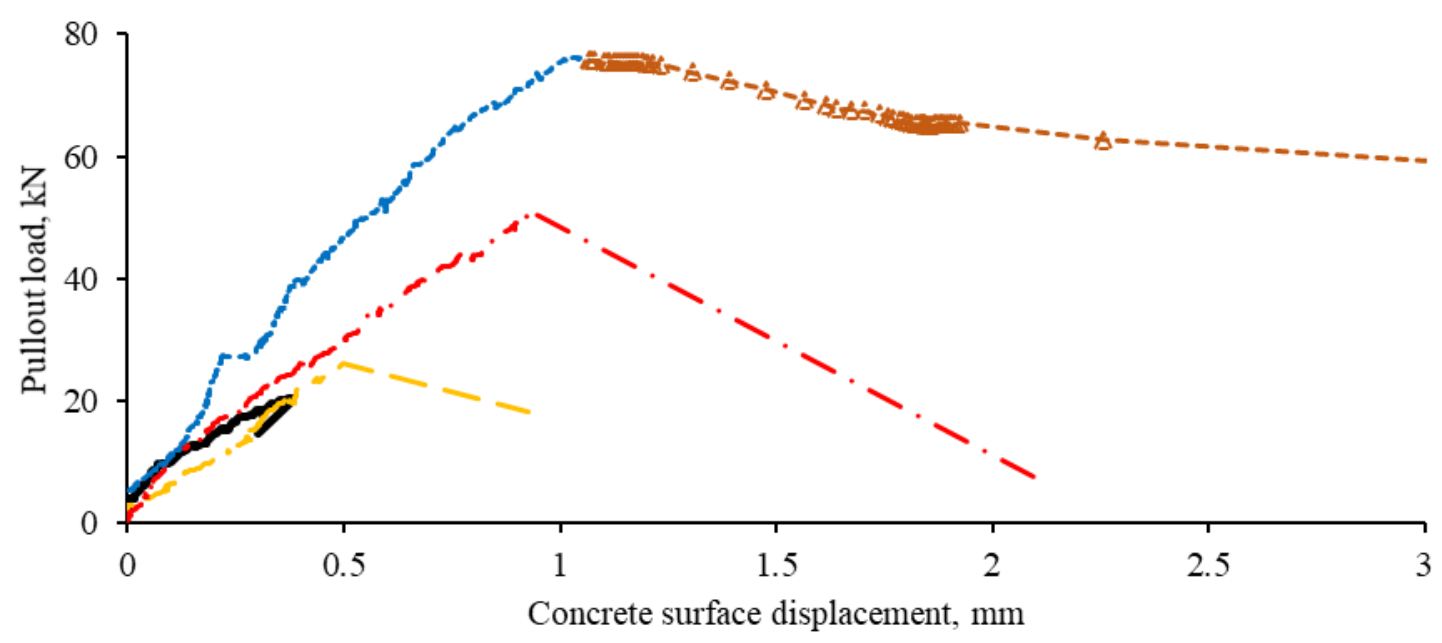

$\longrightarrow$ Embedment $=45 \mathrm{~mm}--90 \mathrm{~mm}--135 \mathrm{~mm} \quad-----270 \mathrm{~mm} \quad--\hat{s}--$ slip-270 $\mathrm{mm}$

Fig. 4.12 Typical pullout load vs. concrete displacement relationships

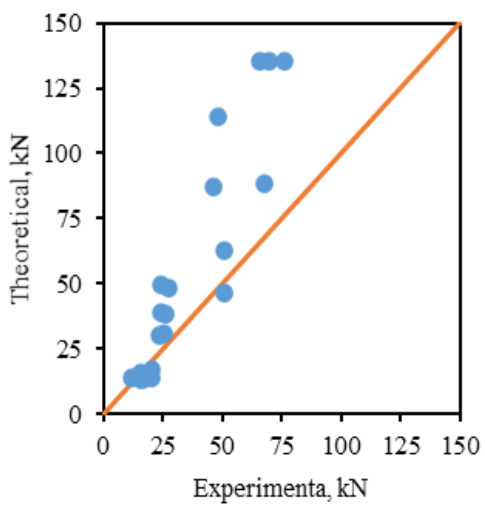

(a)

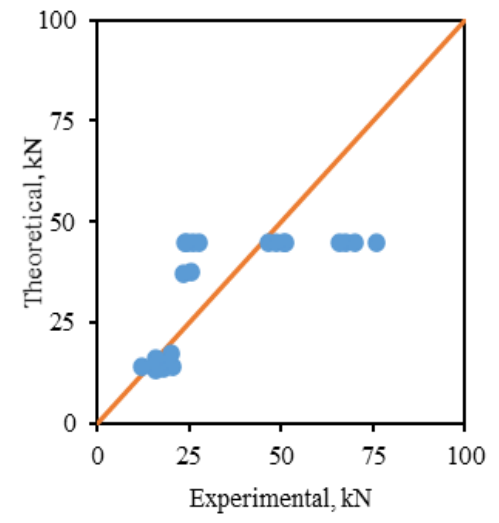

(b)

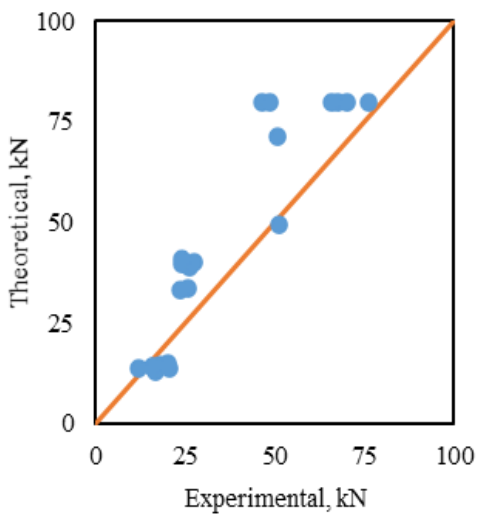

(c)

Fig. 4.13 Experimental vs. predicted tensile strength of CFRP rope anchors; (a) Ozdemir, (b) Ozbakkaloglu and Saatcioglu, and (c) Kim and Smith 


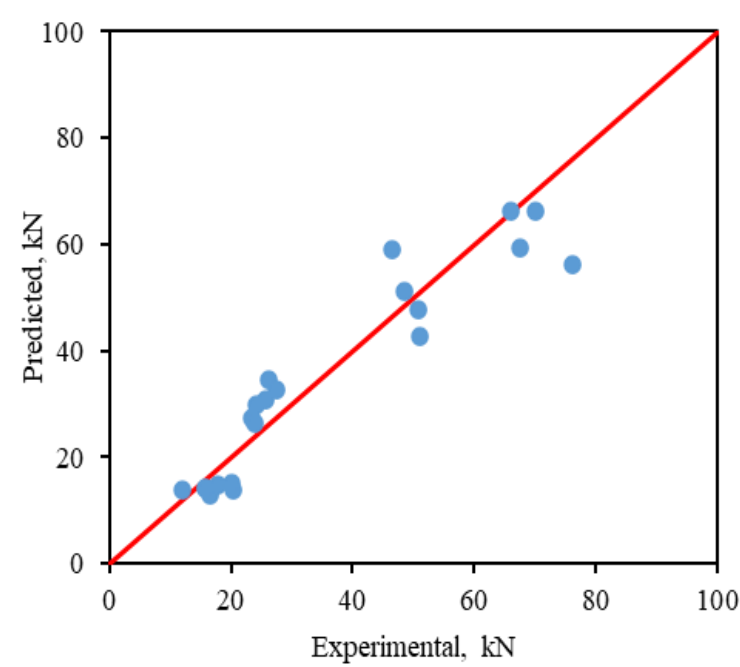

Experimental, $\mathrm{kN}$

Present study

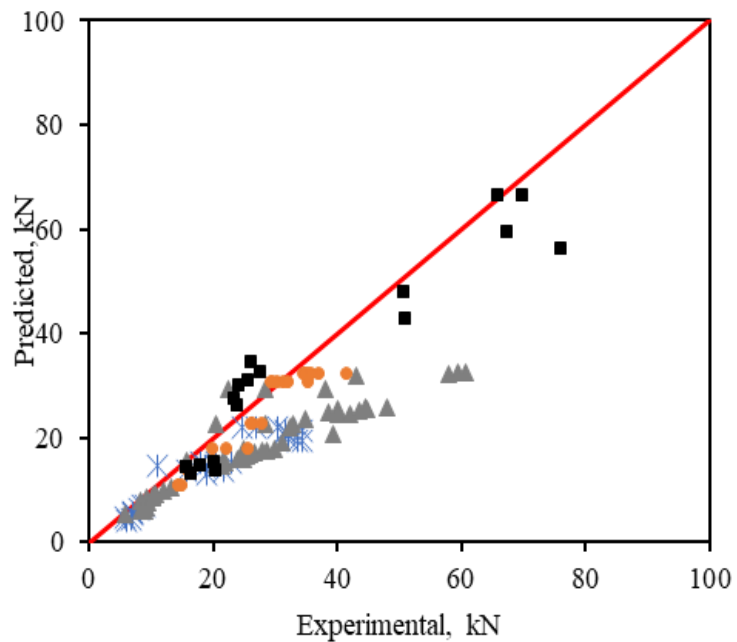

* Kim \& Smith - Ozdemir
$\Delta$ Ozbakkaloglu \& Saatcioglu - Present study

(a)

Fig. 4.14 Experimental tests vs. the proposed modified model for CFRP rope anchors; (a) present study and (b) previous studies in addition to the present study 


\section{References - Chapter 4}

[1] Wu G, Dong ZQ, Wu ZS, Zhang LW. Performance and parametric analysis of flexural strengthening for RC beams with NSM-CFRP bars. J Compos Constr 2014;18. doi:10.1061/(ASCE)CC.1943-5614.0000451.

[2] Zhang SS, Yu T, Chen GM. Reinforced concrete beams strengthened in flexure with near-surface mounted (NSM) CFRP strips: Current status and research needs. Compos Part B Eng 2017;131:30-42. doi:10.1016/j.compositesb.2017.07.072.

[3] Saleh H, Abdouka K, Al-Mahaidi R, Kalfat R. Strengthening of slab-column connections against punching shear using FRP materials: state-of-the-art review. Aust J Struct Eng 2018;19:188-206. doi:10.1080/13287982.2018.1462901.

[4] Limam O, Foret G, Ehrlacher A. RC two-way slabs strengthened with CFRP strips: experimental study and a limit analysis approach. Compos Struct 2003;60:467-71. doi:10.1016/S0263-8223(03)00011-4.

[5] Ma CK, Apandi NM, Sofrie CSY, Ng JH, Lo WH, Awang AZ, et al. Repair and rehabilitation of concrete structures using confinement: A review. Constr Build Mater 2017;133:502-15. doi:10.1016/j.conbuildmat.2016.12.100.

[6] Perrone M, Barros JAO, Aprile A. CFRP-based strengthening technique to increase the flexural and energy dissipation capacities of RC Columns. J Compos Constr 2009;13:372-83. doi:10.1061/(ASCE)CC.1943-5614.0000031. 
[7] Zerkane ASH, Saeed YM, Rad FN. Cyclic loading behavior of CFRP-wrapped nonductile beam-column joints. ACI Spec Publ 2019;331:34-54.

[8] Pohoryles DA, Melo J, Rossetto T, Varum H, Bisby L. Seismic retrofit schemes with FRP for deficient RC beam-column joints: state-of-the-art review. J Compos Constr 2019;23:03119001. doi:10.1061/(ASCE)CC.1943-5614.0000950.

[9] Le Nguyen K, Brun M, Limam A, Ferrier E, Michel L. Pushover experiment and numerical analyses on CFRP-retrofit concrete shear walls with different aspect ratios. Compos Struct 2014;113:403-18. doi:10.1016/j.compstruct.2014.02.026.

[10] Mostofinejad D, Mohammadi Anaei M. Effect of confining of boundary elements of slender RC shear wall by FRP composites and stirrups. Eng Struct 2012;41:1-13. doi:10.1016/j.engstruct.2012.03.019.

[11] Bilotta A, Ceroni F, Ludovico ; M Di, Nigro ; E, Pecce ; M, Manfredi G. Bond efficiency of EBR and NSM FRP systems for strengthening concrete members. J Compos Constr 2011;15:757-72. doi:10.1061/(ASCE)CC.1943-5614.0000204.

[12] Rahimi H, Hutchinson A. Concrete beams strengthened with externally bonded FRP plates. J Compos Constr 2001;5:44-56. doi:10.1061/(ASCE)10900268(2001)5:1(44).

[13] Hiotakis S. Repair and strengthening of reinforced concrete shear walls for earthquake resistance using externally bonded carbon fibre sheets and a novel system. Carleton University, 2004. 
[14] Niu H, Wu Z. Effects of FRP-concrete interface bond properties on the performance of RC beams strengthened in flexure with externally bonded FRP sheets. J Mater Civ Eng 2006;18:723-31. doi:10.1061/(ASCE)0899-1561(2006)18:5(723).

[15] Grelle S V., Sneed LH. Review of anchorage systems for externally bonded FRP laminates. Int J Concr Struct Mater 2013;7:17-33. doi:10.1007/s40069-013-0029-0.

[16] Mostafa A, Razaqpur AG. CFRP anchor for preventing premature debonding of externally bonded FRP laminates from concrete. J Compos Constr 2013;17:641-50. doi:10.1061/(ASCE)CC.1943-5614.0000377.

[17] Ozbakkaloglu T, Fang C, Gholampour A. Influence of FRP anchor configuration on the behavior of FRP plates externally bonded on concrete members. Eng Struct 2017;133:133-50. doi:10.1016/j.engstruct.2016.12.005.

[18] Aules W, Saeed YM, Rad FN. A novel anchorage system for strengthening slender RC columns with externally bonded CFRP composite sheets. Constr Build Mater 2020;245:118423. doi:10.1016/j.conbuildmat.2020.118423.

[19] Kalfat R, Al-Mahaidi R. Development of a hybrid anchor to improve the bond performance of multiple plies of FRP laminates bonded to concrete. Constr Build Mater 2015;94:280-9. doi:10.1016/j.conbuildmat.2015.07.013.

[20] Carozzi FG, Colombi P, Fava G, Poggi C. Mechanical and bond properties of FRP anchor spikes in concrete and masonry blocks. Compos Struct 2018;183:185-98. doi:10.1016/j.compstruct.2017.02.026. 
[21] Villanueva Llauradó P, Ibell T, Fernández Gómez J, González Ramos FJ. Pull-out and shear-strength models for FRP spike anchors. Compos Part B Eng 2017;116:239-52. doi:10.1016/j.compositesb.2017.02.029.

[22] Vrettos I, Kefala E, Triantafillou TC. Innovative flexural strengthening of reinforced concrete columns using carbon-fiber anchors. ACI Struct J 2013;110:63-70. doi:10.14359/51684330.

[23] Del Rey Castillo E, Griffith M, Ingham J. Seismic behavior of RC columns flexurally strengthened with FRP sheets and FRP anchors. Compos Struct 2018;203:38295. doi:10.1016/j.compstruct.2018.07.029.

[24] Li X, Lv HL, Zhang GC, Sha SY, Zhou SC. Seismic retrofitting of rectangular reinforced concrete columns using fiber composites for enhanced flexural strength. J Reinf Plast Compos 2013;32:619-30. doi:10.1177/0731684413477222.

[25] Ding L, Wu G, Yang S, Wu Z. Performance advancement of RC columns by applying basalt FRP composites with NSM and confinement system. J Earthq Tsunami 2013;07:1350007. doi:10.1142/S1793431113500073.

[26] Bournas DA, Triantafillou TC. Flexural strengthening of reinforced concrete columns with near-surface-mounted FRP or stainless steel. ACI Struct J 2009;106:495505.

[27] ACI Committee 440 (ACI 440.3R-12). Guide Test Methods for Fiber-Reinforced Polymers (FRPs) for Reinforcing or Strengthening Concrete Structures. Farmington Hills, MI.: American Concrete Institute; 2012. 
[28] Rolland A, Quiertant M, Khadour A, Chataigner S, Benzarti K, Argoul P. Experimental investigations on the bond behavior between concrete and FRP reinforcing bars. Constr Build Mater 2018;173:136-48. doi:10.1016/j.conbuildmat.2018.03.169.

[29] Caro M, Jemaa Y, Dirar S, Quinn A. Bond performance of deep embedment FRP bars epoxy-bonded into concrete. Eng Struct 2017;147:448-57. doi:10.1016/j.engstruct.2017.05.069.

[30] Godat A, L'Hady A, Chaallal O, Neale KW. Bond behavior of the ETS FRP bar shear-strengthening method. J Compos Constr 2012;16:529-39. doi:10.1061/(ASCE)CC.1943-5614.0000280.

[31] Valerio P, Ibell TJ, Darby AP. Deep embedment of FRP for concrete shear strengthening. Proc Inst Civ Eng - Struct Build 2009;162:311-21. doi:10.1680/stbu.2009.162.5.311.

[32] Al-Obaidi S, Saeed YM, Rad FN. Flexural strengthening of reinforced concrete beams with NSM-CFRP bars using mechanical interlocking. J Build Eng 2020;31:101422. doi:10.1016/j.jobe.2020.101422.

[33] Kim SJ, Smith ST. Behaviour of handmade FRP anchors under tensile load in uncracked concrete. Adv Struct Eng 2009;12:845-65. doi:10.1260/136943309790327716.

[34] Ozbakkaloglu T, Saatcioglu M. Tensile behavior of FRP anchors in concrete. J Compos Constr 2009;13:82-92. doi:10.1061/(ASCE)1090-0268(2009)13:2(82). 
[35] Ozdemir G. Mechanical properties of CFRP anchorages. Middle East Technical University, 2005. doi:10.1002/eqe.4290180114.

[36] Kim SJ, Smith ST. Pullout strength models for FRP anchors in uncracked concrete. J Compos Constr 2010;14:406-14. doi:10.1061/(ASCE)CC.1943-5614.0000097.

[37] ASTM C39 / C39M-18. Standard Test Method for Compressive Strength of Cylindrical Concrete Specimens. West Conshohocken, PA.: 2018. doi:10.1520/C0039_C0039M-18.

[38] Saeed YM, Rad FN. Experimental investigation of CFRP prestressed concrete beams. ACI Spec Publ 2019;331:101-21.

[39] Saeed YM. Behavior of Prestressed Concrete Beams with CFRP Strands. Portland State University, 2016. doi:10.15760/etd.2722.

[40] ASTM E488/ E488M-18. Standard Test Methods for Strength of Anchors in Concrete Elements. West Conshohocken, PA.: 2018. doi:10.1520/E0488_E0488M-18.

[41] Luke P, Chon C, Jirsa J. Use of epoxies for grouting reinforcing bar dowels in concrete. Phil M. Ferguson Structural Engineering Laboratory, The University of Texas at Austin; 1985.

[42] ACI Committee 440 (ACI 440.2R-17). Guide for the Design and Construction of Externally Bonded FRP Systems for Strengthening Concrete Structures. Farmington Hills, MI.: 2017. 
[43] Kaya E, Kutan C, Sheikh S, Ilki A. Flexural retrofit of support regions of reinforced concrete beams with anchored FRP ropes using NSM and ETS methods under reversed cyclic loading. J Compos Constr 2017;21:04016072.

[44] ACI Committee 349 (ACI 349-85). Code requirements for nuclear safety-related concrete structures. Farmington Hills, MI.: 1997.

[45] Fuchs W, Eligehausen R, Breen JB. Concrete capacity design (CCD) approach for fastening to concrete. ACI Struct J 1995;92:73-94.

[46] Cook RA, Doerr G, Klingner R. Bond stress model for design of adhesive anchors. ACI Struct J 1993;90:514-524.

[47] Cook RA. Behavior of chemically bonded anchors. J Struct Eng 1993;119:27442762. doi:10.1061/(ASCE)0733-9445(1993)119:9(2744).

[48] Saeed YM, Aules WA, Rad FN, Raad AM. Tensile behavior of FRP anchors made from CFRP ropes epoxy-bonded to uncracked concrete for flexural strengthening of RC columns. Case Stud Constr Mater 2020;13. doi:10.1016/j.cscm.2020.e00435. 


\section{Chapter 5: Conclusions and Recommendations}

\subsection{Summary and conclusions}

This study is aimed at gaining a better understanding of the process of strengthening and repairing slender $\mathrm{RC}$ columns. The first part of the investigation is focused on strengthening slender RC columns using CFRP sheets, rods, and ropes. All test specimens were designed and constructed based on older codes (pre 1970s). Each specimen consisted of two columns connected in the middle by a stiffer element (concrete stub). The behavior of the strengthened columns was compared to that of the control column which represented the older as-built columns. One column-specimen was strengthened with CFRP confinement only to investigate the effect of CFRP confinement on the lateral response of RC columns. Another column-specimen was strengthened with confinement and NSMCFRP rods. Two column-specimens were strengthened with CFRP confinement and NSMCFRP ropes. CFRP ropes were debonded at the base of the columns in one of the specimens to investigate the effect of debonding CFRP ropes on the ductility of RC columns. Finally, the behaviors of the strengthened columns were compared to a column-specimen (C3Sheet) that was strengthened with CFRP confinement and EB-CFRP sheets in the longitudinal direction. C3-Sheet was tested in a previous study [1], and the results were previously published in a journal paper [2]. C3-Sheet was included in the present study because it was built similar to the specimens tested in the present study, except it was strengthened with EB CFRP sheets. This allowed accurate comparison between strengthening RC columns with EB-CFRP sheets and strengthening columns with NSM- 
CFRP rods or ropes. As part of this study, a theoretical model was proposed to predict the load-displacement relationship of slender RC columns strengthened with EB-CFRP sheets or NSM-CFRP rods or ropes. The model was based on moment-curvature analyses, material properties obtained experimentally, and theoretical equations available in the literature as described in Chapter 2. The results of the theoretical model were compared with the experimental results.

The same technique used in strengthening the columns in the first part of the investigation was used in repairing damaged RC columns. The damaged columns had already been strengthened with CFRP confinement before being damaged. The second part of this investigation is the first of its kind to focus on rapid repair of damaged $\mathrm{RC}$ columns that were enhanced by CFRP confinement before damage. The proposed technique aimed to allow engineers complete the repair in a matter of days. The repaired column-specimen was tested under a combination of axial and cyclic lateral loads. The behavior of the repaired column in terms of lateral strength and ductility was compared to the control specimen and to the strengthened columns.

Finally, whether the process involves strengthening deficient $\mathrm{RC}$ columns or repairing damaged columns using the proposed technique, CFRP ropes in the longitudinal direction have to be anchored to the foundation or to the joint (depending on the location of the rehabilitated column). Therefore, the third part of this investigation focused on the tensile behavior of CFRP ropes epoxy-bonded to uncracked concrete. A total of twenty-one FRP anchors made from CFRP ropes were fabricated and tested under pure tensile load. The parameters were the embedment length, hole diameter, and epoxy type. Previous tests [3- 
5] did not investigate deep embedment of FRP anchors as they focused on using the anchors for flexural or shear strengthening of RC beams with EB FRP sheets anchored at the ends. For the first time, deep embedment lengths (> $100 \mathrm{~mm}$ ) of anchors made from CFRP ropes were investigated in the present study for strengthening or repairing RC columns. Finally, based on the only model available in the literature [6], a modified theoretical model was proposed to predict the tensile strength of CFRP anchors made from CFRP ropes. The results obtained from the model were compared with the results of the current study and previous tests available in the literature.

Based on the results of this work, the following main conclusions can be drawn:

- The strength and ductility of slender RC columns that were designed based on older codes (pre 1970s) can be upgraded using the strengthening technique proposed in this study. NSM-CFRP ropes can be used in flexural strengthening of deficient RC columns.

- For strengthening RC columns, CFRP ropes with higher flexibility, are easier to transport, and easier to install as compared to CFRP rods and sheets.

- The predicted load-displacement relationships obtained from a theoretical model proposed in this study showed good agreement with the experimental results. The proposed model may be used to predict the behavior of RC columns strengthened with CFRP confinement and NSM-CFRP ropes in longitudinal direction.

- The rapid repair technique proposed in this study may be used not only to restore but also to improve the strength of damaged RC columns. The repair process may be completed within a few days and appears to be effective in improving the 
strength and ductility of RC columns. The ductility of the repaired column was larger than the "desired ductility" index of 5.0 when either the idealized or the measured load-displacement relationships was used to evaluate the ductility.

- The pullout tests conducted in this study confirm that FRP anchors can be made using CFRP ropes, and they may be used in strengthening or repairing RC columns.

- The tensile strength of CFRP rope anchors increased with the increase in embedment length. However, the results agreed with previous studies that the hole diameter had no clear effects on the tensile strength of FRP anchors. On the other hand, the bond strength decreased by increasing the hole diameter and embedment length.

- The modified theoretical model proposed in this study may be used to predict the tensile strength of FRP anchors made from CFRP ropes.

\subsection{Recommendations for future work}

The conclusions stated in this study are based on the limited tests conducted in this work. For example, the behavior of slender RC columns strengthened and repaired with CFRP confinement and NSM-CFRP rods and ropes was evaluated based on testing one specimen for each case. Although each specimen consisted of two columns, and the results reported in this document are the average response of the two columns, the conclusions are still based on limited number of tests. Therefore, testing more specimens would help assess the reliability of the results reported in this study. In addition, the conclusions are limited to 
the geometry, concrete strength, steel and CFRP reinforcement ratios of the RC columns tested in this study. Therefore, researchers are encouraged to do more tests to confirm or modify the results reported in this study.

Below are some of the recommendations for future work:

- Full scale tests are required to confirm the viability of the proposed strengthening technique.

- The strengthening technique presented in this work should be tested on RC columns with different geometry and concrete strength before it can be used in real-world practice.

- Debonding of NSM-CFRP ropes at the base to increase the deformability of the column should be further investigated. Investigating debonding the rope at a distance shorter than $150 \mathrm{~mm}$, and segmental debonding of the rope (25-mm to 50mm long segments) are recommended.

- The limited slippage of NSM-CFRP rods appears to be useful to improve the ductility response of strengthened columns, but more tests are required to confirm this observation.

- The proposed rapid repair technique improved the strength and ductility of the damaged column. However, it should be applied to full scale columns to investigate its efficiency and the actual required time to complete the repair.

- Limited tests were conducted in this study to investigate the effects of embedment length, hole diameter, and epoxy type on the tensile behavior of FRP anchors made 
from CFRP ropes. More tests are required to develop a reliable model to predict the pullout capacity of CFRP rope anchors.

- CFRP rope anchors with varying geometric configurations should be tested. For example, distance between adjacent anchors, edge distance, and the number of anchors per tension side of the strengthened/repaired column need to be investigated. 


\section{References - Chapter 5}

[1] Aules WA. Behavior of non-ductile slender reinforced concrete columns retrofit by CFRP under cyclic loading. Portland State University, 2019. doi:10.15760/etd.6688.

[2] Aules W, Saeed YM, Rad FN. A novel anchorage system for strengthening slender RC columns with externally bonded CFRP composite sheets. Constr Build Mater 2020;245:118423. doi:10.1016/j.conbuildmat.2020.118423.

[3] Ozdemir G. Mechanical properties of CFRP anchorages. Middle East Technical University, 2005. doi:10.1002/eqe.4290180114.

[4] Ozbakkaloglu T, Saatcioglu M. Tensile behavior of FRP anchors in concrete. J Compos Constr 2009;13:82-92. doi:10.1061/(ASCE)1090-0268(2009)13:2(82).

[5] Kim SJ, Smith ST. Behaviour of handmade FRP anchors under tensile load in uncracked concrete. Adv Struct Eng 2009;12:845-65. doi:10.1260/136943309790327716.

[6] Kim SJ, Smith ST. Pullout strength models for FRP anchors in uncracked concrete. J Compos Constr 2010;14:406-14. doi:10.1061/(ASCE)CC.19435614.0000097.

[7] Vosooghi A, Saiidi MS. Design guidelines for rapid repair of earthquake-damaged circular RC bridge columns using CFRP. J Bridg Eng 2013;18:827-36. doi:10.1061/(ASCE)BE.1943-5592.0000426. 
[8] Caltrans. Caltrans Seismic Design Criteria, Version 2.0. Sacramento, CA: 2019. 